\title{
Amidate Prodrugs of $O$-2-Alkylated Pyrimidine Acyclic Nucleosides Display Potent Anti-Herpesvirus Activity
}

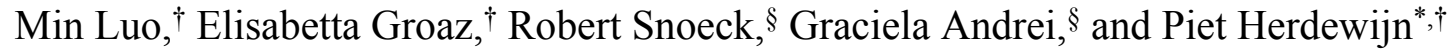

${ }^{\dagger}$ Medicinal Chemistry, Rega Institute for Medical Research, KU Leuven, Herestraat 49, 3000 Leuven, Belgium

$\S$ Laboratory of Virology and Chemotherapy, Rega Institute for Medical Research, KU Leuven, Herestraat 49 bus 1043, 3000 Leuven, Belgium

\section{CONTENTS:}

1. Synthetic schemes of compounds $\mathbf{1 3 a}, \mathbf{1 3 b}$, and $\mathbf{2 4 b}$ S2

2. Experimental procedures and characterization of products

3. HCMV and VZV antiviral assays

4. HBV antiviral assay

5. Anti-HBV activity and cytotoxicity of acyclic nucleoside phosphonamidates in HepG2.2.15 cells 
Scheme S-1. Synthesis of compounds 13a and 13b ${ }^{a}$

${ }^{a}$ Reagents and conditions: (a) $\mathrm{MMTrCl}, \mathrm{Et}_{3} \mathrm{~N}, \quad \mathrm{DMAP}, \quad \mathrm{DCM}, \quad \mathrm{rt}, 12 \mathrm{~h} ;$ (b) diisopropylphosphonomethanol, NaH, THF, 12 h; (c) TsOH. $\mathrm{H}_{2} \mathrm{O}, \mathrm{MeOH}, 5$ h, 50-51\% over 2 steps.

Scheme S-2. Synthesis of compound $24 \mathrm{~b}^{a}$

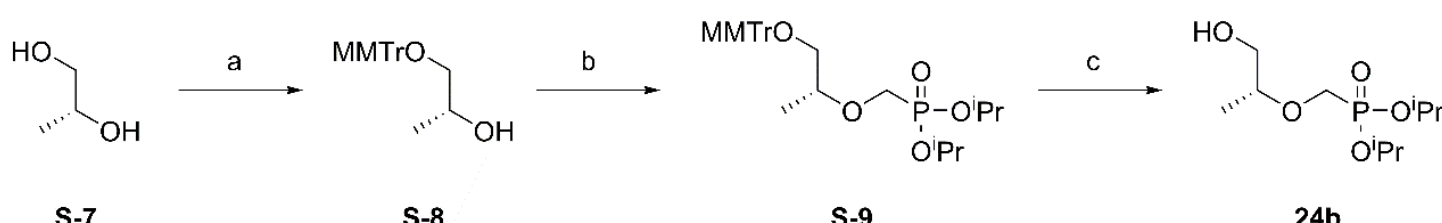

${ }^{a}$ Reagents and conditions: (a) $\mathrm{MMTrCl}, \mathrm{Et}_{3} \mathrm{~N}, \quad \mathrm{DMAP}, \mathrm{DCM}, \quad \mathrm{rt}, 12 \mathrm{~h} ;$ (b) diisopropylphosphonomethanol, NaH, THF, 12 h; (c) TsOH. $\mathrm{H}_{2} \mathrm{O}, \mathrm{MeOH}, 5$ h, $59 \%$ over 2 steps.

\section{Experimental procedures and characterization of products}

\section{General information}

For reactions, all reagents and solvents were purchased from commercial sources and used as obtained. ${ }^{1} \mathrm{H},{ }^{13} \mathrm{C}$, and ${ }^{31} \mathrm{P}$ NMR spectra were recorded on a Bruker Avance 300,500 , or $600 \mathrm{MHz}$ spectrometer using tetramethylsilane as internal standard or by referencing to the residual solvent signal. Coupling constants are reported in hertz $(\mathrm{Hz})$ and were directly obtained from the spectra. NMR splitting patterns are designated as s (singlet), d (doublet), dd (doublet of doublet), $\mathrm{t}$ (triplet), q (quartet), m (multiplet), and br (broad). High-resolution mass spectra (HRMS) were obtained on a quadruple orthogonal acceleration time-of-flight mass spectrometer (Synapt G2 HDMS, Waters, Milford, MA). Samples were infused at $3 \mu \mathrm{L} / \mathrm{min}$, and spectra were obtained in positive (or negative) ionization mode with a resolution of 15000 FWHM using leucine enkephalin as the lock mass. Precoated aluminum sheets $(254 \mathrm{~nm})$ were used for thin layer chromatography (TLC). Intermediate compounds were purified by silica gel column chromatography $(60 \AA, 0.035-0.070 \mathrm{~mm}$, Acros 
Organics). When needed, products were purified by preparative RP-HPLC (Phenomenex Gemini $110 \mathrm{~A}, \mathrm{C} 18,10 \mu \mathrm{m}, 21.2 \mathrm{~mm} \times 250 \mathrm{~mm}$ ) using $\mathrm{CH}_{3} \mathrm{CN} / 0.05 \mathrm{M}$ TEAB buffer or $\mathrm{H}_{2} \mathrm{O} / \mathrm{CH}_{3} \mathrm{CN}$ as elution systems. Purities of all the tested compounds were above $95 \%$ by HPLC analysis.

General Procedure for the alkylation of nucleobases (A). A solution of DIAD (2 equiv or 3 equiv) in anhydrous THF was added dropwise to a mixture of $N^{4}$-acetylcytosine or 5-fluorocytosine ( 1 equiv), the corresponding phosphonate esters (1.3 equiv), and $\mathrm{Ph}_{3} \mathrm{P}$ ( 2 equiv or 3 equiv) in anhydrous THF at room temperature. The reaction mixture was stirred for $12 \mathrm{~h}$, and it was then concentrated under reduced pressure. The crude residue was purified by column chromatography on silica gel. To synthesize compounds $6 \mathbf{a} / \mathbf{b}, \mathbf{1 6} \mathbf{a} / \mathbf{b}$, and $27 \mathbf{a} / \mathbf{b}$, the relevant collected eluate was evaporated and redissolved in $30 \%$ methanolic ammonia. After stirring at $45^{\circ} \mathrm{C}$ for $15 \mathrm{~h}$, the mixture was evaporated to give a crude residue, which was purified by column chromatography on silica gel. To synthesize compounds $7 \mathbf{a} / \mathbf{b}, \mathbf{1 7} \mathbf{a} / \mathbf{b}$, and $\mathbf{2 8} \mathbf{a} / \mathbf{b}$, the relevant collected eluate was evaporated and redissolved in $\mathrm{CH}_{3} \mathrm{CN} / \mathrm{H}_{2} \mathrm{O}(1: 1, \mathrm{v} / \mathrm{v}) .1 \mathrm{M} \mathrm{HCl}$ solution was added at $0{ }^{\circ} \mathrm{C}$ and then the mixture was stirred for another $12 \mathrm{~h}$ at room temperature. The solution was neutralized with saturated sodium bicarbonate. After removal of all the volatiles, the resulting residue was purified by column chromatography on silica gel.

General procedure for the hydrolysis of diester phosphonates (B). Bromotrimethylsilane (8 equiv) was added dropwise to a solution of a phosphonate diesters (1 equiv) and 2,6-lutidine (16 equiv) in anhydrous acetonitrile at $0{ }^{\circ} \mathrm{C}$. After the addition was completed, the mixture was slowly warmed to room temperature and set aside in the dark for $12 \mathrm{~h}$. The reaction was then quenched by addition of $\mathrm{MeOH}$. After removal of all the volatiles, the crude residue was purified by silica gel column chromatography (acetone, $\mathrm{H}_{2} \mathrm{O}$, and $\mathrm{Et}_{3} \mathrm{~N}$ ). The collected eluate was freeze-dried repeatedly until constant mass to give the desired phosphonate acid as a triethylammonium salt.

General procedure for the synthesis of phosphonamidates (C). The relevant phosphonic acid (1 eq.) was mixed with L-aspartic acid amyl diester $\mathrm{HCl}$ salt or L-valine amyl ester $\mathrm{HCl}$ salt (1.7 equiv) and phenol (4.4 equiv) in anhydrous pyridine. Then $\mathrm{Et}_{3} \mathrm{~N}$ (10 equiv) was added and the mixture was stirred at $60{ }^{\circ} \mathrm{C}$ under a nitrogen atmosphere for $15-20$ min. 2,2'-Dithiodipyridine (7 equiv) was mixed in a separate flask with $\mathrm{PPh}_{3}$ (7 equiv) in anhydrous pyridine and the resultant mixture was stirred for 10-15 min to give a clear light yellow solution. This solution was then added to the above 
solution and the combined mixture was stirred at $60{ }^{\circ} \mathrm{C}$ for $12 \mathrm{~h}$. The mixture was then concentrated under reduced pressure to give a residue, which was purified by silica gel chromatography, followed by RP-HPLC (linear gradient, $40-95 \% \mathrm{CH}_{3} \mathrm{CN}$ in water) to give the desired phosphonamidate in pure form as a mixture of $\mathrm{P}(S)$ and $\mathrm{P}(R)$ isomers.

An additional step was required for the synthesis of compounds $\mathbf{2 2} \mathbf{a} / \mathbf{b}$ and $\mathbf{2 3 a} \mathbf{a} / \mathbf{b}$. Thus, to a stirred solution of the corresponding aryloxyphosphonamidate in DCM was added $1 \mathrm{M} \mathrm{BCl}_{3}$ (3 equiv) at $78{ }^{\circ} \mathrm{C}$. The reaction was stirred at this temperature for $1.5 \mathrm{~h}$, then $0{ }^{\circ} \mathrm{C}$ for $0.5 \mathrm{~h}$. After quenched with $\mathrm{NaHCO}_{3}$ solution, the mixture was evaporated to give a crude residue, which was purified by column chromatography on silica gel. The collected eluate was evaporated and redissolved in DCM. Drops of $\mathrm{Et}_{3} \mathrm{~N}$ was added at room temperature and the mixture was stirred for another $2 \mathrm{~h}$. After removal of all the volatiles, the resulting residue was purified by column chromatography on silica gel.

Diethyl (S)-(((1-((4-aminopyrimidin-2-yl)oxy)-3-fluoropropan-2-yl)oxy)methyl)phosphonate (6a). Compound 6a was obtained as a white foam (100 mg, 50\% over 2 steps) according to the procedure A, starting from compound $\mathbf{1}(110 \mathrm{mg}, 0.69 \mathrm{mmol})$, compound 3a (130 mg, $0.53 \mathrm{mmol})$, $\mathrm{Ph}_{3} \mathrm{P}(280 \mathrm{mg}, 1.10 \mathrm{mmol})$, and DIAD $(0.21 \mathrm{~mL}, 1.10 \mathrm{mmol})$ in anhydrous THF $(5 \mathrm{~mL})$, and $30 \%$ methanolic ammonia $(15 \mathrm{~mL})$. The crude residue was purified by column chromatography on silica gel (gradient DCM/MeOH, 40:1, v/v; DCM/MeOH, 30:1, v/v). ${ }^{1} \mathrm{H}$ NMR (300 MHz, $\mathrm{CDCl}_{3}$ ): $\delta 7.92$ $(\mathrm{dd}, J=5.7 \mathrm{~Hz}, 1 \mathrm{H}, \mathrm{H}-6), 6.11$ (d, $J=5.7 \mathrm{~Hz}, 1 \mathrm{H}, \mathrm{H}-5), 5.71$ (s, 2H, NH$\left.H_{2}\right), 4.71-4.60$ (m, 1H, H3'a), 4.56-4.44 (m, 1H, H-3'b), 4.41-4.31 (m, 2H, H-1'), 4.19-3.96 (m, 7H, 2 x $\mathrm{CH}_{2} \mathrm{CH}_{3}, \mathrm{H}-2$ ', $\left.\mathrm{PCH}_{2}\right), 1.32-1.27\left(\mathrm{~m}, 6 \mathrm{H}, 2 \times \mathrm{CH}_{2} \mathrm{CH}_{3}\right) ;{ }^{13} \mathrm{C}$ NMR (75 MHz, $\left.\mathrm{CDCl}_{3}\right): \delta 165.3$ (C-4), 164.7 (C-2), $157.1(\mathrm{C}-6), 100.1(\mathrm{C}-5), 83.0\left(\mathrm{~d},{ }^{1} J_{\mathrm{C}, \mathrm{F}}=172.2 \mathrm{~Hz}, \mathrm{C}-3\right.$ '), $78.8\left(\mathrm{dd},{ }^{2} J_{\mathrm{C}, \mathrm{F}}=19.0 \mathrm{~Hz},{ }^{3} J_{\mathrm{C}, \mathrm{P}}=11.3 \mathrm{~Hz}\right.$, $\mathrm{C}-2$ '), $64.8\left(\mathrm{~d},{ }^{1} J_{\mathrm{C}, \mathrm{P}}=165.0 \mathrm{~Hz}, \mathrm{CH}_{2} \mathrm{P}\right), 64.6\left(\mathrm{~d},{ }^{3} J_{\mathrm{C}, \mathrm{F}}=8.3 \mathrm{~Hz}, \mathrm{C}-1\right.$ ') $, 62.9,62.7\left(2 \times \mathrm{d},{ }^{2} J_{\mathrm{C}, \mathrm{P}}=6.4\right.$ $\left.\mathrm{Hz}, \mathrm{CH}_{2} \mathrm{CH}_{3}\right), 16.5,16.4\left(\mathrm{CH}_{2} \mathrm{CH}_{3}\right)$; ${ }^{31} \mathrm{P}$ NMR $\left(121 \mathrm{MHz}, \mathrm{CDCl}_{3}\right): \delta 20.5$; HRMS for $\mathrm{C}_{12} \mathrm{H}_{22} \mathrm{FN}_{3} \mathrm{O}_{5} \mathrm{P}[\mathrm{M}+\mathrm{H}]^{+}$calcd.: 338.1276 , found: 338.1292 .

\section{Diethyl (R)-(((1-((4-aminopyrimidin-2-yl)oxy)-3-fluoropropan-2-yl)oxy)methyl)phosphonate}

(6b). Compound $\mathbf{6 b}$ was obtained as a white foam (150 mg, 48\% over 2 steps) according to the procedure A, starting from compound 1 (160 mg, $1.10 \mathrm{mmol}$ ) and compound $\mathbf{3 b}$ (200 mg, 0.82 $\mathrm{mmol}), \mathrm{Ph}_{3} \mathrm{P}(430 \mathrm{mg}, 1.63 \mathrm{mmol})$, and DIAD $(0.33 \mathrm{~mL}, 1.63 \mathrm{mmol})$ in anhydrous THF $(10 \mathrm{~mL})$, and $30 \%$ methanolic ammonia $(20 \mathrm{~mL})$. The crude residue was purified by column chromatography 
on silica gel (gradient DCM/MeOH, 40:1, v/v; DCM/MeOH, 30:1, v/v). ${ }^{1} \mathrm{H}$ NMR (500 MHz, $\left.\mathrm{CDCl}_{3}\right): \delta 7.92(\mathrm{~d}, J=5.7 \mathrm{~Hz}, 1 \mathrm{H}, \mathrm{H}-6), 6.11(\mathrm{~d}, J=5.7 \mathrm{~Hz}, 1 \mathrm{H}, \mathrm{H}-5), 5.71\left(\mathrm{~s}, 2 \mathrm{H}, \mathrm{N} H_{2}\right), 4.67-4.48$ (m, 2H, H-3'), 4.39-4.32 (m, 1H, H-1'), 4.17-4.11 (m, 4H, 2 x $\mathrm{CH}_{2} \mathrm{CH}_{3}$ ), 4.06-3.98 (m, 3H, H-2', PCH $\left.H_{2}\right), 1.31-1.28$ (m, 6H, $2 \times \mathrm{CH}_{2} \mathrm{CH}_{3}$ ); ${ }^{13} \mathrm{C} \mathrm{NMR}$ (125 MHz, $\left.\mathrm{CDCl}_{3}\right): \delta 165.3$ (C-4), 164.7 (C-2), $157.0(\mathrm{C}-6), 100.1(\mathrm{C}-5), 83.0\left(\mathrm{~d},{ }^{1} J_{\mathrm{C}, \mathrm{F}}=172.2 \mathrm{~Hz}, \mathrm{C}-3\right.$ '), $78.8\left(\mathrm{dd},{ }^{2} J_{\mathrm{C}, \mathrm{F}}=18.9 \mathrm{~Hz},{ }^{3} J_{\mathrm{C}, \mathrm{P}}=11.3 \mathrm{~Hz}\right.$, $\left.\mathrm{C}-2^{\prime}\right), 64.8\left(\mathrm{~d},{ }^{1} J_{\mathrm{C}, \mathrm{P}}=162.5 \mathrm{~Hz}, \mathrm{CH}_{2} \mathrm{P}\right), 64.6\left(\mathrm{~d},{ }^{3} J_{\mathrm{C}, \mathrm{F}}=8.5 \mathrm{~Hz}, \mathrm{C}-1{ }^{\prime}\right), 62.9,62.7\left(2 \times \mathrm{d},{ }^{2} J_{\mathrm{C}, \mathrm{P}}=6.6\right.$ $\left.\mathrm{Hz}, \mathrm{CH}_{2} \mathrm{CH}_{3}\right), 16.5,16.4\left(\mathrm{CH}_{2} \mathrm{CH}_{3}\right) ;{ }^{31} \mathrm{P}$ NMR $\left(202 \mathrm{MHz}, \mathrm{CDCl}_{3}\right): \delta 20.5$; HRMS for $\mathrm{C}_{12} \mathrm{H}_{22} \mathrm{FN}_{3} \mathrm{O}_{5} \mathrm{P}[\mathrm{M}+\mathrm{H}]^{+}$calcd.: 338.1276 , found: 338.1271 .

Diethyl

(S)-(((1-((4-amino-5-fluoropyrimidin-2-yl)oxy)-3-fluoropropan-2-

yl)oxy)methyl)phosphonate (7a). Compound 7a was obtained as a white foam (44 mg, 30\% over 2 steps) according to the procedure A, starting from compound $2(100 \mathrm{mg}, 0.80 \mathrm{mmol})$ and compound 3a (150 mg, $0.61 \mathrm{mmol}), \mathrm{Ph}_{3} \mathrm{P}(480 \mathrm{mg}, 1.84 \mathrm{mmol})$, and DIAD (0.36 mL, $\left.1.84 \mathrm{mmol}\right)$ in anhydrous THF $(5 \mathrm{~mL})$, and $1 \mathrm{M} \mathrm{HCl}(0.5 \mathrm{~mL})$ in $\mathrm{CH}_{3} \mathrm{CN} / \mathrm{H}_{2} \mathrm{O}(10 \mathrm{~mL}, 1: 1, \mathrm{v} / \mathrm{v})$. The crude residue was purified by column chromatography on silica gel (gradient DCM/MeOH, 40:1, v/v; DCM/MeOH, 30:1, v/v). ${ }^{1} \mathrm{H}$ NMR (300 MHz, $\left.\mathrm{CDCl}_{3}\right): \delta 7.82(\mathrm{~d}, J=2.7 \mathrm{~Hz}, 1 \mathrm{H}, \mathrm{H}-6), 5.88$ (s, 2H, $\mathrm{NH}_{2}$ ), 4.71-4.44 (m, 2H, H-3'), 4.39-4.30 (m, 1H, H-1'), 4.20-3.97 (m, 7H, 2 x $\mathrm{CH}_{2} \mathrm{CH}_{3}, \mathrm{H}-2^{\prime}$, PCH $), 1.33-1.28\left(\mathrm{~m}, 6 \mathrm{H}, 2 \times \mathrm{CH}_{2} \mathrm{CH}_{3}\right) ;{ }^{13} \mathrm{C} \mathrm{NMR}\left(75 \mathrm{MHz}, \mathrm{CDCl}_{3}\right): \delta 160.0(\mathrm{C}-2), 155.0\left(\mathrm{~d},{ }^{1} J_{\mathrm{C}, \mathrm{F}}\right.$ $=13.6 \mathrm{~Hz}, \mathrm{C}-4), 142.8\left(\mathrm{~d},{ }^{2} J_{\mathrm{C}, \mathrm{F}}=247.5 \mathrm{~Hz}, \mathrm{C}-5\right), 140.7\left(\mathrm{~d},{ }^{2} J_{\mathrm{C}, \mathrm{F}}=20.4 \mathrm{~Hz}, \mathrm{C}-6\right), 82.9\left(\mathrm{~d},{ }^{1} J_{\mathrm{C}, \mathrm{F}}=\right.$ 172.2 Hz, C-3'), $78.7\left(\mathrm{dd},{ }^{2} J_{\mathrm{C}, \mathrm{F}}=19.1 \mathrm{~Hz},{ }^{3} J_{\mathrm{C}, \mathrm{P}}=10.5 \mathrm{~Hz}, \mathrm{C}-2\right.$ '), $65.4\left(\mathrm{~d},{ }^{3} J_{\mathrm{C}, \mathrm{F}}=8.2 \mathrm{~Hz}, \mathrm{C}-1\right.$ '), 64.9 $\left(\mathrm{d},{ }^{1} J_{\mathrm{C}, \mathrm{P}}=165.0 \mathrm{~Hz}, \mathrm{CH}_{2} \mathrm{P}\right), 62.8,62.7,62.9\left(\mathrm{CH}_{2} \mathrm{CH}_{3}\right), 16.6,16.5\left(\mathrm{CH}_{2} \mathrm{CH}_{3}\right) ;{ }^{31} \mathrm{P} \mathrm{NMR}(125 \mathrm{MHz}$, $\mathrm{CDCl}_{3}$ ): $\delta$ 21.1; HRMS for $\mathrm{C}_{12} \mathrm{H}_{21} \mathrm{~F}_{2} \mathrm{~N}_{3} \mathrm{O}_{5} \mathrm{P}[\mathrm{M}+\mathrm{H}]^{+}$calcd.: 356.1181 , found: 356.1176 .

\section{Diethyl}

(R)-(((1-((4-amino-5-fluoropyrimidin-2-yl)oxy)-3-fluoropropan-2-

yl)oxy)methyl)phosphonate (7b). Compound $\mathbf{7 b}$ was obtained as a white foam (90 mg, 31\% over 2 steps) according to the procedure A, starting from compound $8(140 \mathrm{mg}, 1.10 \mathrm{mmol})$ and compound 3b (200 mg, $0.82 \mathrm{mmol}), \mathrm{Ph}_{3} \mathrm{P}(640 \mathrm{mg}, 2.56 \mathrm{mmol})$, and DIAD (0.48 mL, $\left.2.46 \mathrm{mmol}\right)$ in anhydrous THF $(10 \mathrm{~mL})$, and $1 \mathrm{M} \mathrm{HCl}(0.5 \mathrm{~mL})$ in $\mathrm{CH}_{3} \mathrm{CN} / \mathrm{H}_{2} \mathrm{O}(10 \mathrm{~mL}, 1: 1, \mathrm{v} / \mathrm{v})$. The crude residue was purified by column chromatography on silica gel (gradient DCM/MeOH, 40:1, v/v; DCM/MeOH, 30:1, v/v). ${ }^{1} \mathrm{H}$ NMR (500 MHz, $\mathrm{CDCl}_{3}$ ): $\delta 7.87$ (d, J=2.6 Hz, 1H, H-6), 5.62 (s, 2H, $\mathrm{NH}_{2}$ ), 4.69-4.52 (m, 2H, H-3'), 4.41-4.33 (m, 1H, H-1'), 4.21-4.15 (m, 4H, 2 x $\mathrm{CH}_{2} \mathrm{CH}_{3}$ ), 4.10-4.01 (m, 3H, H-2', PCH $), 1.35-1.32\left(\mathrm{~m}, 6 \mathrm{H}, 2 \times \mathrm{CH}_{2} \mathrm{CH}_{3}\right) ;{ }^{13} \mathrm{C} \mathrm{NMR}\left(125 \mathrm{MHz}, \mathrm{CDCl}_{3}\right): \delta 160.0(\mathrm{C}-$ 
2), $154.9\left(\mathrm{~d},{ }^{1} J_{\mathrm{C}, \mathrm{F}}=13.4 \mathrm{~Hz}, \mathrm{C}-4\right), 142.8\left(\mathrm{~d},{ }^{2} J_{\mathrm{C}, \mathrm{F}}=247.4 \mathrm{~Hz}, \mathrm{C}-5\right), 140.7\left(\mathrm{~d},{ }^{2} J_{\mathrm{C}, \mathrm{F}}=20.3 \mathrm{~Hz}, \mathrm{C}-6\right)$, $82.9\left(\mathrm{~d},{ }^{1} J_{\mathrm{C}, \mathrm{F}}=172.6 \mathrm{~Hz}, \mathrm{C}-3\right.$ '), $78.7\left(\mathrm{dd},{ }^{2} J_{\mathrm{C}, \mathrm{F}}=19.2 \mathrm{~Hz},{ }^{3} J_{\mathrm{C}, \mathrm{P}}=10.6 \mathrm{~Hz}, \mathrm{C}-2\right), 65.4\left(\mathrm{~d},{ }^{3} J_{\mathrm{C}, \mathrm{F}}=8.1\right.$ $\mathrm{Hz}, \mathrm{C}-1$ ') $64.9\left(\mathrm{~d},{ }^{1} J_{\mathrm{C}, \mathrm{P}}=162.5 \mathrm{~Hz}, \mathrm{CH}_{2} \mathrm{P}\right), 62.8,62.7\left(\mathrm{CH}_{2} \mathrm{CH}_{3}\right), 16.6,16.5\left(\mathrm{CH}_{2} \mathrm{CH}_{3}\right) ;{ }^{31} \mathrm{P} \mathrm{NMR}$ (125 MHz, $\mathrm{CDCl}_{3}$ ): $\delta$ 21.1; HRMS for $\mathrm{C}_{12} \mathrm{H}_{21} \mathrm{~F}_{2} \mathrm{~N}_{3} \mathrm{O}_{5} \mathrm{P}[\mathrm{M}+\mathrm{H}]^{+}$calcd.: 356.1181 , found: 356.1185 . (S)-(((1-((4-aminopyrimidin-2-yl)oxy)-3-fluoropropan-2-yl)oxy)methyl)phosphonic acid (8a). Compound $8 \mathbf{a}$ was obtained as a white foam $(28 \mathrm{mg}, 70 \%)$ according to the procedure $\mathrm{B}$, starting from compound $6 \mathbf{6}(50 \mathrm{mg}, 0.14 \mathrm{mmol})$, bromotrimethylsilane $(0.15 \mathrm{~mL}, 1.12 \mathrm{mmol})$, and 2,6lutidine $(0.26 \mathrm{~mL}, 2.30 \mathrm{mmol})$ in anhydrous acetonitrile $(5 \mathrm{~mL})$. The crude residue was purified by column chromatography on silica gel (gradient acetone $/ \mathrm{H}_{2} \mathrm{O} / \mathrm{Et}_{3} \mathrm{~N}, 5: 1: 1$, v/v/v; acetone $/ \mathrm{H}_{2} \mathrm{O} / \mathrm{Et}_{3} \mathrm{~N}$, 4:1:1, v/v/v). ${ }^{1} \mathrm{H}$ NMR (300 MHz, $\left.\mathrm{D}_{2} \mathrm{O}\right): \delta 7.75(\mathrm{~d}, J=6.0 \mathrm{~Hz}, 1 \mathrm{H}, \mathrm{H}-6), 6.16(\mathrm{~d}, J=6.0 \mathrm{~Hz}, 1 \mathrm{H}$, H-5), 4.75-4.46 (m, 2H, H-3'), 4.27 (d, $J=5.0 \mathrm{~Hz}, 2 \mathrm{H}, \mathrm{H}-1^{\prime}$ ) , 3.98-3.87 (m, 1H, H-2'), 3.53 (d, $J=$ 9.1 Hz, 2H, $\mathrm{PCH}_{2}$ ); ${ }^{13} \mathrm{C}$ NMR (75 MHz, $\mathrm{D}_{2} \mathrm{O}$ ): $\delta 165.3$ (C-4), 163.7 (C-2), 155.6 (C-6), 100.2 (C5), $82.3\left(\mathrm{~d},{ }^{1} J_{\mathrm{C}, \mathrm{F}}=165.9 \mathrm{~Hz}, \mathrm{C}-3\right.$ ') $, 78.9\left(\mathrm{dd},{ }^{2} J_{\mathrm{C}, \mathrm{F}}=18.6 \mathrm{~Hz},{ }^{3} J_{\mathrm{C}, \mathrm{P}}=10.9 \mathrm{~Hz}, \mathrm{C}-2{ }^{\prime}\right), 67.8\left(\mathrm{~d},{ }^{1} J_{\mathrm{C}, \mathrm{P}}=\right.$ $\left.149.9 \mathrm{~Hz}, \mathrm{CH}_{2} \mathrm{P}\right), 64.2\left(\mathrm{~d},{ }^{3} J_{\mathrm{C}, \mathrm{F}}=7.6 \mathrm{~Hz}, \mathrm{C}-1\right.$ '); ${ }^{31} \mathrm{P}$ NMR $\left(121 \mathrm{MHz}, \mathrm{D}_{2} \mathrm{O}\right): \delta 12.7$; HRMS for $\mathrm{C}_{8} \mathrm{H}_{12} \mathrm{FN}_{3} \mathrm{O}_{5} \mathrm{P}[\mathrm{M}-\mathrm{H}]^{-}$calcd.: 280.0504 , found: 280.0505 .

(R)-(((1-((4-aminopyrimidin-2-yl)oxy)-3-fluoropropan-2-yl)oxy)methyl)phosphonic acid (8b). Compound $\mathbf{8 b}$ was obtained as a white foam $(62 \mathrm{mg}, 70 \%)$ according to the procedure B, starting from compound $\mathbf{6 b}(110 \mathrm{mg}, 0.33 \mathrm{mmol})$, bromotrimethylsilane $(0.34 \mathrm{~mL}, 2.61 \mathrm{mmol})$, and 2,6lutidine $(0.60 \mathrm{~mL}, 5.22 \mathrm{mmol})$ in anhydrous acetonitrile $(10 \mathrm{~mL})$. The crude residue was purified by column chromatography on silica gel (gradient acetone/ $\mathrm{H}_{2} \mathrm{O} / \mathrm{Et}_{3} \mathrm{~N}, \quad 5: 1: 1$, v/v/v; acetone $\left./ \mathrm{H}_{2} \mathrm{O} / \mathrm{Et}_{3} \mathrm{~N}, 4: 1: 1, \mathrm{v} / \mathrm{v} / \mathrm{v}\right) .{ }^{1} \mathrm{H}$ NMR $\left(300 \mathrm{MHz}, \mathrm{D}_{2} \mathrm{O}\right): \delta 7.74(\mathrm{~d}, J=6.1 \mathrm{~Hz}, 1 \mathrm{H}, \mathrm{H}-6), 6.15$ (dd, $J=6.0,1.0 \mathrm{~Hz}, 1 \mathrm{H}, \mathrm{H}-5), 4.75-4.46$ (m, 2H, H-3'), 4.33-4.23 (m, 2H, H-1'), 4.03-3.91 (m, 1H, H-2'), 3.65 (d, $\left.J=9.2 \mathrm{~Hz}, 2 \mathrm{H}, \mathrm{PCH}_{2}\right) ;{ }^{13} \mathrm{C}$ NMR (75 MHz, $\left.\mathrm{D}_{2} \mathrm{O}\right): \delta 165.2(\mathrm{C}-4), 163.4(\mathrm{C}-2), 155.1$ (C-6), $100.2(\mathrm{C}-5), 82.3\left(\mathrm{~d},{ }^{1} J_{\mathrm{C}, \mathrm{F}}=166.5 \mathrm{~Hz}, \mathrm{C}-3\right.$ ') $77.2\left(\mathrm{dd},{ }^{2} J_{\mathrm{C}, \mathrm{F}}=18.6 \mathrm{~Hz},{ }^{3} J_{\mathrm{C}, \mathrm{P}}=10.9 \mathrm{~Hz}, \mathrm{C}-\right.$ $\left.2^{\prime}\right), 66.7\left(\mathrm{~d},{ }^{1} J_{\mathrm{C}, \mathrm{P}}=154.2 \mathrm{~Hz}, \mathrm{CH}_{2} \mathrm{P}\right), 64.3\left(\mathrm{~d},{ }^{3} J_{\mathrm{C}, \mathrm{F}}=7.7 \mathrm{~Hz}, \mathrm{C}-1\right.$ ') ${ }^{31} \mathrm{P}$ NMR $\left(121 \mathrm{MHz}, \mathrm{D}_{2} \mathrm{O}\right): \delta$ 14.2; HRMS for $\mathrm{C}_{8} \mathrm{H}_{12} \mathrm{FN}_{3} \mathrm{O}_{5} \mathrm{P}$ [M-H]- calcd.: 280.0504, found: 280.0513.

(S)-(((1-((4-amino-5-fluoropyrimidin-2-yl)oxy)-3-fluoropropan-2-yl)oxy)methyl)phosphonic acid (9a). Compound 9a was obtained as a white foam (27 mg, 65\%) according to the procedure B, starting from compound $7 \mathbf{a}(50 \mathrm{mg}, 0.14 \mathrm{mmol})$, bromotrimethylsilane $(0.15 \mathrm{~mL}, 1.12 \mathrm{mmol})$, and 2,6-lutidine $(0.26 \mathrm{~mL}, 2.30 \mathrm{mmol})$ in anhydrous acetonitrile $(5 \mathrm{~mL})$. The crude residue was purified 
by column chromatography on silica gel (gradient acetone $/ \mathrm{H}_{2} \mathrm{O} / \mathrm{Et}_{3} \mathrm{~N}, \quad 5: 1: 1$, $\mathrm{v} / \mathrm{v} / \mathrm{v}$; acetone $\left./ \mathrm{H}_{2} \mathrm{O} / \mathrm{Et}_{3} \mathrm{~N}, 4: 1: 1, \mathrm{v} / \mathrm{v} / \mathrm{v}\right) .{ }^{1} \mathrm{H}$ NMR (500 MHz, CD3OD): $\delta 7.81$ (d, $\left.J=3.4 \mathrm{~Hz}, 1 \mathrm{H}, \mathrm{H}-6\right)$, 4.72-4.53 (m, 2H, H-3'), 4.45-4.32 (m, 2H, H-1'), 4.00-3.92 (m, 1H, H-2'), 3.82-3.73 (m, 2H, $\mathrm{PCH}_{2}$ ); ${ }^{13} \mathrm{C}$ NMR (125 MHz, CD3OD): $\delta 161.5(\mathrm{C}-2), 157.0\left(\mathrm{~d},{ }^{1} J_{\mathrm{C}, \mathrm{F}}=13.6 \mathrm{~Hz}, \mathrm{C}-4\right), 143.6\left(\mathrm{~d},{ }^{2} J_{\mathrm{C}, \mathrm{F}}=245.7\right.$ $\mathrm{Hz}, \mathrm{C}-5), 140.8\left(\mathrm{~d},{ }^{2} J_{\mathrm{C}, \mathrm{F}}=21.3 \mathrm{~Hz}, \mathrm{C}-6\right), 83.6\left(\mathrm{~d},{ }^{1} J_{\mathrm{C}, \mathrm{F}}=170.1 \mathrm{~Hz}, \mathrm{C}-3\right.$ '), $79.4\left(\mathrm{dd},{ }^{2} J_{\mathrm{C}, \mathrm{F}}=18.8 \mathrm{~Hz}\right.$, ${ }^{3} J_{\mathrm{C}, \mathrm{P}}=11.5 \mathrm{~Hz}, \mathrm{C}-2$ '), $69.0\left(\mathrm{~d},{ }^{1} J_{\mathrm{C}, \mathrm{P}}=156.7 \mathrm{~Hz}, \mathrm{CH}_{2} \mathrm{P}\right), 66.2\left(\mathrm{~d},{ }^{3} J_{\mathrm{C}, \mathrm{F}}=7.5 \mathrm{~Hz}, \mathrm{C}-1\right.$ '); ${ }^{31} \mathrm{P}$ NMR (121 MHz, CD3OD): $\delta$ 13.7; HRMS for $\mathrm{C}_{8} \mathrm{H}_{11} \mathrm{~F}_{2} \mathrm{~N}_{3} \mathrm{O}_{5} \mathrm{P}$ [M-H]- calcd.: 298.0410, found: 298.0409. (R)-(((1-((4-amino-5-fluoropyrimidin-2-yl)oxy)-3-fluoropropan-2-yl)oxy)methyl)phosphonic acid (9b). Compound $9 \mathrm{~b}$ was obtained as a white foam (54 mg, 65\%) according to the procedure B, starting from compound $7 \mathbf{b}(100 \mathrm{mg}, 0.28 \mathrm{mmol})$, bromotrimethylsilane $(0.30 \mathrm{~mL}, 2.25 \mathrm{mmol})$, and 2,6-lutidine $(0.52 \mathrm{~mL}, 4.50 \mathrm{mmol})$ in anhydrous acetonitrile $(10 \mathrm{~mL})$. The crude residue was purified by column chromatography on silica gel (gradient acetone $/ \mathrm{H}_{2} \mathrm{O} / \mathrm{Et}_{3} \mathrm{~N}, 5: 1: 1, \mathrm{v} / \mathrm{v} / \mathrm{v}$; acetone $\left./ \mathrm{H}_{2} \mathrm{O} / \mathrm{Et}_{3} \mathrm{~N}, 4: 1: 1, \mathrm{v} / \mathrm{v} / \mathrm{v}\right) .{ }^{1} \mathrm{H}$ NMR (500 MHz, CD3OD): $\delta 7.81$ (d, $\left.J=3.4 \mathrm{~Hz}, 1 \mathrm{H}, \mathrm{H}-6\right)$, 4.72-4.52 (m, 2H, H-3'), 4.45-4.32 (m, 2H, H-1'), 4.00-3.92 (m, 1H, H-2'), 3.82-3.73 (m, 2H, $\mathrm{PCH}_{2}$ ); ${ }^{13} \mathrm{C}$ NMR (125 MHz, CD3OD): $\delta 161.5(\mathrm{C}-2), 157.0\left(\mathrm{~d},{ }^{1} J_{\mathrm{C}, \mathrm{F}}=14.0 \mathrm{~Hz}, \mathrm{C}-4\right), 143.6\left(\mathrm{~d},{ }^{2} J_{\mathrm{C}, \mathrm{F}}=245.6\right.$ $\mathrm{Hz}, \mathrm{C}-5), 140.8\left(\mathrm{~d},{ }^{2} J_{\mathrm{C}, \mathrm{F}}=21.3 \mathrm{~Hz}, \mathrm{C}-6\right), 83.6\left(\mathrm{~d},{ }^{1} J_{\mathrm{C}, \mathrm{F}}=170.0 \mathrm{~Hz}, \mathrm{C}-3\right.$ '), $79.4\left(\mathrm{dd},{ }^{2} J_{\mathrm{C}, \mathrm{F}}=18.8 \mathrm{~Hz}\right.$, ${ }^{3} J_{\mathrm{C}, \mathrm{P}}=11.3 \mathrm{~Hz}, \mathrm{C}-2$ '), $69.0\left(\mathrm{~d},{ }^{1} J_{\mathrm{C}, \mathrm{P}}=157.0 \mathrm{~Hz}, C \mathrm{H}_{2} \mathrm{P}\right), 66.2\left(\mathrm{~d},{ }^{3} J_{\mathrm{C}, \mathrm{F}}=7.7 \mathrm{~Hz}, \mathrm{C}-1\right.$ ') ${ }^{31} \mathrm{P}$ NMR (121 MHz, CD3OD): $\delta$ 14.2; HRMS for $\mathrm{C}_{8} \mathrm{H}_{11} \mathrm{~F}_{2} \mathrm{~N}_{3} \mathrm{O}_{5} \mathrm{P}$ [M-H] calcd.: 298.0410, found: 298.0413.

yl)oxy)methyl)(phenoxy)phosphoryl)-L-aspartate (10a). Compound 10a was obtained as a colorless oil (12 mg, 28\%) according to the procedure C, starting from compound $\mathbf{8 a}$ (20 mg, 0.07 $\mathrm{mmol}$ ), aspartic acid ester $\mathrm{HCl}$ salt ( $38 \mathrm{mg}, 0.12 \mathrm{mmol}), \mathrm{PhOH}(30 \mathrm{mg}, 0.32 \mathrm{mmol}), \mathrm{Et}_{3} \mathrm{~N}(0.10 \mathrm{~mL}$, $0.70 \mathrm{mmol}), 2,2^{\prime}$-dithiodipyridine $(110 \mathrm{mg}, 0.50 \mathrm{mmol})$, and $\mathrm{PPh}_{3}(130 \mathrm{mg}, 0.50 \mathrm{mmol})$ in anhydrous pyridine $(3 \mathrm{~mL})$. The crude residue was purified by column chromatography on silica gel (gradient DCM/MeOH, 40:1, v/v; 30:1, v/v). ${ }^{1} \mathrm{H}$ NMR (300 MHz, $\left.\mathrm{CD}_{3} \mathrm{CN}\right): \delta 7.94,7.93(2 \mathrm{~d}, J$ $=6.0 \mathrm{~Hz}, 1 \mathrm{H}, \mathrm{H}-6), 7.38-7.16(\mathrm{~m}, 5 \mathrm{H}, \mathrm{Ar} H), 6.19,6.17(2 \mathrm{~s}, 1 \mathrm{H}, \mathrm{H}-5), 5.61\left(\mathrm{~s}, 2 \mathrm{H}, \mathrm{N} H_{2}\right), 4.75-3.93$ (m, 13H, H-3', H-2', H-1', 2 x OCH ${ }_{2}\left(\mathrm{CH}_{2}\right)_{3} \mathrm{CH}_{3}, \mathrm{PCH}_{2}$, H- $\alpha-\mathrm{Asp}, \mathrm{NHPO}$ ), 2.86-2.63 (m, 2H, H- $\beta-$ Asp), 1.64-1.52 (m, 4H, 2 x OCH$\left.{ }_{2} \mathrm{CH}_{2}\left(\mathrm{CH}_{2}\right)_{2} \mathrm{CH}_{3}\right), 1.34-1.27$ (m, 8H, $\left.2 \times \mathrm{O}\left(\mathrm{CH}_{2}\right)_{2}\left(\mathrm{CH}_{2}\right)_{2} \mathrm{CH}_{3}\right)$, 0.93-0.87 (m, 6H, $\left.2 \times \mathrm{O}\left(\mathrm{CH}_{2}\right)_{4} \mathrm{CH}_{3}\right) ;{ }^{13} \mathrm{C} \mathrm{NMR}\left(75 \mathrm{MHz}, \mathrm{CD}_{3} \mathrm{CN}\right): \delta 173.0\left(\mathrm{~d},{ }^{3} J_{\mathrm{C}, \mathrm{P}}=4.4 \mathrm{~Hz}, \mathrm{CO}-\right.$ $\alpha), 172.8\left(\mathrm{~d},{ }^{3} J_{\mathrm{C}, \mathrm{P}}=4.5 \mathrm{~Hz}, C \mathrm{O}-\alpha\right), 171.5(\mathrm{CO}-\beta), 166.6(\mathrm{C}-4), 165.9(\mathrm{C}-2), 158.0(\mathrm{C}-6), 151.3(\mathrm{Ar}-$ 
C), $130.6(\operatorname{Ar}-C), 125.8(\operatorname{Ar}-C), 122.0\left(\mathrm{~d},{ }^{3} J_{\mathrm{C}, \mathrm{P}}=4.0 \mathrm{~Hz}, \mathrm{Ar}-\mathrm{C}\right), 121.9\left(\mathrm{~d},{ }^{3} J_{\mathrm{C}, \mathrm{P}}=4.3 \mathrm{~Hz}, \mathrm{Ar}-\mathrm{C}\right)$, $100.6(\mathrm{C}-5), 83.9\left(\mathrm{~d},{ }^{1} J_{\mathrm{C}, \mathrm{F}}=168.0 \mathrm{~Hz}, \mathrm{C}-3\right.$ '), $82.7\left(\mathrm{~d},{ }^{1} J_{\mathrm{C}, \mathrm{F}}=168.0 \mathrm{~Hz}, \mathrm{C}-3\right.$ '), 80.1, 80.0, 79.9, 79.7, 79.6, 79.5, $79.3\left(\mathrm{C}-2{ }^{\prime}\right), 66.9\left(\mathrm{~d},{ }^{1} J_{\mathrm{C}, \mathrm{P}}=152.3 \mathrm{~Hz}, \mathrm{CH}_{2} \mathrm{P}\right), 66.7\left(\mathrm{~d},{ }^{1} J_{\mathrm{C}, \mathrm{P}}=150.0 \mathrm{~Hz}, \mathrm{CH}_{2} \mathrm{P}\right), 66.5$, 66.4, 65.7, 65.4, 65.3, $65.2\left(\mathrm{OCH}_{2}\left(\mathrm{CH}_{2}\right)_{3} \mathrm{CH}_{3}, \mathrm{C}-1\right.$ '), 51.7, 51.5 (C- $\alpha$-Asp), 39.8 (d, ${ }^{3} J_{\mathrm{C}, \mathrm{P}}=3.9 \mathrm{~Hz}$, C- $\beta$-Asp), 39.6 (d, ${ }^{3} J_{\mathrm{C}, \mathrm{P}}=4.2 \mathrm{~Hz}, \mathrm{C}-\beta$-Asp), 29.0, 28.9, 28.8, $28.7\left(\mathrm{OCH}_{2}\left(\mathrm{CH}_{2}\right)_{2} \mathrm{CH}_{2} \mathrm{CH}_{3}\right), 23.0$, $22.9\left(\mathrm{O}\left(\mathrm{CH}_{2}\right)_{3} \mathrm{CH}_{2} \mathrm{CH}_{3}\right), 14.3\left(\mathrm{O}\left(\mathrm{CH}_{2}\right)_{4} \mathrm{CH}_{3}\right) ;{ }^{31} \mathrm{P}$ NMR (121 MHz, $\left.\mathrm{CD}_{3} \mathrm{CN}\right): \delta$ 22.5, 21.9; HRMS for $\mathrm{C}_{28} \mathrm{H}_{41} \mathrm{FN}_{4} \mathrm{O}_{8} \mathrm{P}$ [M-H]- calcd.: 611.2651, found: 611.2642 .

Dipentyl

(((((R)-1-((4-aminopyrimidin-2-yl)oxy)-3-fluoropropan-2yl)oxy)methyl)(phenoxy)phosphoryl)-L-aspartate (10b). Compound 10b was obtained as a colorless oil (31 mg, 24\%) according to the procedure B, starting from compound $\mathbf{8 b}$ (60 mg, 0.21 mmol), aspartic acid ester $\mathrm{HCl}$ salt (114 mg, $0.36 \mathrm{mmol}), \mathrm{PhOH}(90 \mathrm{mg}, 0.96 \mathrm{mmol}), \mathrm{Et}_{3} \mathrm{~N}(0.30$ $\mathrm{mL}, 2.10 \mathrm{mmol}), 2,2^{\prime}$-dithiodipyridine $(330 \mathrm{mg}, 1.50 \mathrm{mmol})$, and $\mathrm{PPh}_{3}(390 \mathrm{mg}, 1.50 \mathrm{mmol})$ in anhydrous pyridine $(5 \mathrm{~mL})$. The crude residue was purified by column chromatography on silica gel (gradient DCM/MeOH, 40:1, v/v; 30:1, v/v). ${ }^{1} \mathrm{H}$ NMR (300 MHz, $\left.\mathrm{CD}_{3} \mathrm{CN}\right): \delta 7.94,7.92(2 \mathrm{~s}$, 1H, H-6), 7.39-7.19 (m, 5H, ArH), 6.18, 6.16 (2s, 1H, H-5), 5.73 (s, 2H, NH $\left.H_{2}\right), 4.75-3.93$ (m, 13H, H-3', H-2', H-1', 2 x OCH $\left.{ }_{2}\left(\mathrm{CH}_{2}\right)_{3} \mathrm{CH}_{3}, \mathrm{PCH}_{2}, \mathrm{H}-\alpha-\mathrm{Asp}, \mathrm{NHPO}\right), 2.86-2.59$ (m, 2H, H- $\beta$-Asp), 1.63$1.51\left(\mathrm{~m}, 4 \mathrm{H}, 2 \times \mathrm{OCH}_{2} \mathrm{CH}_{2}\left(\mathrm{CH}_{2}\right)_{2} \mathrm{CH}_{3}\right), 1.39-1.24\left(\mathrm{~m}, 8 \mathrm{H}, 2 \times \mathrm{O}\left(\mathrm{CH}_{2}\right)_{2}\left(\mathrm{CH}_{2}\right)_{2} \mathrm{CH}_{3}\right), 0.95-0.87(\mathrm{~m}$, $\left.6 \mathrm{H}, 2 \times \mathrm{O}\left(\mathrm{CH}_{2}\right)_{4} \mathrm{CH}_{3}\right) ;{ }^{13} \mathrm{C}$ NMR $\left(75 \mathrm{MHz}, \mathrm{CD}_{3} \mathrm{CN}\right): \delta 172.8,172.7(\mathrm{CO}-\alpha), 171.6,171.5(\mathrm{CO}-\beta)$, 166.6 (C-4), 165.9 (C-2), 157.9 (C-6), 151.4 (Ar-C), 130.6 (Ar-C), 125.8, 125.7 (Ar-C), 122.0 (d, $\left.{ }^{3} J_{\mathrm{C}, \mathrm{P}}=4.1 \mathrm{~Hz}, \mathrm{Ar}-\mathrm{C}\right), 121.9\left(\mathrm{~d},{ }^{3} J_{\mathrm{C}, \mathrm{P}}=4.4 \mathrm{~Hz}, \mathrm{Ar}-\mathrm{C}\right), 100.7,100.6(\mathrm{C}-5), 83.8\left(\mathrm{~d},{ }^{1} J_{\mathrm{C}, \mathrm{F}}=165.0 \mathrm{~Hz}\right.$, C-3'), 80.2, 80.0, 79.9, 79.7, 79.6, 79.5, $79.3\left(\mathrm{C}-2\right.$ ') $67.0\left(\mathrm{~d},{ }^{1} J_{\mathrm{C}, \mathrm{P}}=157.5 \mathrm{~Hz}, \mathrm{CH}_{2} \mathrm{P}\right), 66.6\left(\mathrm{~d},{ }^{1} J_{\mathrm{C}, \mathrm{P}}\right.$ $\left.=150.0 \mathrm{~Hz}, \mathrm{CH}_{2} \mathrm{P}\right), 66.5,66.4,65.7,65.6\left(\mathrm{OCH}_{2}\left(\mathrm{CH}_{2}\right)_{3} \mathrm{CH}_{3}\right), 65.3\left(\mathrm{~d},{ }^{3} J_{\mathrm{C}, \mathrm{F}}=7.5 \mathrm{~Hz}, \mathrm{C}-1\right.$ '), 51.5 (C- $\alpha$-Asp), $39.8\left(\mathrm{~d},{ }^{3} J_{\mathrm{C}, \mathrm{P}}=4.0 \mathrm{~Hz}, \mathrm{C}-\beta-\mathrm{Asp}\right), 39.6\left(\mathrm{~d},{ }^{3} J_{\mathrm{C}, \mathrm{P}}=3.9 \mathrm{~Hz}, \mathrm{C}-\beta-\mathrm{Asp}\right), 29.0,28.9,28.8$,

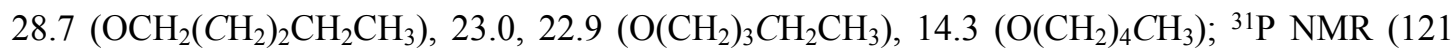
$\mathrm{MHz}, \mathrm{CD}_{3} \mathrm{CN}$ ): $\delta 22.8,21.8$; HRMS for $\mathrm{C}_{28} \mathrm{H}_{41} \mathrm{FN}_{4} \mathrm{O}_{8} \mathrm{P}$ [M-H] calcd.: 611.2651, found: 611.2650. Pentyl (((((S)-1-((4-aminopyrimidin-2-yl)oxy)-3-fluoropropan-2yl)oxy)methyl)(phenoxy)phosphoryl)-L-valinate (11a). Compound 11a was obtained as a colorless oil (40 mg, 54\%) according to the procedure C, starting from compound $8 \mathbf{a}$ (40 mg, 0.14 mmol), L-valine amyl ester $\mathrm{HCl}$ salt (53 mg, $0.24 \mathrm{mmol}), \mathrm{PhOH}(57 \mathrm{mg}, 0.61 \mathrm{mmol}), \mathrm{Et}_{3} \mathrm{~N}(0.20$ $\mathrm{mL}, 1.40 \mathrm{mmol}), 2,2^{\prime}$-dithiodipyridine $(210 \mathrm{mg}, 0.97 \mathrm{mmol})$, and $\mathrm{PPh}_{3}(250 \mathrm{mg}, 0.97 \mathrm{mmol})$ in 
anhydrous pyridine $(5 \mathrm{~mL})$. The crude residue was purified by column chromatography on silica gel (gradient DCM/MeOH, 40:1, v/v; 30:1, v/v). ${ }^{1} \mathrm{H}$ NMR (300 MHz, CDCl3): $\delta$ 7.97, 7.96 (2d, $J$ $=6.0 \mathrm{~Hz}, 1 \mathrm{H}, \mathrm{H}-6), 7.33-7.07(\mathrm{~m}, 5 \mathrm{H}, \mathrm{Ar} H), 6.11,6.09(2 \mathrm{~s}, 1 \mathrm{H}, \mathrm{H}-5), 5.36,5.35\left(2 \mathrm{~s}, 2 \mathrm{H}, \mathrm{NH}_{2}\right)$, 4.73-3.68 (m, 11H, H-3', H-2', H-1', $\mathrm{OCH}_{2}\left(\mathrm{CH}_{2}\right)_{3} \mathrm{CH}_{3}, \mathrm{PCH}_{2}$, Val-CHCH$\left.\left(\mathrm{CH}_{3}\right)_{2}, \mathrm{NHPO}\right)$, 2.09$1.98\left(\mathrm{~m}, 1 \mathrm{H}\right.$, Val-CHCH$\left.\left(\mathrm{CH}_{3}\right)_{2}\right), 1.61-1.54\left(\mathrm{~m}, 2 \mathrm{H}, \mathrm{OCH}_{2} \mathrm{CH}_{2}\left(\mathrm{CH}_{2}\right)_{2} \mathrm{CH}_{3}\right), 1.32-1.27(\mathrm{~m}, 4 \mathrm{H}$, $\left.\mathrm{O}\left(\mathrm{CH}_{2}\right)_{2}\left(\mathrm{CH}_{2}\right)_{2} \mathrm{CH}_{3}\right), 0.94-0.80$ (m, 9H, O $\left(\mathrm{CH}_{2}\right)_{4} \mathrm{CH}_{3}$, Val-CHCH$\left.\left(\mathrm{CH}_{3}\right)_{2}\right) ;{ }^{13} \mathrm{C}$ NMR $(75 \mathrm{MHz}$, CDCl3): $\delta 173.2\left(\mathrm{~d},{ }^{3} J_{\mathrm{C}, \mathrm{P}}=3.3 \mathrm{~Hz}\right.$, Val-CO), $173.0\left(\mathrm{~d},{ }^{3} J_{\mathrm{C}, \mathrm{P}}=4.5 \mathrm{~Hz}, \mathrm{Val}-\mathrm{CO}\right), 165.1(\mathrm{C}-4), 164.9$ (C-2), 157.5 (C-6), 150.3 (Ar-C), 129.7 (Ar-C), 125.0, 124.9 (Ar-C), 121.2 (d, ${ }^{3} J_{\mathrm{C}, \mathrm{P}}=4.2 \mathrm{~Hz}, \mathrm{Ar}-$ C), $121.1\left(\mathrm{~d},{ }^{3} J_{\mathrm{C}, \mathrm{P}}=4.4 \mathrm{~Hz}, \mathrm{Ar}-\mathrm{C}\right), 100.0(\mathrm{C}-5), 83.1\left(\mathrm{~d},{ }^{1} J_{\mathrm{C}, \mathrm{F}}=172.5 \mathrm{~Hz}, \mathrm{C}-3{ }^{\prime}\right), 82.8\left(\mathrm{~d},{ }^{1} J_{\mathrm{C}, \mathrm{F}}=\right.$ 165.0 Hz, C-3'), 79.1, 79.0, 78.8, 78.7 (C-2'), 67.1, 67.0, 65.5, 65.4, 65.0, 64.7, 64.6, $64.5\left(\mathrm{CH}_{2} \mathrm{P}\right.$, $\mathrm{OCH}_{2}\left(\mathrm{CH}_{2}\right)_{3} \mathrm{CH}_{3}, \mathrm{C}-1$ ') $, 59.4,59.3\left(\right.$ Val- $\left.\mathrm{CHCH}\left(\mathrm{CH}_{3}\right)_{2}\right), 32.5\left(\mathrm{~d},{ }^{3} J_{\mathrm{C}, \mathrm{P}}=4.7 \mathrm{~Hz}\right.$, Val- $\left.\mathrm{CHCH}\left(\mathrm{CH}_{3}\right)_{2}\right)$, $32.3\left(\mathrm{~d},{ }^{3} J_{\mathrm{C}, \mathrm{P}}=4.5 \mathrm{~Hz}\right.$, Val- $\left.\mathrm{CHCH}\left(\mathrm{CH}_{3}\right)_{2}\right), 28.4,28.3,28.1\left(\mathrm{OCH}_{2}\left(\mathrm{CH}_{2}\right)_{2} \mathrm{CH}_{2} \mathrm{CH}_{3}\right), 22.4$ $\left(\mathrm{O}\left(\mathrm{CH}_{2}\right)_{3} \mathrm{CH}_{2} \mathrm{CH}_{3}\right), 19.1,18.9,17.3\left(\mathrm{Val}-\mathrm{CHCH}\left(\mathrm{CH}_{3}\right)_{2}\right), 14.0\left(\mathrm{O}\left(\mathrm{CH}_{2}\right)_{4} \mathrm{CH}_{3}\right) ;{ }^{31} \mathrm{P}$ NMR $(121 \mathrm{MHz}$, $\left.\mathrm{CDCl}_{3}\right): \delta$ 23.4, 22.8; HRMS for $\mathrm{C}_{24} \mathrm{H}_{36} \mathrm{FN}_{4} \mathrm{O}_{6} \mathrm{P}[\mathrm{M}+\mathrm{H}]^{+}$calcd.: 527.2429 , found: 527.2438.

Pentyl (((( $R)$-1-((4-aminopyrimidin-2-yl)oxy)-3-fluoropropan-2yl)oxy)methyl)(phenoxy)phosphoryl)-L-valinate (11b). Compound 11b was obtained as a colorless oil (35 mg, 47\%) according to the procedure C, starting from compound $\mathbf{8 b}$ (40 mg, 0.14 mmol), L-valine amyl ester $\mathrm{HCl}$ salt (53 mg, $0.24 \mathrm{mmol}), \mathrm{PhOH}$ (57 mg, $0.61 \mathrm{mmol}), \mathrm{Et}_{3} \mathrm{~N}(0.20$ $\mathrm{mL}, 1.40 \mathrm{mmol}), 2,2^{\prime}$-dithiodipyridine $(210 \mathrm{mg}, 0.97 \mathrm{mmol})$, and $\mathrm{PPh}_{3}(250 \mathrm{mg}, 0.97 \mathrm{mmol})$ in anhydrous pyridine $(5 \mathrm{~mL})$. The crude residue was purified by column chromatography on silica gel (gradient DCM/MeOH, 40:1, v/v; 30:1, v/v). ${ }^{1} \mathrm{H}$ NMR (300 MHz, CDCl3): $\delta$ 7.97, 7.95 (2s, $1 \mathrm{H}$, H-6), 7.32-7.12 (m, 5H, ArH), 6.11,6.10 (2s, 1H, H-5), 5.50, $5.45\left(2 \mathrm{~s}, 2 \mathrm{H}, \mathrm{NH}_{2}\right), 4.75-3.59(\mathrm{~m}, 11 \mathrm{H}$, H-3', H-2', H-1', $\mathrm{OCH}_{2}\left(\mathrm{CH}_{2}\right)_{3} \mathrm{CH}_{3}, \mathrm{PCH}_{2}$, Val-CHCH$\left.\left(\mathrm{CH}_{3}\right)_{2}, \mathrm{NHPO}\right), 2.09-2.02$ (m, 1H, Val$\left.\mathrm{CHCH}\left(\mathrm{CH}_{3}\right)_{2}\right), 1.62-1.55\left(\mathrm{~m}, 2 \mathrm{H}, \mathrm{OCH}_{2} \mathrm{CH}_{2}\left(\mathrm{CH}_{2}\right)_{2} \mathrm{CH}_{3}\right), 1.32-1.26\left(\mathrm{~m}, 4 \mathrm{H}, \mathrm{O}\left(\mathrm{CH}_{2}\right)_{2}\left(\mathrm{CH}_{2}\right)_{2} \mathrm{CH}_{3}\right)$, 0.92-0.79 (m, 9H, O $\left(\mathrm{CH}_{2}\right)_{4} \mathrm{CH}_{3}$, Val-CHCH $\left.\left(\mathrm{CH}_{3}\right)_{2}\right) ;{ }^{13} \mathrm{C} \mathrm{NMR}$ (75 MHz, CDCl3): $\delta 173.2\left(\mathrm{~d},{ }^{3} J_{\mathrm{C}, \mathrm{P}}\right.$ $=3.7 \mathrm{~Hz}, \mathrm{Val}-\mathrm{CO}), 173.0\left(\mathrm{~d},{ }^{3} J_{\mathrm{C}, \mathrm{P}}=3.0 \mathrm{~Hz}, \mathrm{Val}-\mathrm{CO}\right), 165.2,165.1(\mathrm{C}-4), 164.9(\mathrm{C}-2), 157.4(\mathrm{C}-6)$, 150.5, 150.4, 150.3 (Ar-C), 129.7 (Ar-C), $125.0\left(\right.$ Ar-C), $121.2\left(\mathrm{~d},{ }^{3} J_{\mathrm{C}, \mathrm{P}}=4.3 \mathrm{~Hz}, \mathrm{Ar}-\mathrm{C}\right), 120.9$ (d, $\left.{ }^{3} J_{\mathrm{C}, \mathrm{P}}=4.5 \mathrm{~Hz}, \mathrm{Ar}-\mathrm{C}\right), 100.1,100.0(\mathrm{C}-5), 83.2\left(\mathrm{~d},{ }^{1} J_{\mathrm{C}, \mathrm{F}}=172.5 \mathrm{~Hz}, \mathrm{C}-3\right.$ '), $82.9\left(\mathrm{~d},{ }^{1} J_{\mathrm{C}, \mathrm{F}}=165.0 \mathrm{~Hz}\right.$, C-3'), 79.4, 79.2, 79.1, 79.0, 78.9, 78.8 (C-2'), 67.1, 66.9, 65.5, 65.4, 65.0, 64.9, 64.6, 64.6, 64.5 $\left(\mathrm{CH}_{2} \mathrm{P}, \mathrm{OCH}_{2}\left(\mathrm{CH}_{2}\right)_{3} \mathrm{CH}_{3}, \mathrm{C}-1\right.$ ') $)$ 59.4, $59.3\left(\mathrm{Val}-\mathrm{CHCH}\left(\mathrm{CH}_{3}\right)_{2}\right), 32.5\left(\mathrm{~d},{ }^{3} J_{\mathrm{C}, \mathrm{P}}=4.9 \mathrm{~Hz}\right.$, Val- 
$\left.\mathrm{CHCH}\left(\mathrm{CH}_{3}\right)_{2}\right), 32.2\left(\mathrm{~d},{ }^{3} J_{\mathrm{C}, \mathrm{P}}=4.7 \mathrm{~Hz}\right.$, Val- $\left.\mathrm{CHCH}\left(\mathrm{CH}_{3}\right)_{2}\right), 28.4,28.3,28.1\left(\mathrm{OCH}_{2}\left(\mathrm{CH}_{2}\right)_{2} \mathrm{CH}_{2} \mathrm{CH}_{3}\right)$, $22.3\left(\mathrm{O}\left(\mathrm{CH}_{2}\right)_{3} \mathrm{CH}_{2} \mathrm{CH}_{3}\right), 19.0,18.9,17.4,17.2\left(\mathrm{Val}-\mathrm{CHCH}\left(\mathrm{CH}_{3}\right)_{2}\right), 14.0\left(\mathrm{O}_{\left.\left(\mathrm{CH}_{2}\right)_{4} \mathrm{CH}_{3}\right)}{ }^{31}{ }^{\mathrm{P}} \mathrm{NMR}\right.$ (121 MHz, $\mathrm{CDCl}_{3}$ ): $\delta$ 23.6, 22.7; HRMS for $\mathrm{C}_{24} \mathrm{H}_{36} \mathrm{FN}_{4} \mathrm{O}_{6} \mathrm{P}[\mathrm{M}+\mathrm{H}]^{+}$calcd.: 527.2429, found: 527.2444

Pentyl

((((S)-1-((4-amino-5-fluoropyrimidin-2-yl)oxy)-3-fluoropropan-2yl)oxy)methyl)(phenoxy)phosphoryl)-L-valinate (12a). Compound 12a was obtained as a colorless oil (52 mg, 40\%) according to the procedure C, starting from compound 9a (70 mg, 0.24 mmol), L-valine amyl ester $\mathrm{HCl}$ salt (90 mg, $0.40 \mathrm{mmol}), \mathrm{PhOH}(100 \mathrm{mg}, 1.04 \mathrm{mmol}), \mathrm{Et}_{3} \mathrm{~N}$ (0.33 $\mathrm{mL}, 2.40 \mathrm{mmol}), 2,2^{\prime}$-dithiodipyridine $(370 \mathrm{mg}, 1.67 \mathrm{mmol})$, and $\mathrm{PPh}_{3}(440 \mathrm{mg}, 1.67 \mathrm{mmol})$ in anhydrous pyridine $(5 \mathrm{~mL})$. The crude residue was purified by column chromatography on silica gel (gradient DCM/MeOH, 40:1, v/v; 30:1, v/v). ${ }^{1} \mathrm{H}$ NMR (300 MHz, CDCl3): $\delta$ 7.86, $7.85(2 \mathrm{~s}, 1 \mathrm{H}$, H-6), 7.33-7.10 (m, 5H, ArH), $5.56\left(\mathrm{~s}, 2 \mathrm{H}, \mathrm{NH} \mathrm{H}_{2}\right), 4.70-3.67$ (m, 11H, H-3', H-2', H-1', $\mathrm{OCH}_{2}\left(\mathrm{CH}_{2}\right)_{3} \mathrm{CH}_{3}, \mathrm{PCH}_{2}$, Val-CHCH$\left.\left(\mathrm{CH}_{3}\right)_{2}, \mathrm{NHPO}\right), 2.07-1.95$ (m, 1H, Val-CHCH$\left.\left(\mathrm{CH}_{3}\right)_{2}\right), 1.61-$ $1.54\left(\mathrm{~m}, 2 \mathrm{H}, \mathrm{OCH}_{2} \mathrm{CH}_{2}\left(\mathrm{CH}_{2}\right)_{2} \mathrm{CH}_{3}\right), 1.35-1.25\left(\mathrm{~m}, 4 \mathrm{H}, \mathrm{O}\left(\mathrm{CH}_{2}\right)_{2}\left(\mathrm{CH}_{2}\right)_{2} \mathrm{CH}_{3}\right), 0.94-0.79$ (m, 9H, $\mathrm{O}\left(\mathrm{CH}_{2}\right)_{4} \mathrm{CH}_{3}$, Val-CHCH$\left.\left(\mathrm{CH}_{3}\right)_{2}\right) ;{ }^{13} \mathrm{C} \mathrm{NMR}(75 \mathrm{MHz}, \mathrm{CDCl}): \delta 173.3\left(\mathrm{~d},{ }^{3} J_{\mathrm{C}, \mathrm{P}}=3.6 \mathrm{~Hz}, \mathrm{Val}-\mathrm{CO}\right)$, 173.1 (Val-CO), 160.0 (C-2), 155.0, 154.9, 154.8, 154.7 (C-4), 150.3 (Ar-C), $142.9\left(\mathrm{~d},{ }^{2} J_{\mathrm{C}, \mathrm{F}}=247.2\right.$ $\mathrm{Hz}, \mathrm{C}-5), 142.8\left(\mathrm{~d},{ }^{2} J_{\mathrm{C}, \mathrm{F}}=247.2 \mathrm{~Hz}, \mathrm{C}-5\right), 140.9\left(\mathrm{~d},{ }^{2} J_{\mathrm{C}, \mathrm{F}}=22.5 \mathrm{~Hz}, \mathrm{C}-6\right), 140.9\left(\mathrm{~d},{ }^{2} J_{\mathrm{C}, \mathrm{F}}=15.0 \mathrm{~Hz}\right.$, C-6), 129.7, 125.0, 124.9, 121.2, 121.1, $121.0(\mathrm{Ar}-\mathrm{C}), 82.9\left(\mathrm{~d},{ }^{1} J_{\mathrm{C}, \mathrm{F}}=172.5 \mathrm{~Hz}, \mathrm{C}-3^{\prime}\right), 82.7\left(\mathrm{~d},{ }^{1} J_{\mathrm{C}, \mathrm{F}}\right.$ $\left.=172.5 \mathrm{~Hz}, \mathrm{C}-3^{\prime}\right), 79.0,78.9,78.8,78.7,78.6,78.5$ (C-2'), 67.1, 67.0, 65.5, 65.4, 65.3, 65.2, 65.0, $64.9\left(\mathrm{CH}_{2} \mathrm{P}, \mathrm{OCH}_{2}\left(\mathrm{CH}_{2}\right)_{3} \mathrm{CH}_{3}, \mathrm{C}-1\right.$ '), 59.4, $59.3\left(\mathrm{Val}-\mathrm{CHCH}\left(\mathrm{CH}_{3}\right)_{2}\right), 32.5\left(\mathrm{~d},{ }^{3} J_{\mathrm{C}, \mathrm{P}}=4.8 \mathrm{~Hz}\right.$, Val$\left.\mathrm{CHCH}\left(\mathrm{CH}_{3}\right)_{2}\right), 32.3\left(\mathrm{~d},{ }^{3} J_{\mathrm{C}, \mathrm{P}}=4.6 \mathrm{~Hz}\right.$, Val- $\left.\mathrm{CHCH}\left(\mathrm{CH}_{3}\right)_{2}\right), 28.4,28.3,28.1\left(\mathrm{OCH}_{2}\left(\mathrm{CH}_{2}\right)_{2} \mathrm{CH}_{2} \mathrm{CH}_{3}\right)$,

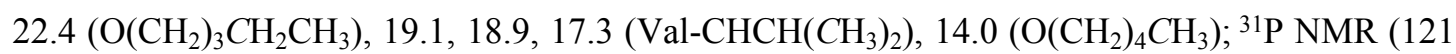
$\mathrm{MHz}, \mathrm{CDCl}_{3}$ ): $\delta$ 23.4, 22.9; HRMS for $\mathrm{C}_{24} \mathrm{H}_{36} \mathrm{~F}_{2} \mathrm{~N}_{4} \mathrm{O}_{6} \mathrm{P}[\mathrm{M}+\mathrm{H}]^{+}$calcd.: 545.2335, found: 545.2335. Pentyl (((((R)-1-((4-amino-5-fluoropyrimidin-2-yl)oxy)-3-fluoropropan-2yl)oxy)methyl)(phenoxy)phosphoryl)-L-valinate (12b). Compound 12b was obtained as a colorless oil (17 mg, 40\%) according to the procedure C, starting from compound $9 \mathbf{b}$ ( $24 \mathrm{mg}, 0.08$ mmol), L-valine amyl ester $\mathrm{HCl}$ salt (30 mg, $0.13 \mathrm{mmol}), \mathrm{PhOH}(33 \mathrm{mg}, 0.35 \mathrm{mmol}), \mathrm{Et}_{3} \mathrm{~N}(0.11$ $\mathrm{mL}, 0.80 \mathrm{mmol}), 2,2^{\prime}$-dithiodipyridine $(122 \mathrm{mg}, 0.56 \mathrm{mmol})$, and $\mathrm{PPh}_{3}(150 \mathrm{mg}, 0.56 \mathrm{mmol})$ in anhydrous pyridine $(5 \mathrm{~mL})$. The crude residue was purified by column chromatography on silica gel (gradient DCM/MeOH, 40:1, v/v; 30:1, v/v). ${ }^{1} \mathrm{H}$ NMR (300 MHz, CDCl3): $\delta$ 7.87, 7.86 (2s, $1 \mathrm{H}$, 
H-6), 7.32-7.10 (m, 5H, ArH), 5.53, $5.46\left(2 \mathrm{~s}, 2 \mathrm{H}, \mathrm{NH}_{2}\right), 4.74-3.57(\mathrm{~m}, 11 \mathrm{H}, \mathrm{H}-3$ ', H-2', H-1', $\mathrm{OCH}_{2}\left(\mathrm{CH}_{2}\right)_{3} \mathrm{CH}_{3}, \mathrm{PCH} H_{2}$, Val-CHCH$\left.\left(\mathrm{CH}_{3}\right)_{2}, \mathrm{NHPO}\right), 2.10-2.00\left(\mathrm{~m}, 1 \mathrm{H}, \mathrm{Val}-\mathrm{CHCH}\left(\mathrm{CH}_{3}\right)_{2}\right), 1.63-$ $1.54\left(\mathrm{~m}, 2 \mathrm{H}, \mathrm{OCH}_{2} \mathrm{CH}_{2}\left(\mathrm{CH}_{2}\right)_{2} \mathrm{CH}_{3}\right), 1.35-1.26\left(\mathrm{~m}, 4 \mathrm{H}, \mathrm{O}\left(\mathrm{CH}_{2}\right)_{2}\left(\mathrm{CH}_{2}\right)_{2} \mathrm{CH}_{3}\right), 0.93-0.78(\mathrm{~m}, 9 \mathrm{H}$, $\mathrm{O}\left(\mathrm{CH}_{2}\right)_{4} \mathrm{CH}_{3}$, Val-CHCH$\left.\left(\mathrm{CH}_{3}\right)_{2}\right) ;{ }^{13} \mathrm{C} \mathrm{NMR}(75 \mathrm{MHz}, \mathrm{CDCl} 3): \delta 173.3\left(\mathrm{~d},{ }^{3} J_{\mathrm{C}, \mathrm{P}}=3.4 \mathrm{~Hz}\right.$, Val-CO), $173.1\left(\mathrm{~d},{ }^{3} J_{\mathrm{C}, \mathrm{P}}=3.1 \mathrm{~Hz}, \mathrm{Val}-\mathrm{CO}\right), 160.1,160.0(\mathrm{C}-2), 155.0,154.9,154.8,154.7$ (C-4), 150,6, 150.5, $150.3(\mathrm{Ar}-\mathrm{C}), 142.9\left(\mathrm{~d},{ }^{2} J_{\mathrm{C}, \mathrm{F}}=247.5 \mathrm{~Hz}, \mathrm{C}-5\right), 142.8\left(\mathrm{~d},{ }^{2} J_{\mathrm{C}, \mathrm{F}}=247.5 \mathrm{~Hz}, \mathrm{C}-5\right), 141.0\left(\mathrm{~d},{ }^{2} J_{\mathrm{C}, \mathrm{F}}=\right.$ $22.5 \mathrm{~Hz}, \mathrm{C}-6), 140.9$ (d, $\left.{ }^{2} J_{\mathrm{C}, \mathrm{F}}=22.5 \mathrm{~Hz}, \mathrm{C}-6\right), 129.7,125.0,124.9,121.3,121.2,121.0,120.9(\mathrm{Ar}-$ C), $83.0\left(\mathrm{~d},{ }^{1} J_{\mathrm{C}, \mathrm{F}}=165.0 \mathrm{~Hz}, \mathrm{C}-3\right.$ '), $82.8\left(\mathrm{~d},{ }^{1} J_{\mathrm{C}, \mathrm{F}}=172.5 \mathrm{~Hz}, \mathrm{C}-3\right.$ ') $, 79.4,79.2,79.1,79.0,78.9$, 78.8, 78.7, 78.6 (C-2'), 67.2, 67.0, 65.5, 65.4, 65.3, 65.2, 65.1, $64.9\left(\mathrm{CH}_{2} \mathrm{P}, \mathrm{OCH}_{2}\left(\mathrm{CH}_{2}\right)_{3} \mathrm{CH}_{3}, \mathrm{C}-\right.$ 1'), 59.3, $59.2\left(\mathrm{Val}-\mathrm{CHCH}\left(\mathrm{CH}_{3}\right)_{2}\right), 32.5\left(\mathrm{~d},{ }^{3} J_{\mathrm{C}, \mathrm{P}}=4.9 \mathrm{~Hz}, \mathrm{Val}-\mathrm{CHCH}\left(\mathrm{CH}_{3}\right)_{2}\right), 32.2\left(\mathrm{~d},{ }^{3} J_{\mathrm{C}, \mathrm{P}}=4.8\right.$

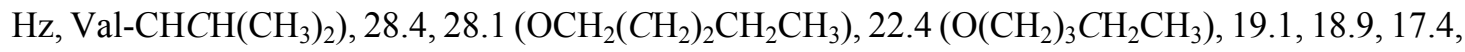

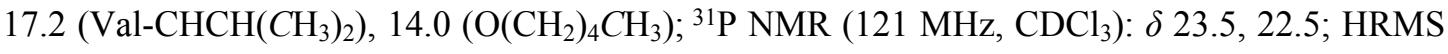
for $\mathrm{C}_{24} \mathrm{H}_{36} \mathrm{~F}_{2} \mathrm{~N}_{4} \mathrm{O}_{6} \mathrm{P}[\mathrm{M}+\mathrm{H}]^{+}$calcd.: 545.2335 , found: 545.2341 .

\section{Diisopropyl $\quad(S)$-(((1-(benzyloxy)-3-hydroxypropan-2-yl)oxy)methyl)phosphonate $\quad$ (13a).} $\operatorname{MMTrCl}(2.40 \mathrm{~g}, 7.80 \mathrm{mmol})$ was added to a mixture of $\mathbf{S}-\mathbf{1}(1.10 \mathrm{~g}, 6.40 \mathrm{mmol}), \mathrm{Et}_{3} \mathrm{~N}(1.6 \mathrm{~mL})$, and DMAP (74 mg, $0.60 \mathrm{mmol})$ in DCM $(50 \mathrm{~mL})$ at room temperature, and the reaction was stirred for further $12 \mathrm{~h}$. It was then washed with saturated aq. $\mathrm{NaHCO}_{3}(100 \mathrm{~mL})$ and brine $(100 \mathrm{~mL})$. The organic layer was separated, dried over $\mathrm{Na}_{2} \mathrm{SO}_{4}$, filtered, and concentrated under reduced pressure to give a crude residue, which was purified by column chromatography on silica gel (petroleum ether/EtOAc, 6:1, v/v; etroleum ether/EtOAc, 5:1, v/v). The collected eluate was evaporated and redissolved in THF $(50 \mathrm{~mL})$. Next, $\mathrm{NaH}(350 \mathrm{mg}, 9.10 \mathrm{mmol})$ and triflate diisopropylphosphonomethanol $(3.00 \mathrm{~g}, 9.10 \mathrm{mmol})$ were added at $0{ }^{\circ} \mathrm{C}$, and the reaction was allowed to reach room temperature and stirred for $12 \mathrm{~h}$. It was then quenched by addition of $\mathrm{MeOH}$, and then concentrated under reduced pressure. The crude product was dissolved in EtOAc $(100 \mathrm{~mL})$, washed with brine, dried over $\mathrm{Na}_{2} \mathrm{SO}_{4}$, filtered, and concentrated under reduced pressure to afford a residue, which was dissolved in $\mathrm{MeOH}(100 \mathrm{~mL}) . \mathrm{TsOH} . \mathrm{H}_{2} \mathrm{O}(230 \mathrm{mg}, 1.20 \mathrm{mmol})$ was then added, and the reaction was heated at $60{ }^{\circ} \mathrm{C}$ for $5 \mathrm{~h}$. After cooling, the solution was evaporated to remove the volatiles. The crude residue was purified by column chromatography on silica gel (gradient DCM/MeOH, 50:1, v/v; DCM/MeOH, 40:1) to give compound 13a (1.10 g, 50\% over 3 steps) as a colorless oil. ${ }^{1} \mathrm{H} \mathrm{NMR}\left(300 \mathrm{MHz}, \mathrm{CDCl}_{3}\right)$ : $\delta$ 7.35-7.27 (m, 5H, $\left.\mathrm{ArH}\right), 4.81-4.70(\mathrm{~m}, 2 \mathrm{H}$, 
$\left.\mathrm{CH}\left(\mathrm{CH}_{3}\right)_{2}\right), 4.53$ (s, 2H, OCH $\left.{ }_{2} \mathrm{Ph}\right), 4.09-4.01$ (m, 1H, H-1'a), 3.86-3.78 (m, 1H, H-1'b), 3.76-3.51 (m, 5H, H-2', $\left.\mathrm{PCH}_{2}, \mathrm{H}_{-3}{ }^{\prime}\right), 1.35-1.31\left(\mathrm{~m}, 12 \mathrm{H}, \mathrm{CH}\left(\mathrm{CH}_{3}\right)_{2}\right) ;{ }^{13} \mathrm{C} \mathrm{NMR}\left(75 \mathrm{MHz}, \mathrm{CDCl}_{3}\right): \delta 138.2$ (Ar-C), $128.5(\operatorname{Ar}-C), 127.8(\operatorname{Ar}-C), 127.7(\operatorname{Ar}-C), 82.7\left(\mathrm{~d},{ }^{3} J_{\mathrm{C}, \mathrm{P}}=8.1 \mathrm{~Hz}, \mathrm{C}-2^{\prime}\right), 73.7\left(\mathrm{OCH}_{2} \mathrm{Ph}\right)$,

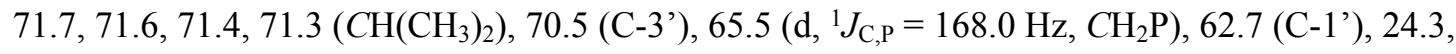
24.2, $24.1\left(\mathrm{CH}\left(\mathrm{CH}_{3}\right)_{2}\right) ;{ }^{31} \mathrm{P}$ NMR (121 MHz, $\left.\mathrm{CDCl}_{3}\right): \delta 21.0$; HRMS for $\mathrm{C}_{17} \mathrm{H}_{29} \mathrm{O}_{6} \mathrm{P}[\mathrm{M}+\mathrm{H}]^{+}$calcd.: 361.1774, found: 361.1771 .

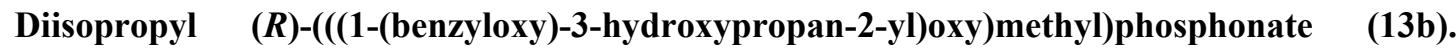

Compound 13b was obtained as a colorless oil ( $3.00 \mathrm{~g}, 51 \%$ over 3 steps) according to the procedure used for the preparation of 13a, starting from compound S-2 (3.00 g, $16.5 \mathrm{mmol}), \mathrm{Et}_{3} \mathrm{~N}(4.6 \mathrm{~mL})$, and DMAP (200 mg, $1.65 \mathrm{mmol})$ in DCM (100 mL), followed by NaH $(950 \mathrm{mg}, 24.7 \mathrm{mmol})$ and triflate diisopropylphosphonomethanol $(8.10 \mathrm{~g}, 24.7 \mathrm{mmol})$ in THF $(150 \mathrm{~mL})$, and finally TsOH. $\mathrm{H}_{2} \mathrm{O}(630 \mathrm{mg}, 3.30 \mathrm{mmol})$ in $\mathrm{MeOH}(100 \mathrm{~mL})$. The crude residue was purified by column chromatography on silica gel (gradient DCM/MeOH, 50:1, v/v; DCM/MeOH, 40:1, v/v). ${ }^{1} \mathrm{H}$ NMR (300 MHz, $\left.\mathrm{CDCl}_{3}\right): \delta$ 7.34-7.28 (m, 5H, $\left.\mathrm{Ar} H\right), 4.83-4.68\left(\mathrm{~m}, 2 \mathrm{H}, \mathrm{CH}\left(\mathrm{CH}_{3}\right)_{2}\right), 4.53\left(\mathrm{~s}, 2 \mathrm{H}, \mathrm{OCH}_{2} \mathrm{Ph}\right)$, 4.05 (dd, $J=14.1,7.4 \mathrm{~Hz}, 1 \mathrm{H}, \mathrm{H}-1$ 'a), 3.83 (dd, $J=14.1,8.3 \mathrm{~Hz}, 1 \mathrm{H}, \mathrm{H}-1$ 'b), 3.76-3.52 (m, 5H, H-2', $\left.\mathrm{PCH}_{2}, \mathrm{H}-3^{\prime}\right), 1.35-1.31$ (m, 12H, $\left.\mathrm{CH}\left(\mathrm{CH}_{3}\right)_{2}\right) ;{ }^{13} \mathrm{C}$ NMR (75 MHz, $\mathrm{CDCl}_{3}$ ): $\delta 138.1(\mathrm{Ar}-\mathrm{C})$, $128.5(\mathrm{Ar}-\mathrm{C}), 127.8(\mathrm{Ar}-\mathrm{C}), 127.7(\mathrm{Ar}-\mathrm{C}), 82.6\left(\mathrm{~d},{ }^{3} J_{\mathrm{C}, \mathrm{P}}=8.3 \mathrm{~Hz}, \mathrm{C}-2^{\prime}\right), 73.6\left(\mathrm{OCH}_{2} \mathrm{Ph}\right), 71.6,71.5$, 71.3, $71.2\left(\mathrm{CH}\left(\mathrm{CH}_{3}\right)_{2}\right), 70.4\left(\mathrm{C}-3^{\prime}\right), 65.4\left(\mathrm{~d},{ }^{1} J_{\mathrm{C}, \mathrm{P}}=168.0 \mathrm{~Hz}, \mathrm{CH}_{2} \mathrm{P}\right), 62.5\left(\mathrm{C}-1^{\prime}\right), 24.2,24.1$ $\left(\mathrm{CH}\left(\mathrm{CH}_{3}\right)_{2}\right) ;{ }^{31} \mathrm{P}$ NMR $\left(121 \mathrm{MHz}, \mathrm{CDCl}_{3}\right): \delta 21.1$; HRMS for $\mathrm{C}_{17} \mathrm{H}_{29} \mathrm{O}_{6} \mathrm{P}[\mathrm{M}+\mathrm{H}]^{+}$calcd.: 361.1774, found: 361.1771 .

\section{Diisopropyl}

(R)-(((1-((4-aminopyrimidin-2-yl)oxy)-3-(benzyloxy)propan-2-

yl)oxy)methyl)phosphonate (16a). Compound 16a was obtained as a white foam (67 mg, 53\% over 2 steps) according to the procedure A, starting from compound 1 (55 mg, $0.36 \mathrm{mmol})$, compound 13a (100 mg, $0.28 \mathrm{mmol}), \mathrm{Ph}_{3} \mathrm{P}$ (146 mg, $\left.0.55 \mathrm{mmol}\right)$, and DIAD (0.11 mL, $\left.0.55 \mathrm{mmol}\right)$ in anhydrous THF $(5 \mathrm{~mL})$, and 30\% methanolic ammonia $(15 \mathrm{~mL})$. The crude residue was purified by column chromatography on silica gel (gradient DCM/MeOH, 40:1, v/v; DCM/MeOH, 30:1, v/v). ${ }^{1} \mathrm{H}$ NMR (600 MHz, CDCl $): \delta 7.97$ (d, $\left.J=5.7 \mathrm{~Hz}, 1 \mathrm{H}, \mathrm{H}-6\right), 7.33-7.27$ (m, 5H, ArH), 6.10 (d, $J=$ $5.7 \mathrm{~Hz}, 1 \mathrm{H}, \mathrm{H}-6), 5.44$ (s, 2H, NH$\left.H_{2}\right), 4.76-4.72\left(\mathrm{~m}, 2 \mathrm{H}, \mathrm{CH}\left(\mathrm{CH}_{3}\right)_{2}\right), 4.55$ (s, 2H, OCH $\left.{ }_{2} \mathrm{Ph}\right), 4.41-$ 4.40 (m, 2H, H-1'), 4.02-4.00 (m, 3H, H-2', PCH $), 3.71-3.69$ (m, 2H, H-3'), 1.32-1.29 (m, 12H, $\left.\mathrm{CH}\left(\mathrm{CH}_{3}\right)_{2}\right) ;{ }^{13} \mathrm{C}$ NMR $\left(150 \mathrm{MHz}, \mathrm{CDCl}_{3}\right): \delta$ 165.1, 165.0 (C-4,C-2), 157.3 (C-6), $138.2(\mathrm{Ar}-\mathrm{C})$, 
128.5 (Ar-C), $127.8(\mathrm{Ar}-\mathrm{C}), 127.7(\mathrm{Ar}-\mathrm{C}), 99.9(\mathrm{C}-5), 79.3\left(\mathrm{~d},{ }^{3} J_{\mathrm{C}, \mathrm{P}}=12.1 \mathrm{~Hz}, \mathrm{C}-2^{\prime}\right), 73.6\left(\mathrm{OCH}_{2} \mathrm{Ph}\right)$,

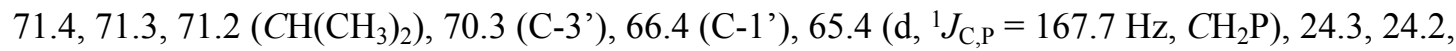
$24.1\left(\mathrm{CH}\left(\mathrm{CH}_{3}\right)_{2}\right) ;{ }^{31} \mathrm{P}$ NMR $\left(121 \mathrm{MHz}, \mathrm{CDCl}_{3}\right): \delta$ 19.5; HRMS for $\mathrm{C}_{21} \mathrm{H}_{33} \mathrm{~N}_{3} \mathrm{O}_{6} \mathrm{P}[\mathrm{M}+\mathrm{H}]^{+}$calcd.: 454.2101, found: 454.2100 .

\section{Diisopropyl}

(S)-(((1-((4-aminopyrimidin-2-yl)oxy)-3-(benzyloxy)propan-2-

yl)oxy)methyl)phosphonate (16b). Compound 16b was obtained as a white foam (160 mg, $42 \%$ over 2 steps) according to the procedure A, starting from compound 1 (166 mg, $1.08 \mathrm{mmol})$, compound 13b (300 mg, $0.83 \mathrm{mmol}), \mathrm{Ph}_{3} \mathrm{P}$ (440 mg, $1.66 \mathrm{mmol}$ ), and DIAD (0.33 mL, $\left.1.66 \mathrm{mmol}\right)$ in anhydrous THF $(10 \mathrm{~mL})$, and 30\% methanolic ammonia $(20 \mathrm{~mL})$. The crude residue was purified by column chromatography on silica gel (gradient DCM/MeOH, 40:1, v/v; DCM/MeOH, 30:1, v/v). ${ }^{1} \mathrm{H}$ NMR $\left(500 \mathrm{MHz}, \mathrm{CDCl}_{3}\right): \delta 7.93(\mathrm{~d}, J=5.7 \mathrm{~Hz}, 1 \mathrm{H}, \mathrm{H}-6), 7.34-7.26(\mathrm{~m}, 5 \mathrm{H}, \mathrm{Ar} H), 6.11(\mathrm{~d}, J=$ $5.8 \mathrm{~Hz}, 1 \mathrm{H}, \mathrm{H}-6), 5.85\left(\mathrm{~s}, 2 \mathrm{H}, \mathrm{NH}_{2}\right), 4.77-4.70\left(\mathrm{~m}, 2 \mathrm{H}, \mathrm{CH}\left(\mathrm{CH}_{3}\right)_{2}\right), 4.54\left(\mathrm{~s}, 2 \mathrm{H}, \mathrm{OCH}_{2} \mathrm{Ph}\right), 4.43-$ 4.35 (m, 2H, H-1'), 4.04-3.97 (m, 3H, H-2', $\mathrm{PCH}_{2}$ ), 3.71-3.65 (m, 2H, H-3'), 1.32-1.28 (m, 12H, $\left.\mathrm{CH}\left(\mathrm{CH}_{3}\right)_{2}\right) ;{ }^{13} \mathrm{C} \mathrm{NMR}\left(125 \mathrm{MHz}, \mathrm{CDCl}_{3}\right): \delta 165.3(\mathrm{C}-4), 164.9$ (C-2), 156.9 (C-6), $138.1(\mathrm{Ar}-\mathrm{C})$, 128.4 (Ar-C), $127.7(\mathrm{Ar}-\mathrm{C}), 100.0(\mathrm{C}-5), 79.3\left(\mathrm{~d},{ }^{3} J_{\mathrm{C}, \mathrm{P}}=12.3 \mathrm{~Hz}, \mathrm{C}-2^{\prime}\right), 73.6\left(\mathrm{OCH}_{2} \mathrm{Ph}\right), 71.4,71.2$ $\left(\mathrm{CH}\left(\mathrm{CH}_{3}\right)_{2}\right), 70.2\left(\mathrm{C}-3^{\prime}\right), 66.4\left(\mathrm{C}-1^{\prime}\right), 65.4\left(\mathrm{~d},{ }^{1} J_{\mathrm{C}, \mathrm{P}}=168.0 \mathrm{~Hz}, \mathrm{CH}_{2} \mathrm{P}\right), 24.2,24.1,24.0\left(\mathrm{CH}\left(\mathrm{CH}_{3}\right)_{2}\right)$; ${ }^{31} \mathrm{P}$ NMR (121 MHz, $\mathrm{CDCl}_{3}$ ): $\delta$ 19.8; HRMS for $\mathrm{C}_{21} \mathrm{H}_{33} \mathrm{~N}_{3} \mathrm{O}_{6} \mathrm{P}[\mathrm{M}+\mathrm{H}]^{+}$calcd.: 454.2101, found: 454.2102

\section{Diisopropyl} (R)-(((1-((4-amino-5-fluoropyrimidin-2-yl)oxy)-3-(benzyloxy)propan-2yl)oxy)methyl)phosphonate (17a). Compound 17a was obtained as a white foam (60 mg, 46\% over 2 steps) according to the procedure A, starting from compound $2(47 \mathrm{mg}, 0.36 \mathrm{mmol})$ and compound 13a (100 mg, $0.28 \mathrm{mmol}), \mathrm{Ph}_{3} \mathrm{P}(220 \mathrm{mg}, 0.84 \mathrm{mmol})$, and DIAD (0.16 mL, $\left.0.84 \mathrm{mmol}\right)$ in anhydrous THF $(5 \mathrm{~mL})$, and $1 \mathrm{M} \mathrm{HCl}(0.5 \mathrm{~mL})$ in $\mathrm{CH}_{3} \mathrm{CN} / \mathrm{H}_{2} \mathrm{O}(10 \mathrm{~mL}, 1: 1, \mathrm{v} / \mathrm{v})$. The crude residue was purified by column chromatography on silica gel (gradient petroleum/EtOAc, 1:2, v/v; petroleum/EtOAc, 1:3, v/v, EtOAc). ${ }^{1} \mathrm{H}$ NMR $\left(300 \mathrm{MHz}, \mathrm{CDCl}_{3}\right): \delta 7.84(\mathrm{~d}, J=2.8 \mathrm{~Hz}, 1 \mathrm{H}, \mathrm{H}-6)$, 7.33-7.26 (m, 5H, $\mathrm{Ar} H), 5.83\left(\mathrm{~s}, 2 \mathrm{H}, \mathrm{NH}_{2}\right), 4.78-4.70\left(\mathrm{~m}, 2 \mathrm{H}, \mathrm{CH}\left(\mathrm{CH}_{3}\right)_{2}\right), 4.55\left(\mathrm{~s}, 2 \mathrm{H}, \mathrm{OCH}_{2} \mathrm{Ph}\right)$, 4.38-4.35 (m, 2H, H-1'), 4.02-3.97 (m, 3H, H-2', $\mathrm{PCH}_{2}$ ), 3.68-3.66 (m, 2H, H-3'), 1.30 (t, $J=6.1$ $\left.\mathrm{Hz}, 12 \mathrm{H}, \mathrm{CH}\left(\mathrm{CH}_{3}\right)_{2}\right) ;{ }^{13} \mathrm{C}$ NMR $\left(75 \mathrm{MHz}, \mathrm{CDCl}_{3}\right): \delta 160.3(\mathrm{C}-2), 154.9\left(\mathrm{~d},{ }^{1} J_{\mathrm{C}, \mathrm{F}}=13.7 \mathrm{~Hz}, \mathrm{C}-4\right)$, $142.8\left(\mathrm{~d},{ }^{2} J_{\mathrm{C}, \mathrm{F}}=247.2 \mathrm{~Hz}, \mathrm{C}-5\right), 140.7\left(\mathrm{~d},{ }^{2} J_{\mathrm{C}, \mathrm{F}}=20.3 \mathrm{~Hz}, \mathrm{C}-6\right), 138.3(\mathrm{Ar}-\mathrm{C}), 128.5$ (Ar-C), 127.7 $(\mathrm{Ar}-\mathrm{C}), 79.3\left(\mathrm{~d},{ }^{3} J_{\mathrm{C}, \mathrm{P}}=11.1 \mathrm{~Hz}, \mathrm{C}-2^{\prime}\right), 73.6\left(\mathrm{OCH}_{2} \mathrm{Ph}\right), 71.3,71.2,71.1\left(\mathrm{CH}\left(\mathrm{CH}_{3}\right)_{2}\right), 70.2\left(\mathrm{C}-3^{\prime}\right)$, 
$67.2\left(\mathrm{C}-1{ }^{\prime}\right), 65.5\left(\mathrm{~d},{ }^{1} J_{\mathrm{C}, \mathrm{P}}=167.6 \mathrm{~Hz}, \mathrm{CH}_{2} \mathrm{P}\right), 24.2,24.1,24.0\left(\mathrm{CH}\left(\mathrm{CH}_{3}\right)_{2}\right) ;{ }^{31} \mathrm{P}$ NMR $(121 \mathrm{MHz}$, $\left.\mathrm{CDCl}_{3}\right): \delta$ 19.7; HRMS for $\mathrm{C}_{21} \mathrm{H}_{32} \mathrm{FN}_{3} \mathrm{O}_{6} \mathrm{P}[\mathrm{M}+\mathrm{H}]^{+}$calcd.: 472.2009, found: 472.2007 .

Diisopropyl

(S)-(((1-((4-amino-5-fluoropyrimidin-2-yl)oxy)-3-(benzyloxy)propan-2-

yl)oxy)methyl)phosphonate (17b). Compound $\mathbf{1 7 b}$ was obtained as a white foam (120 mg, 31\% over 2 steps) according to the procedure A, starting from compound 2 (140 mg, $1.08 \mathrm{mmol})$ and compound 13b (300 mg, $0.83 \mathrm{mmol}), \mathrm{Ph}_{3} \mathrm{P}(650 \mathrm{mg}, 2.50 \mathrm{mmol})$, and DIAD (0.49 mL, $\left.2.50 \mathrm{mmol}\right)$ in anhydrous THF $(10 \mathrm{~mL})$, and $1 \mathrm{M} \mathrm{HCl}(0.5 \mathrm{~mL})$ in $\mathrm{CH}_{3} \mathrm{CN} / \mathrm{H}_{2} \mathrm{O}(10 \mathrm{~mL}, 1: 1, \mathrm{v} / \mathrm{v})$. The crude residue was purified by column chromatography on silica gel (gradient petroleum/EtOAc, 1:2, v/v; petroleum/EtOAc, 1:3, v/v, EtOAc). ${ }^{1} \mathrm{H}$ NMR (300 MHz, $\mathrm{CDCl}_{3}$ ): $\delta 7.83$ (d, $\left.J=2.8 \mathrm{~Hz}, 1 \mathrm{H}, \mathrm{H}-6\right)$, 7.33-7.27 (m, 5H, $\mathrm{ArH}), 6.03$ (s, 2H, NH$\left.H_{2}\right), 4.79-4.69$ (m, 2H, $\left.\mathrm{CH}\left(\mathrm{CH}_{3}\right)_{2}\right), 4.55$ (s, 2H, OCH${ }_{2} \mathrm{Ph}$ ), 4.40-4.30 (m, 2H, H-1'), 4.04-3.98 (m, 3H, H-2', $\mathrm{PCH}_{2}$ ), 3.69-3.66 (m, 2H, H-3'), 1.30 (t, $J=6.1$ $\left.\mathrm{Hz}, 12 \mathrm{H}, \mathrm{CH}\left(\mathrm{CH}_{3}\right)_{2}\right) ;{ }^{13} \mathrm{C} \mathrm{NMR}\left(75 \mathrm{MHz}, \mathrm{CDCl}_{3}\right): \delta 160.3(\mathrm{C}-2), 155.0\left(\mathrm{~d},{ }^{1} J_{\mathrm{C}, \mathrm{F}}=13.7 \mathrm{~Hz}, \mathrm{C}-4\right)$, $142.8\left(\mathrm{~d},{ }^{2} J_{\mathrm{C}, \mathrm{F}}=247.0 \mathrm{~Hz}, \mathrm{C}-5\right), 140.6\left(\mathrm{~d},{ }^{2} J_{\mathrm{C}, \mathrm{F}}=20.4 \mathrm{~Hz}, \mathrm{C}-6\right), 138.2(\mathrm{Ar}-\mathrm{C}), 128.5(\mathrm{Ar}-\mathrm{C}), 127.7$ (Ar-C), $79.2\left(\mathrm{~d},{ }^{3} J_{\mathrm{C}, \mathrm{P}}=11.1 \mathrm{~Hz}, \mathrm{C}-2^{\prime}\right), 73.6\left(\mathrm{OCH}_{2} \mathrm{Ph}\right), 71.3,71.2,71.1\left(\mathrm{CH}_{(}\left(\mathrm{CH}_{3}\right)_{2}\right), 70.2\left(\mathrm{C}-3^{\prime}\right)$, $67.2\left(\mathrm{C}-1\right.$ ') $, 65.4\left(\mathrm{~d},{ }^{1} J_{\mathrm{C}, \mathrm{P}}=167.8 \mathrm{~Hz}, \mathrm{CH}_{2} \mathrm{P}\right), 24.2,24.1,24.0\left(\mathrm{CH}\left(\mathrm{CH}_{3}\right)_{2}\right) ;{ }^{31} \mathrm{P} \mathrm{NMR}(121 \mathrm{MHz}$, $\mathrm{CDCl}_{3}$ ): $\delta$ 19.7; HRMS for $\mathrm{C}_{21} \mathrm{H}_{32} \mathrm{FN}_{3} \mathrm{O}_{6} \mathrm{P}[\mathrm{M}+\mathrm{H}]^{+}$calcd.: 472.2009, found: 472.2016 .

(R)-(((1-((4-aminopyrimidin-2-yl)oxy)-3-(benzyloxy)propan-2-yl)oxy)methyl)phosphonic acid (18a). Compound 18a was obtained as a white foam $(80 \mathrm{mg}, 70 \%)$ according to the procedure B, starting from compound $16 \mathrm{a}(150 \mathrm{mg}, 0.33 \mathrm{mmol})$, bromotrimethylsilane $(0.35 \mathrm{~mL}, 2.65 \mathrm{mmol})$, and 2,6-lutidine $(0.61 \mathrm{~mL}, 5.29 \mathrm{mmol})$ in anhydrous acetonitrile $(10 \mathrm{~mL})$. The crude residue was purified by column chromatography on silica gel (gradient acetone $/ \mathrm{H}_{2} \mathrm{O} / \mathrm{Et}_{3} \mathrm{~N}, 5: 1: 1, \mathrm{v} / \mathrm{v} / \mathrm{v}$; acetone $\left./ \mathrm{H}_{2} \mathrm{O} / \mathrm{Et}_{3} \mathrm{~N}, 4: 1: 1, \mathrm{v} / \mathrm{v} / \mathrm{v}\right) .{ }^{1} \mathrm{H} \mathrm{NMR}(300 \mathrm{MHz}, \mathrm{CD} 3 \mathrm{OD}): \delta 7.85$ (d, $\left.J=6.0 \mathrm{~Hz}, 1 \mathrm{H}, \mathrm{H}-6\right)$, 7.37-7.26 (m, 5H, ArH), 6.19 (d, $J=5.9 \mathrm{~Hz}, 1 \mathrm{H}, \mathrm{H}-5), 4.56$ (s, 2H, OCH$\left.{ }_{2} \mathrm{Ph}\right), 4.44$ (d, J=5.0 Hz, 2H, H-1'), 3.97-3.94 (m, 1H, H-2'), 3.84-3.73 (m, 4H, H-3', PCH $)$ ); ${ }^{13} \mathrm{C}$ NMR (75 MHz, CD3OD): $\delta 167.3(\mathrm{C}-4), 165.7$ (C-2), 156.4 (C-6), $139.6(\mathrm{Ar}-C), 129.3$ (Ar-C), 128.8 (Ar-C), 128.6 (Ar-C), $100.4(\mathrm{C}-5), 80.0\left(\mathrm{~d},{ }^{3} J_{\mathrm{C}, \mathrm{P}}=11.5 \mathrm{~Hz}, \mathrm{C}-2^{\prime}\right), 74.5\left(\mathrm{OCH}_{2} \mathrm{Ph}\right), 70.7\left(\mathrm{C}-3{ }^{\prime}\right), 68.6\left(\mathrm{~d},{ }^{1} J_{\mathrm{C}, \mathrm{P}}=158.0 \mathrm{~Hz}\right.$, $\left.\mathrm{CH}_{2} \mathrm{P}\right), 67.1$ (C-1'); ${ }^{31} \mathrm{P}$ NMR (121 MHz, CD3OD): $\delta$ 14.8; HRMS for $\mathrm{C}_{15} \mathrm{H}_{19} \mathrm{~N}_{3} \mathrm{O}_{6} \mathrm{P}[\mathrm{M}-\mathrm{H}]^{-}$calcd.: 368.1017, found: 368.1010 .

(S)-(((1-((4-aminopyrimidin-2-yl)oxy)-3-(benzyloxy)propan-2-yl)oxy)methyl)phosphonic acid

(18b). Compound 18b was obtained as a white foam ( $85 \mathrm{mg}, 75 \%$ ) according to the procedure B, 
starting from compound $\mathbf{1 6 b}(150 \mathrm{mg}, 0.33 \mathrm{mmol})$, bromotrimethylsilane $(0.35 \mathrm{~mL}, 2.65 \mathrm{mmol})$, and 2,6-lutidine $(0.61 \mathrm{~mL}, 5.29 \mathrm{mmol})$ in anhydrous acetonitrile $(10 \mathrm{~mL})$. The crude residue was purified by column chromatography on silica gel (gradient acetone $/ \mathrm{H}_{2} \mathrm{O} / \mathrm{Et}_{3} \mathrm{~N}, 5: 1: 1, \mathrm{v} / \mathrm{v} / \mathrm{v}$; acetone $\left./ \mathrm{H}_{2} \mathrm{O} / \mathrm{Et}_{3} \mathrm{~N}, 4: 1: 1, \mathrm{v} / \mathrm{v} / \mathrm{v}\right) .{ }^{1} \mathrm{H}$ NMR (600 MHz, CD3OD): $\delta 7.82(\mathrm{~d}, J=5.9 \mathrm{~Hz}, 1 \mathrm{H}, \mathrm{H}-6)$, 7.33-7.24 (m, 5H, $\mathrm{Ar} H), 6.14$ (d, $J=5.9 \mathrm{~Hz}, 1 \mathrm{H}, \mathrm{H}-5), 4.55$ (d, $\left.2 \mathrm{H}, J=1.8 \mathrm{~Hz}, \mathrm{OCH}_{2} \mathrm{Ph}\right), 4.44-4.41$ (m, 2H, H-1'), 3.92-3.90 (m, 1H, H-2'), 3.81-3.70 (m, 4H, H-3', $\left.\mathrm{PCH}_{2}\right) ;{ }^{13} \mathrm{C}$ NMR (150 MHz, CD3OD): $\delta 167.3$ (C-4), 166.1 (C-2), 157.0 (C-6), 139.7 (Ar-C), 129.3 (Ar-C), 128.9 (Ar-C), 128.6 (Ar-C), $100.3(\mathrm{C}-5), 80.0\left(\mathrm{~d},{ }^{3} J_{\mathrm{C}, \mathrm{P}}=11.1 \mathrm{~Hz}, \mathrm{C}-2^{\prime}\right), 74.5\left(\mathrm{OCH}_{2} \mathrm{Ph}\right), 70.7\left(\mathrm{C}-3{ }^{\prime}\right), 68.9\left(\mathrm{~d},{ }^{1} J_{\mathrm{C}, \mathrm{P}}=\right.$ $\left.156.5 \mathrm{~Hz}, \mathrm{CH}_{2} \mathrm{P}\right), 66.8\left(\mathrm{C}-1^{\prime}\right)$; ${ }^{31} \mathrm{P}$ NMR (121 MHz, CD3OD): $\delta$ 14.1; HRMS for $\mathrm{C}_{15} \mathrm{H}_{19} \mathrm{~N}_{3} \mathrm{O}_{6} \mathrm{P}$ [MH]- calcd.: 368.1017 , found: 368.1016 .

\section{(R)-(((1-((4-amino-5-fluoropyrimidin-2-yl)oxy)-3-(benzyloxy)propan-2-}

yl)oxy)methyl)phosphonic acid (19a). Compound 19a was obtained as a white foam (97 mg, 70\%) according to the procedure $\mathrm{B}$, starting from compound 17a (170 $\mathrm{mg}, 0.36 \mathrm{mmol})$, bromotrimethylsilane $(0.38 \mathrm{~mL}, 2.88 \mathrm{mmol})$, and 2,6-lutidine $(0.67 \mathrm{~mL}, 5.77 \mathrm{mmol})$ in anhydrous acetonitrile $(10 \mathrm{~mL})$. The crude residue was purified by column chromatography on silica gel (gradient acetone $/ \mathrm{H}_{2} \mathrm{O} / \mathrm{Et}_{3} \mathrm{~N}, 8: 1: 1, \mathrm{v} / \mathrm{v} / \mathrm{v}$; acetone $\left./ \mathrm{H}_{2} \mathrm{O} / \mathrm{Et}_{3} \mathrm{~N}, 6: 1: 1, \mathrm{v} / \mathrm{v} / \mathrm{v}\right) .{ }^{1} \mathrm{H}$ NMR $(300 \mathrm{MHz}$, CD3OD): $\delta 7.82(\mathrm{~d}, J=3.4 \mathrm{~Hz}, 1 \mathrm{H}, \mathrm{H}-6), 7.37-7.28(\mathrm{~m}, 5 \mathrm{H}, \mathrm{Ar} H), 4.57$ (s, 2H, OCH $\left.\mathrm{H}_{2} \mathrm{Ph}\right), 4.41(\mathrm{~d}$, $\left.J=5.2 \mathrm{~Hz}, 2 \mathrm{H}, \mathrm{H}-1^{\prime}\right), 3.96-3.92$ (m, 1H, H-2'), 3.82-3.72 (m, 4H, H-3', $\left.\mathrm{PCH}_{2}\right) ;{ }^{13} \mathrm{C}$ NMR (75 MHz, CD3OD): $\delta 161.7(\mathrm{C}-2), 157.0\left(\mathrm{~d},{ }^{1} J_{\mathrm{C}, \mathrm{F}}=13.8 \mathrm{~Hz}, \mathrm{C}-4\right), 143.6\left(\mathrm{~d},{ }^{2} J_{\mathrm{C}, \mathrm{F}}=245.7 \mathrm{~Hz}, \mathrm{C}-5\right), 140.8(\mathrm{~d}$, $\left.{ }^{2} J_{\mathrm{C}, \mathrm{F}}=21.1 \mathrm{~Hz}, \mathrm{C}-6\right), 139.7(\mathrm{Ar}-\mathrm{C}), 129.3(\mathrm{Ar}-\mathrm{C}), 128.9(\mathrm{Ar}-\mathrm{C}), 128.6(\mathrm{Ar}-\mathrm{C}), 79.9\left(\mathrm{~d},{ }^{3} J_{\mathrm{C}, \mathrm{P}}=11.1\right.$ $\left.\mathrm{Hz}, \mathrm{C}-2^{\prime}\right), 74.5\left(\mathrm{OCH}_{2} \mathrm{Ph}\right), 70.8\left(\mathrm{C}-3{ }^{\prime}\right), 68.5\left(\mathrm{~d},{ }^{1} J_{\mathrm{C}, \mathrm{P}}=150.0 \mathrm{~Hz}, \mathrm{CH}_{2} \mathrm{P}\right), 67.6\left(\mathrm{C}-1^{\prime}\right) ;{ }^{31} \mathrm{P}$ NMR (121 MHz, CD3OD): $\delta$ 14.7; HRMS for $\mathrm{C}_{15} \mathrm{H}_{18} \mathrm{FN}_{3} \mathrm{O}_{6} \mathrm{P}$ [M-H]- calcd.: 386.0923 , found: 386.0921 .

\section{(S)-(((1-((4-amino-5-fluoropyrimidin-2-yl)oxy)-3-(benzyloxy)propan-2-}

yl)oxy)methyl)phosphonic acid (19b). Compound 19b was obtained as a white foam (69 mg, 70\%) according to the procedure $\mathrm{B}$, starting from compound $\mathbf{1 7 b}(120 \mathrm{mg}, 0.25 \mathrm{mmol})$, bromotrimethylsilane $(0.27 \mathrm{~mL}, 2.04 \mathrm{mmol})$, and 2,6-lutidine $(0.47 \mathrm{~mL}, 4.07 \mathrm{mmol})$ in anhydrous acetonitrile $(10 \mathrm{~mL})$. The crude residue was purified by column chromatography on silica gel (gradient acetone $/ \mathrm{H}_{2} \mathrm{O} / \mathrm{Et}_{3} \mathrm{~N}, 8: 1: 1, \mathrm{v} / \mathrm{v} / \mathrm{v}$; acetone $\left./ \mathrm{H}_{2} \mathrm{O} / \mathrm{Et}_{3} \mathrm{~N}, 6: 1: 1, \mathrm{v} / \mathrm{v} / \mathrm{v}\right) .{ }^{1} \mathrm{H} \mathrm{NMR}(600 \mathrm{MHz}$, CD3OD): $\delta 7.80$ (d, $J=3.4 \mathrm{~Hz}, 1 \mathrm{H}, \mathrm{H}-6), 7.34-7.24$ (m, 5H, $\mathrm{ArH}), 4.55$ (s, 2H, OCH $\left.\mathrm{P}_{2} \mathrm{Ph}\right), 4.39$ (dd, $\left.J=5.1,1.7 \mathrm{~Hz}, 2 \mathrm{H}, \mathrm{H}-1^{\prime}\right), 3.92-3.90$ (m, 1H, H-2'), 3.81-3.69 (m, 4H, H-3', $\left.\mathrm{PCH}_{2}\right) ;{ }^{13} \mathrm{C}$ NMR $(150$ 
MHz, CD3OD): $\delta 161.7(\mathrm{C}-2), 157.0\left(\mathrm{~d},{ }^{1} J_{\mathrm{C}, \mathrm{F}}=14.2 \mathrm{~Hz}, \mathrm{C}-4\right), 143.6\left(\mathrm{~d},{ }^{2} J_{\mathrm{C}, \mathrm{F}}=245.0 \mathrm{~Hz}, \mathrm{C}-5\right)$, $140.7\left(\mathrm{~d},{ }^{2} J_{\mathrm{C}, \mathrm{F}}=21.1 \mathrm{~Hz}, \mathrm{C}-6\right), 139.6(\mathrm{Ar}-C), 129.3(\mathrm{Ar}-\mathrm{C}), 128.9(\mathrm{Ar}-\mathrm{C}), 128.6(\mathrm{Ar}-C), 79.9(\mathrm{~d}$, $\left.{ }^{3} J_{\mathrm{C}, \mathrm{P}}=11.7 \mathrm{~Hz}, \mathrm{C}-2^{\prime}\right), 74.5\left(\mathrm{OCH}_{2} \mathrm{Ph}\right), 70.7\left(\mathrm{C}-3^{\prime}\right), 68.6\left(\mathrm{~d},{ }^{1} J_{\mathrm{C}, \mathrm{P}}=157.4 \mathrm{~Hz}, \mathrm{CH}_{2} \mathrm{P}\right), 67.5\left(\mathrm{C}-1^{\prime}\right)$; ${ }^{31} \mathrm{P}$ NMR (121 MHz, CD3OD): $\delta$ 14.5; HRMS for $\mathrm{C}_{15} \mathrm{H}_{18} \mathrm{FN}_{3} \mathrm{O}_{6} \mathrm{P}[\mathrm{M}-\mathrm{H}]^{-}$calcd.: 386.0923, found: 386.0921 .

Pentyl ((5S)-5-(((4-aminopyrimidin-2-yl)oxy)methyl)-2-oxido-1,4,2-dioxaphosphinan-2-yl)-Lvalinate (22a). Compound 22a was obtained as a colorless oil (20 mg, 30\% over 2 steps) according to the procedure $\mathrm{C}$, starting from compound $18 \mathrm{a}(57 \mathrm{mg}, 0.16 \mathrm{mmol})$, L-valine amyl ester $\mathrm{HCl}$ salt (60 mg, $0.27 \mathrm{mmol}), \mathrm{PhOH}(65 \mathrm{mg}, 0.69 \mathrm{mmol}), \mathrm{Et}_{3} \mathrm{~N}(0.22 \mathrm{~mL}, 1.60 \mathrm{mmol}), 2,2^{\prime}$-dithiodipyridine (240 mg, $1.10 \mathrm{mmol})$, and $\mathrm{PPh}_{3}(287 \mathrm{mg}, 1.10 \mathrm{mmol})$ in anhydrous pyridine $(5 \mathrm{~mL})$, and $1 \mathrm{M} \mathrm{BCl}_{3}$ $(0.48 \mathrm{~mL}, 0.48 \mathrm{mmol})$ in DCM $(5 \mathrm{~mL})$. The crude residue was purified by column chromatography on silica gel (gradient DCM/MeOH, 20:1, v/v; 15:1, v/v). ${ }^{1} \mathrm{H}$ NMR (300 MHz, CD3OD): $\delta 7.87$, $7.85(2 \mathrm{~d}, J=6.0 \mathrm{~Hz}, 1 \mathrm{H}, \mathrm{H}-6), 6.18,6.15(2 \mathrm{~d}, J=6.0 \mathrm{~Hz}, 1 \mathrm{H}, \mathrm{H}-5), 4.52-3.73$ (m, 10H, H-3', H2', H-1', $\mathrm{OCH}_{2}\left(\mathrm{CH}_{2}\right)_{3} \mathrm{CH}_{3}, \mathrm{PCH}$, Val-CHCH$\left.\left(\mathrm{CH}_{3}\right)_{2}\right), 2.16-2.09$ (m, 1H, Val-CHCH$\left.\left(\mathrm{CH}_{3}\right)_{2}\right)$, 1.71$1.64\left(\mathrm{~m}, 2 \mathrm{H}, \mathrm{OCH}_{2} \mathrm{CH}_{2}\left(\mathrm{CH}_{2}\right)_{2} \mathrm{CH}_{3}\right), 1.42-1.35\left(\mathrm{~m}, 4 \mathrm{H}, \mathrm{O}\left(\mathrm{CH}_{2}\right)_{2}\left(\mathrm{CH}_{2}\right)_{2} \mathrm{CH}_{3}\right), 1.02-0.89$ (m, 9H, $\mathrm{O}\left(\mathrm{CH}_{2}\right)_{4} \mathrm{CH}_{3}$, Val-CHCH$\left.\left(\mathrm{CH}_{3}\right)_{2}\right) ;{ }^{13} \mathrm{C}$ NMR $(75 \mathrm{MHz}, \mathrm{CD} 3 \mathrm{OD}): \delta 174.5\left(\mathrm{~d},{ }^{3} J_{\mathrm{C}, \mathrm{P}}=3.3 \mathrm{~Hz}\right.$, ValCO), $174.3\left(\mathrm{~d},{ }^{3} J_{\mathrm{C}, \mathrm{P}}=2.4 \mathrm{~Hz}\right.$, Val-CO), $167.3(\mathrm{C}-4), 165.8,165.7$ (C-2), 157.1, $157.0(\mathrm{C}-6), 100.6$ (C-5), $75.4\left(\mathrm{~d},{ }^{3} J_{\mathrm{C}, \mathrm{P}}=4.4 \mathrm{~Hz}, \mathrm{C}-2\right.$ ') $74.5\left(\mathrm{~d},{ }^{3} J_{\mathrm{C}, \mathrm{P}}=4.4 \mathrm{~Hz}, \mathrm{C}-2\right.$ ') $, 71.3,71.2$ (C-3'), 67.8, 66.5, 66.3, 66.0, 65.9, 65.7, 64.7, $64.5\left(\mathrm{CH}_{2} \mathrm{P}, \mathrm{OCH}_{2}\left(\mathrm{CH}_{2}\right)_{3} \mathrm{CH}_{3}, \mathrm{C}-1\right.$ '), 60.6, $60.4\left(\mathrm{Val}-\mathrm{CHCH}\left(\mathrm{CH}_{3}\right)_{2}\right)$, 32.9, 32.8, 32.7 (Val-CHCH$\left.\left(\mathrm{CH}_{3}\right)_{2}\right)$, 29.4, $29.2\left(\mathrm{OCH}_{2}\left(\mathrm{CH}_{2}\right)_{2} \mathrm{CH}_{2} \mathrm{CH}_{3}\right), 23.3\left(\mathrm{O}\left(\mathrm{CH}_{2}\right)_{3} \mathrm{CH}_{2} \mathrm{CH}_{3}\right)$,

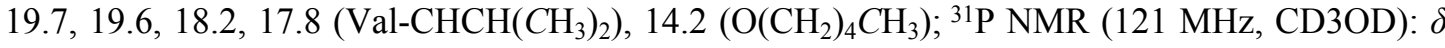
18.4, 17.8; HRMS for $\mathrm{C}_{18} \mathrm{H}_{32} \mathrm{~N}_{4} \mathrm{O}_{6} \mathrm{P}[\mathrm{M}+\mathrm{H}]^{+}$calcd.: 431.2054, found: 431.2048 .

Pentyl ((5R)-5-(((4-aminopyrimidin-2-yl)oxy)methyl)-2-oxido-1,4,2-dioxaphosphinan-2-yl)-Lvalinate (22b). Compound 22b was obtained as a colorless oil (23 mg, 30\% over 2 steps) according to the procedure $\mathrm{C}$, starting from compound $\mathbf{1 8 b}$ ( $66 \mathrm{mg}, 0.18 \mathrm{mmol})$, L-valine amyl ester $\mathrm{HCl}$ salt (68 mg, $0.30 \mathrm{mmol}), \mathrm{PhOH}$ (74 mg, $0.78 \mathrm{mmol}), \mathrm{Et}_{3} \mathrm{~N}$ (0.25 mL, $\left.1.80 \mathrm{mmol}\right), 2,2^{\prime}$-dithiodipyridine (275 mg, $1.25 \mathrm{mmol})$, and $\mathrm{PPh}_{3}(328 \mathrm{mg}, 1.25 \mathrm{mmol})$ in anhydrous pyridine $(5 \mathrm{~mL})$, and $1 \mathrm{M} \mathrm{BCl}_{3}$ $(0.54 \mathrm{~mL}, 0.54 \mathrm{mmol})$ in DCM $(5 \mathrm{~mL})$. The crude residue was purified by column chromatography on silica gel (gradient DCM/MeOH, 20:1, v/v; 15:1, v/v). ${ }^{1} \mathrm{H}$ NMR (300 MHz, CD3OD): $\delta$ 7.84, $7.83(2 \mathrm{~d}, J=6.0 \mathrm{~Hz}, 1 \mathrm{H}, \mathrm{H}-6), 6.16,6.15(2 \mathrm{~d}, J=6.0 \mathrm{~Hz}, 1 \mathrm{H}, \mathrm{H}-5), 4.48-3.68$ (m, 10H, H-3', H- 
2', H-1', $\mathrm{OCH}_{2}\left(\mathrm{CH}_{2}\right)_{3} \mathrm{CH}_{3}, \mathrm{PCH}{ }_{2}$, Val-CHCH$\left.\left(\mathrm{CH}_{3}\right)_{2}\right), 2.19-2.06$ (m, 1H, Val-CHCH$\left.\left(\mathrm{CH}_{3}\right)_{2}\right), 1.68$ $1.63\left(\mathrm{~m}, 2 \mathrm{H}, \mathrm{OCH}_{2} \mathrm{CH}_{2}\left(\mathrm{CH}_{2}\right)_{2} \mathrm{CH}_{3}\right), 1.39-1.33\left(\mathrm{~m}, 4 \mathrm{H}, \mathrm{O}\left(\mathrm{CH}_{2}\right)_{2}\left(\mathrm{CH}_{2}\right)_{2} \mathrm{CH}_{3}\right), 0.99-0.88(\mathrm{~m}, 9 \mathrm{H}$, $\mathrm{O}\left(\mathrm{CH}_{2}\right)_{4} \mathrm{CH}_{3}$, Val- $\left.\mathrm{CHCH}\left(\mathrm{CH}_{3}\right)_{2}\right) ;{ }^{13} \mathrm{C}$ NMR (75 MHz, CD3OD): $\delta$ 174.7, 174.6 (Val-CO), 167.3 (C-4), 165.8, 165.7 (C-2), 157.2 (C-6), 100.6 (C-5), 75.5 (d, ${ }^{3} J_{\mathrm{C}, \mathrm{P}}=4.4 \mathrm{~Hz}, \mathrm{C}-2$ '), 75.0 (d, ${ }^{3} J_{\mathrm{C}, \mathrm{P}}=$ 5.2 Hz, C-2'), 71.5, 71.4, 71.3 (C-3'), 68.5, 66.7, 66.3, 66.0, 65.8, $64.5\left(\mathrm{CH}_{2} \mathrm{P}, \mathrm{OCH}_{2}\left(\mathrm{CH}_{2}\right)_{3} \mathrm{CH}_{3}\right.$, C-1'), 60.6, 59.8 (Val- $\left.\mathrm{CHCH}\left(\mathrm{CH}_{3}\right)_{2}\right), \quad 33.1, \quad 33.0, \quad 32.5 \quad\left(\mathrm{Val}-\mathrm{CHCH}\left(\mathrm{CH}_{3}\right)_{2}\right), \quad 29.4, \quad 29.2$

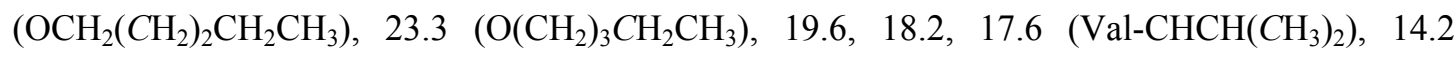
$\left(\mathrm{O}\left(\mathrm{CH}_{2}\right)_{4} \mathrm{CH}_{3}\right) ;{ }^{31} \mathrm{P}$ NMR (121 MHz, CD3OD): $\delta$ 18.8, 18.3; HRMS for $\mathrm{C}_{18} \mathrm{H}_{32} \mathrm{~N}_{4} \mathrm{O}_{6} \mathrm{P}[\mathrm{M}+\mathrm{H}]^{+}$calcd.: 431.2054, found: 431.2051

Pentyl

((5S)-5-(((4-amino-5-fluoropyrimidin-2-yl)oxy)methyl)-2-oxido-1,4,2-

dioxaphosphinan-2-yl)-L-valinate (23a). Compound 23a was obtained as a colorless oil (36 mg, $25 \%$ over 2 steps) according to the procedure $\mathrm{C}$, starting from compound $19 \mathrm{a}(120 \mathrm{mg}, 0.32 \mathrm{mmol})$, L-valine amyl ester $\mathrm{HCl}$ salt (122 mg, $0.55 \mathrm{mmol}), \mathrm{PhOH}(133 \mathrm{mg}, 1.42 \mathrm{mmol}), \mathrm{Et}_{3} \mathrm{~N}(0.44 \mathrm{~mL}$, $3.22 \mathrm{mmol}$ ), 2,2'-dithiodipyridine (500 $\mathrm{mg}, 2.25 \mathrm{mmol}$ ), and $\mathrm{PPh}_{3}(590 \mathrm{mg}, 2.25 \mathrm{mmol})$ in anhydrous pyridine $(5 \mathrm{~mL})$, and $1 \mathrm{M} \mathrm{BCl}_{3}(0.95 \mathrm{~mL}, 0.95 \mathrm{mmol})$ in $\mathrm{DCM}(5 \mathrm{~mL}) .$. The crude residue was purified by column chromatography on silica gel (gradient DCM/MeOH, 50:1, v/v; 40:1, v/v). ${ }^{1} \mathrm{H}$ NMR (300 MHz, CD3OD): 7.82, 7.81 (2d, $\left.J=3.5 \mathrm{~Hz}, 1 \mathrm{H}, \mathrm{H}-6\right), 4.51-3.72$ (m, 10H, H-3', H2', H-1', $\mathrm{OCH}_{2}\left(\mathrm{CH}_{2}\right)_{3} \mathrm{CH}_{3}, \mathrm{PCH}$, Val-CHCH$\left.\left(\mathrm{CH}_{3}\right)_{2}\right), 2.18-2.02$ (m, 1H, Val-CHCH $\left.\left(\mathrm{CH}_{3}\right)_{2}\right), 1.71$ $1.62\left(\mathrm{~m}, 2 \mathrm{H}, \mathrm{OCH}_{2} \mathrm{CH}_{2}\left(\mathrm{CH}_{2}\right)_{2} \mathrm{CH}_{3}\right), 1.42-1.26\left(\mathrm{~m}, 4 \mathrm{H}, \mathrm{O}\left(\mathrm{CH}_{2}\right)_{2}\left(\mathrm{CH}_{2}\right)_{2} \mathrm{CH}_{3}\right), 1.00-0.86(\mathrm{~m}, 9 \mathrm{H}$, $\mathrm{O}\left(\mathrm{CH}_{2}\right)_{4} \mathrm{CH}_{3}$, Val-CHCH$\left.\left(\mathrm{CH}_{3}\right)_{2}\right) ;{ }^{13} \mathrm{C}$ NMR $(75 \mathrm{MHz}, \mathrm{CD} 3 \mathrm{OD}): \delta 174.5\left(\mathrm{~d},{ }^{3} J_{\mathrm{C}, \mathrm{P}}=3.7 \mathrm{~Hz}\right.$, Val$C O), 174.3\left(\mathrm{~d},{ }^{3} J_{\mathrm{C}, \mathrm{P}}=2.5 \mathrm{~Hz}\right.$, Val-CO), 161.3, $161.2(\mathrm{C}-2), 157.0\left(\mathrm{~d},{ }^{1} J_{\mathrm{C}, \mathrm{F}}=14.1 \mathrm{~Hz}, \mathrm{C}-4\right), 143.8$ $\left(\mathrm{d},{ }^{2} J_{\mathrm{C}, \mathrm{F}}=245.5 \mathrm{~Hz}, \mathrm{C}-5\right), 140.8\left(\mathrm{~d},{ }^{2} J_{\mathrm{C}, \mathrm{F}}=21.1 \mathrm{~Hz}, \mathrm{C}-6\right), 75.4\left(\mathrm{~d},{ }^{3} J_{\mathrm{C}, \mathrm{P}}=4.4 \mathrm{~Hz}, \mathrm{C}-2\right.$ ') $74.5(\mathrm{~d}$, $\left.{ }^{3} J_{\mathrm{C}, \mathrm{P}}=5.2 \mathrm{~Hz}, \mathrm{C}-2^{\prime}\right), 71.2,71.1\left(\mathrm{C}-3^{\prime}\right), 67.8,66.6,66.5,66.4,66.3,66.0,64.7\left(\mathrm{CH}_{2} \mathrm{P}\right.$, $\mathrm{OCH}_{2}\left(\mathrm{CH}_{2}\right)_{3} \mathrm{CH}_{3}, \mathrm{C}-1$ '), 60.6, 60.3 (Val- $\left.\mathrm{CHCH}\left(\mathrm{CH}_{3}\right)_{2}\right)$, 32.9, 32.8, 32.7 (Val-CHCH$\left.\left(\mathrm{CH}_{3}\right)_{2}\right)$, , 29.4,

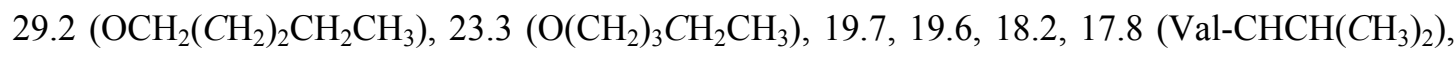

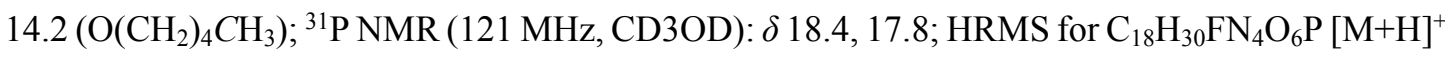
calcd.: 449.1960, found: 449.1960 .

Pentyl

((5R)-5-(((4-amino-5-fluoropyrimidin-2-yl)oxy)methyl)-2-oxido-1,4,2-

dioxaphosphinan-2-yl)-L-valinate (23b). Compound 23b was obtained as a colorless oil (15 mg, $25 \%$ over 2 steps) according to the procedure C, starting from compound $19 b$ ( $50 \mathrm{mg}, 0.13 \mathrm{mmol}$ ), 
L-valine amyl ester $\mathrm{HCl}$ salt (50 mg, $0.22 \mathrm{mmol}), \mathrm{PhOH}$ (54 mg, $0.57 \mathrm{mmol}), \mathrm{Et}_{3} \mathrm{~N}$ (0.18 mL, 1.30 mmol), 2,2'-dithiodipyridine (200 mg, $0.90 \mathrm{mmol})$, and $\mathrm{PPh}_{3}(240 \mathrm{mg}, 0.90 \mathrm{mmol})$ in anhydrous pyridine $(5 \mathrm{~mL})$, and $1 \mathrm{M} \mathrm{BCl}_{3}(0.40 \mathrm{~mL}, 040 \mathrm{mmol})$ in DCM $(5 \mathrm{~mL})$. The crude residue was purified by column chromatography on silica gel (gradient DCM/MeOH, 50:1, v/v; 40:1, v/v). ${ }^{1} \mathrm{H}$ NMR (300 MHz, CDCl3): $\delta 7.88,7.87$ (2s, 1H, H-6), 5.47, 5.40 (2s, 2H, NH $\left.H_{2}\right), 4.59-3.17$ (m, 10H, H-3', H-2', H-1', $\mathrm{OCH}_{2}\left(\mathrm{CH}_{2}\right)_{3} \mathrm{CH}_{3}, \quad \mathrm{PCH}_{2}, \quad$ Val- $\left.\mathrm{CHCH}\left(\mathrm{CH}_{3}\right)_{2}\right), 2.17-2.11$ (m, 1H, Val$\left.\mathrm{CHCH}\left(\mathrm{CH}_{3}\right)_{2}\right), 1.66-1.62\left(\mathrm{~m}, 2 \mathrm{H}, \mathrm{OCH}_{2} \mathrm{CH}_{2}\left(\mathrm{CH}_{2}\right)_{2} \mathrm{CH}_{3}\right), 1.35-1.30\left(\mathrm{~m}, 4 \mathrm{H}, \mathrm{O}\left(\mathrm{CH}_{2}\right)_{2}\left(\mathrm{CH}_{2}\right)_{2} \mathrm{CH}_{3}\right)$, 1.02-0.85 (m, 9H, $\mathrm{O}\left(\mathrm{CH}_{2}\right)_{4} \mathrm{CH}_{3}$, Val-CHCH$\left.\left.\left(\mathrm{CH}_{3}\right)_{2}\right) ;{ }^{13} \mathrm{C} \mathrm{NMR} \mathrm{(150} \mathrm{MHz,} \mathrm{CDCl} 3\right): \delta 173.8,173.3$ (Val-CO), 159.8 (C-2), 154.9, 154.8, 154.7 (C-4), 142.9 (d, $\left.{ }^{2} J_{\mathrm{C}, \mathrm{F}}=247.9 \mathrm{~Hz}, \mathrm{C}-5\right), 140.9,140.8$, $140.7(\mathrm{C}-6), 74.1\left(\mathrm{~d},{ }^{3} J_{\mathrm{C}, \mathrm{P}}=4.3 \mathrm{~Hz}, \mathrm{C}-2\right), 70.3\left(\mathrm{~d},{ }^{2} J_{\mathrm{C}, \mathrm{P}}=4.1 \mathrm{~Hz}, \mathrm{C}-2{ }^{\prime}\right), 70.0\left(\mathrm{~d},{ }^{2} J_{\mathrm{C}, \mathrm{P}}=6.4 \mathrm{~Hz}, \mathrm{C}-\right.$ $\left.3^{\prime}\right), 73.9\left(\mathrm{~d},{ }^{2} J_{\mathrm{C}, \mathrm{P}}=4.1 \mathrm{~Hz}, \mathrm{C}-3\right.$ ' $), 67.0,66.3,66.1,65.7,65.6,65.5,65.4\left(\mathrm{CH}_{2} \mathrm{P}, \mathrm{OCH}_{2}\left(\mathrm{CH}_{2}\right)_{3} \mathrm{CH}_{3}\right.$, C-1'), 59.2, $57.5\left(\right.$ Val- $\left.\mathrm{CHCH}\left(\mathrm{CH}_{3}\right)_{2}\right), 32.2\left(\mathrm{~d},{ }^{3} J_{\mathrm{C}, \mathrm{P}}=5.9 \mathrm{~Hz}, \mathrm{Val}-\mathrm{CHCH}\left(\mathrm{CH}_{3}\right)_{2}\right), 31.9\left(\mathrm{~d},{ }^{3} J_{\mathrm{C}, \mathrm{P}}=\right.$ 4.5 Hz, Val-CHCH$\left.\left(\mathrm{CH}_{3}\right)_{2}\right), 28.4,28.1\left(\mathrm{OCH}_{2}\left(\mathrm{CH}_{2}\right)_{2} \mathrm{CH}_{2} \mathrm{CH}_{3}\right), 22.4\left(\mathrm{O}\left(\mathrm{CH}_{2}\right)_{3} \mathrm{CH}_{2} \mathrm{CH}_{3}\right), 19.3,17.1$ (Val-CHCH $\left.\left(\mathrm{CH}_{3}\right)_{2}\right), 14.1\left(\mathrm{O}\left(\mathrm{CH}_{2}\right)_{4} \mathrm{CH}_{3}\right) ;{ }^{31} \mathrm{P}$ NMR (121 MHz, CDCl3): $\delta$ 16.6, 16.5; HRMS for $\mathrm{C}_{18} \mathrm{H}_{30} \mathrm{FN}_{4} \mathrm{O}_{6} \mathrm{P}[\mathrm{M}+\mathrm{H}]^{+}$calcd.: 449.1960, found: 449.1958 .

Diisopropyl (R)-(((1-hydroxypropan-2-yl)oxy)methyl)phosphonate (24b). $\mathrm{MMTrCl}$ (7.9 g, 25.6 mmol) was added to the mixture of $(R)-1,2$-propanediol S-7 $(1.50 \mathrm{~g}, 19.7 \mathrm{mmol}), \mathrm{Et}_{3} \mathrm{~N}(5.5 \mathrm{~mL})$, and DMAP (240 mg, $1.97 \mathrm{mmol})$ in DCM $(100 \mathrm{~mL})$ at room temperature, and the reaction was stirred for further $12 \mathrm{~h}$. The mixture was washed with saturated aq. $\mathrm{NaHCO}_{3}(100 \mathrm{~mL})$ and brine $(100 \mathrm{~mL})$. The organic layer was separated, dried over $\mathrm{Na}_{2} \mathrm{SO}_{4}$, filtered, and concentrated under reduced pressure to give a crude residue, which was purified by column chromatography on silica gel (petroleum ether/EtOAc, 4:1, v/v; etroleum ether/EtOAc, 3:1, v/v). The collected eluate was evaporated and redissolved in THF $(150 \mathrm{~mL})$. Next, NaH $(980 \mathrm{mg}, 25.6 \mathrm{mmol})$ and triflate diisopropylphosphonomethanol $(8.41 \mathrm{~g}, 25.6 \mathrm{mmol})$ were added at $0{ }^{\circ} \mathrm{C}$. Then the reaction was allowed to reach room temperature and stirred for $12 \mathrm{~h}$. It was then quenched by addition of $\mathrm{MeOH}$, and concentrated under reduced pressure. The crude product was dissolved in EtOAc $(200 \mathrm{~mL})$, washed with brine, dried over $\mathrm{Na}_{2} \mathrm{SO}_{4}$, filtered, and concentrated under reduced pressure to afford a residue, which was dissolved in $\mathrm{MeOH}(100 \mathrm{~mL})$. Then, TsOH. $\mathrm{H}_{2} \mathrm{O}$ (750 mg, $\left.3.50 \mathrm{mmol}\right)$ was added, and the reaction was heated at $60{ }^{\circ} \mathrm{C}$ for $5 \mathrm{~h}$. After cooling, the solution was evaporated to remove the volatiles. The crude residue was purified by column chromatography on silica gel 
(gradient DCM/MeOH, 8:1, v/v; DCM/acetone, 4:1, v/v; DCM/acetone, 2:1, v/v) to give compound 24b (2.90 g, 59\% over 3 steps) as a colorless oil. ${ }^{1} \mathrm{H}$ NMR (300 MHz, $\left.\mathrm{CDCl}_{3}\right): \delta 4.81-4.69(\mathrm{~m}, 2 \mathrm{H}$, $\left.\mathrm{CH}\left(\mathrm{CH}_{3}\right)_{2}\right), 3.93-3.47$ (m, 5H, $\left.\mathrm{PCH} H_{2}, \mathrm{H}-2^{\prime}, \mathrm{H}^{\prime} 1^{\prime}\right), 1.34-1.31\left(\mathrm{~m}, 12 \mathrm{H}, \mathrm{CH}\left(\mathrm{CH}_{3}\right)_{2}\right), 1.11(\mathrm{~d}, J=6.3$ $\left.\mathrm{Hz}, 3 \mathrm{H}, \mathrm{CHCH}_{3}\right) ;{ }^{13} \mathrm{C} \mathrm{NMR}(75 \mathrm{MHz}, \mathrm{MeOD}): \delta 79.9\left(\mathrm{~d},{ }^{3} J_{\mathrm{C}, \mathrm{P}}=12.5 \mathrm{~Hz}, \mathrm{C}-2{ }^{\prime}\right), 71.7,71.6,71.4$, $71.3\left(\mathrm{CH}\left(\mathrm{CH}_{3}\right)_{2}\right), 66.2\left(\mathrm{C}-1\right.$ '), $63.9\left(\mathrm{~d},{ }^{1} J_{\mathrm{C}, \mathrm{P}}=169.6 \mathrm{~Hz}, \mathrm{CH}_{2} \mathrm{P}\right), 24.2,24.1,24.0\left(\mathrm{CH}\left(\mathrm{CH}_{3}\right)_{2}\right), 15.9$ $\left(\mathrm{CHCH}_{3}\right) ;{ }^{31} \mathrm{P}$ NMR (121 MHz, MeOD): $\delta$ 21.4; HRMS for $\mathrm{C}_{10} \mathrm{H}_{24} \mathrm{O}_{5} \mathrm{P}[\mathrm{M}+\mathrm{H}]^{+}$calcd.: 255.1356, found: 255.1345 .

Diisopropyl (S)-(((1-((4-aminopyrimidin-2-yl)oxy)propan-2-yl)oxy)methyl)phosphonate (27a). Compound 27a was obtained as a white foam (190 mg, 35\% over 2 steps) according to the procedure A, starting from compound $\mathbf{1}(320 \mathrm{mg}, 2.05 \mathrm{mmol})$, compound 24a (400 mg, $1.57 \mathrm{mmol}), \mathrm{Ph}_{3} \mathrm{P}(830$ $\mathrm{mg}, 3.15 \mathrm{mmol})$, and DIAD $(0.62 \mathrm{~mL}, 3.15 \mathrm{mmol})$ in anhydrous THF $(10 \mathrm{~mL})$, and $30 \%$ methanolic ammonia $(20 \mathrm{~mL})$. The crude residue was purified by column chromatography on silica gel (gradient DCM/MeOH, 30:1, v/v; DCM/MeOH, 20:1, v/v). ${ }^{1} \mathrm{H}$ NMR (500 MHz, $\mathrm{CDCl}_{3}$ ): $\delta 7.93$ (d, $J=5.8$ Hz, 1H, H-6), 6.14 (d, $J=5.8 \mathrm{~Hz}, 1 \mathrm{H}, \mathrm{H}-5), 6.06\left(\mathrm{~s}, 2 \mathrm{H}, \mathrm{NH} \mathrm{H}_{2}\right), 4.79-4.72\left(\mathrm{~m}, 2 \mathrm{H}, \mathrm{CH}\left(\mathrm{CH}_{3}\right)_{2}\right), 4.29-$ 4.22 (m, 2H, H-1'), 3.94-3.85 (m, 3H, H-2', $\left.\mathrm{PCH}_{2}\right), 1.34-1.25$ (m, 15H, $\left.\mathrm{CH}\left(\mathrm{CH}_{3}\right)_{2}, \mathrm{CH}_{3}\right) ;{ }^{13} \mathrm{C} \mathrm{NMR}$ $\left(125 \mathrm{MHz}, \mathrm{CDCl}_{3}\right): \delta 165.5(\mathrm{C}-4), 165.0(\mathrm{C}-2), 156.7(\mathrm{C}-6), 100.1(\mathrm{C}-5), 76.3\left(\mathrm{~d},{ }^{3} J_{\mathrm{C}, \mathrm{P}}=13.0 \mathrm{~Hz}\right.$,

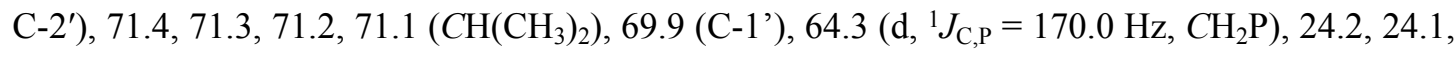
$24.0\left(\mathrm{CH}\left(\mathrm{CH}_{3}\right)_{2}\right), 16.8\left(\mathrm{CH}_{3}\right) ;{ }^{31} \mathrm{P}$ NMR (121 MHz, $\left.\mathrm{CDCl}_{3}\right): \delta 20.3$; HRMS for $\mathrm{C}_{14} \mathrm{H}_{27} \mathrm{~N}_{3} \mathrm{O}_{5} \mathrm{P}$ $[\mathrm{M}+\mathrm{H}]^{+}$calcd.: 348.1683 , found: 348.1679 .

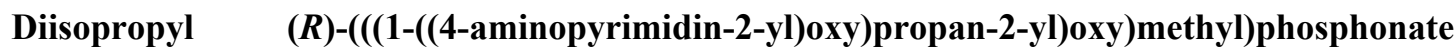

(27b). Compound 27b was obtained as a white foam ( $170 \mathrm{mg}, 31 \%$ over 2 steps) according to the procedure A, starting from compound 2 (320 mg, $2.05 \mathrm{mmol}$ ), compound $\mathbf{2 4 b}$ (400 $\mathrm{mg}, 1.57 \mathrm{mmol}$ ), $\mathrm{Ph}_{3} \mathrm{P}(830 \mathrm{mg}, 3.15 \mathrm{mmol})$, and DIAD $(0.62 \mathrm{~mL}, 3.15 \mathrm{mmol})$ in anhydrous THF $(10 \mathrm{~mL})$, and $30 \%$ methanolic ammonia $(20 \mathrm{~mL})$. The crude residue was purified by column chromatography on silica gel (gradient DCM/MeOH, 30:1, v/v; DCM/MeOH, 20:1, v/v). ${ }^{1} \mathrm{H}$ NMR (300 MHz, $\left.\mathrm{CDCl}_{3}\right): \delta 7.92$ (d, $J=5.8 \mathrm{~Hz}, 1 \mathrm{H}, \mathrm{H}-6), 6.26\left(\mathrm{~s}, 2 \mathrm{H}, \mathrm{N} H_{2}\right), 6.15$ (d, $\left.J=5.8 \mathrm{~Hz}, 1 \mathrm{H}, \mathrm{H}-5\right), 4.79-4.70(\mathrm{~m}, 2 \mathrm{H}$, $\left.\mathrm{CH}\left(\mathrm{CH}_{3}\right)_{2}\right), 4.25-4.23$ (m, 2H, H-1'), 3.94-3.86 (m, 3H, H-2', $\mathrm{PCH}$ ), 1.35-1.24 (m, 15H, $\mathrm{CH}\left(\mathrm{CH}_{3}\right)_{2}$, $\mathrm{CH}_{3}$ ); ${ }^{13} \mathrm{C}$ NMR (75 MHz, CDCl $): \delta 165.5$ (C-4), 165.0 (C-2), 156.8 (C-6), 100.0 (C-5), 76.3 (d, $\left.{ }^{3} J_{\mathrm{C}, \mathrm{P}}=12.8 \mathrm{~Hz}, \mathrm{C}-2^{\prime}\right), 71.4,71.3,71.2,71.1\left(\mathrm{CH}\left(\mathrm{CH}_{3}\right)_{2}\right), 69.9\left(\mathrm{C}-1^{\prime}\right), 64.3\left(\mathrm{~d},{ }^{1} J_{\mathrm{C}, \mathrm{P}}=169.2 \mathrm{~Hz}\right.$, $\left.\mathrm{CH}_{2} \mathrm{P}\right), 24.2,24.1,24.0\left(\mathrm{CH}\left(\mathrm{CH}_{3}\right)_{2}\right), 16.8\left(\mathrm{CH}_{3}\right) ;{ }^{31} \mathrm{P} \mathrm{NMR}\left(121 \mathrm{MHz}, \mathrm{CDCl}_{3}\right): \delta 20.3$; HRMS for 
$\mathrm{C}_{14} \mathrm{H}_{27} \mathrm{~N}_{3} \mathrm{O}_{5} \mathrm{P}[\mathrm{M}+\mathrm{H}]^{+}$calcd.: 348.1683 , found: 348.1682 .

\section{Diisopropyl}

(S)-(((1-((4-amino-5-fluoropyrimidin-2-yl)oxy)propan-2-

yl)oxy)methyl)phosphonate (28a). Compound 28a was obtained as a white foam (200 mg, 35\% over 2 steps) according to the procedure A, starting from compound 2 (270 mg, $2.05 \mathrm{mmol})$ and compound 24a (400 mg, $1.57 \mathrm{mmol}), \mathrm{Ph}_{3} \mathrm{P}(1.24 \mathrm{~g}, 4.72 \mathrm{mmol})$, and DIAD (0.93 mL, $\left.4.72 \mathrm{mmol}\right)$ in anhydrous THF $(10 \mathrm{~mL})$, and $1 \mathrm{M} \mathrm{HCl}(0.5 \mathrm{~mL})$ in $\mathrm{CH}_{3} \mathrm{CN} / \mathrm{H}_{2} \mathrm{O}(10 \mathrm{~mL}, 1: 1, \mathrm{v} / \mathrm{v})$. The crude residue was purified by column chromatography on silica gel (gradient petroleum/EtOAc, 1:2, v/v; petroleum/EtOAc, 1:3, v/v, EtOAc). ${ }^{1} \mathrm{H}$ NMR $\left(300 \mathrm{MHz}, \mathrm{CDCl}_{3}\right): \delta 7.86(\mathrm{~d}, J=2.8 \mathrm{~Hz}, 1 \mathrm{H}, \mathrm{H}-6)$, 6.40 (s, 2H, $\mathrm{NH}_{2}$ ), 4.80-4.72 (m, 2H, $\left.\mathrm{CH}\left(\mathrm{CH}_{3}\right)_{2}\right), 4.24-4.17$ (m, 2H, H-1'), 3.96-3.86 (m, 3H, H-2', PCH $\left.H_{2}\right), 1.36-1.24\left(\mathrm{~m}, 15 \mathrm{H}, \mathrm{CH}\left(\mathrm{CH}_{3}\right)_{2}, \mathrm{CH}_{3}\right) ;{ }^{13} \mathrm{C} \mathrm{NMR}\left(75 \mathrm{MHz}, \mathrm{CDCl}_{3}\right): \delta 160.3(\mathrm{C}-2), 155.3(\mathrm{~d}$, $\left.{ }^{1} J_{\mathrm{C}, \mathrm{F}}=13.6 \mathrm{~Hz}, \mathrm{C}-4\right), 142.8\left(\mathrm{~d},{ }^{2} J_{\mathrm{C}, \mathrm{F}}=247.1 \mathrm{~Hz}, \mathrm{C}-5\right), 140.2\left(\mathrm{~d},{ }^{2} J_{\mathrm{C}, \mathrm{F}}=20.3 \mathrm{~Hz}, \mathrm{C}-6\right), 76.1\left(\mathrm{~d},{ }^{3} J_{\mathrm{C}, \mathrm{P}}\right.$

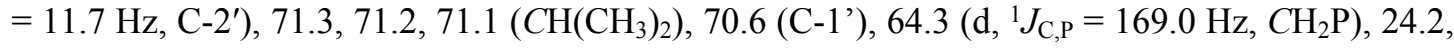
24.1, 24.0, $23.9\left(\mathrm{CH}\left(\mathrm{CH}_{3}\right)_{2}\right), 16.8\left(\mathrm{CH}_{3}\right)$; ${ }^{31} \mathrm{P}$ NMR (121 MHz, $\left.\mathrm{CDCl}_{3}\right): \delta$ 20.1; HRMS for $\mathrm{C}_{14} \mathrm{H}_{26} \mathrm{FN}_{3} \mathrm{O}_{5} \mathrm{P}[\mathrm{M}+\mathrm{H}]^{+}$calcd.: 366.1588 , found: 366.1586 .

\section{Diisopropyl}

(R)-(((1-((4-amino-5-fluoropyrimidin-2-yl)oxy)propan-2-

yl)oxy)methyl)phosphonate (28b). Compound 28b was obtained as a white foam (190 mg, 35\% over 2 steps) according to the procedure A, starting from compound $2(270 \mathrm{mg}, 2.05 \mathrm{mmol})$ and compound 24b (400 mg, $1.57 \mathrm{mmol}), \mathrm{Ph}_{3} \mathrm{P}(1.24 \mathrm{~g}, 4.72 \mathrm{mmol})$, and DIAD (0.93 mL, $\left.4.72 \mathrm{mmol}\right)$ in anhydrous THF $(10 \mathrm{~mL})$, and $1 \mathrm{M} \mathrm{HCl}(0.5 \mathrm{~mL})$ in $\mathrm{CH}_{3} \mathrm{CN} / \mathrm{H}_{2} \mathrm{O}(10 \mathrm{~mL}, 1: 1, \mathrm{v} / \mathrm{v})$. The crude residue was purified by column chromatography on silica gel (gradient petroleum/EtOAc, 1:2, v/v; petroleum/EtOAc, 1:3, v/v, EtOAc). ${ }^{1} \mathrm{H}$ NMR $\left(300 \mathrm{MHz}, \mathrm{CDCl}_{3}\right): \delta 7.82(\mathrm{~d}, J=2.8 \mathrm{~Hz}, 1 \mathrm{H}, \mathrm{H}-6)$, 6.41 (s, 2H, NH $\left.H_{2}\right), 4.82-4.71$ (m, 2H, $\left.\mathrm{CH}\left(\mathrm{CH}_{3}\right)_{2}\right), 4.24-4.18$ (m, 2H, H-1'), 3.97-3.84 (m, 3H, H-2', $\left.\mathrm{PCH}_{2}\right), 1.36-1.24\left(\mathrm{~m}, 15 \mathrm{H}, \mathrm{CH}\left(\mathrm{CH}_{3}\right)_{2}, \mathrm{CH}_{3}\right) ;{ }^{13} \mathrm{C} \mathrm{NMR}\left(75 \mathrm{MHz}, \mathrm{CDCl}_{3}\right): \delta 160.3(\mathrm{C}-2), 155.3(\mathrm{~d}$, $\left.{ }^{1} J_{\mathrm{C}, \mathrm{F}}=13.8 \mathrm{~Hz}, \mathrm{C}-4\right), 142.8\left(\mathrm{~d},{ }^{2} J_{\mathrm{C}, \mathrm{F}}=247.2 \mathrm{~Hz}, \mathrm{C}-5\right), 140.2\left(\mathrm{~d},{ }^{2} J_{\mathrm{C}, \mathrm{F}}=20.5 \mathrm{~Hz}, \mathrm{C}-6\right), 76.1\left(\mathrm{~d},{ }^{3} J_{\mathrm{C}, \mathrm{P}}\right.$

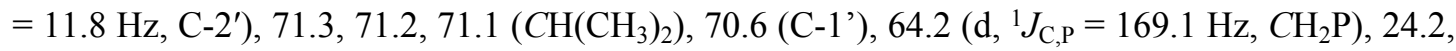
24.1, 24.0, $23.9\left(\mathrm{CH}\left(\mathrm{CH}_{3}\right)_{2}\right), 16.7\left(\mathrm{CH}_{3}\right) ;{ }^{31} \mathrm{P}$ NMR $\left(121 \mathrm{MHz}, \mathrm{CDCl}_{3}\right)$ : $\delta$ 20.2; HRMS for $\mathrm{C}_{14} \mathrm{H}_{26} \mathrm{FN}_{3} \mathrm{O}_{5} \mathrm{P}[\mathrm{M}+\mathrm{H}]^{+}$calcd.: 366.1588 , found: 366.1593 .

(S)-(((1-((4-aminopyrimidin-2-yl)oxy)propan-2-yl)oxy)methyl)phosphonic acid (29a). Compound 29a was obtained as a white foam (105 mg, 70\%) according to the procedure B, starting from compound $27 \mathbf{a}(200 \mathrm{mg}, 0.58 \mathrm{mmol})$, bromotrimethylsilane $(0.61 \mathrm{~mL}, 4.61 \mathrm{mmol})$, and 2,6- 
lutidine $(1.10 \mathrm{~mL}, 9.21 \mathrm{mmol})$ in anhydrous acetonitrile $(10 \mathrm{~mL})$. The crude residue was purified by column chromatography on silica gel (gradient acetone $/ \mathrm{H}_{2} \mathrm{O} / \mathrm{Et}_{3} \mathrm{~N}, \quad 5: 1: 1$, $\mathrm{v} / \mathrm{v} / \mathrm{v}$; acetone $\left./ \mathrm{H}_{2} \mathrm{O} / \mathrm{Et}_{3} \mathrm{~N}, 4: 1: 1, \mathrm{v} / \mathrm{v} / \mathrm{v}\right) .{ }^{1} \mathrm{H}$ NMR $(300 \mathrm{MHz}, \mathrm{CD} 3 \mathrm{OD}): \delta 7.85$ (d, $\left.J=5.9 \mathrm{~Hz}, 1 \mathrm{H}, \mathrm{H}-6\right)$, 6.19 (d, $J=5.9 \mathrm{~Hz}, 1 \mathrm{H}, \mathrm{H}-5), 4.34-4.20$ (m, 2H, H-1'), 3.91-3.70 (m, 1H, H-2'), 3.73-3.70 (m, 2H, PCH $\left.H_{2}\right), 1.33-1.27$ (m, 3H, $\left.\mathrm{CH}_{3}\right) ;{ }^{13} \mathrm{C}$ NMR (75 MHz, CD3OD): $\delta 167.3$ (C-4), $166.0(\mathrm{C}-2), 156.8$ (C-6), $100.4(\mathrm{C}-5), 76.8\left(\mathrm{~d},{ }^{3} J_{\mathrm{C}, \mathrm{P}}=12.3 \mathrm{~Hz}, \mathrm{C}-2^{\prime}\right), 70.7\left(\mathrm{C}-1\right.$ ') $67.4\left(\mathrm{~d},{ }^{1} J_{\mathrm{C}, \mathrm{P}}=159.1 \mathrm{~Hz}, \mathrm{CH}_{2} \mathrm{P}\right)$, 17.1 $\left(\mathrm{CH}_{3}\right) ;{ }^{31} \mathrm{P}$ NMR (121 MHz, CD3OD): $\delta$ 15.1; HRMS for $\mathrm{C}_{8} \mathrm{H}_{13} \mathrm{~N}_{3} \mathrm{O}_{5} \mathrm{P}[\mathrm{M}-\mathrm{H}]^{-}$calcd.: 262.0598, found: 262.0605 .

(R)-(((1-((4-aminopyrimidin-2-yl)oxy)propan-2-yl)oxy)methyl)phosphonic acid (29b). Compound 29b was obtained as a white foam (90 mg, 70\%) according to the procedure B, starting from compound $27 \mathbf{b}(170 \mathrm{mg}, 0.49 \mathrm{mmol})$, bromotrimethylsilane $(0.52 \mathrm{~mL}, 3.92 \mathrm{mmol})$, and 2,6lutidine $(0.91 \mathrm{~mL}, 7.83 \mathrm{mmol})$ in anhydrous acetonitrile $(10 \mathrm{~mL})$. The crude residue was purified by column chromatography on silica gel (gradient acetone $/ \mathrm{H}_{2} \mathrm{O} / \mathrm{Et}_{3} \mathrm{~N}, 5: 1: 1, \mathrm{v} / \mathrm{v} / \mathrm{v}$; acetone/ $\left.\mathrm{H}_{2} \mathrm{O} / \mathrm{Et}_{3} \mathrm{~N}, 4: 1: 1, \mathrm{v} / \mathrm{v} / \mathrm{v}\right) .{ }^{1} \mathrm{H}$ NMR (300 MHz, CD3OD): $\delta 7.85$ (d, $\left.J=5.9 \mathrm{~Hz}, 1 \mathrm{H}, \mathrm{H}-6\right)$, 6.17 (d, J = 5.9 Hz, 1H, H-5), 4.35-4.20 (m, 2H, H-1'), 3.93-3.83 (m, 1H, H-2'), 3.69-3.63 (m, 2H, PCH $H_{2}$ ), 1.31-1.26 (m, 3H, $\left.\mathrm{CH}_{3}\right) ;{ }^{13} \mathrm{C}$ NMR (75 MHz, CD3OD): $\delta 167.3$ (C-4), 166.2 (C-2), 157.0 (C-6), $100.3(\mathrm{C}-5), 76.8\left(\mathrm{~d},{ }^{3} J_{\mathrm{C}, \mathrm{P}}=12.6 \mathrm{~Hz}, \mathrm{C}-2^{\prime}\right), 70.7\left(\mathrm{C}-1\right.$ '), $67.5\left(\mathrm{~d},{ }^{1} J_{\mathrm{C}, \mathrm{P}}=158.5 \mathrm{~Hz}, \mathrm{CH}_{2} \mathrm{P}\right)$, 17.1 $\left(\mathrm{CH}_{3}\right) ;{ }^{31} \mathrm{P}$ NMR (121 MHz, CD3OD): $\delta$ 14.8; HRMS for $\mathrm{C}_{8} \mathrm{H}_{13} \mathrm{~N}_{3} \mathrm{O}_{5} \mathrm{P}[\mathrm{M}-\mathrm{H}]^{-}$calcd.: 262.0598, found: 262.0604 .

(S)-(((1-((4-amino-5-fluoropyrimidin-2-yl)oxy)propan-2-yl)oxy)methyl)phosphonic acid (30a). Compound 30a was obtained as a white foam (91 mg, 70\%) according to the procedure B, starting from compound 28a (170 mg, $0.47 \mathrm{mmol})$, bromotrimethylsilane (0.49 mL, $3.72 \mathrm{mmol})$, and 2,6lutidine $(0.86 \mathrm{~mL}, 7.45 \mathrm{mmol})$ in anhydrous acetonitrile $(10 \mathrm{~mL})$. The crude residue was purified by column chromatography on silica gel (gradient acetone $/ \mathrm{H}_{2} \mathrm{O} / \mathrm{Et}_{3} \mathrm{~N}, \quad 5: 1: 1$, $\mathrm{v} / \mathrm{v} / \mathrm{v}$; acetone $\left./ \mathrm{H}_{2} \mathrm{O} / \mathrm{Et}_{3} \mathrm{~N}, 4: 1: 1, \mathrm{v} / \mathrm{v} / \mathrm{v}\right) .{ }^{1} \mathrm{H}$ NMR (300 MHz, CD3OD): $\delta 7.84$ (d, $\left.J=3.5 \mathrm{~Hz}, 1 \mathrm{H}, \mathrm{H}-6\right)$, 4.32-4.18 (m, 2H, H-1'), 3.90-3.69 (m, 3H, H-2', PCH $), 1.33-1.28$ (m, 3H, $\mathrm{CH}_{3}$ ); ${ }^{13} \mathrm{C}$ NMR $(75$ MHz, CD3OD): $\delta 161.7$ (C-2), $157.0\left(\mathrm{~d},{ }^{1} J_{\mathrm{C}, \mathrm{F}}=13.8 \mathrm{~Hz}, \mathrm{C}-4\right), 143.6\left(\mathrm{~d},{ }^{2} J_{\mathrm{C}, \mathrm{F}}=245.1 \mathrm{~Hz}, \mathrm{C}-5\right)$, $140.7\left(\mathrm{~d},{ }^{2} J_{\mathrm{C}, \mathrm{F}}=21.2 \mathrm{~Hz}, \mathrm{C}-6\right), 76.8\left(\mathrm{~d},{ }^{3} J_{\mathrm{C}, \mathrm{P}}=12.4 \mathrm{~Hz}, \mathrm{C}-2^{\prime}\right), 71.4\left(\mathrm{C}-1^{\prime}\right), 67.3\left(\mathrm{~d},{ }^{1} J_{\mathrm{C}, \mathrm{P}}=159.1 \mathrm{~Hz}\right.$, $\left.\mathrm{CH}_{2} \mathrm{P}\right), 17.1\left(\mathrm{CH}_{3}\right)$; ${ }^{31} \mathrm{P}$ NMR (121 MHz, CD3OD): $\delta$ 15.2; HRMS for $\mathrm{C}_{8} \mathrm{H}_{12} \mathrm{FN}_{3} \mathrm{O}_{5} \mathrm{P}[\mathrm{M}-\mathrm{H}]^{-}$calcd.: 280.0504, found: 280.0498 . 
(30b). Compound 30b was obtained as a white foam ( $85 \mathrm{mg}, 65 \%)$ according to the procedure B, starting from compound $\mathbf{2 8 b}(170 \mathrm{mg}, 0.47 \mathrm{mmol})$, bromotrimethylsilane $(0.49 \mathrm{~mL}, 3.72 \mathrm{mmol})$, and 2,6-lutidine $(0.86 \mathrm{~mL}, 7.45 \mathrm{mmol})$ in anhydrous acetonitrile $(10 \mathrm{~mL})$. The crude residue was purified by column chromatography on silica gel (gradient acetone $/ \mathrm{H}_{2} \mathrm{O} / \mathrm{Et}_{3} \mathrm{~N}, 5: 1: 1$, v/v/v; acetone/ $\left.\mathrm{H}_{2} \mathrm{O} / \mathrm{Et}_{3} \mathrm{~N}, 4: 1: 1, \mathrm{v} / \mathrm{v} / \mathrm{v}\right) .{ }^{1} \mathrm{H}$ NMR (300 MHz, CD3OD): $\delta 7.83$ (d, $\left.J=3.4 \mathrm{~Hz}, 1 \mathrm{H}, \mathrm{H}-6\right)$, 4.33-4.17 (m, 2H, H-1'), 3.90-3.67 (m, 3H, H-2', $\left.\mathrm{PCH}_{2}\right), 1.32-1.29$ (m, 3H, $\left.\mathrm{CH}_{3}\right) ;{ }^{13} \mathrm{C}$ NMR $(75$ MHz, CD3OD): $\delta 161.8(\mathrm{C}-2), 157.0\left(\mathrm{~d},{ }^{1} J_{\mathrm{C}, \mathrm{F}}=14.1 \mathrm{~Hz}, \mathrm{C}-4\right), 143.6\left(\mathrm{~d},{ }^{2} J_{\mathrm{C}, \mathrm{F}}=245.2 \mathrm{~Hz}, \mathrm{C}-5\right)$, $140.8\left(\mathrm{~d},{ }^{2} J_{\mathrm{C}, \mathrm{F}}=21.2 \mathrm{~Hz}, \mathrm{C}-6\right), 76.8\left(\mathrm{~d},{ }^{3} J_{\mathrm{C}, \mathrm{P}}=12.2 \mathrm{~Hz}, \mathrm{C}-2^{\prime}\right), 71.4\left(\mathrm{C}-1^{\prime}\right), 67.4\left(\mathrm{~d},{ }^{1} J_{\mathrm{C}, \mathrm{P}}=158.7 \mathrm{~Hz}\right.$, $\left.\mathrm{CH}_{2} \mathrm{P}\right), 17.1\left(\mathrm{CH}_{3}\right)$; ${ }^{31} \mathrm{P}$ NMR (121 MHz, CD3OD): $\delta$ 15.0; HRMS for $\mathrm{C}_{8} \mathrm{H}_{12} \mathrm{FN}_{3} \mathrm{O}_{5} \mathrm{P}[\mathrm{M}-\mathrm{H}]-$ calcd.: 280.0504, found: 280.0503 .

Pentyl (((((S)-1-((4-aminopyrimidin-2-yl)oxy)propan-2-yl)oxy)methyl)(phenoxy)phosphoryl)L-valinate (31a). Compound 31a was obtained as a colorless oil (42 mg, 40\%) according to the procedure $\mathrm{C}$, starting from compound $29 \mathrm{a}(54 \mathrm{mg}, 0.21 \mathrm{mmol})$, L-valine amyl ester $\mathrm{HCl}$ salt (78 $\mathrm{mg}, 0.35 \mathrm{mmol}), \mathrm{PhOH}$ ( $85 \mathrm{mg}, 0.90 \mathrm{mmol}), \mathrm{Et}_{3} \mathrm{~N}$ (0.29 mL, $\left.2.10 \mathrm{mmol}\right), 2,2^{\prime}$-dithiodipyridine (320 $\mathrm{mg}, 1.44 \mathrm{mmol})$, and $\mathrm{PPh}_{3}(380 \mathrm{mg}, 1.44 \mathrm{mmol})$ in anhydrous pyridine $(5 \mathrm{~mL})$. The crude residue was purified by column chromatography on silica gel (gradient DCM/MeOH, 40:1, v/v; 30:1, v/v). ${ }^{1} \mathrm{H}$ NMR (300 MHz, CDCl3): $\delta$ 7.95, 7.93 (2s, 1H, H-6), 7.31-7.10 (m, 5H, ArH), 6.09, 6.08 (2d, $J$ $=6.0 \mathrm{~Hz}, 1 \mathrm{H}, \mathrm{H}-5), 5.65,5.60\left(2 \mathrm{~s}, 2 \mathrm{H}, \mathrm{NH} H_{2}\right), 4.75-3.59$ (m, 9H, H-2', H-1', $\mathrm{OCH}_{2}\left(\mathrm{CH}_{2}\right)_{3} \mathrm{CH}_{3}, \mathrm{PCH}_{2}$, Val- $\left.\mathrm{CHCH}\left(\mathrm{CH}_{3}\right)_{2}, \quad \mathrm{~N} H \mathrm{PO}\right), \quad 2.07-1.99 \quad\left(\mathrm{~m}, \quad 1 \mathrm{H}, \quad \mathrm{Val}-\mathrm{CHCH}\left(\mathrm{CH}_{3}\right)_{2}\right), \quad 1.62-1.55 \quad(\mathrm{~m}, \quad 2 \mathrm{H}$, $\left.\mathrm{OCH}_{2} \mathrm{CH}_{2}\left(\mathrm{CH}_{2}\right)_{2} \mathrm{CH}_{3}\right), 1.32-1.26\left(\mathrm{~m}, 7 \mathrm{H}, \mathrm{CHCH}_{3}, \mathrm{O}\left(\mathrm{CH}_{2}\right)_{2}\left(\mathrm{CH}_{2}\right)_{2} \mathrm{CH}_{3}\right), 0.92-0.80$ (m, 9H, $\mathrm{O}\left(\mathrm{CH}_{2}\right)_{4} \mathrm{CH}_{3}$, Val-CHCH$\left.\left(\mathrm{CH}_{3}\right)_{2}\right) ;{ }^{13} \mathrm{C}$ NMR (75 MHz, $\mathrm{CDCl}$ ): $\delta 173.1$ (Val-CO), 165.3, 165.2, 165.1 (C-4, C-2), 157.2, 157.1 (C-6), 150.5, 150.3 (Ar-C), 129.6 (Ar-C), 124.9, 124.8 (Ar-C), 121.3 $\left(\mathrm{d},{ }^{3} J_{\mathrm{C}, \mathrm{P}}=4.3 \mathrm{~Hz}, \mathrm{Ar}-\mathrm{C}\right), 120.9\left(\mathrm{~d},{ }^{3} J_{\mathrm{C}, \mathrm{P}}=4.5 \mathrm{~Hz}, \mathrm{Ar}-\mathrm{C}\right), 100.0,99.9$ (C-5), 77.0, 76.8, 76.5, 76.4 (C-2'), 70.0, 69.9 (C-1'), 66.0, 65.7, 65.4, 63.9, $63.7\left(\mathrm{CH}_{2} \mathrm{P}, \mathrm{OCH}_{2}\left(\mathrm{CH}_{2}\right)_{3} \mathrm{CH}_{3}\right), 59.2$ (Val$\left.\mathrm{CHCH}\left(\mathrm{CH}_{3}\right)_{2}\right), \quad 32.5, \quad 32.4,32.3$ (Val-CHCH$\left.\left(\mathrm{CH}_{3}\right)_{2}\right), 28.3,28.1\left(\mathrm{OCH}_{2}\left(\mathrm{CH}_{2}\right)_{2} \mathrm{CH}_{2} \mathrm{CH}_{3}\right), 22.3$

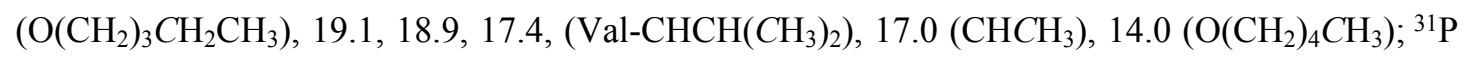
NMR (121 MHz, $\left.\mathrm{CDCl}_{3}\right): \delta 24.5,23.8$; HRMS for $\mathrm{C}_{24} \mathrm{H}_{38} \mathrm{~N}_{4} \mathrm{O}_{6} \mathrm{P}[\mathrm{M}+\mathrm{H}]^{+}$calcd.: 509.2523, found: 509.2523 . 
yl)oxy)methyl)(phenoxy)phosphoryl)-L-valinate (31b). Compound 31b was obtained as a colorless oil (60 mg, 40\%) according to the procedure C, starting from compound $29 \mathbf{b}$ (77 mg, 0.29 mmol), L-valine amyl ester $\mathrm{HCl}$ salt (110 mg, $0.50 \mathrm{mmol}), \mathrm{PhOH}(120 \mathrm{mg}, 1.29 \mathrm{mmol}), \mathrm{Et}_{3} \mathrm{~N}$ (0.40 $\mathrm{mL}, 2.90 \mathrm{mmol}$ ), 2,2'-dithiodipyridine (450 mg, $2.05 \mathrm{mmol}$ ), and $\mathrm{PPh}_{3}(540 \mathrm{mg}, 2.05 \mathrm{mmol})$ in anhydrous pyridine $(5 \mathrm{~mL})$. The crude residue was purified by column chromatography on silica gel (gradient DCM/MeOH, 40:1, v/v; 30:1, v/v). ${ }^{1} \mathrm{H}$ NMR (300 MHz, CDCl3): $\delta 7.93,7.92(2 \mathrm{~d}, J$ $=6.0 \mathrm{~Hz}, 1 \mathrm{H}, \mathrm{H}-6), 7.32-7.07(\mathrm{~m}, 5 \mathrm{H}, \operatorname{Ar} H), 6.08,6.07(2 \mathrm{~d}, J=6.0 \mathrm{~Hz}, 1 \mathrm{H}, \mathrm{H}-5), 5.86,5.72(2 \mathrm{~s}$, 2H, $\left.\mathrm{NH}_{2}\right), 4.28-3.66$ (m, 9H, H-2', H-1', $\mathrm{OCH}_{2}\left(\mathrm{CH}_{2}\right)_{3} \mathrm{CH}_{3}, \mathrm{PCH}_{2}$, Val-CHCH$\left.\left(\mathrm{CH}_{3}\right)_{2}, \mathrm{NHPO}\right), 2.06-$ $2.02\left(\mathrm{~m}, 1 \mathrm{H}, \mathrm{Val}-\mathrm{CHCH}\left(\mathrm{CH}_{3}\right)_{2}\right), 1.61-1.55\left(\mathrm{~m}, 2 \mathrm{H}, \mathrm{OCH}_{2} \mathrm{CH}_{2}\left(\mathrm{CH}_{2}\right)_{2} \mathrm{CH}_{3}\right), 1.33-1.22(\mathrm{~m}, 7 \mathrm{H}$, $\left.\mathrm{CHCH}_{3}, \mathrm{O}\left(\mathrm{CH}_{2}\right)_{2}\left(\mathrm{CH}_{2}\right)_{2} \mathrm{CH}_{3}\right), 0.94-0.80\left(\mathrm{~m}, 9 \mathrm{H}, \mathrm{O}\left(\mathrm{CH}_{2}\right)_{4} \mathrm{CH}_{3}, \mathrm{Val}-\mathrm{CHCH}\left(\mathrm{CH}_{3}\right)_{2}\right) ;{ }^{13} \mathrm{C}$ NMR $(75$ MHz, CDCl3): $\delta 173.2\left(\mathrm{~d},{ }^{3} J_{\mathrm{C}, \mathrm{P}}=3.7 \mathrm{~Hz}, \mathrm{Val}-\mathrm{CO}\right), 173.1\left(\mathrm{~d},{ }^{3} J_{\mathrm{C}, \mathrm{P}}=2.8 \mathrm{~Hz}, \mathrm{Val}-\mathrm{CO}\right), 165.3(\mathrm{C}-4)$, 165.1 (C-2), 157.1, 157.0 (C-6), 150.5, 150.4 (Ar-C), 129.6 (Ar-C), 124.9, 124.8 (Ar-C), 121.1, 121.0 (Ar-C), 99.9 (C-5), 76.6, 76.5, 76.3, 76.2 (C-2'), 70.0, 69.8 (C-1'), 65.9 65.7, 65.4, 65.3, 63.9, $63.7\left(\mathrm{CH}_{2} \mathrm{P}, \mathrm{OCH}_{2}\left(\mathrm{CH}_{2}\right)_{3} \mathrm{CH}_{3}\right), 59.3,59.2\left(\mathrm{Val}-\mathrm{CHCH}\left(\mathrm{CH}_{3}\right)_{2}\right), 32.4\left(\mathrm{~d},{ }^{3} J_{\mathrm{C}, \mathrm{P}}=4.7 \mathrm{~Hz}\right.$, Val$\left.\mathrm{CHCH}\left(\mathrm{CH}_{3}\right)_{2}\right), 32.3\left(\mathrm{~d},{ }^{3} \mathrm{~J}_{\mathrm{C}, \mathrm{P}}=4.6 \mathrm{~Hz}\right.$, Val-CHCH$\left.\left(\mathrm{CH}_{3}\right)_{2}\right), 28.3,28.1\left(\mathrm{OCH}_{2}\left(\mathrm{CH}_{2}\right)_{2} \mathrm{CH}_{2} \mathrm{CH}_{3}\right), 22.3$ $\left(\mathrm{O}\left(\mathrm{CH}_{2}\right)_{3} \mathrm{CH}_{2} \mathrm{CH}_{3}\right), \quad 19.0, \quad 18.8, \quad 17.4,17.3$ (Val- $\left.\mathrm{CHCH}\left(\mathrm{CH}_{3}\right)_{2}\right), \quad 16.9,16.7\left(\mathrm{CHCH}_{3}\right), \quad 14.0$ $\left(\mathrm{O}\left(\mathrm{CH}_{2}\right)_{4} \mathrm{CH}_{3}\right) ;{ }^{31} \mathrm{P} \mathrm{NMR}\left(121 \mathrm{MHz}, \mathrm{CDCl}_{3}\right): \delta 24.3,23.9 ; \mathrm{HRMS}$ for $\mathrm{C}_{24} \mathrm{H}_{38} \mathrm{~N}_{4} \mathrm{O}_{6} \mathrm{P}[\mathrm{M}+\mathrm{H}]^{+}$calcd.: 509.2523, found: 509.2527 .

\section{Pentyl}

(((((S)-1-((4-amino-5-fluoropyrimidin-2-yl)oxy)propan-2-

yl)oxy)methyl)(phenoxy)phosphoryl)-L-valinate (32a). Compound 32a was obtained as a colorless oil (40 mg, 45\%) according to the procedure C, starting from compound 30a (47 mg, 0.17 mmol), L-valine amyl ester $\mathrm{HCl}$ salt $(63 \mathrm{mg}, 0.28 \mathrm{mmol}), \mathrm{PhOH}(70 \mathrm{mg}, 0.73 \mathrm{mmol}), \mathrm{Et}_{3} \mathrm{~N}(0.23$ $\mathrm{mL}, 1.70 \mathrm{mmol}), 2,2^{\prime}$-dithiodipyridine $(260 \mathrm{mg}, 1.17 \mathrm{mmol})$, and $\mathrm{PPh}_{3}(310 \mathrm{mg}, 1.17 \mathrm{mmol})$ in anhydrous pyridine $(5 \mathrm{~mL})$. The crude residue was purified by column chromatography on silica gel (gradient DCM/MeOH, 40:1, v/v; 30:1, v/v). ${ }^{1} \mathrm{H}$ NMR (300 MHz, CDCl3): $\delta 7.85,7.84$ (2d, $J$ $=3.0 \mathrm{~Hz}, 1 \mathrm{H}, \mathrm{H}-6), 7.31-7.09(\mathrm{~m}, 5 \mathrm{H}, \mathrm{ArH}), 5.79,5.74\left(2 \mathrm{~s}, 2 \mathrm{H}, \mathrm{N} H_{2}\right), 4.33-3.55$ (m, 9H, H-2', H1', $\mathrm{OCH}_{2}\left(\mathrm{CH}_{2}\right)_{3} \mathrm{CH}_{3}, \mathrm{PCH}_{2}$, Val-CHCH$\left.\left(\mathrm{CH}_{3}\right)_{2}, \mathrm{NHPO}\right), 2.07-1.98$ (m, 1H, Val-CHCH$\left.\left(\mathrm{CH}_{3}\right)_{2}\right)$, 1.62-1.53 (m, 2H, $\left.\mathrm{OCH}_{2} \mathrm{CH}_{2}\left(\mathrm{CH}_{2}\right)_{2} \mathrm{CH}_{3}\right), 1.34-1.21\left(\mathrm{~m}, 7 \mathrm{H}, \mathrm{CHCH}_{3}, \mathrm{O}\left(\mathrm{CH}_{2}\right)_{2}\left(\mathrm{CH}_{2}\right)_{2} \mathrm{CH}_{3}\right), 0.93-$ $0.80\left(\mathrm{~m}, 9 \mathrm{H}, \mathrm{O}\left(\mathrm{CH}_{2}\right)_{4} \mathrm{CH}_{3}\right.$, Val-CHCH$\left.\left(\mathrm{CH}_{3}\right)_{2}\right) ;{ }^{13} \mathrm{C} \mathrm{NMR}(75 \mathrm{MHz}, \mathrm{CDCl}$ ): $\delta 173.2,173.1$ (ValCO), 160.4, 160.3 (C-2), 155.1, 155.0, 154.9, 154.8 (C-4), 150.7, 150,6, 150.5, 150.4 (Ar-C), 142.8 
$\left(\mathrm{d},{ }^{2} J_{\mathrm{C}, \mathrm{F}}=247.5 \mathrm{~Hz}, \mathrm{C}-5\right), 140.7\left(\mathrm{~d},{ }^{2} J_{\mathrm{C}, \mathrm{F}}=22.5 \mathrm{~Hz}, \mathrm{C}-6\right), 140.6\left(\mathrm{~d},{ }^{2} J_{\mathrm{C}, \mathrm{F}}=22.5 \mathrm{~Hz}, \mathrm{C}-6\right), 129.6$, 124.9, 121.3, 121.2, 120.9 (Ar-C), 77.0, 76.9, 76.4, 76.3 (C-2'), 70.6, 70.5 (C-1'), 66.0, 65.7, 65.4, 65.3, 64.0, $63.7\left(\mathrm{CH}_{2} \mathrm{P}, \mathrm{OCH}_{2}\left(\mathrm{CH}_{2}\right)_{3} \mathrm{CH}_{3}\right), 59.2\left(\mathrm{Val}-\mathrm{CHCH}\left(\mathrm{CH}_{3}\right)_{2}\right), 32.5,32.4,32.3$ (Val$\left.\mathrm{CHCH}\left(\mathrm{CH}_{3}\right)_{2}\right), 28.4,28.3,28.1\left(\mathrm{OCH}_{2}\left(\mathrm{CH}_{2}\right)_{2} \mathrm{CH}_{2} \mathrm{CH}_{3}\right), 22.3\left(\mathrm{O}\left(\mathrm{CH}_{2}\right)_{3} \mathrm{CH}_{2} \mathrm{CH}_{3}\right), 19.1,18.8,17.4$,

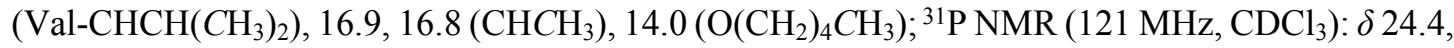
23.5; HRMS for $\mathrm{C}_{24} \mathrm{H}_{37} \mathrm{FN}_{4} \mathrm{O}_{6} \mathrm{P}[\mathrm{M}+\mathrm{H}]^{+}$calcd.: 527.2429, found: 527.2426.

Pentyl

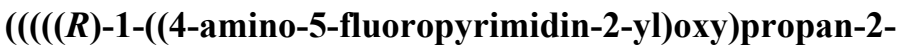
yl)oxy)methyl)(phenoxy)phosphoryl)-L-valinate (32b). Compound 32b was obtained as a colorless oil (35 mg, 40\%) according to the procedure C, starting from compound $\mathbf{3 0 b}$ (47 mg, 0.17 mmol), L-valine amyl ester $\mathrm{HCl}$ salt $(63 \mathrm{mg}, 0.28 \mathrm{mmol}), \mathrm{PhOH}(70 \mathrm{mg}, 0.73 \mathrm{mmol}), \mathrm{Et}_{3} \mathrm{~N}(0.23$ $\mathrm{mL}, 1.70 \mathrm{mmol}), 2,2^{\prime}$-dithiodipyridine $(260 \mathrm{mg}, 1.17 \mathrm{mmol})$, and $\mathrm{PPh}_{3}(310 \mathrm{mg}, 1.17 \mathrm{mmol})$ in anhydrous pyridine $(5 \mathrm{~mL})$. The crude residue was purified by column chromatography on silica gel (gradient DCM/MeOH, 40:1, v/v; 30:1, v/v). ${ }^{1} \mathrm{H}$ NMR (300 MHz, CDCl3): $\delta 7.84,7.83$ (2d, $J$ $=3.0 \mathrm{~Hz}, 1 \mathrm{H}, \mathrm{H}-6), 7.32-7.11(\mathrm{~m}, 5 \mathrm{H}, \mathrm{ArH}), 5.93,5.81\left(2 \mathrm{~s}, 2 \mathrm{H}, \mathrm{NH}_{2}\right), 4.31-3.64\left(\mathrm{~m}, 9 \mathrm{H}, \mathrm{H}-2^{\prime}, \mathrm{H}-\right.$ 1', $\mathrm{OCH}_{2}\left(\mathrm{CH}_{2}\right)_{3} \mathrm{CH}_{3}, \mathrm{PCH}$, Val-CHCH$\left.\left(\mathrm{CH}_{3}\right)_{2}, \mathrm{NHPO}\right), 2.07-2.01$ (m, 1H, Val-CHCH$\left.\left(\mathrm{CH}_{3}\right)_{2}\right)$, 1.63-1.53 (m, $\left.2 \mathrm{H}, \mathrm{OCH}_{2} \mathrm{CH}_{2}\left(\mathrm{CH}_{2}\right)_{2} \mathrm{CH}_{3}\right), 1.35-1.21\left(\mathrm{~m}, 7 \mathrm{H}, \mathrm{CHCH}_{3}, \mathrm{O}\left(\mathrm{CH}_{2}\right)_{2}\left(\mathrm{CH}_{2}\right)_{2} \mathrm{CH}_{3}\right), 0.94-$ $0.79\left(\mathrm{~m}, 9 \mathrm{H}, \mathrm{O}\left(\mathrm{CH}_{2}\right)_{4} \mathrm{CH}_{3}\right.$, Val-CHCH$\left.\left(\mathrm{CH}_{3}\right)_{2}\right) ;{ }^{13} \mathrm{C} \mathrm{NMR}(150 \mathrm{MHz}, \mathrm{CDCl} 3): \delta 173.1,173.0$ (ValCO), 160.1, 160.0 (C-2), 154.9, 154.8 (C-4), 150.2, 150.1 (Ar-C), $142.6\left(\mathrm{~d},{ }^{2} J_{\mathrm{C}, \mathrm{F}}=255.0 \mathrm{~Hz}, \mathrm{C}-5\right)$, $140.2\left(\mathrm{~d},{ }^{2} J_{\mathrm{C}, \mathrm{F}}=30.0 \mathrm{~Hz}, \mathrm{C}-6\right), 140.1\left(\mathrm{~d},{ }^{2} J_{\mathrm{C}, \mathrm{F}}=30.0 \mathrm{~Hz}, \mathrm{C}-6\right), 129.4,124.7,124.6,120.9(\mathrm{Ar}-\mathrm{C})$, $76.2\left(\mathrm{~d},{ }^{3} J_{\mathrm{C}, \mathrm{P}}=11.1 \mathrm{~Hz}, \mathrm{C}-2^{\prime}\right), 75.8\left(\mathrm{~d},{ }^{3} J_{\mathrm{C}, \mathrm{P}}=11.4 \mathrm{~Hz}, \mathrm{C}-2\right.$ ') $70.4,70.2\left(\mathrm{C}-1^{\prime}\right), 65.2,65.1$ $\left(\mathrm{OCH}_{2}\left(\mathrm{CH}_{2}\right)_{3} \mathrm{CH}_{3}\right), 64.6\left(\mathrm{~d},{ }^{1} J_{\mathrm{C}, \mathrm{P}}=150 \mathrm{~Hz}, \mathrm{CH}_{2} \mathrm{P}\right), 64.4\left(\mathrm{~d},{ }^{1} J_{\mathrm{C}, \mathrm{P}}=150 \mathrm{~Hz}, \mathrm{CH}_{2} \mathrm{P}\right), 59.1,59.0($ Val$\left.\mathrm{CHCH}\left(\mathrm{CH}_{3}\right)_{2}\right), 32.2\left(\mathrm{~d},{ }^{3} J_{\mathrm{C}, \mathrm{P}}=4.5 \mathrm{~Hz}, \mathrm{Val}-\mathrm{CHCH}\left(\mathrm{CH}_{3}\right)_{2}\right), 32.1\left(\mathrm{~d},{ }^{3} J_{\mathrm{C}, \mathrm{P}}=4.5 \mathrm{~Hz}\right.$, Val$\left.\mathrm{CHCH}\left(\mathrm{CH}_{3}\right)_{2}\right), 28.1,27.9\left(\mathrm{OCH}_{2}\left(\mathrm{CH}_{2}\right)_{2} \mathrm{CH}_{2} \mathrm{CH}_{3}\right), 22.2,22, .1\left(\mathrm{O}\left(\mathrm{CH}_{2}\right)_{3} \mathrm{CH}_{2} \mathrm{CH}_{3}\right), 18.9,18.6,17.1$,

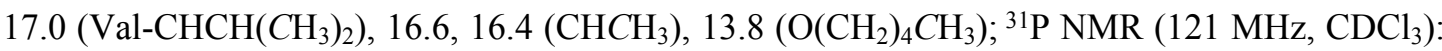
$\delta$ 24.1, 23.9; HRMS for $\mathrm{C}_{24} \mathrm{H}_{37} \mathrm{FN}_{4} \mathrm{O}_{6} \mathrm{P}[\mathrm{M}+\mathrm{H}]^{+}$calcd.: 527.2429, found: 527.2435.

\section{HCMV and VZV antiviral assays}

The compounds were evaluated against the following viruses: varicella-zoster virus (VZV) strain Oka, TK ${ }^{-}$VZV strain 07-1, and human cytomegalovirus (HCMV) strains AD-169 and Davis. The antiviral assays were based on the inhibition of virus-induced cytopathicity (HSV and HCMV) or 
plaque formation (VZV) in human embryonic lung (HEL) fibroblasts. Confluent cell cultures in microtiter 96 -well plates were inoculated with $100 \mathrm{CCID}_{50}$ of virus $\left(1 \mathrm{CCID}_{50}\right.$ being the virus dose to infect $50 \%$ of the cell cultures) or with 20 plaque forming units (PFU) (VZV). After $2 \mathrm{~h}$ of adsorption, the viral inoculum was removed and the cultures were further incubated in the presence of varying concentrations of the test compounds. Viral cytopathicity or plaque formation was recorded after 5 (VZV), or 6-7 (HCMV) days post-infection. The antiviral activity was expressed as the $\mathrm{EC}_{50}$ or compound concentration required to inhibit virus-induced cytopathicity or viral plaque formation by $50 \%$. The cytostatic activity measurements are based on the inhibition of cell growth. HEL cells were seeded at a rate of $5 \times 10^{3}$ cells/well into 96-well microtiter plates and allowed to proliferate for $24 \mathrm{~h}$. Then, a medium containing different concentrations of the test compounds was added. After 3 days of incubation at $37^{\circ} \mathrm{C}$, the cell number was determined with a Coulter counter. The cytostatic concentration was calculated as the $\mathrm{CC}_{50}$, or the compound concentration required to reduce cell proliferation by $50 \%$ relative to the number of cells in the untreated controls. $\mathrm{CC}_{50}$ values were estimated from graphic plots of the number of cells (percentage of control) as a function of the concentration of the test compounds. Alternatively, the cytotoxicity of the test compounds was expressed as the minimum cytotoxic concentration (MCC) or the compound concentration that causes a microscopically detectable alteration of the cell morphology. The selectivity index (SI) for each compound was calculated as the ratio $\mathrm{CC}_{50} / \mathrm{EC}_{50}$.

\section{HBV antiviral assay}

The primary anti-HBV assay was performed as previously described ${ }^{28}$ with modifications to use real-time qPCR (TaqMan) to measure extracellular HBV DNA copy number associated with virions released from HepG2.2.15 cells. The HepG2.2.15 cell line is a stable human hepatoblastoma cell line that contains two copies of the HBV wild-type strain ayw1 genome and constitutively produces high levels of HBV. ${ }^{25}$ Briefly, HepG2.2.15 cells were plated in 96-well microtiter plates at $1.5 \times$ 104 cells/well in Dulbecco's Modified Eagle's Medium supplemented with 2\% FBS, $380 \mu \mathrm{g} / \mathrm{mL}$ G418, $2.0 \mathrm{mM} \mathrm{L}$ glutamine, 100 units $/ \mathrm{mL}$ penicillin, $100 \mu \mathrm{g} / \mathrm{mL}$ streptomycin, and $0.1 \mathrm{mM}$ nonessential amino acids. Only the interior wells are utilized to reduce "edge effects" observed during cell culture; the exterior wells are filled with complete medium to help minimize sample evaporation. After 16-24 h, the confluent monolayer of HepG2.2.15 cells was washed and the 
medium was replaced with complete medium containing various concentrations of a test compound in triplicate. Lamivudine (3TC) was used as the positive control, while media alone was added to cells as a negative control (virus control, VC). Three days later, the culture medium is replaced with fresh medium containing the appropriately diluted test compounds. Six days following the initial administration of the test compound, the cell culture supernatant was collected, treated with Pronase, and then used in a real-time quantitative TaqMan qPCR assay. The qPCR assay targets the HBV precore/core region of the genome using the primers HBV-F (5'CCAAATGCCCCTATCCTATCA-3) and HBV-R (5'-GAGGCGAGGGAGTTCTTCTTCTA-3'). The PCR-amplified HBV DNA was detected in real-time by monitoring increases in fluorescent signal that result from the exonucleolytic degradation of a quenched fluorescent probe molecule ([6FAM]-CGGAAACTACTGTTGTTAGACGACGAGGCAG-[TAMRA]) that hybridized to the amplified HBV DNA. For each PCR amplification, a standard curve was simultaneously generated using dilutions of purified HBV DNA. Antiviral activity was calculated from the reduction in HBV DNA levels $\left(\mathrm{EC}_{50}\right.$ and $\mathrm{EC}_{90}$ values determined). A tetrazolium dye (MTS; 3-(4,5-dimethylthiazol2-yl)-5-(3-carboxymethoxyphenyl)-2-(4-sulfophenyl)-2H-tetrazolium; CellTiter96 Reagent, Promega) uptake assay was then employed to measure cell viability, which was used to calculate toxicity $\left(\mathrm{CC}_{50}\right)$. 
4. Table 1. Anti-HBV Activity and Cytotoxicity of Acyclic Nucleoside Phosphonamidates in HepG2.2.15 cells (Primary Assay)

\begin{tabular}{lccc}
\hline Compound & $\mathrm{EC}_{50} \mathrm{a}(\mu \mathrm{M})$ & $\mathrm{EC}_{90}{ }^{\mathrm{b}}(\mu \mathrm{M})$ & $\mathrm{CC}_{50}{ }^{\mathrm{c}}(\mu \mathrm{M})$ \\
\hline 10a & 25.8 & 82.8 & 33.0 \\
10b & 2.10 & 44.8 & 32.6 \\
11a & 54.36 & $>100$ & $>100$ \\
11b & 2.48 & 49.2 & $>100$ \\
12a & 26.2 & 82.2 & 32.6 \\
12b & 8.71 & $>100$ & 99.6 \\
22a & $>100$ & $>100$ & $>100$ \\
22b & $>100$ & $>100$ & $>100$ \\
23a & $>100$ & $>100$ & $>100$ \\
23b & $>100$ & $>100$ & $>100$ \\
31a & 46.0 & $>100$ & $>100$ \\
31b & 65.6 & $>100$ & $>100$ \\
32a & 38.3 & $>100$ & 34.2 \\
32b & 41.1 & $>100$ & 34.4 \\
Lamivudine & 0.03 & 1.06 & $>1.00$ \\
Entecavir & 0.00038 & 0.21 & 2.00 \\
\hline
\end{tabular}

${ }^{a}$ Effective concentration required to reduce HBV replication by $50 \%$; ${ }^{\mathrm{b}}$ Effective concentration required to reduce HBV replication by $90 \%$; ${ }^{c}$ Cytotoxic concentration required to reduce cell viability by $50 \%$. 


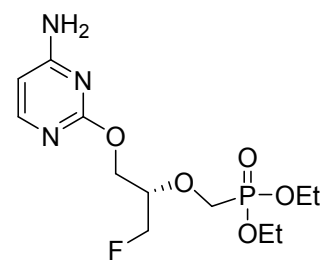

$6 a$

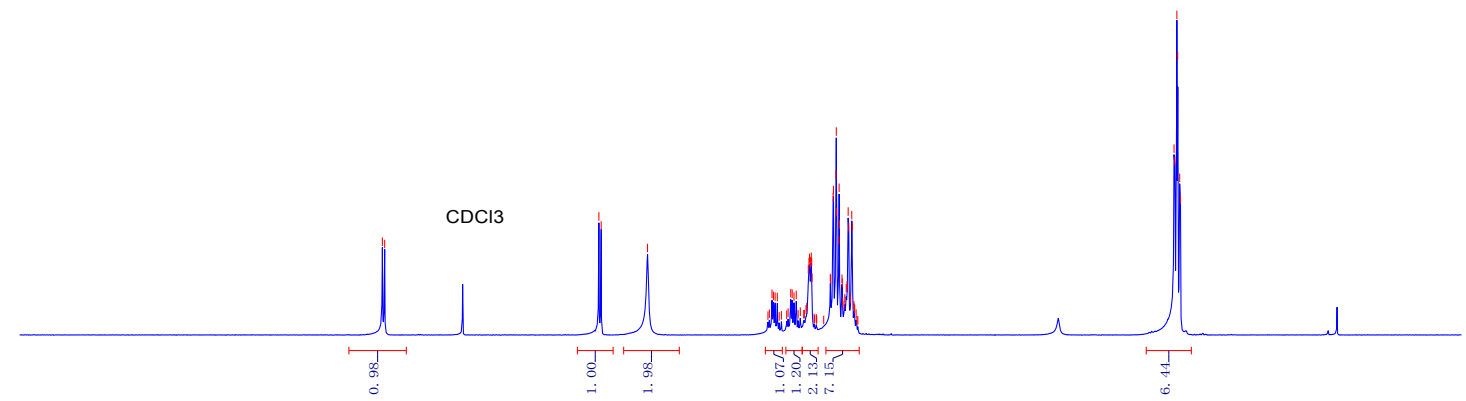

$\begin{array}{lllllllllllllllllllllllllllllll}10.5 & 10.0 & 9.5 & 9.0 & 8.5 & 8.0 & 7.5 & 7.0 & 6.5 & 6.0 & 5.5 & 5.0 & 4.5 & 4.0 & 3.5 & 3.0 & 2.5 & 2.0 & 1.5 & 1.0 & 0.5 & 0.0 & -0.5 & -1 .\end{array}$

Solvent $\mathrm{CDCl} 3$

Nucleus 13C

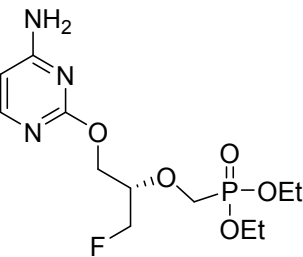

$6 a$

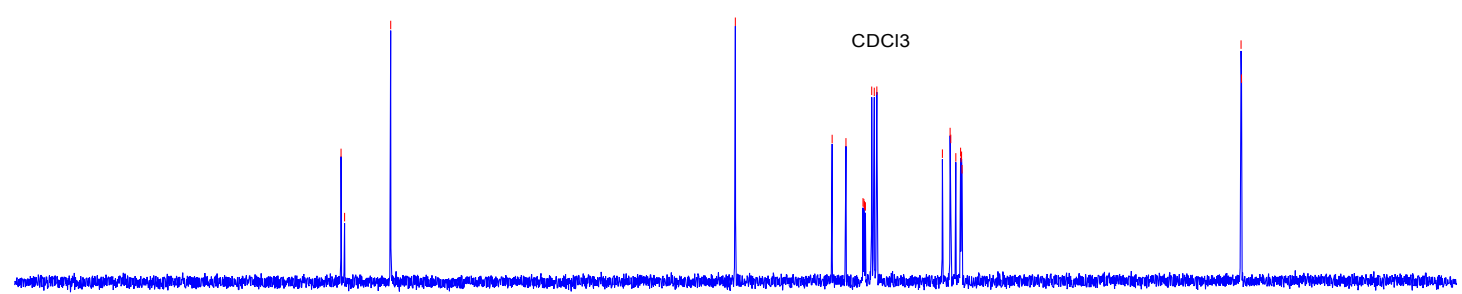

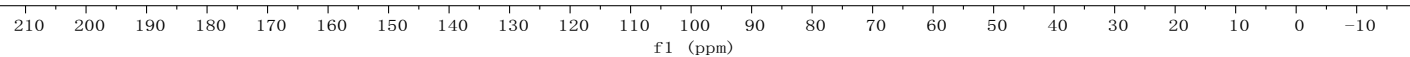


Solvent $\mathrm{CDCl} 3$

Nucleus 31P

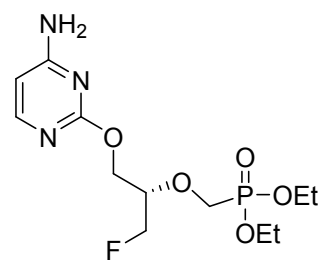

$6 a$

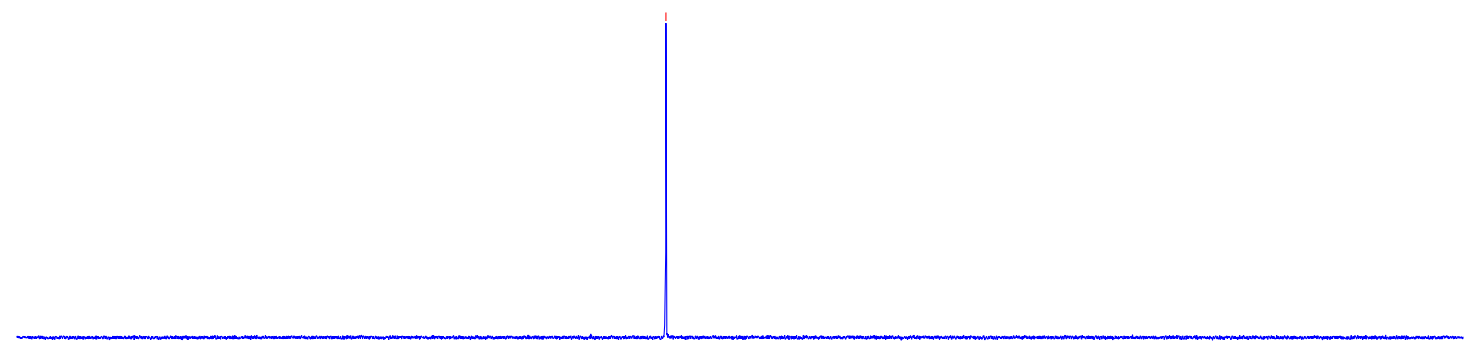

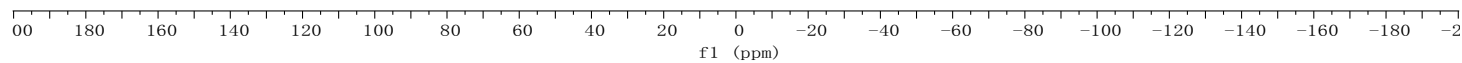

Solvent $\mathrm{CDCl} 3$

Nucleus 1H

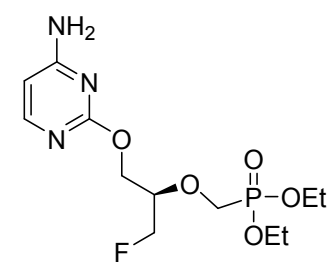

6b

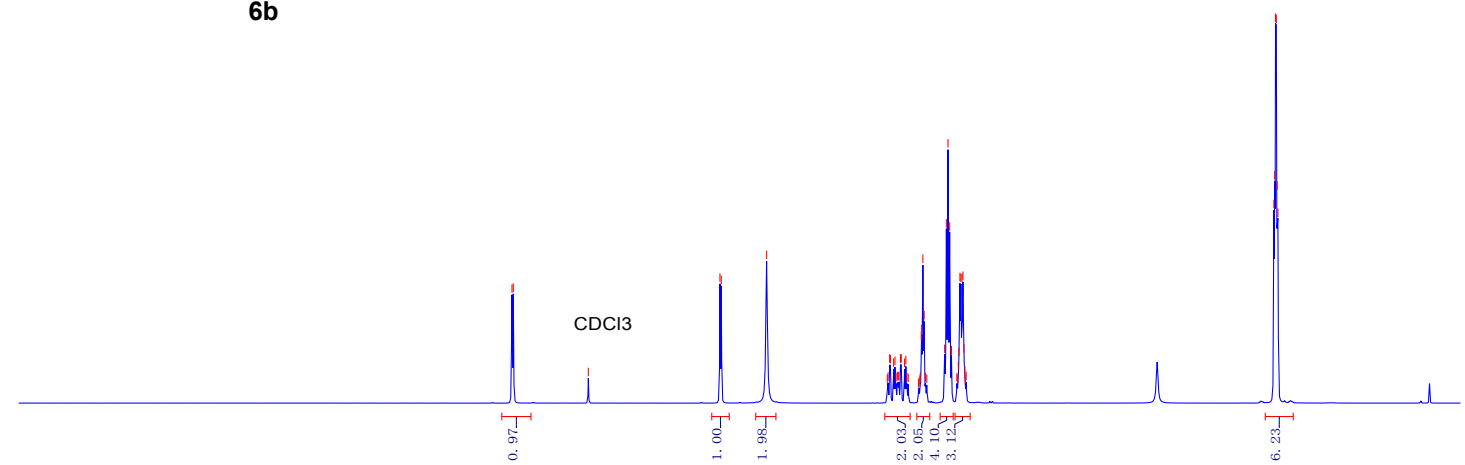

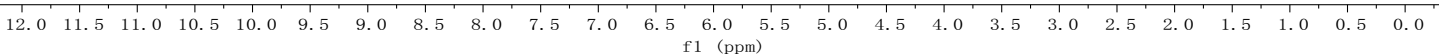




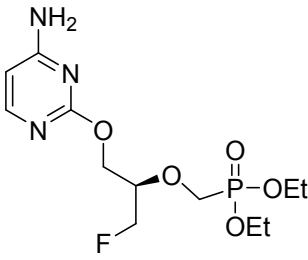

$6 \mathbf{b}$

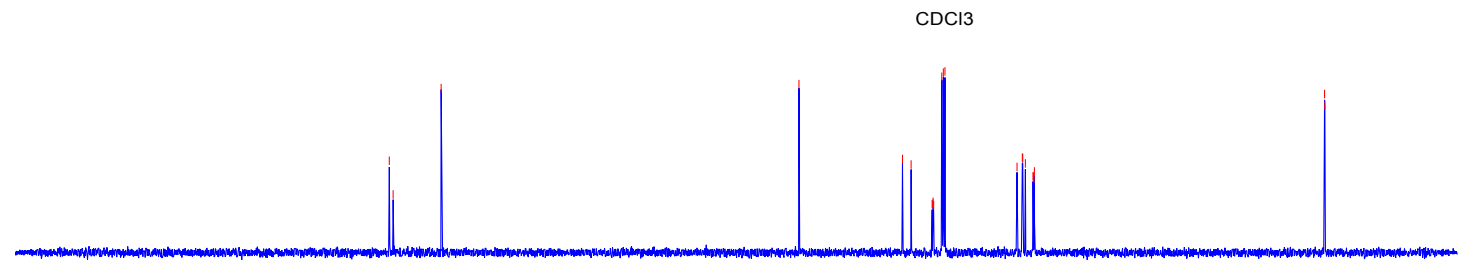

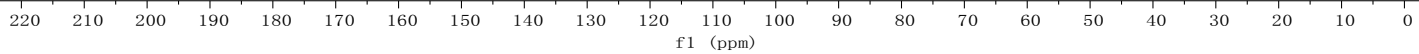

Solvent $\mathrm{CDCl} 3$

Nucleus 31P

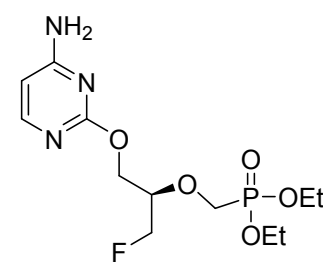

6b

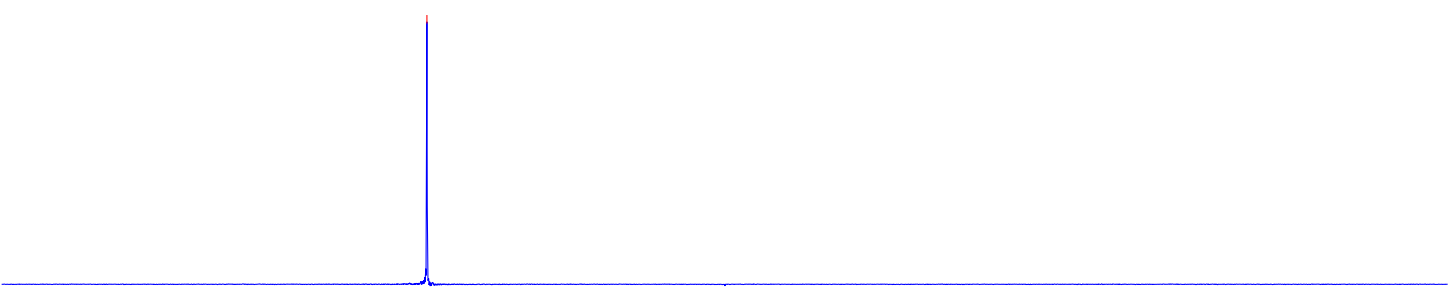

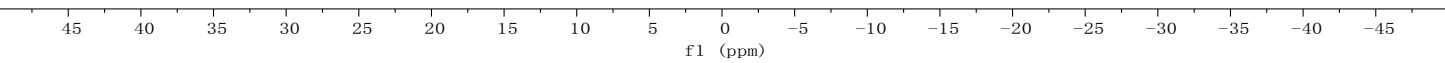




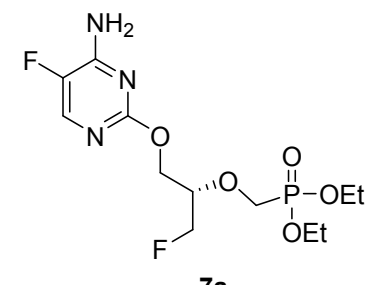

$7 a$
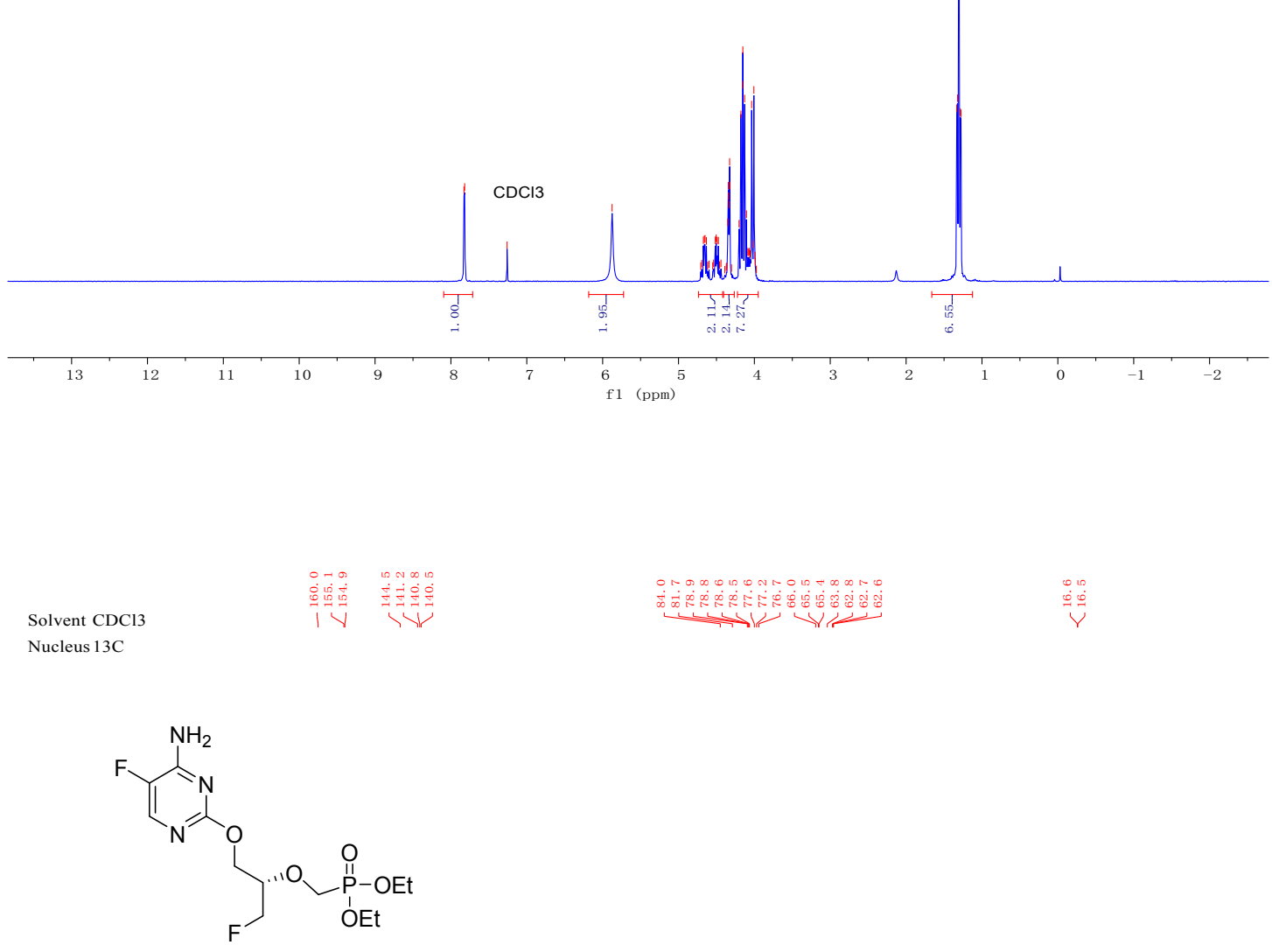

$7 a$

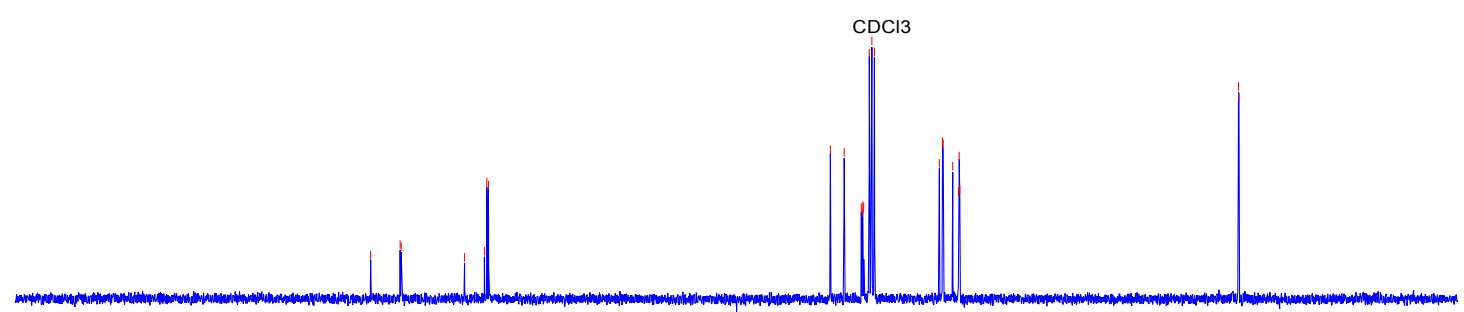

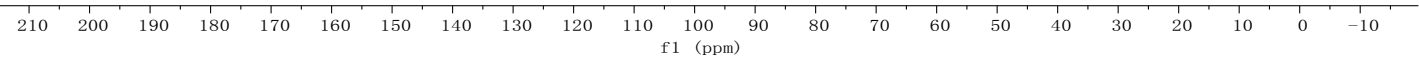


Solvent $\mathrm{CDCl} 3$

Nucleus 31P

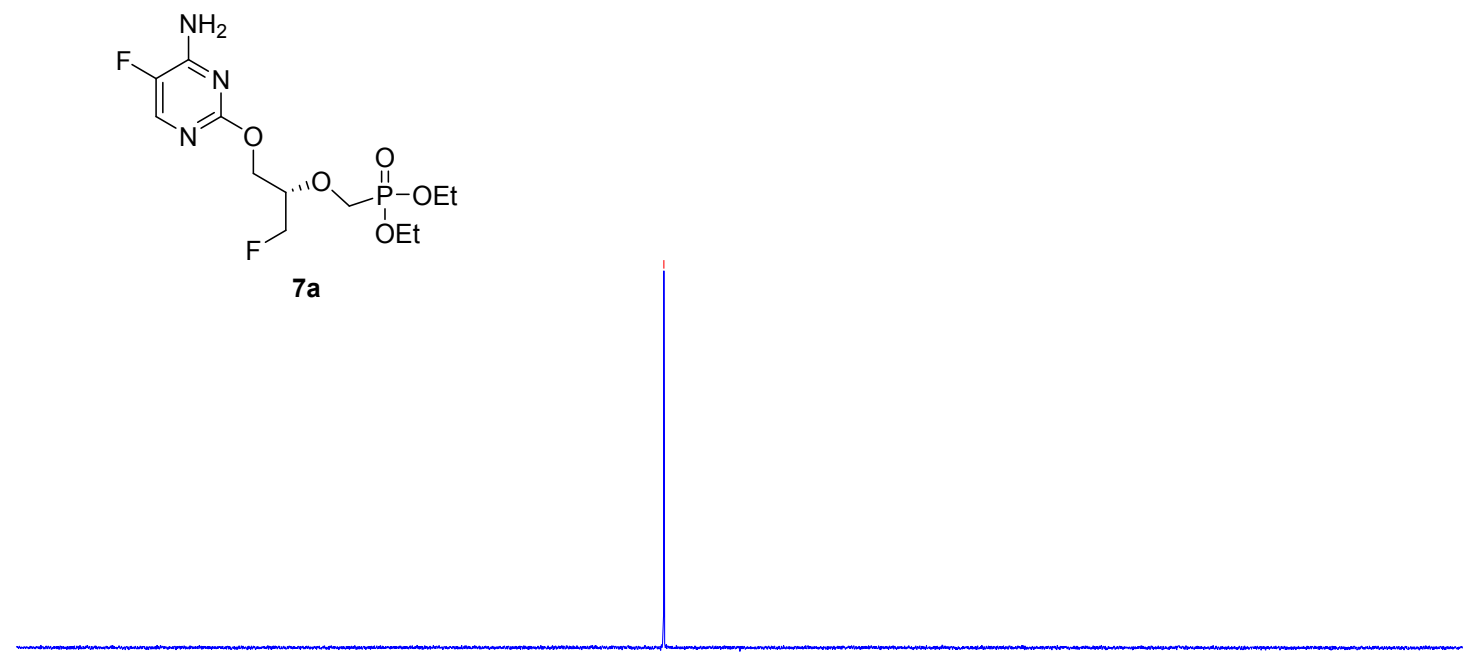

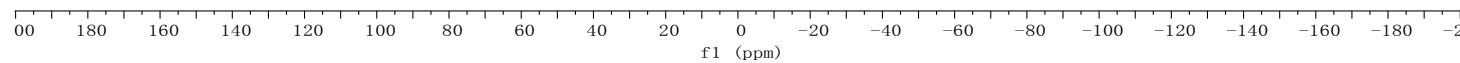
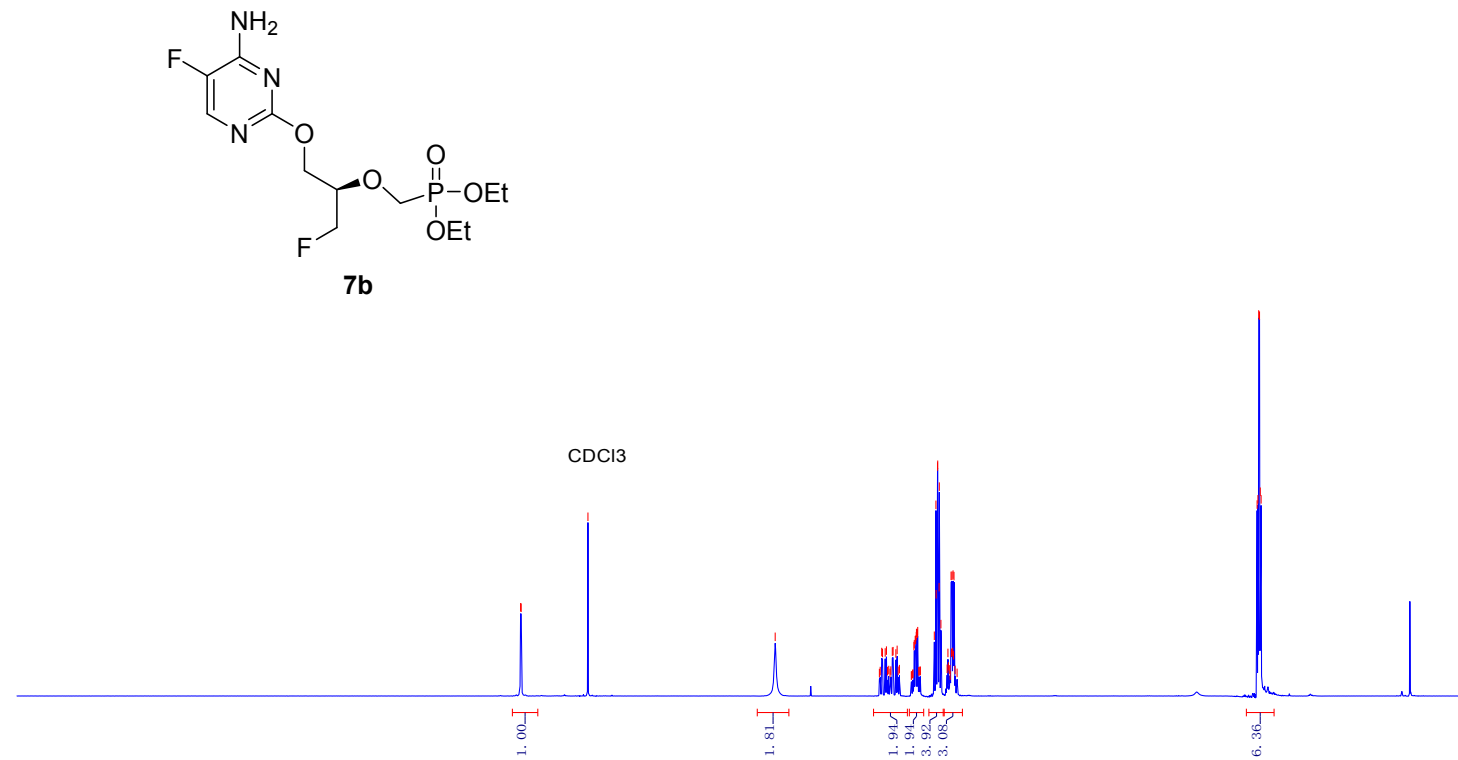

\begin{tabular}{rlllllllllllllllllllllllllllll}
\hline 12.0 & 11.5 & 11.0 & 10.5 & 10.0 & 9.5 & 9.0 & 8.5 & 8.0 & 7.5 & 7.0 & 6.5 & 6.0 & 5.5 & 5.0 & 4.5 & 4.0 & 3.5 & 3.0 & 2.5 & 2.0 & 1.5 & 1.0 & 0.5 & 0.0
\end{tabular} 


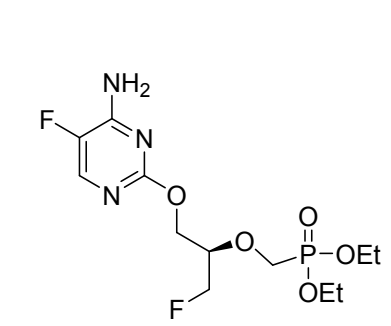

7b
$\mathrm{CDCl} 3$

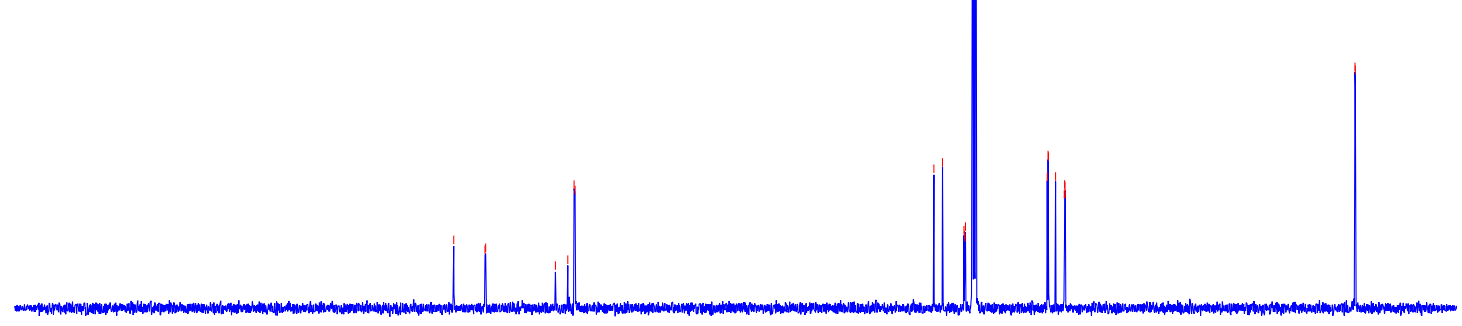

Solvent $\mathrm{CDCl} 3$

Nucleus 31P

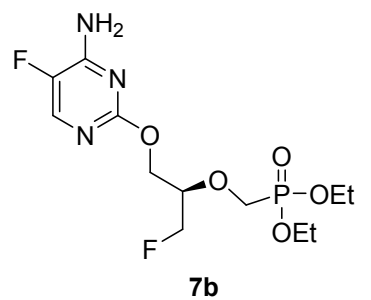

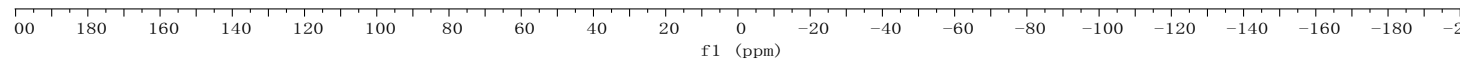


Solvent D2O

Nucleus 1H

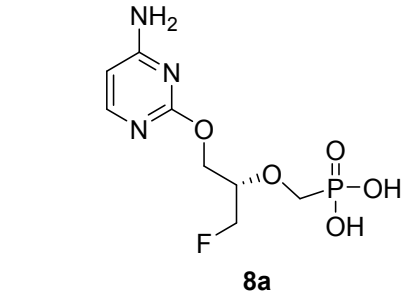

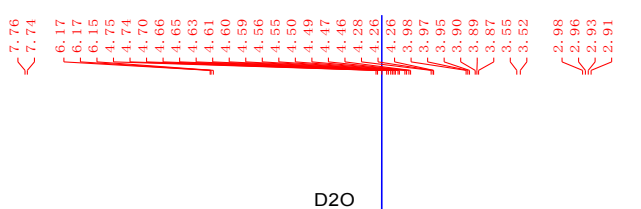

D2O
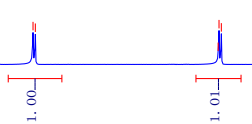

位

$\begin{array}{llllllllllllllllllllllllllllllll}11.5 & 11.0 & 10.5 & 10.0 & 9.5 & 9.0 & 8.5 & 8.0 & 7.5 & 7.0 & 6.5 & 6.0 & 5.5 & 5.0 & 4.5 & 4.0 & 3.5 & 3.0 & 2.5 & 2.0 & 1.5 & 1.0 & 0.5 & 0.0 & -0\end{array}$

Solvent D2O

$\begin{array}{ll}m & 0 \\ 00 & 0 \\ 0 & 0 \\ 11 & 1\end{array}$

Nucleus 13C
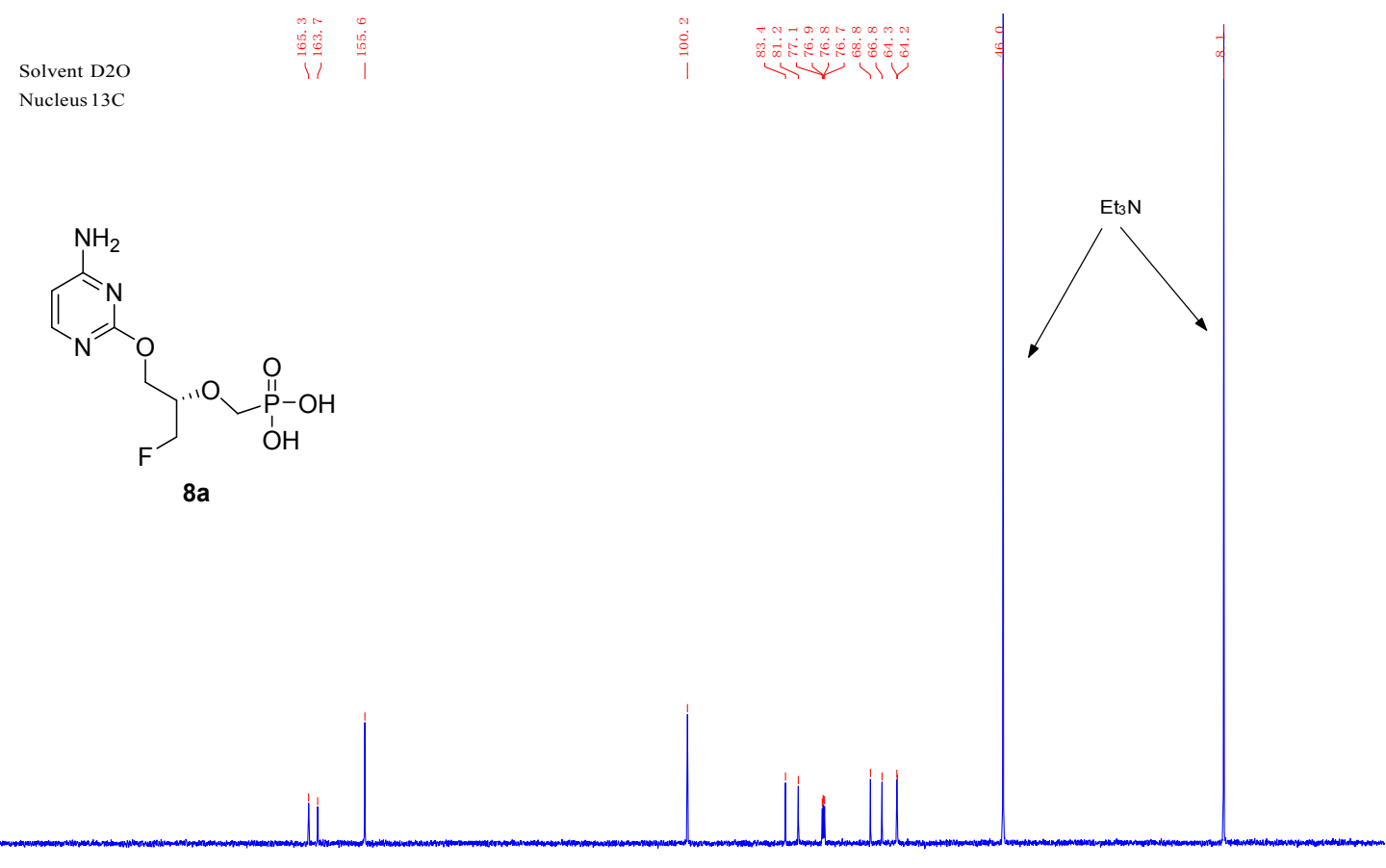

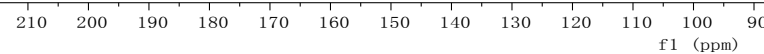

$\begin{array}{llll}80 & 70 & 60 & 50\end{array}$ 


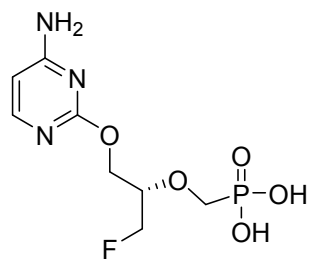

$8 a$

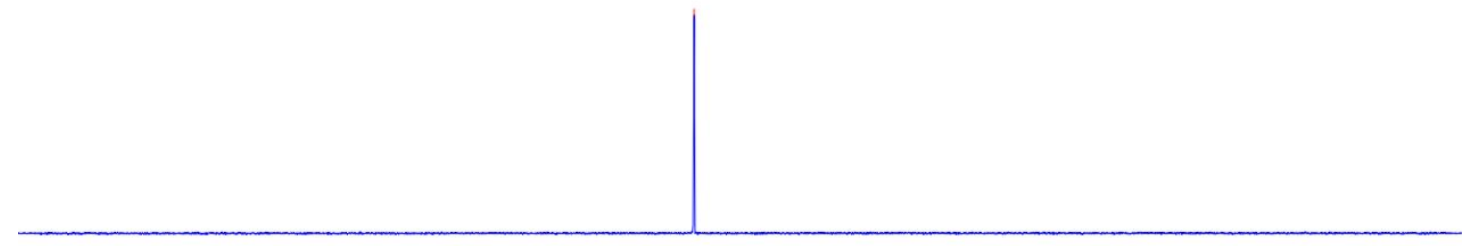

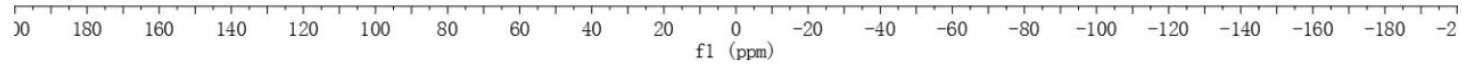
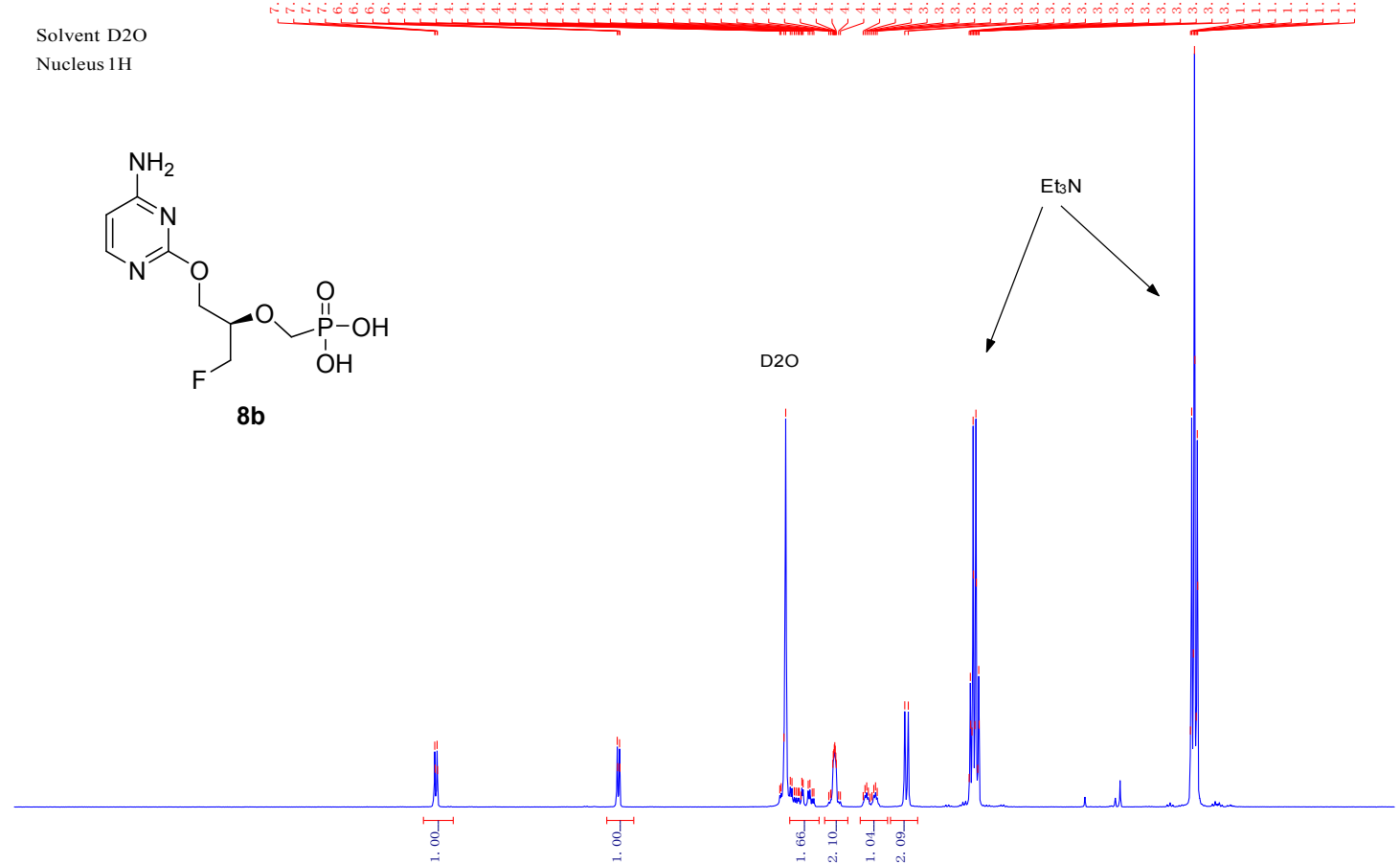

\begin{tabular}{lllllllllllllllllllllllll}
\hline 11.0 & 10.5 & 10.0 & 9.5 & 9.0 & 8.5 & 8.0 & 7.5 & 7.0 & 6.5 & 6.0 & 5.5 & 5.0 & 4.5 & 4.0 & 3.5 & 3.0 & 2.5 & 2.0 & 1.5 & 1.0 & 0.5 & 0.0 & -0.
\end{tabular} 


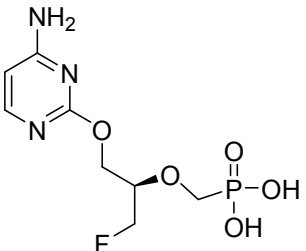

8b

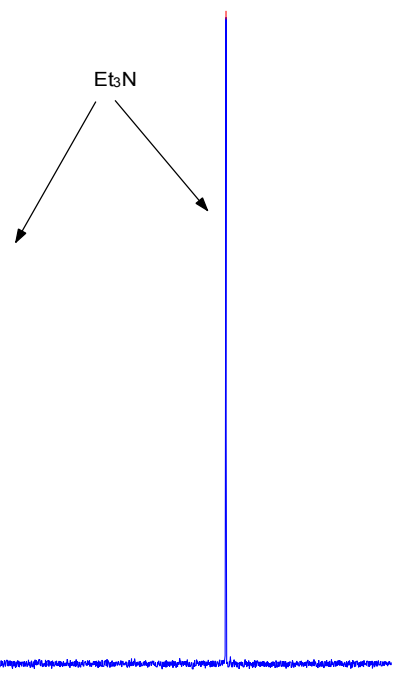

Solvent D2O

Nucleus 31P

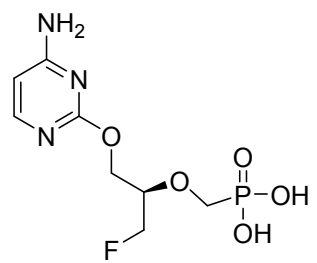

$8 b$

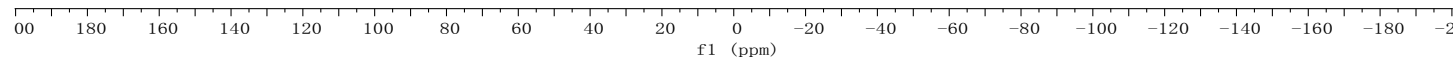




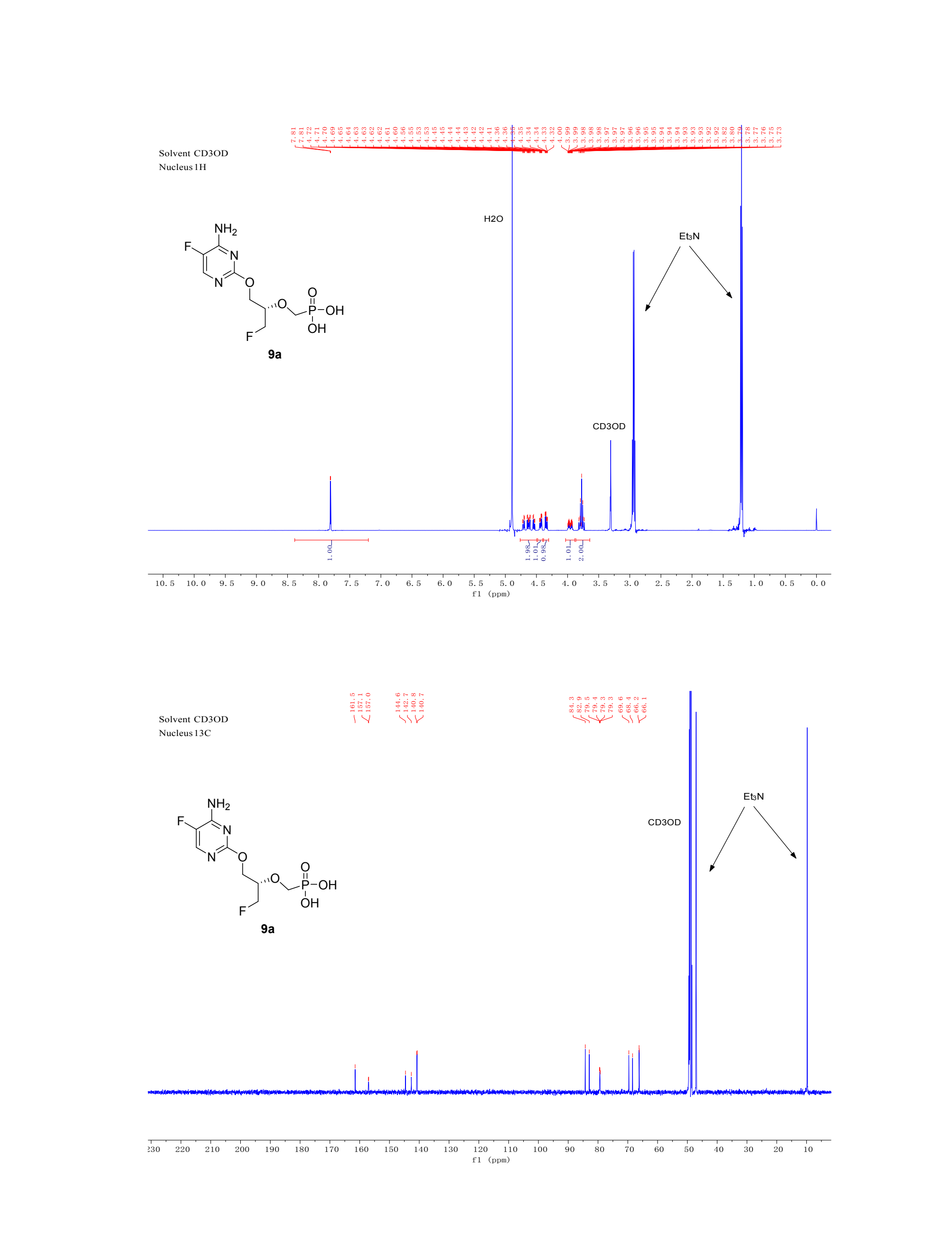




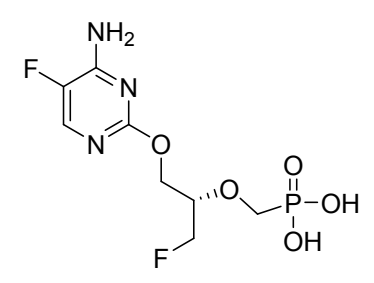

$9 a$

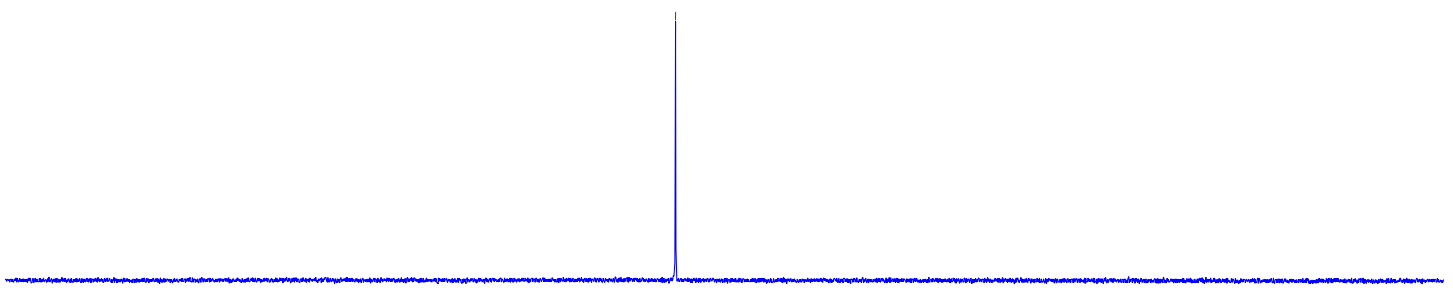

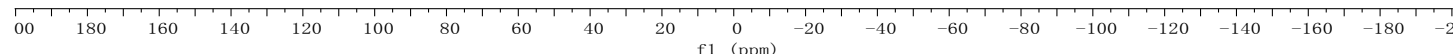
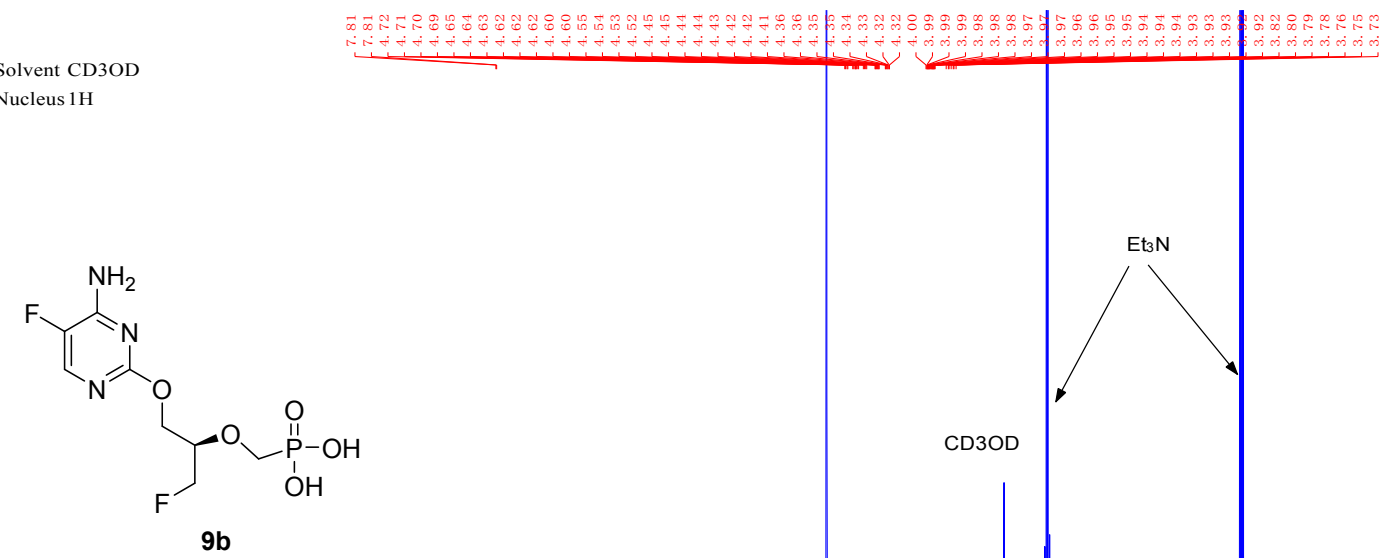

Solvent CD3OD

Nucleus $1 \mathrm{H}$

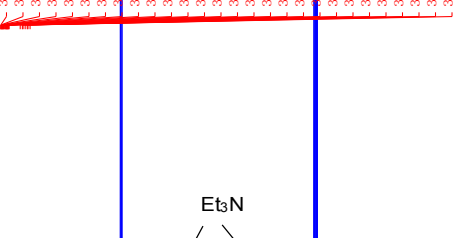

init

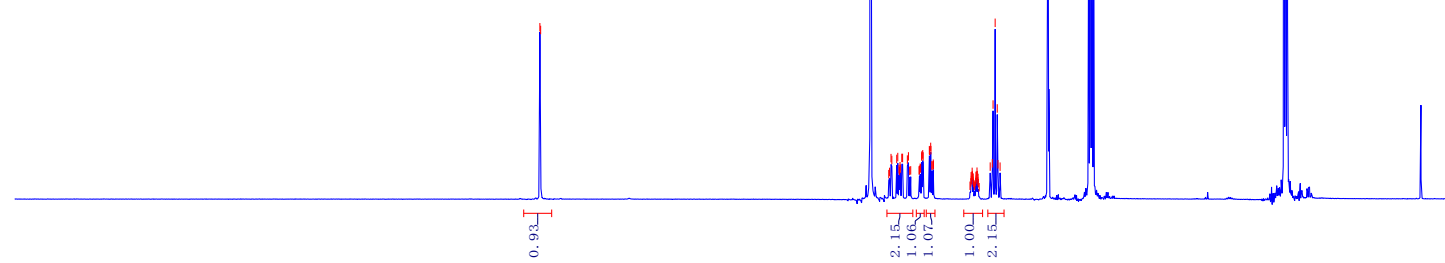

$\begin{array}{lllllllllllllllllllllllllllll}12.0 & 11.5 & 11.0 & 10.5 & 10.0 & 9.5 & 9.0 & 8.5 & 8.0 & 7.5 & 7.0 & 6.5 & 6.0 & 5.5 & 5.0 & 4.5 & 4.0 & 3.5 & 3.0 & 2.5 & 2.0 & 1.5 & 1.0 & 0.5 & 0.0\end{array}$ f1 (ppm) 


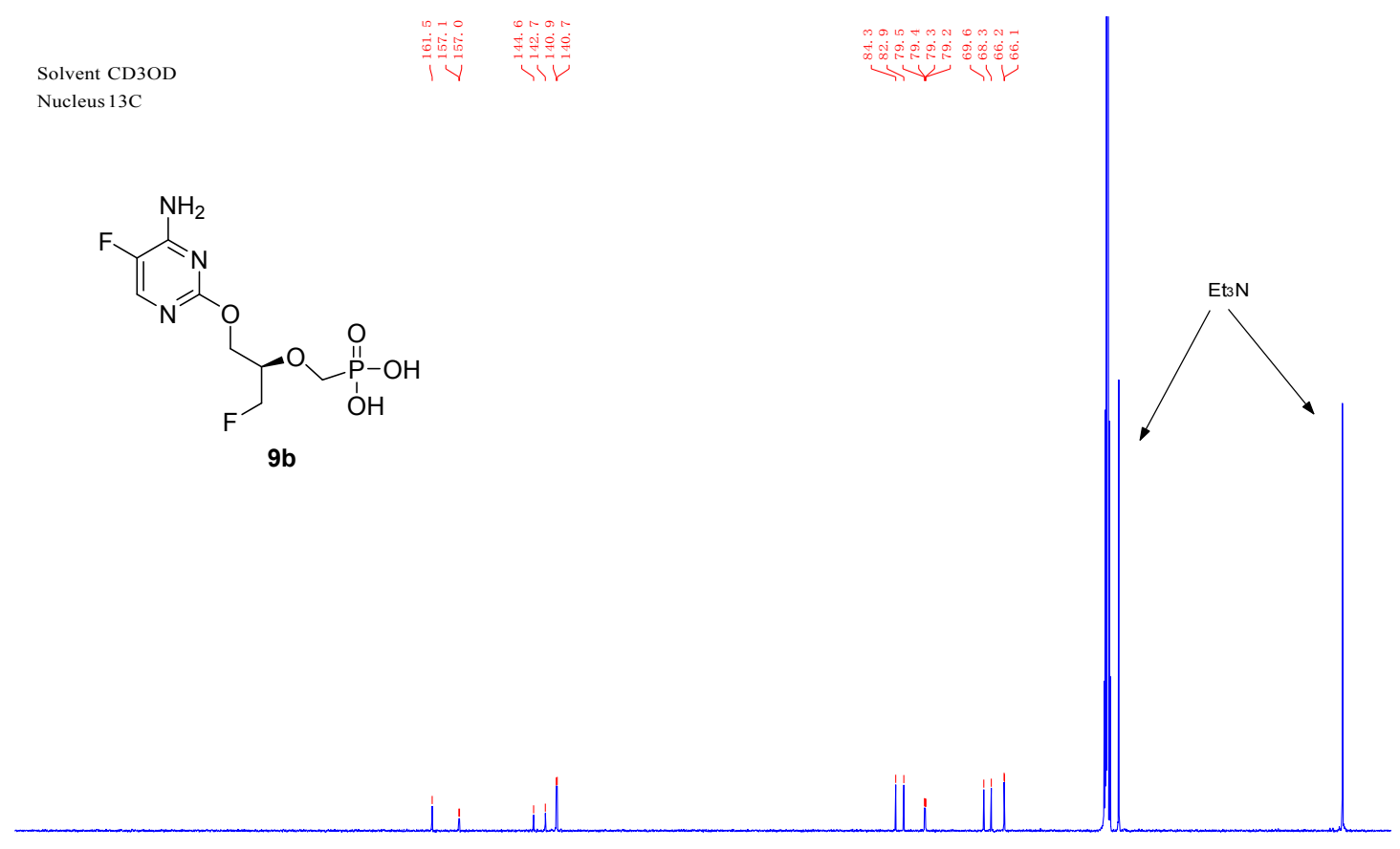

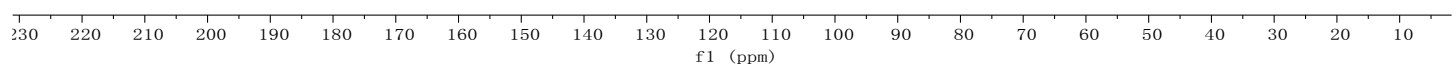

Solvent CD3OD

Nucleus 31P

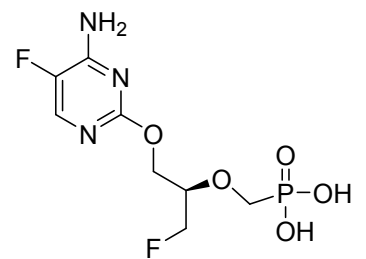

9b

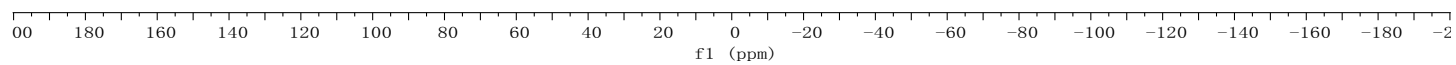




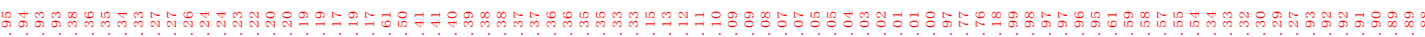
Solvent CDSCN

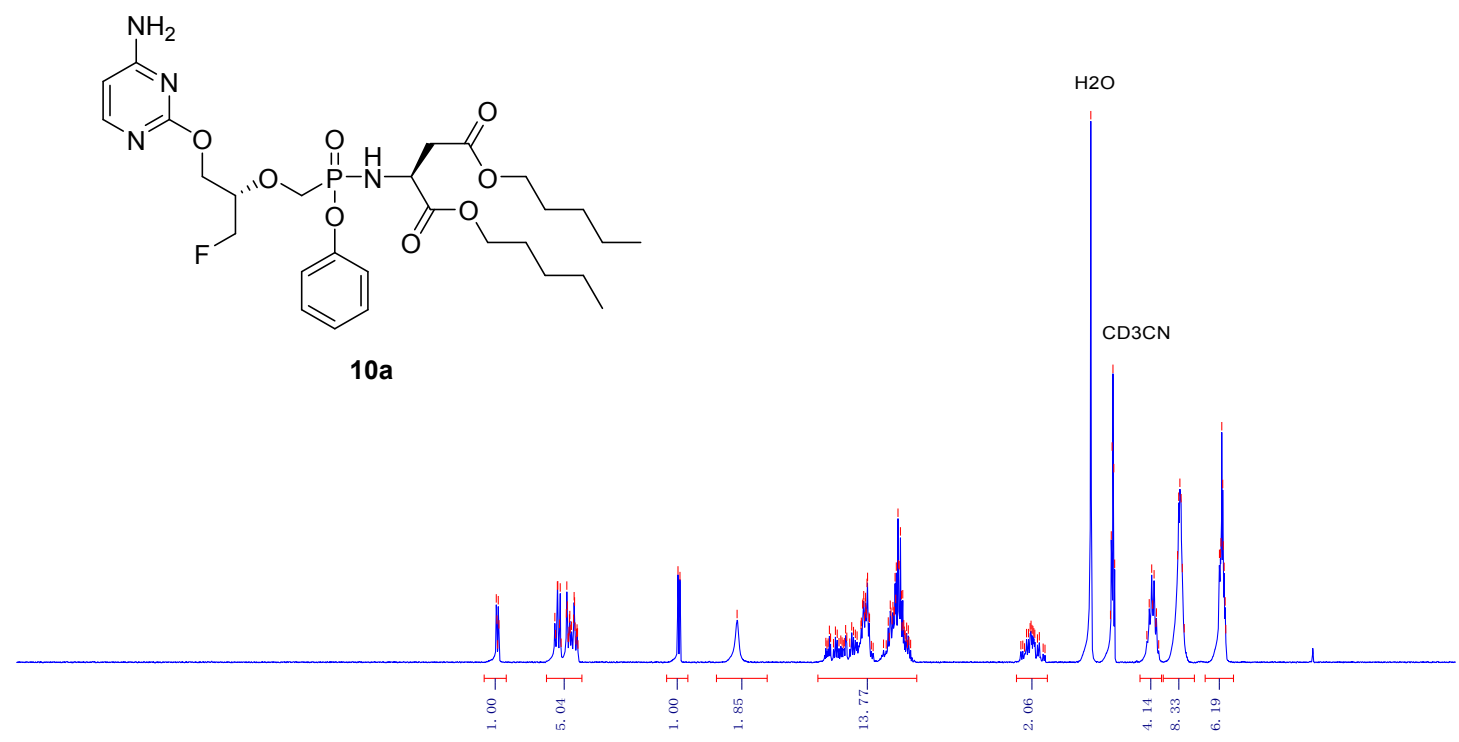

$\begin{array}{lllllllllllllllllllllllllllllllllllllllll}2.5 & 12.0 & 11.5 & 11.0 & 10.5 & 10.0 & 9.5 & 9.0 & 8.5 & 8.0 & 7.5 & 7.0 & 6.5 & 6.0 & 5.5 & 5.0 & 4.5 & 4.0 & 3.5 & 3.0 & 2.5 & 2.0 & 1.5 & 1.0 & 0.5 & 0.0 & -0.5 & -1.0\end{array}$

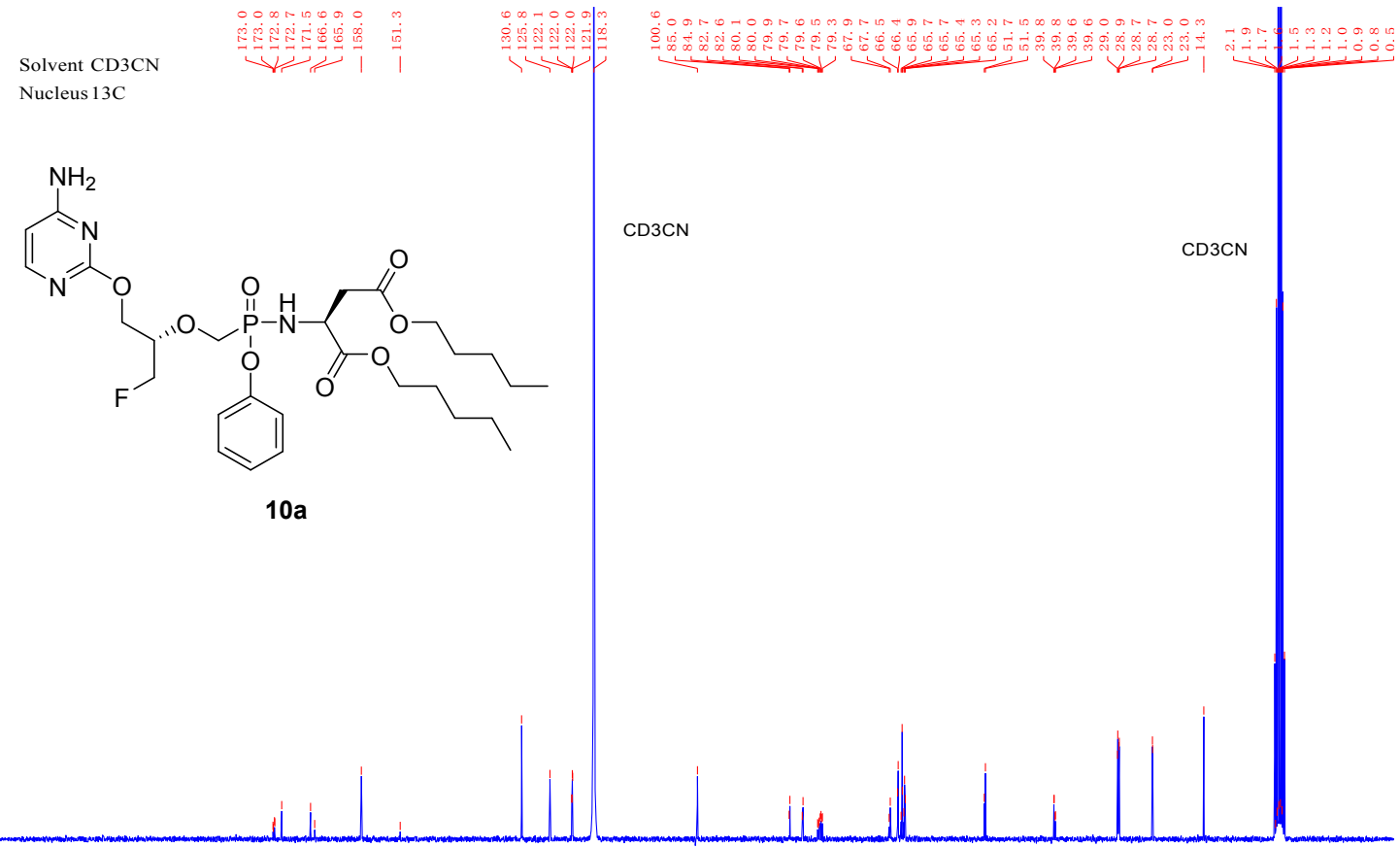

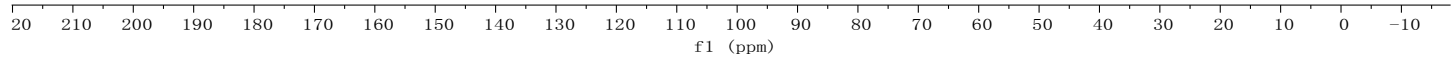




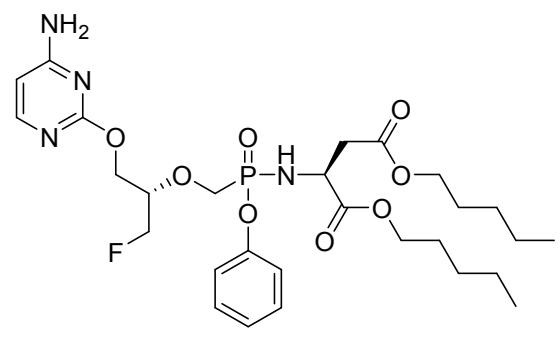

$10 a$
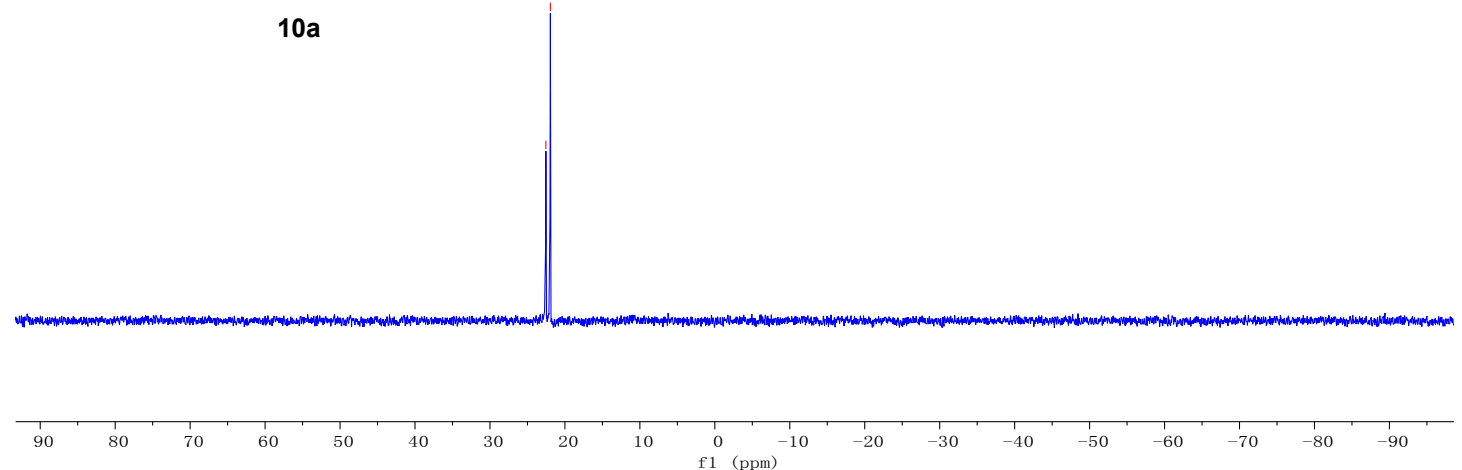

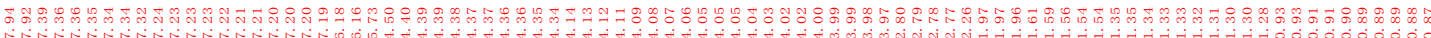
Solvent CD3CN

Nucleus 1H

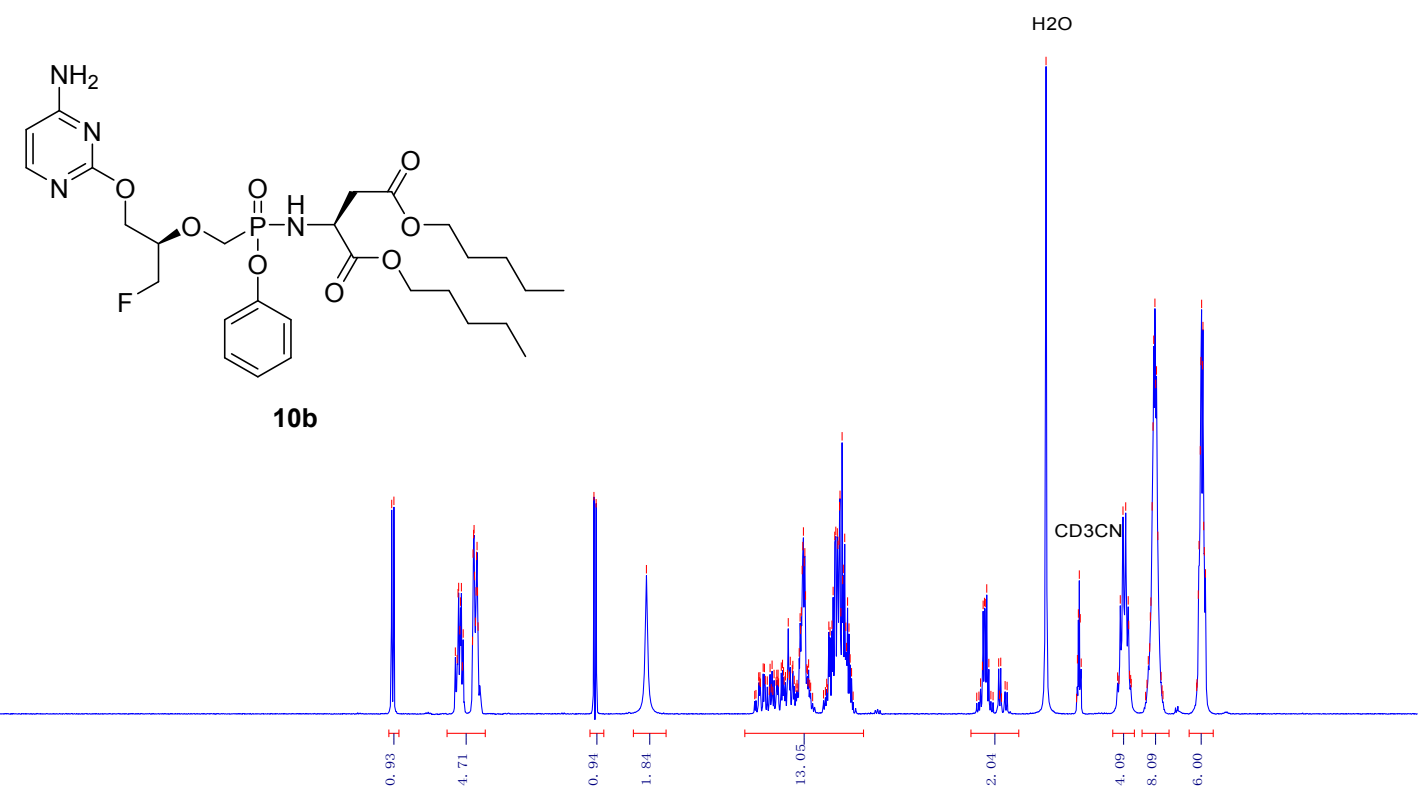

\begin{tabular}{llllllllllllllllllllllllllllllllll}
\hline 1.5 & 11.0 & 10.5 & 10.0 & 9.5 & 9.0 & 8.5 & 8.0 & 7.5 & 7.0 & 6.5 & 6.0 & 5.5 & 5.0 & 4.5 & 4.0 & 3.5 & 3.0 & 2.5 & 2.0 & 1.5 & 1.0 & 0.5 & 0.0 & -0.5
\end{tabular} 


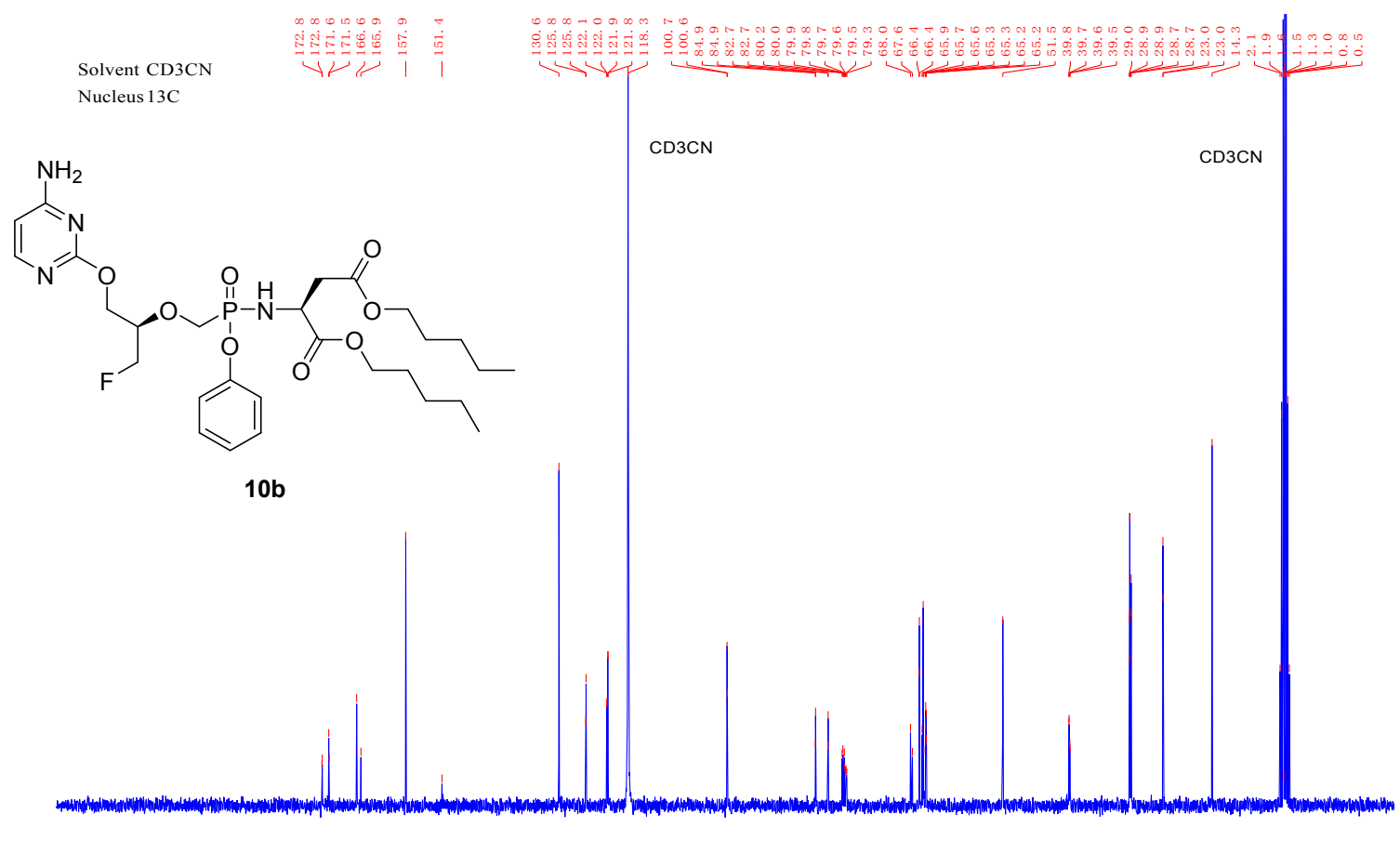

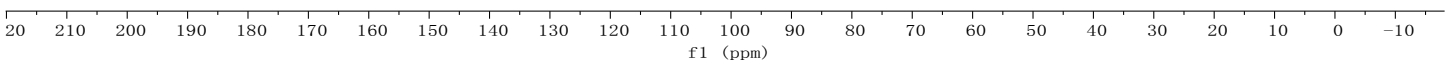

Solvent $\mathrm{CD} 3 \mathrm{CN}$

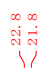

Nucleus 31P

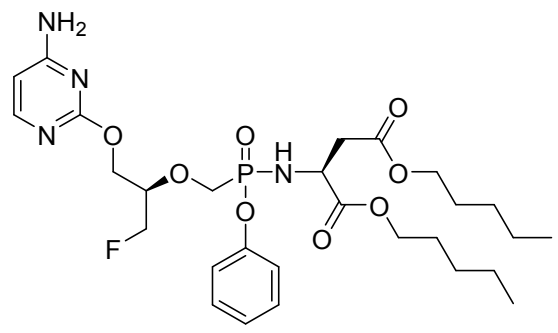

$10 \mathrm{~b}$

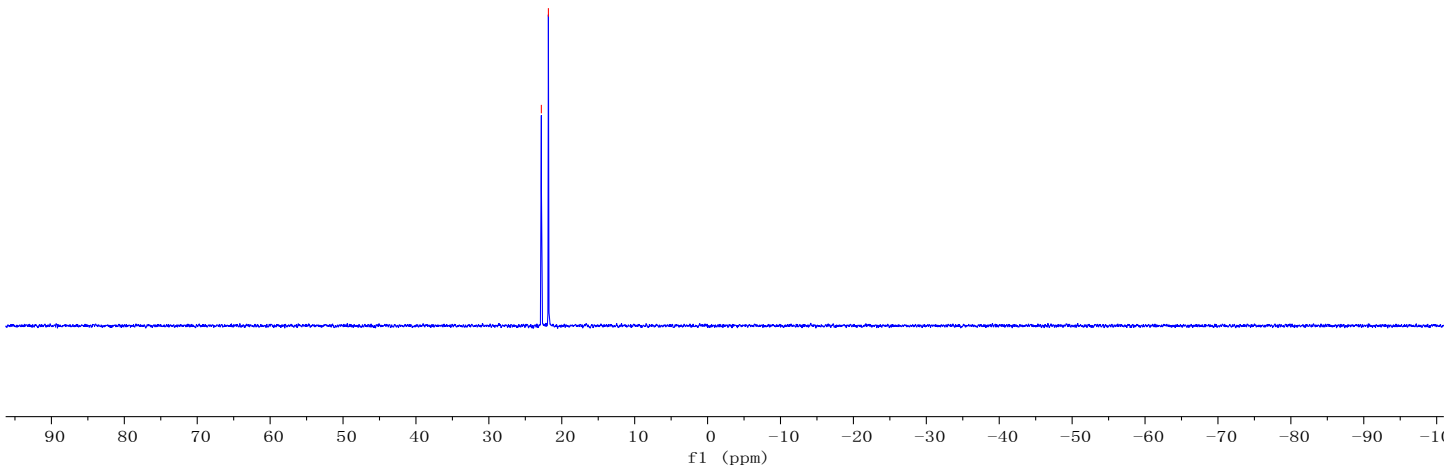




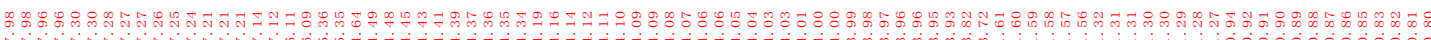
Solvent $\mathrm{CDCl} 3$

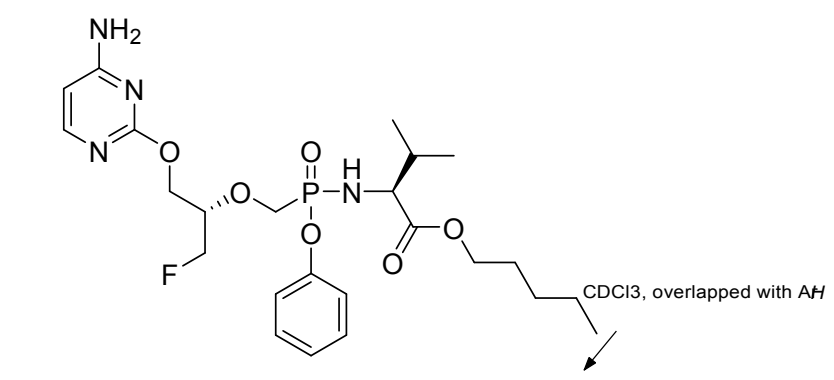

$11 \mathrm{a}$
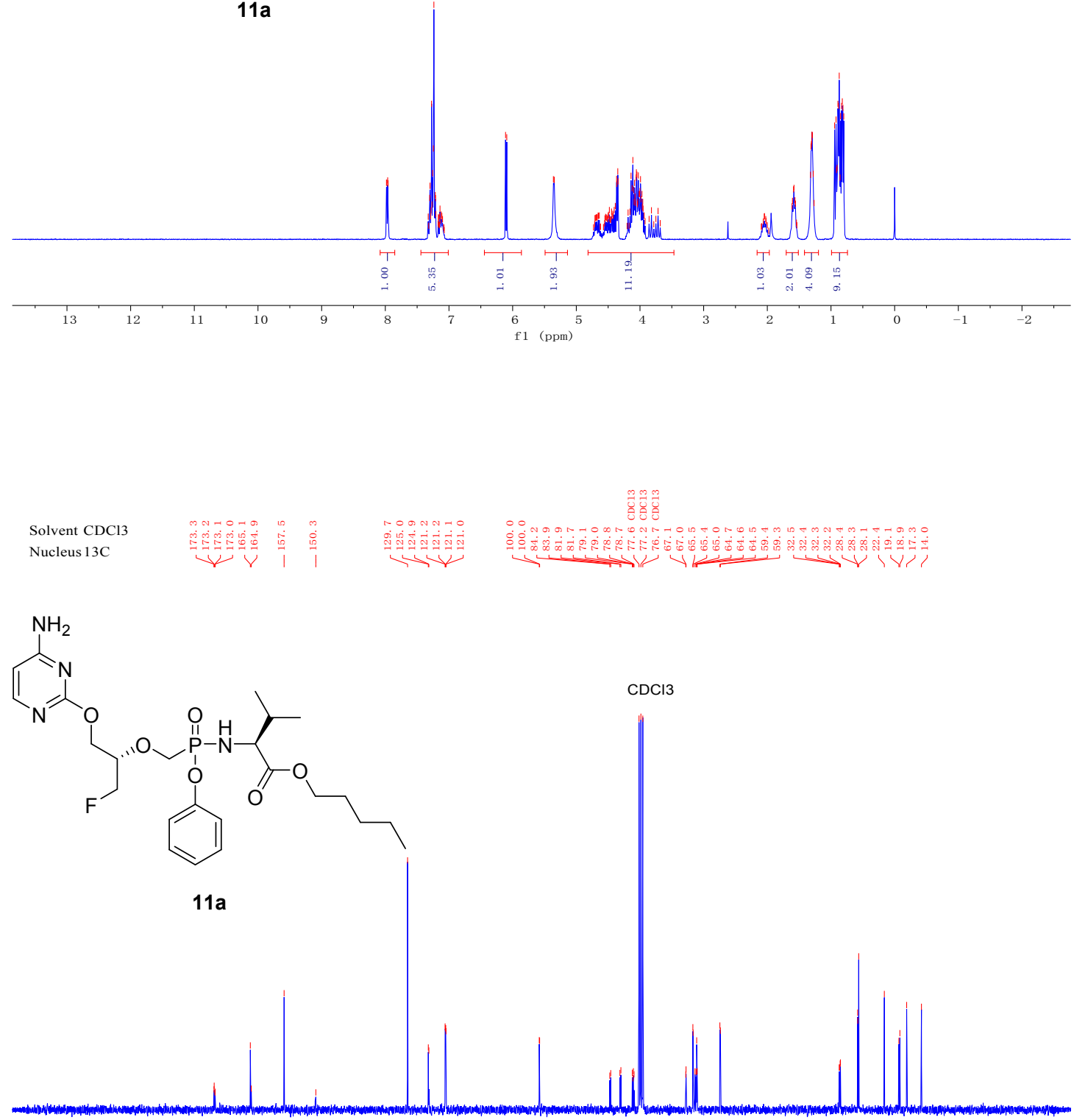

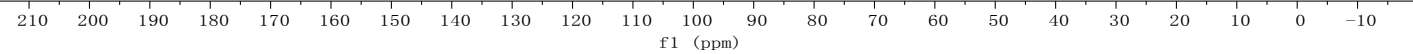


Solvent $\mathrm{CDC13}$

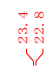

Nucleus $31 \mathrm{P}$
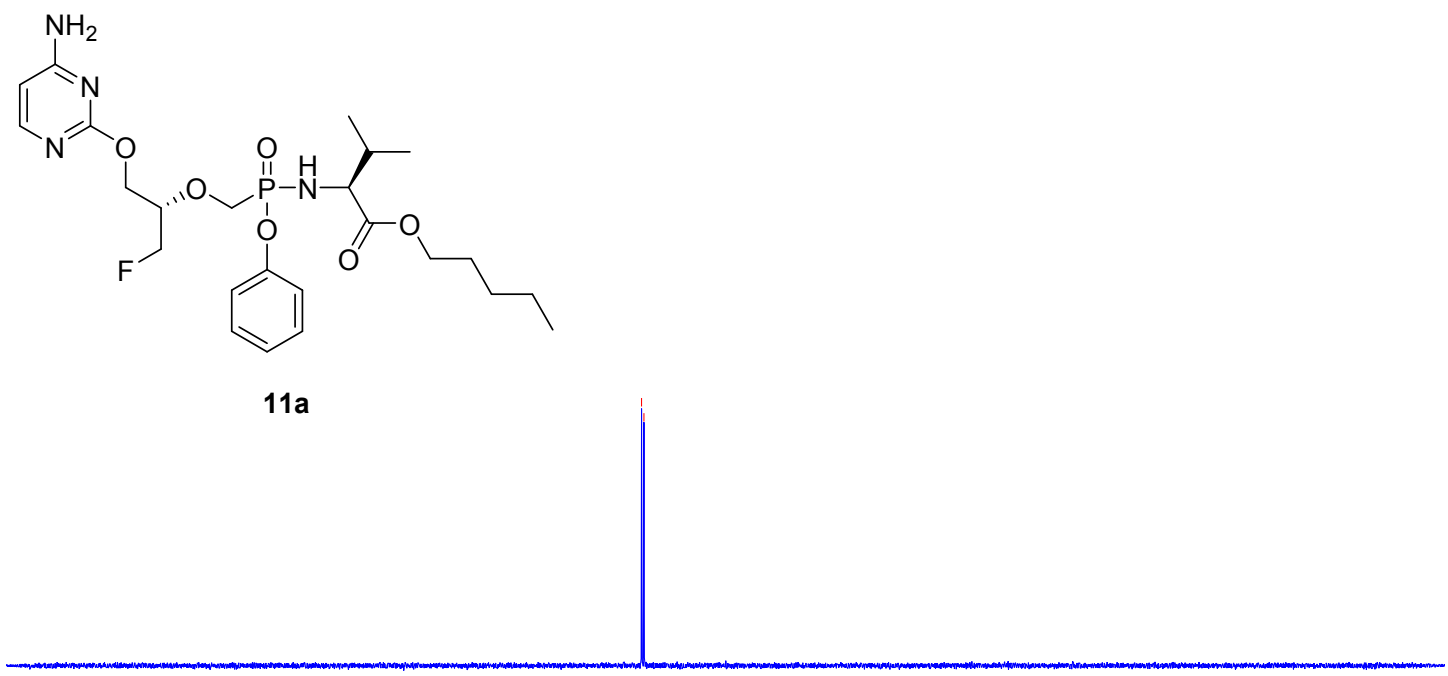

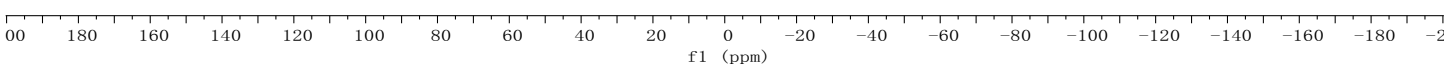

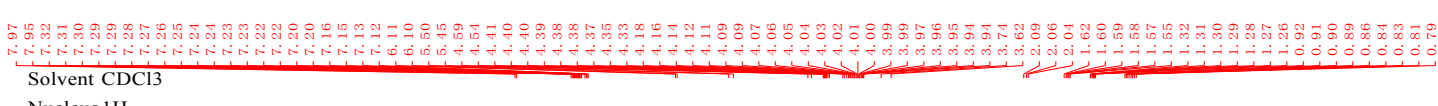

Nucleus 1H
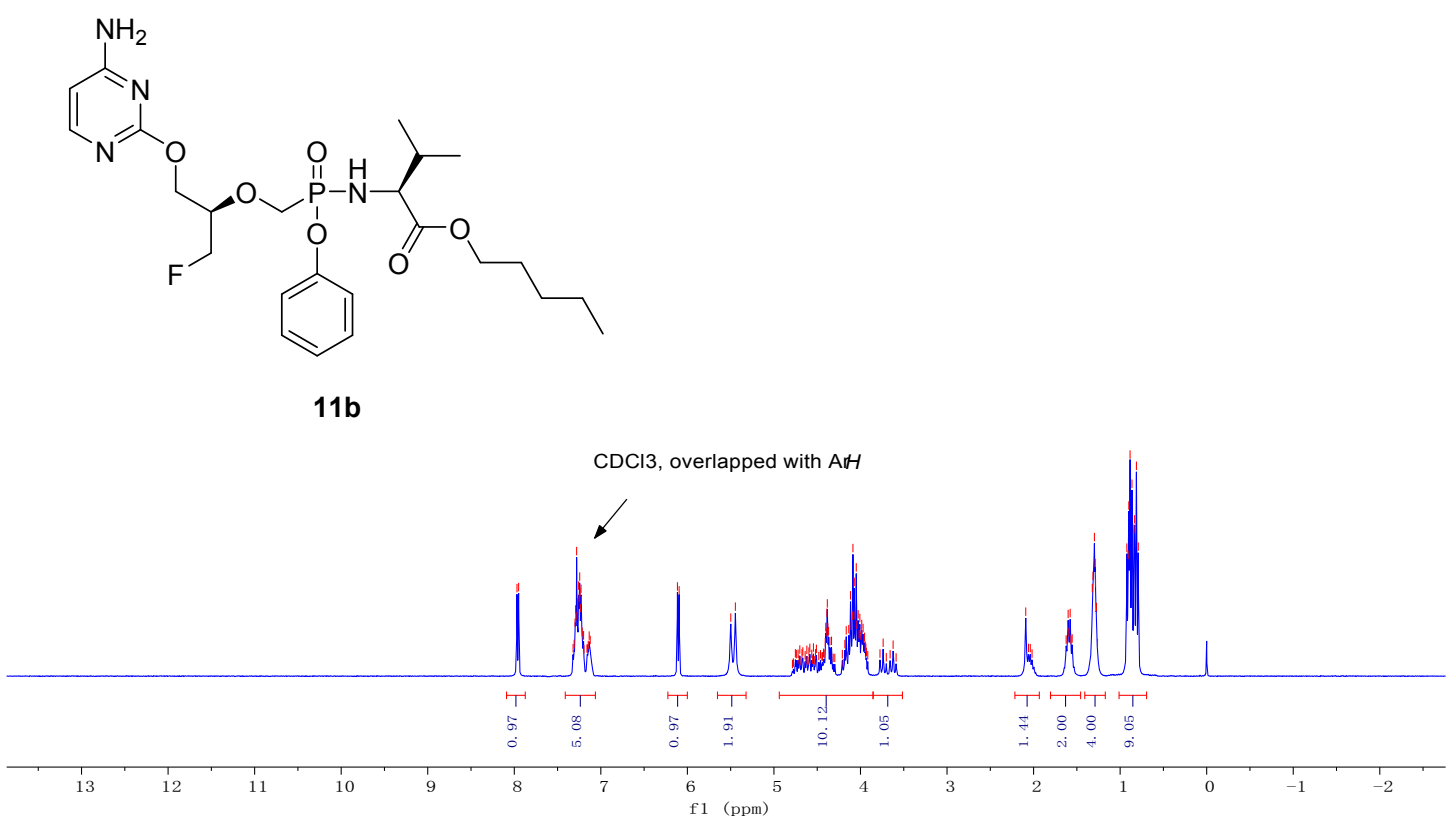
Solvent $\mathrm{CDCl} 3$

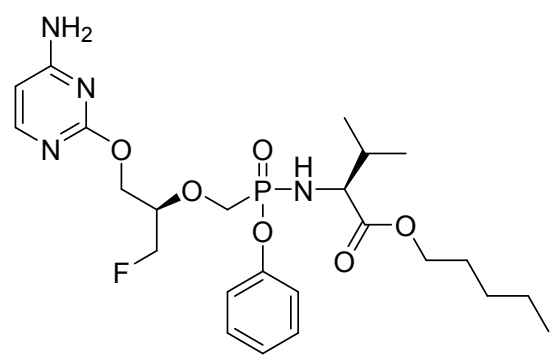

11b

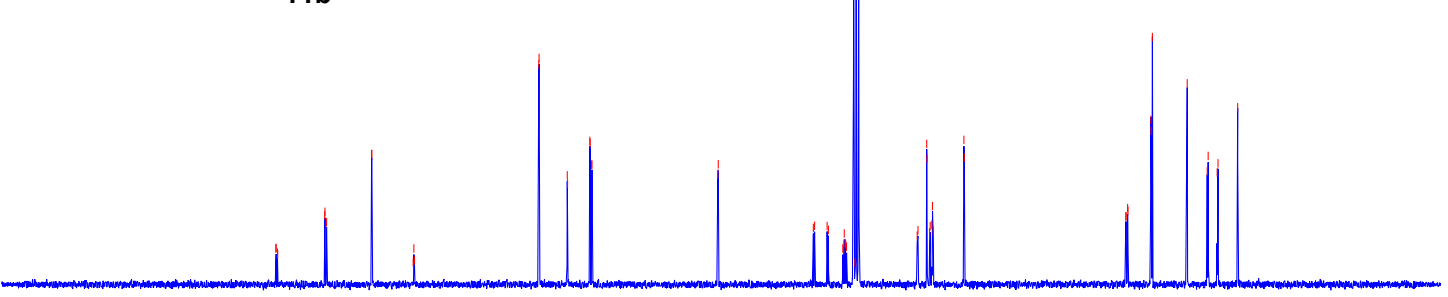

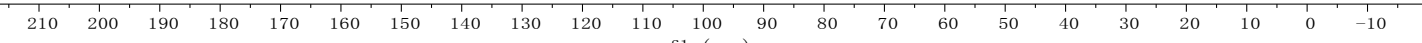

Solvent $\mathrm{CDCl}_{3}$

Nucleus 1H

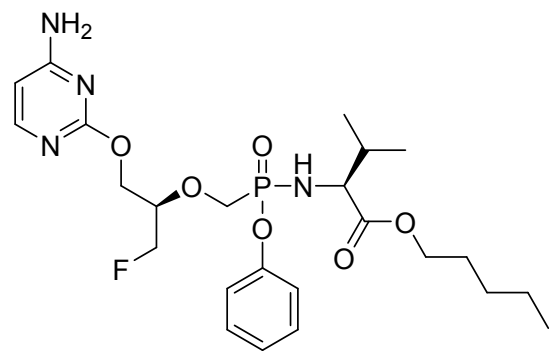

11b

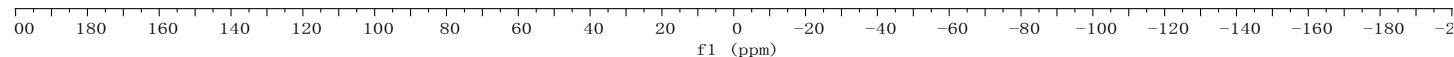




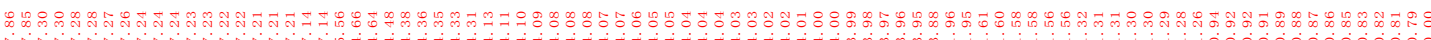
Solvent $\mathrm{CDCl} 3$

Nucleus 1H

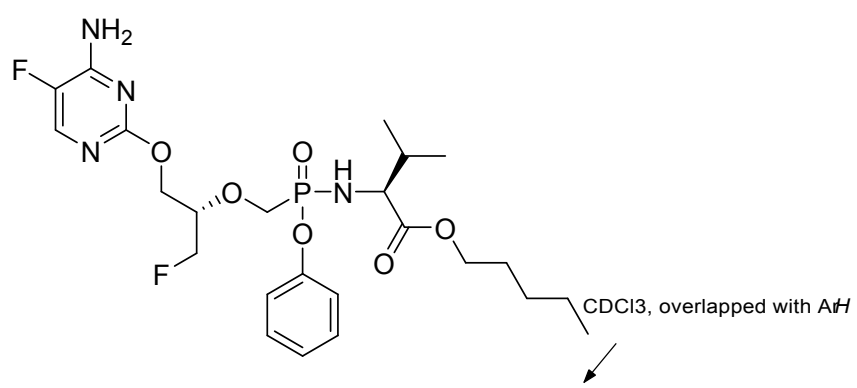

$12 \mathrm{a}$

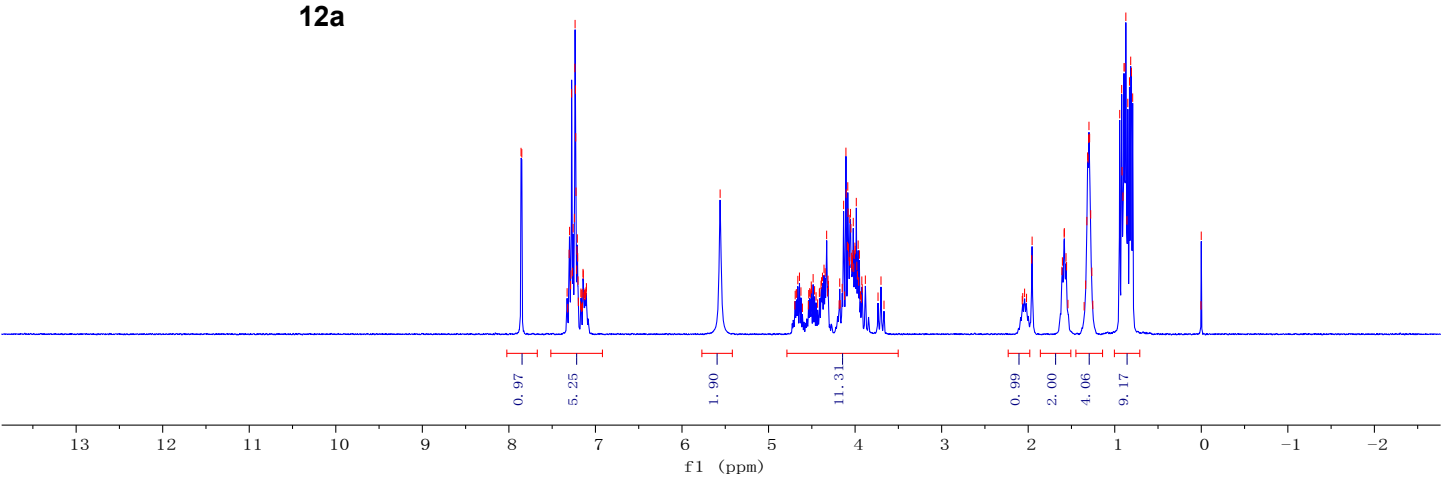

Solvent $\mathrm{CDCl} 3$

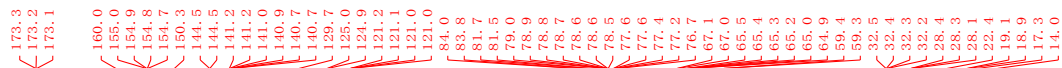

Nucleus 13C<smiles>Nc1nc(Cl)ncc1F</smiles>

$\mathrm{CDCl} 3$

$12 a$

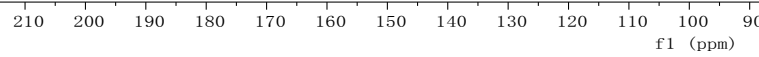




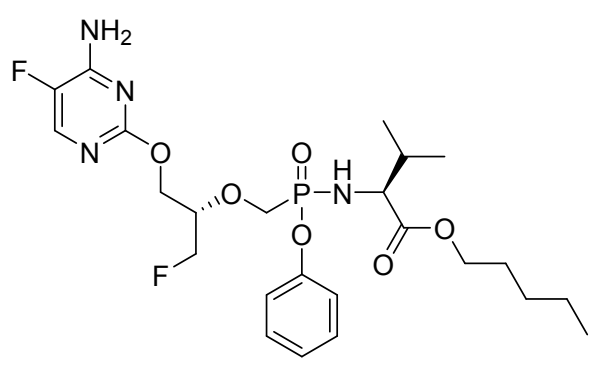

$12 a$

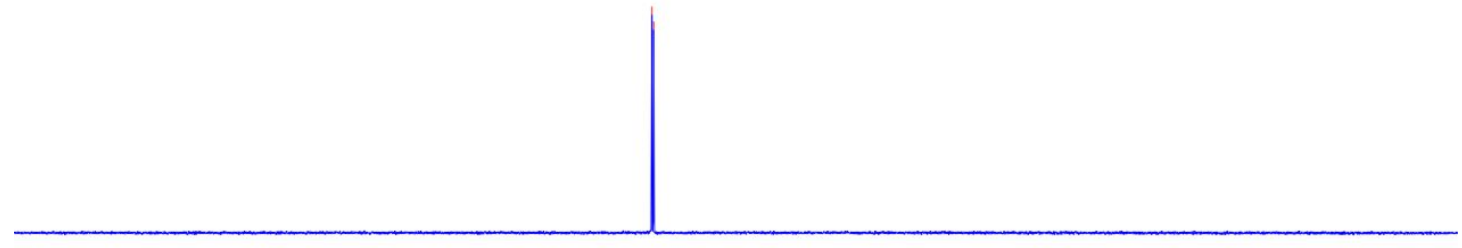

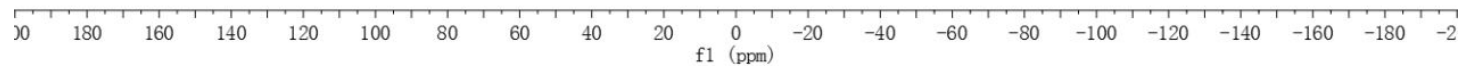

$\begin{array}{lll}6 & 0\end{array}$ Solvent $\mathrm{CDCl} 3$

Nucleus 1H

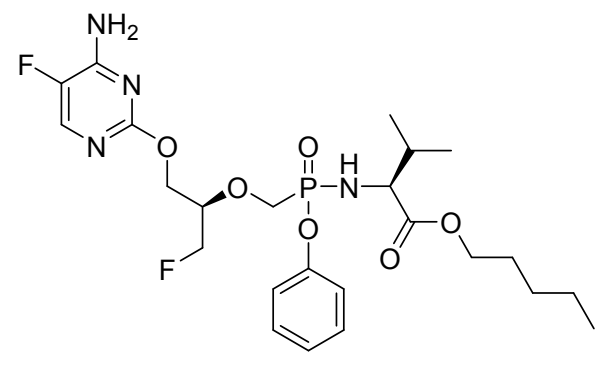

$12 b$

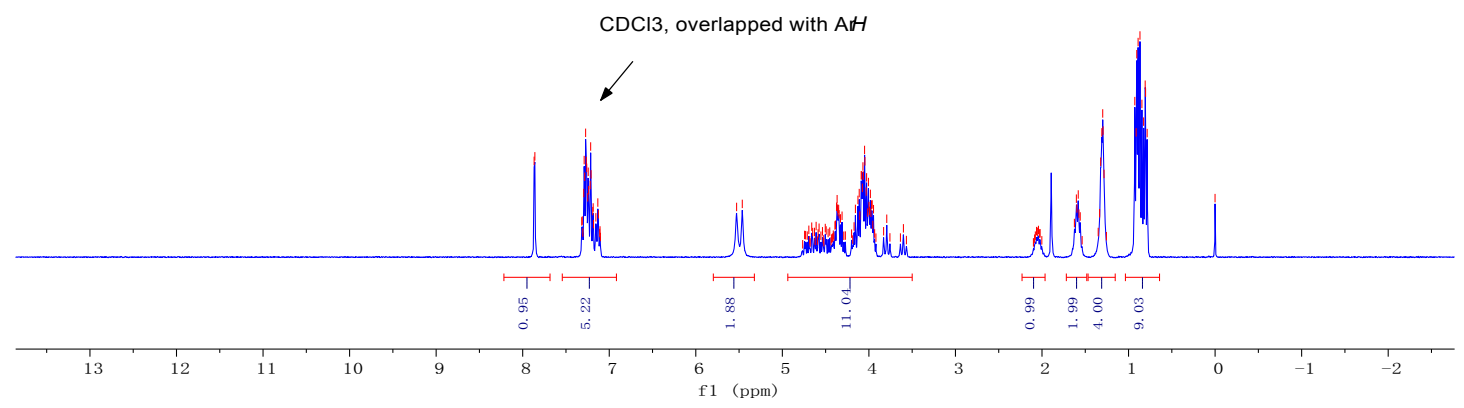



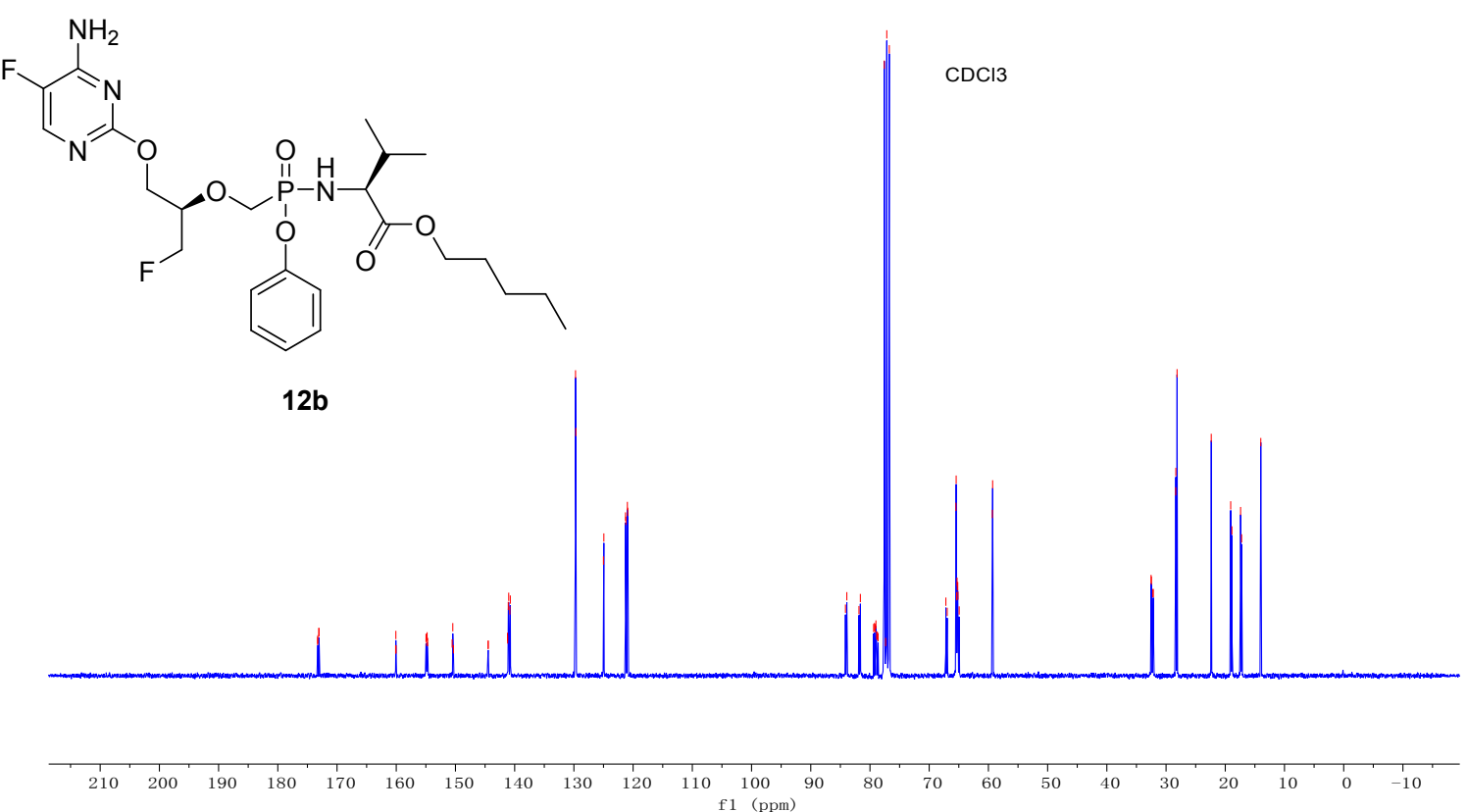

Solvent $\mathrm{CDCl}$

Nucleus 31P

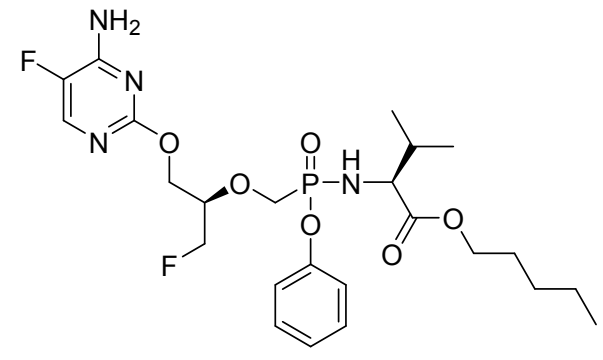

$12 b$

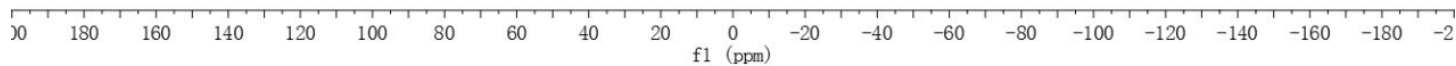



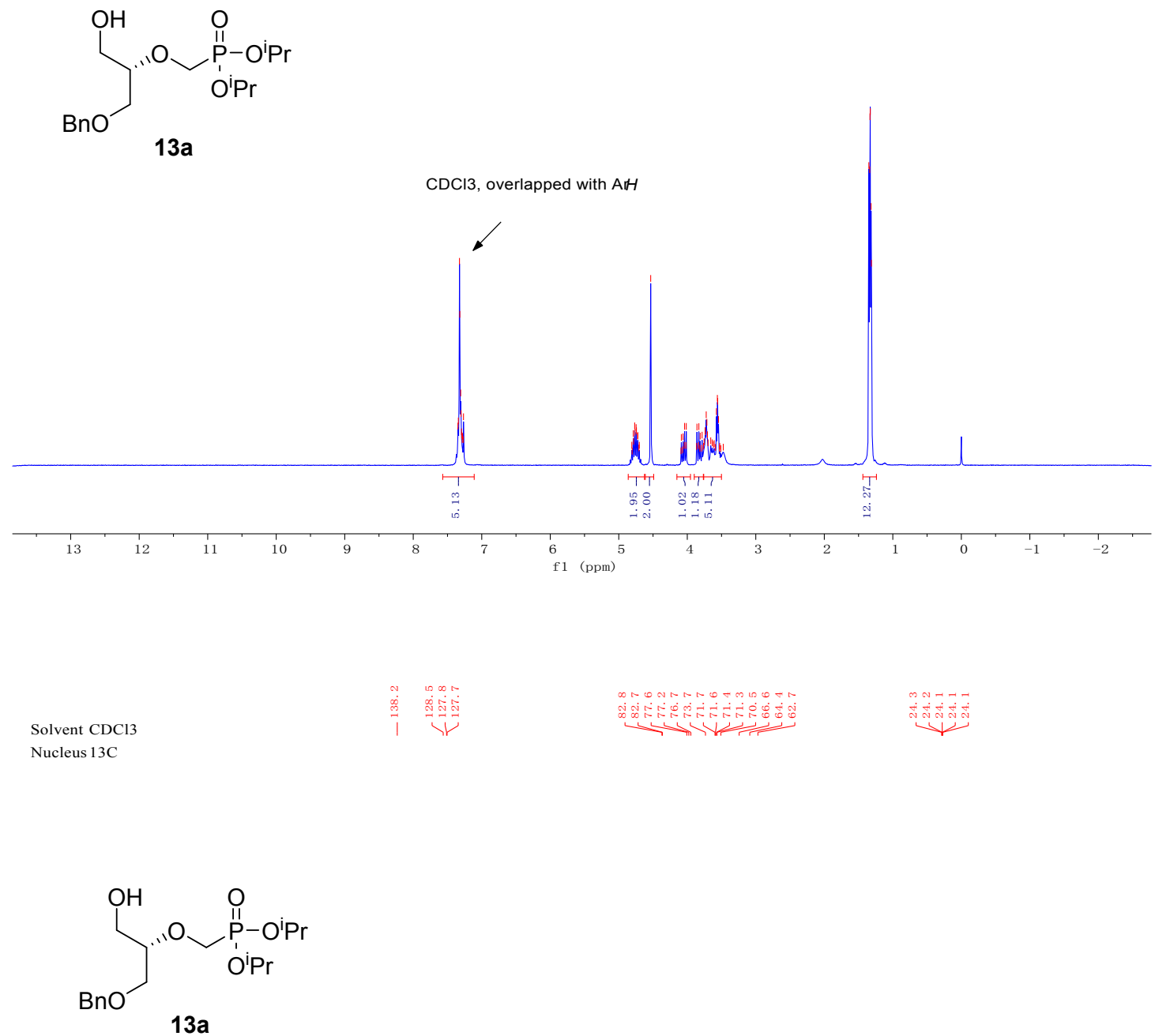

$\mathrm{CDCl} 3$

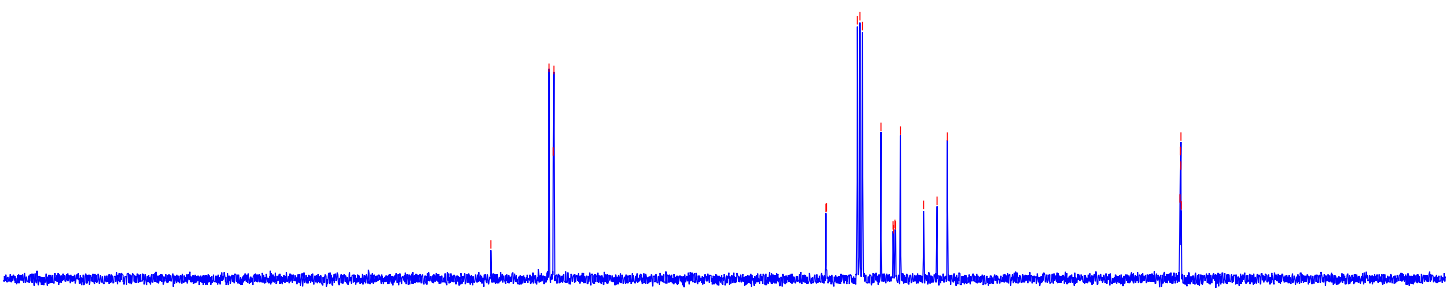

\begin{tabular}{lllllllllllllllllllllllll}
\hline & 1 \\
210 & 200 & 190 & 180 & 170 & 160 & 150 & 140 & 130 & 120 & 110 & 100 & 90 & 80 & 70 & 60 & 50 & 40 & 30 & 20 & 10 & 0 & -10
\end{tabular} 


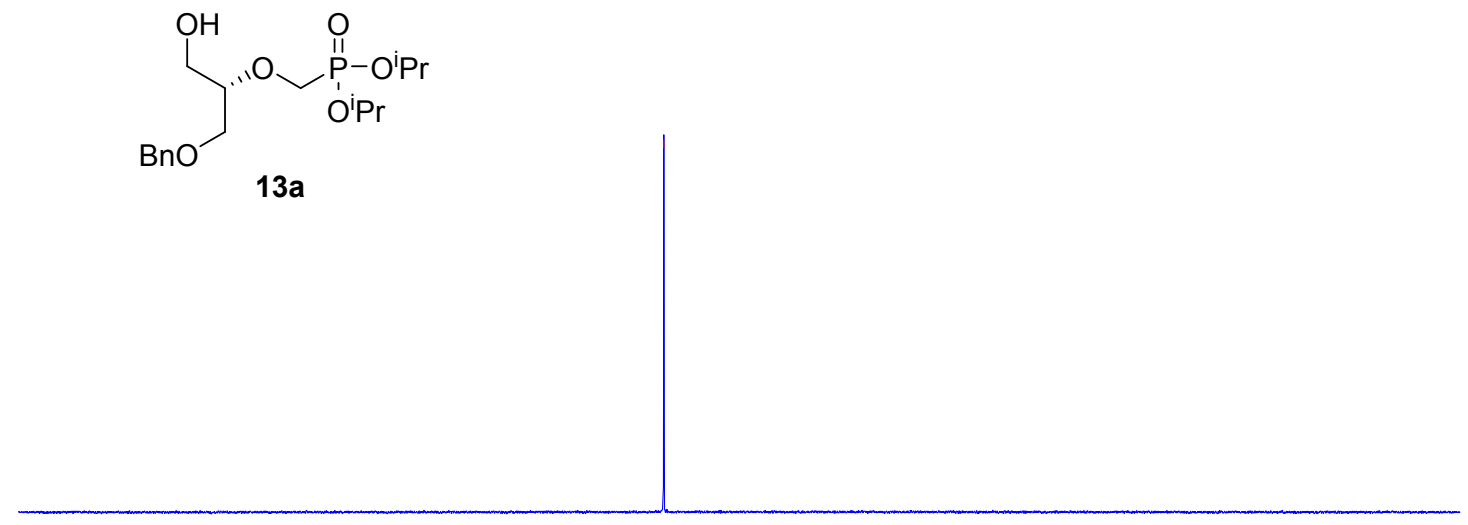

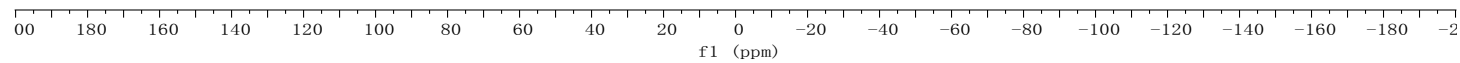

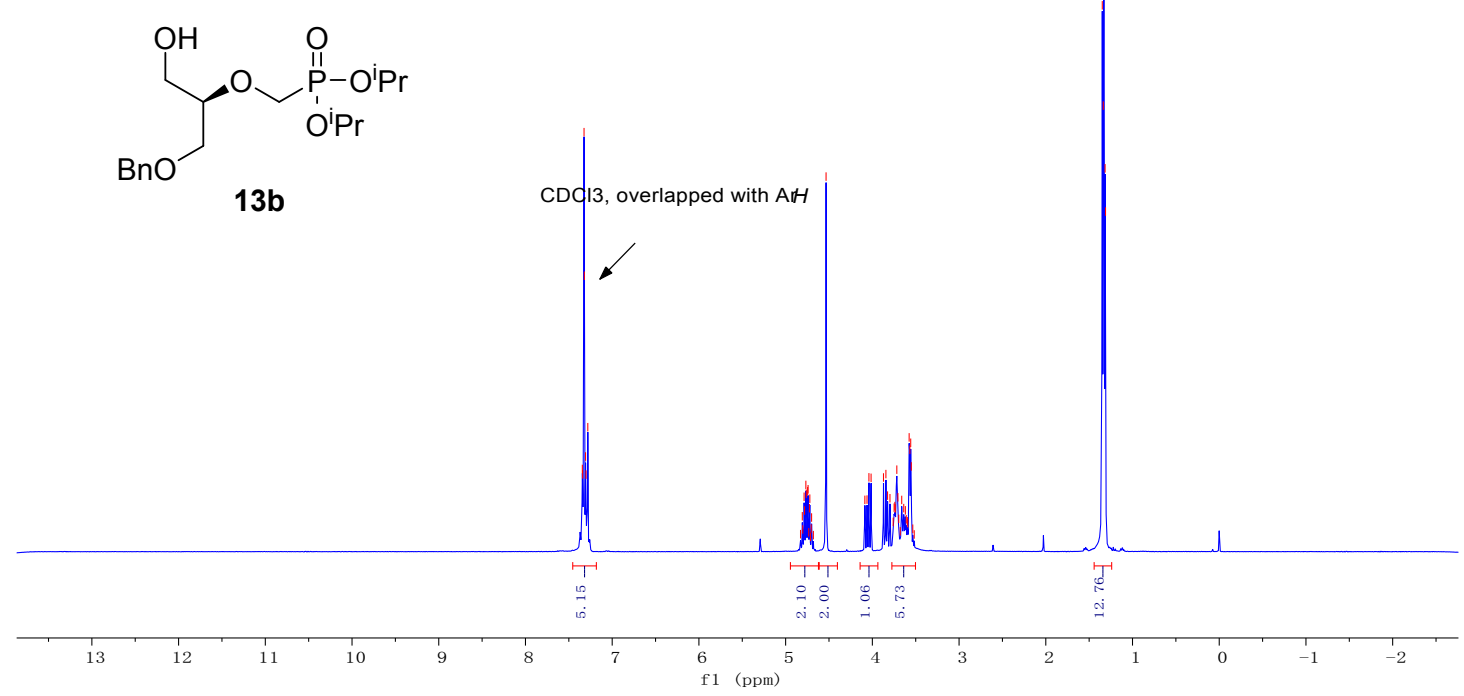




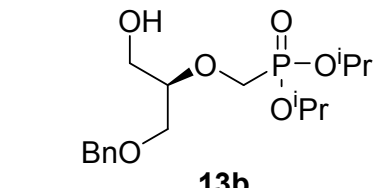

$13 b$

Solvent $\mathrm{CDCl} 3$

Nucleus 31P<smiles>CCCCCCOC(CO)COP(=O)(OC(C)C)OC(C)C</smiles>

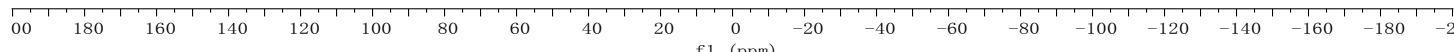



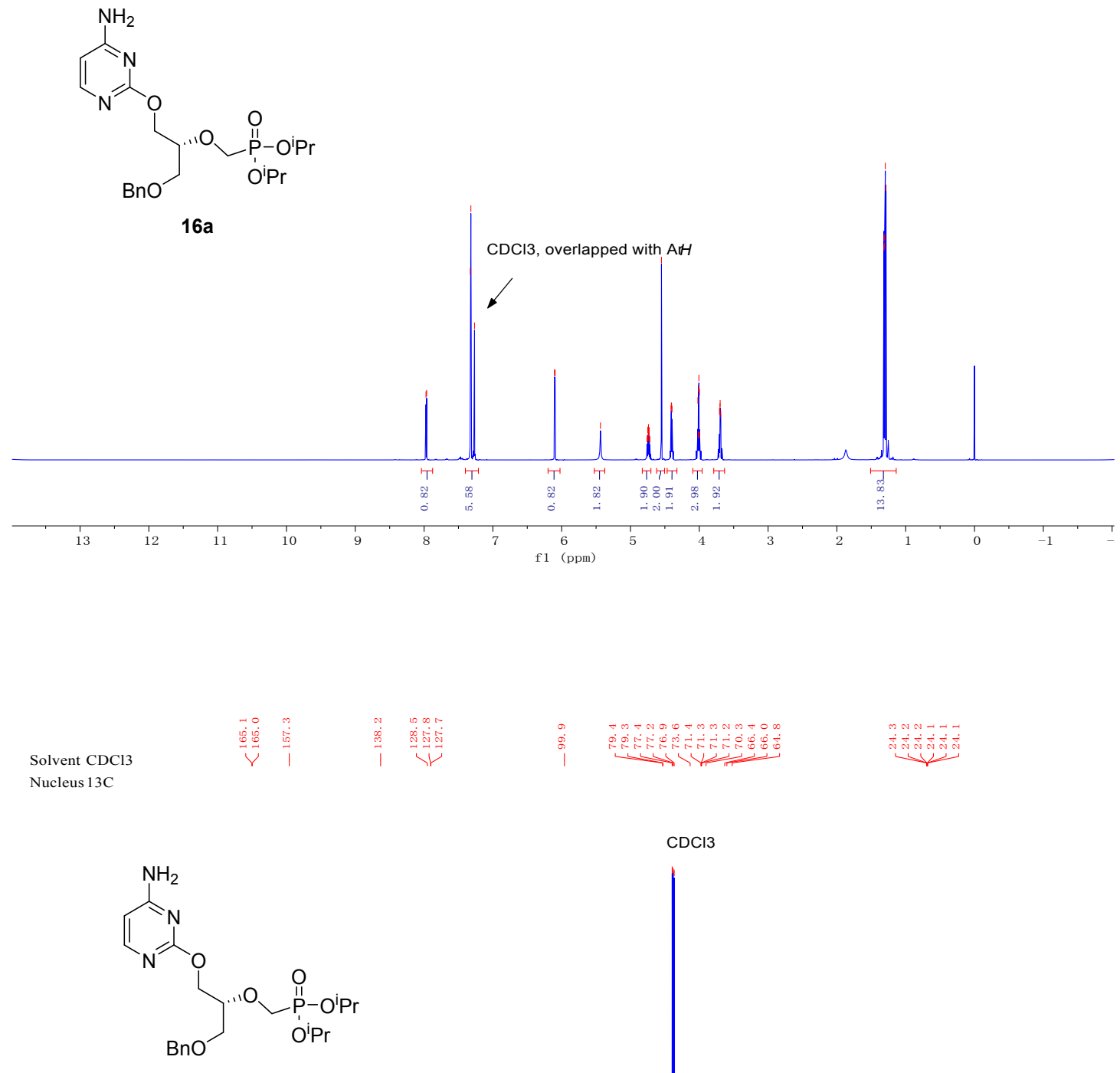

$\mathrm{CDCl} 3$

$16 a$

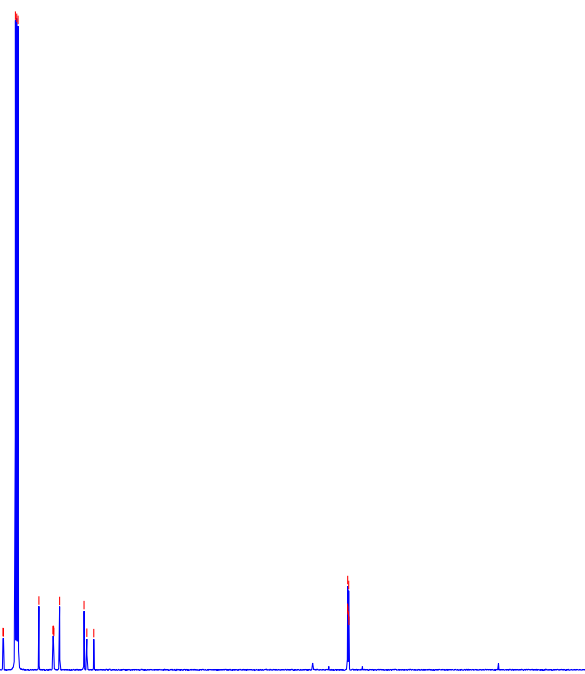

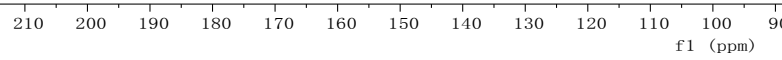




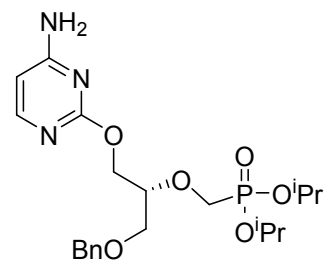

$16 a$

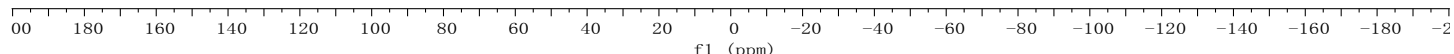

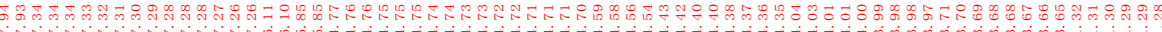
Solvent $\mathrm{CDCl}_{3}$

Nucleus 1H

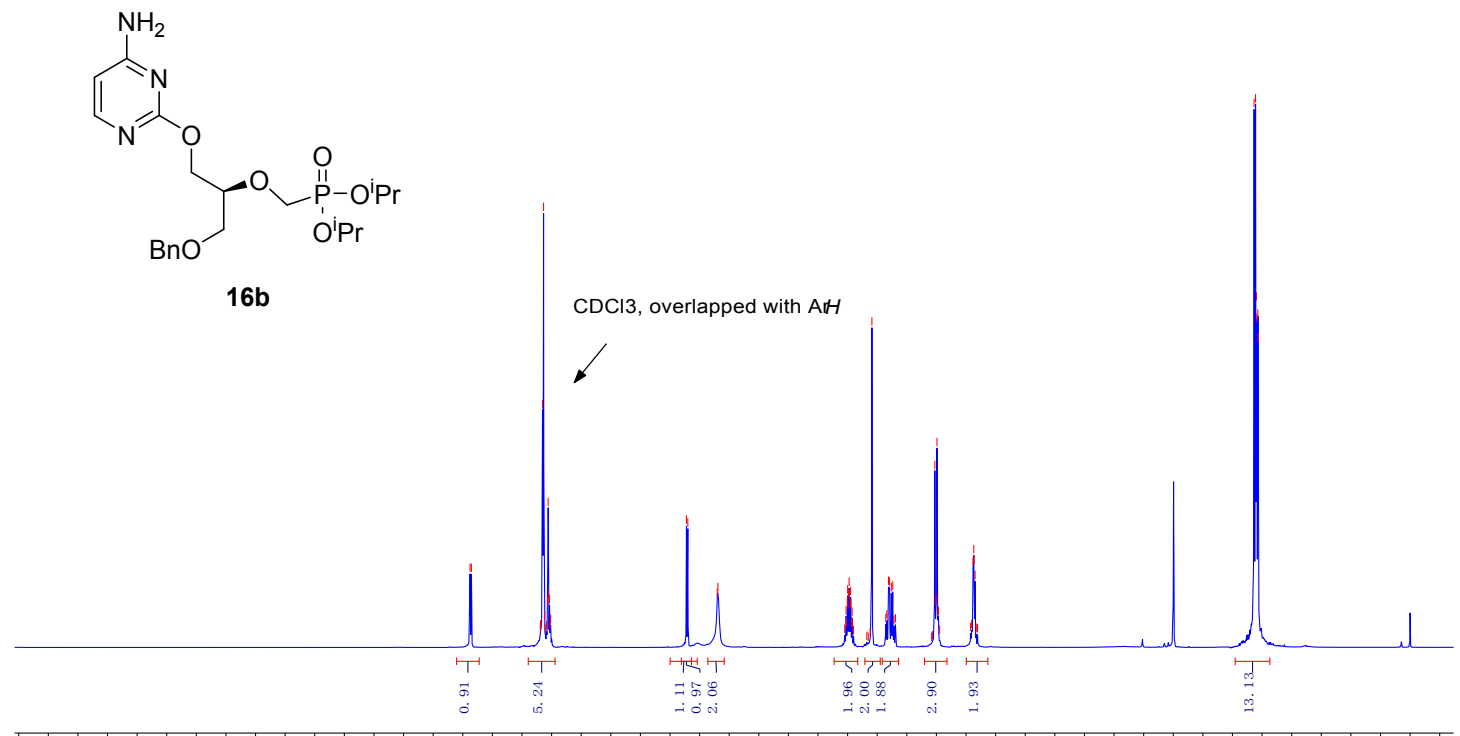
$\begin{array}{llllllllllllllllllllllllllllllll}11.5 & 11.0 & 10.5 & 10.0 & 9.5 & 9.0 & 8.5 & 8.0 & 7.5 & 7.0 & 6.5 & 6.0 & 5.5 & 5.0 & 4.5 & 4.0 & 3.5 & 3.0 & 2.5 & 2.0 & 1.5 & 1.0 & 0.5 & 0.0\end{array}$ 

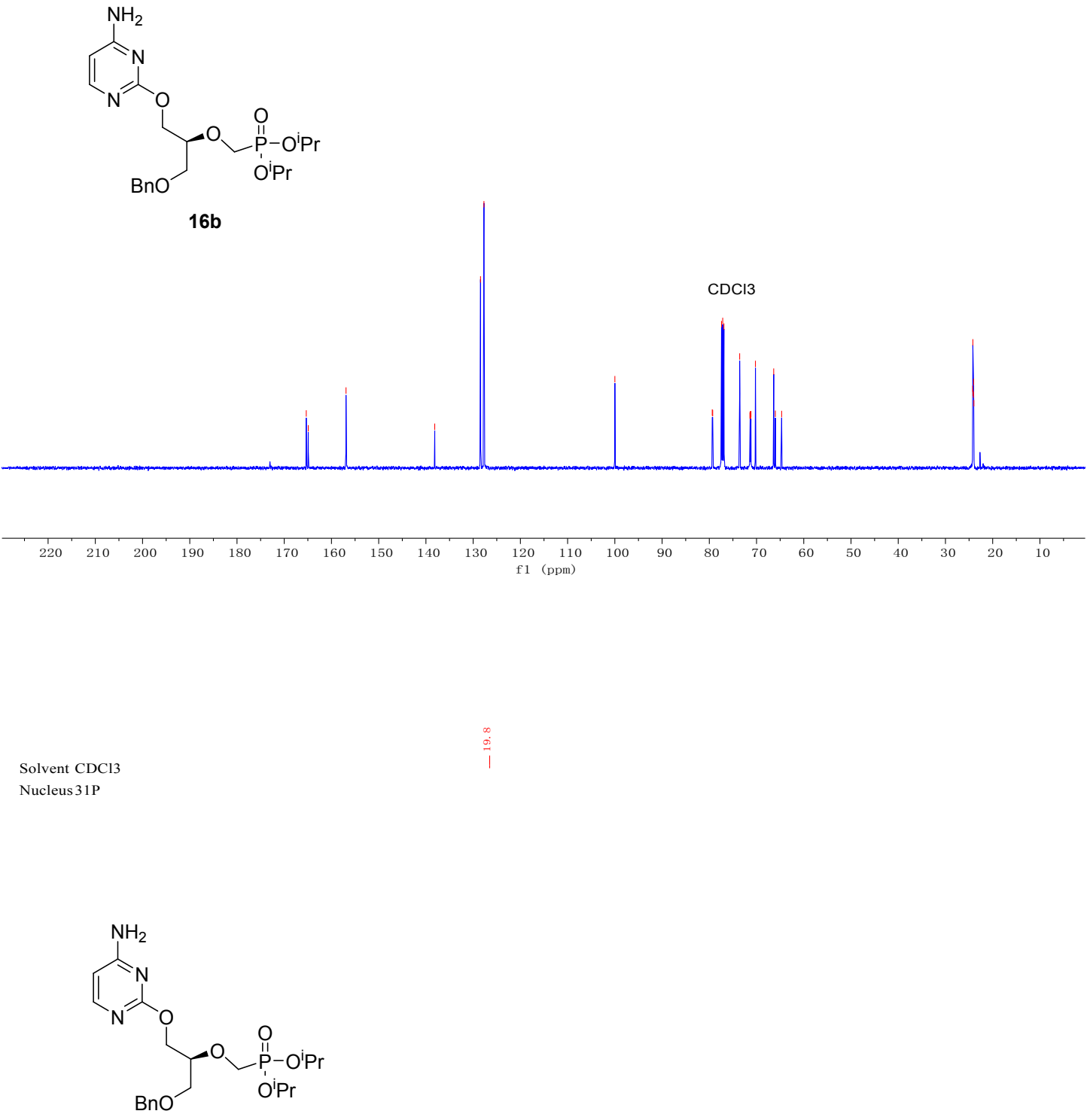

$16 b$

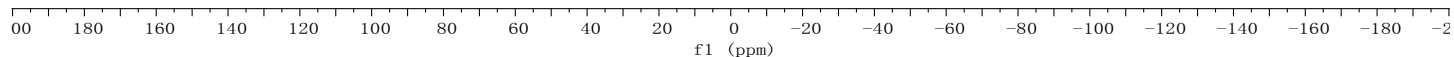




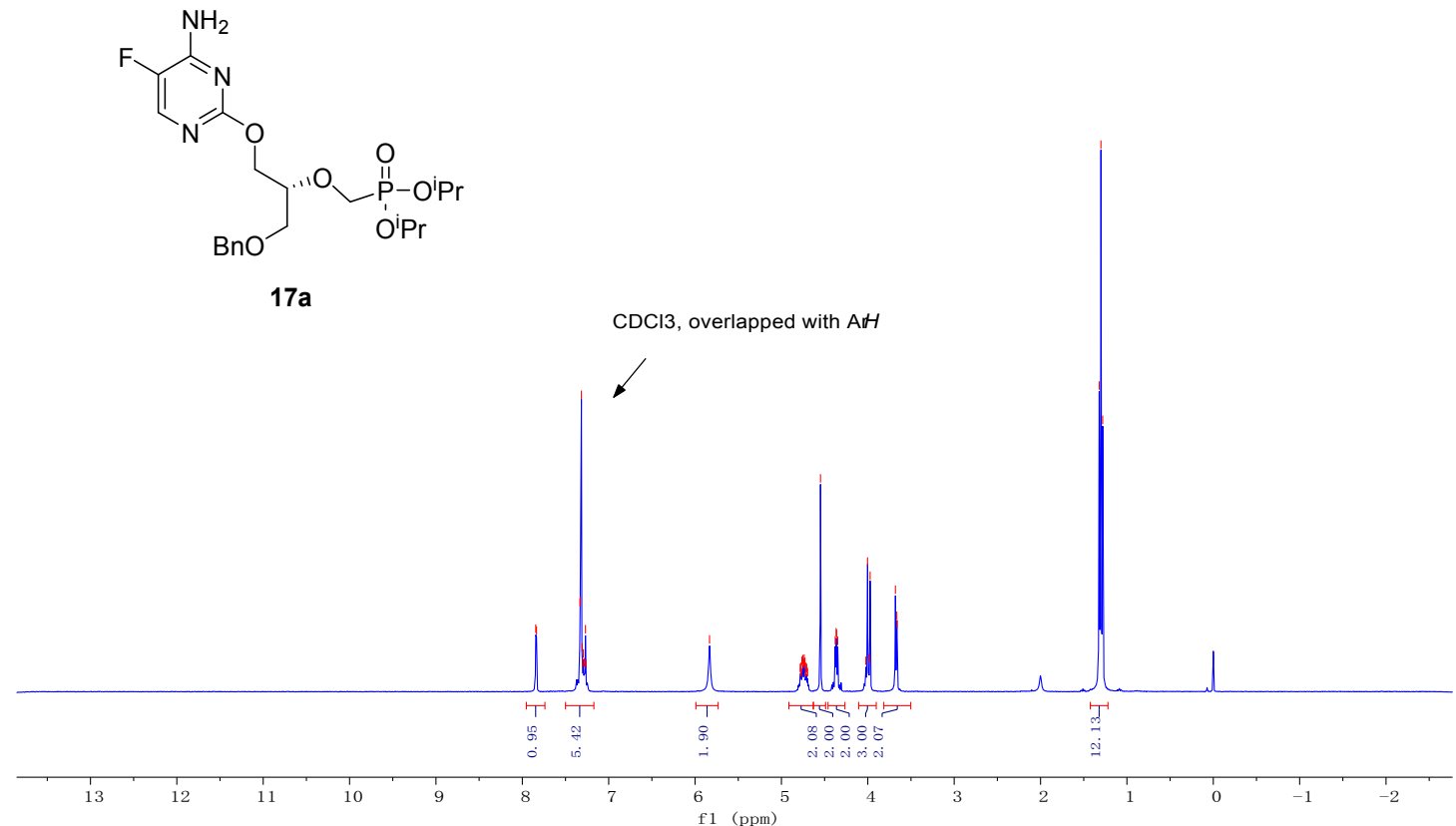

Solvent $\mathrm{CDCl} 3$

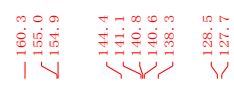

Nucleus 13C

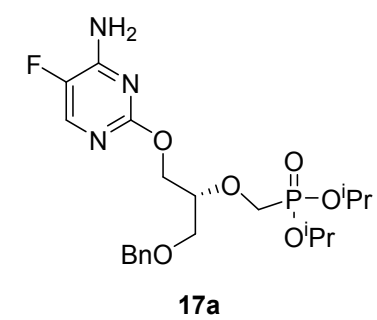

$17 a$

$\mathrm{CDCl} 3$

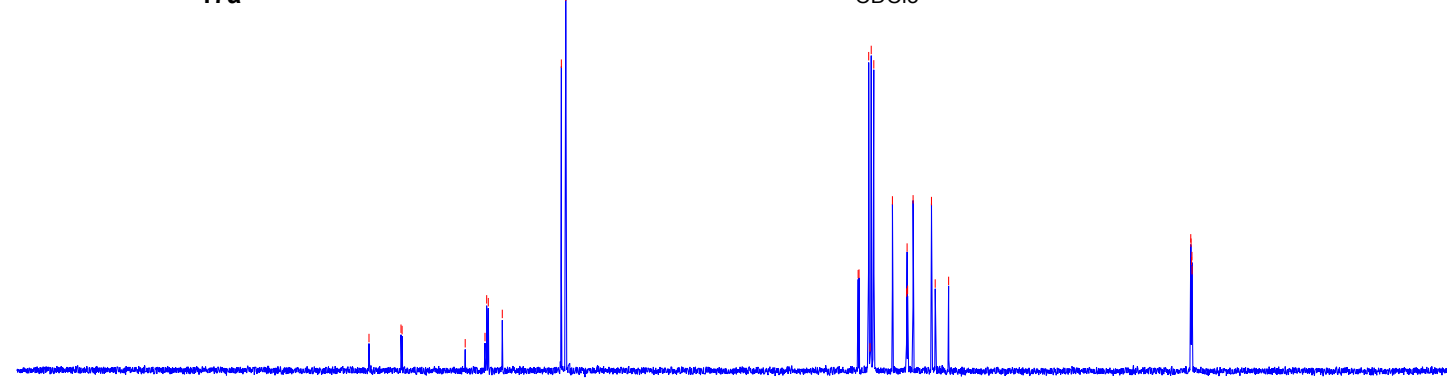

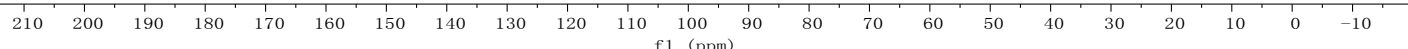




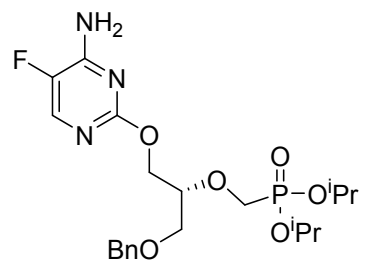

$17 a$

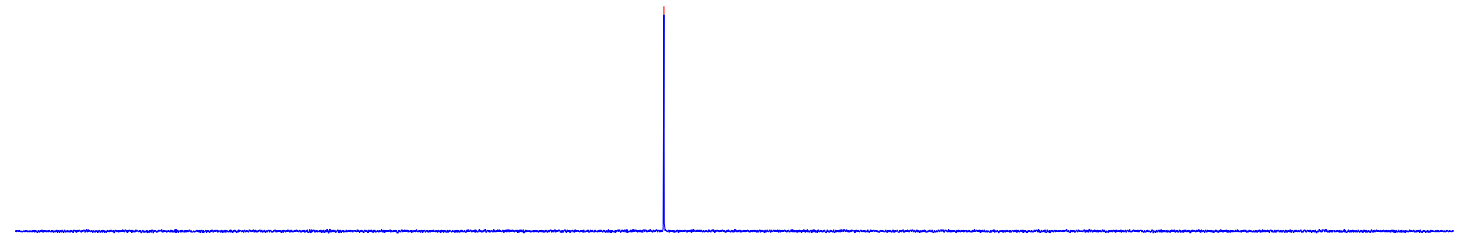

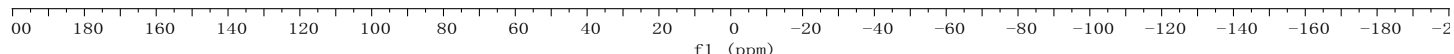

Solvent $\mathrm{CDCl} 3$

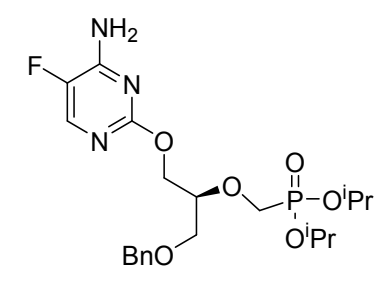

$17 b$

CDCl3, overlapped with AtH

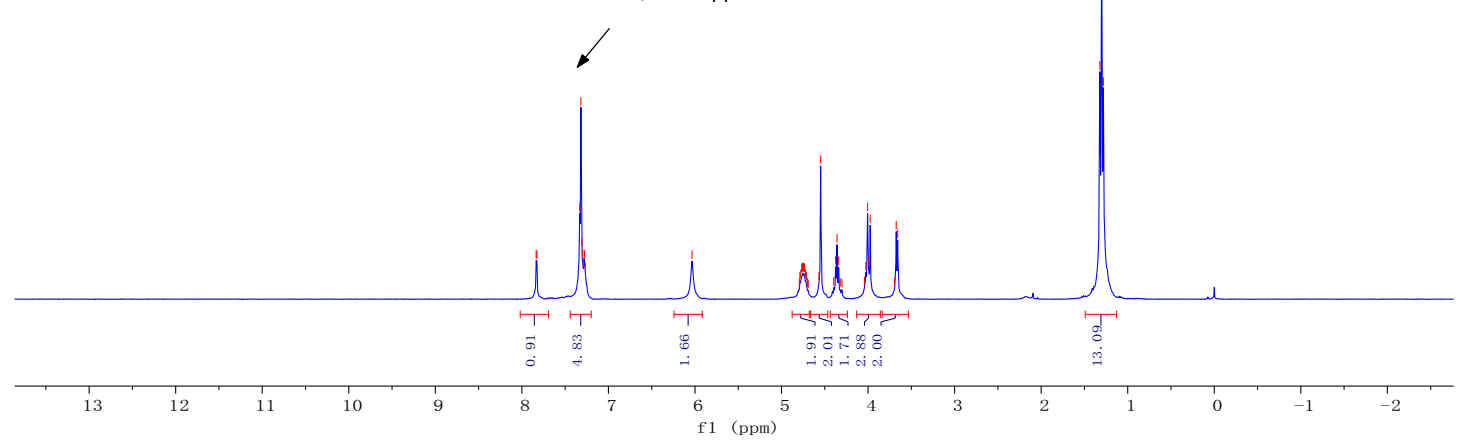




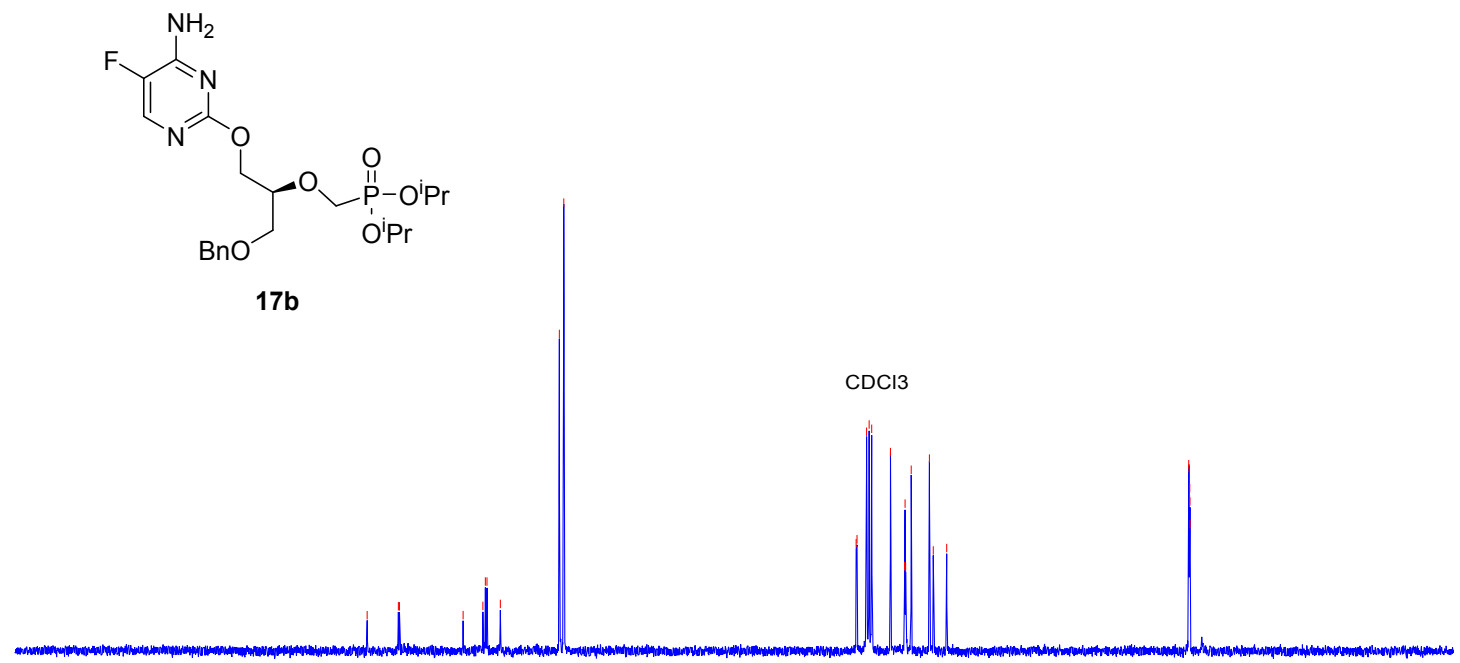

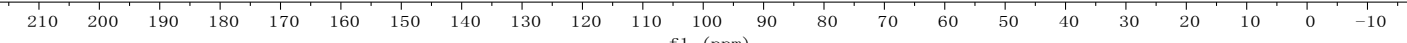

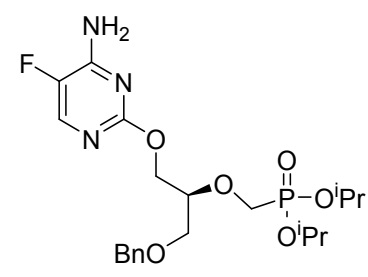

17b

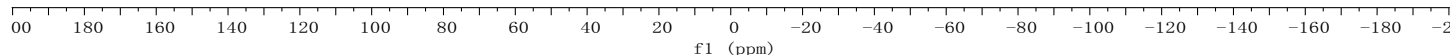




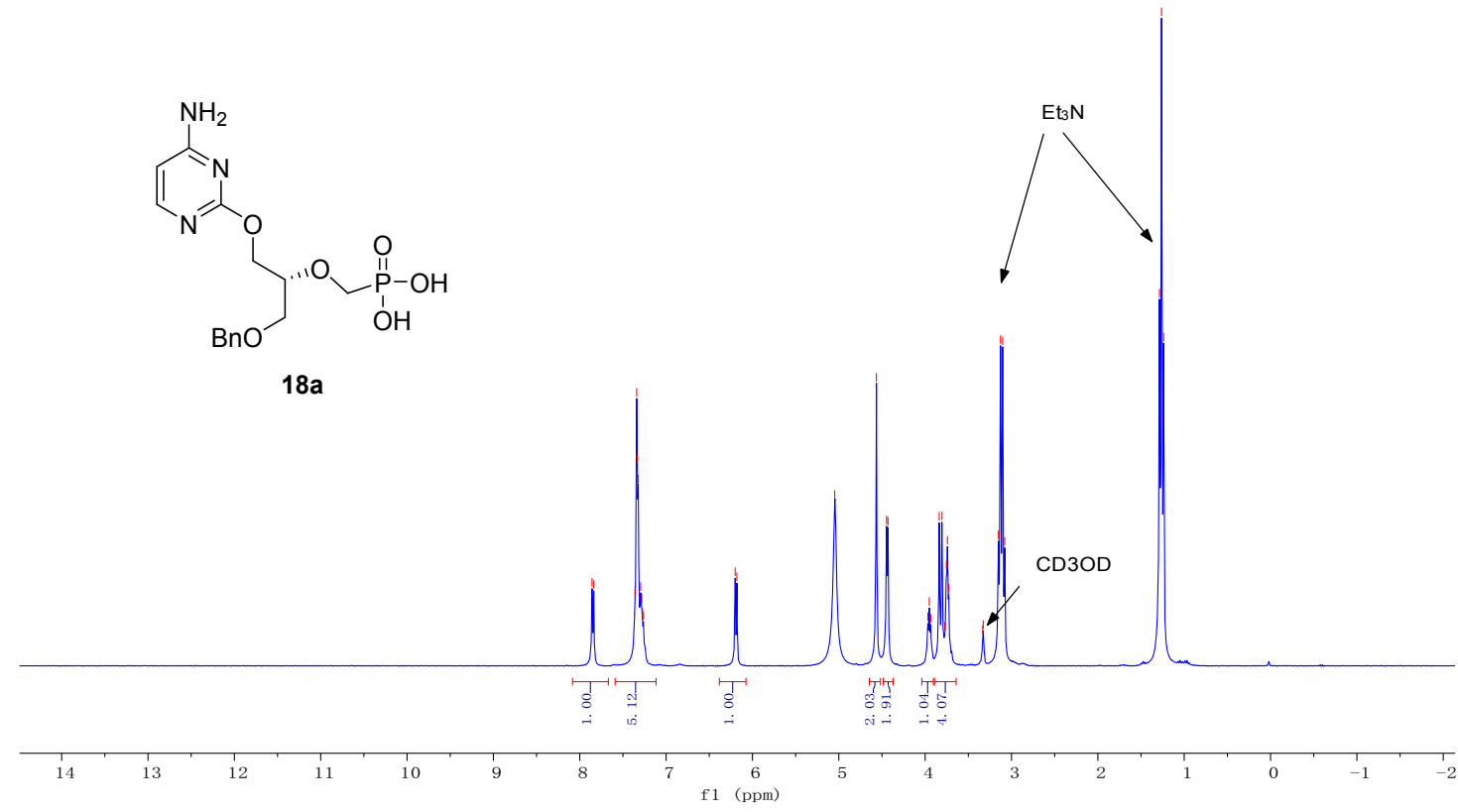

Solvent CD3OD

Nucleus 13C

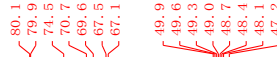

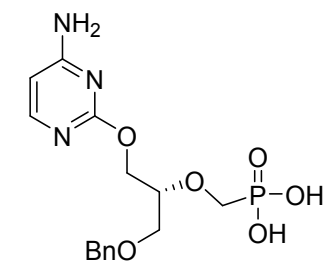

$18 a$

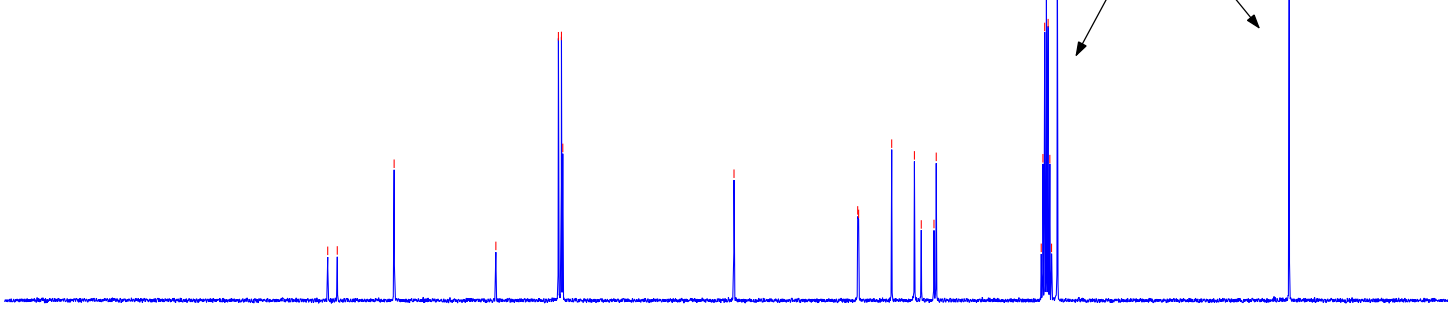

\begin{tabular}{llllllllllllllllllllllllll}
\hline 20 & 210 & 200 & 190 & 180 & 170 & 160 & 150 & 140 & 130 & 120 & 110 & 100 & 90 & 80 & 70 & 60 & 50 & 40 & 30 & 20 & 10 & 0 & -10 \\
\hline
\end{tabular} 


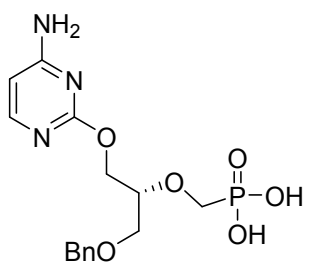

$18 a$

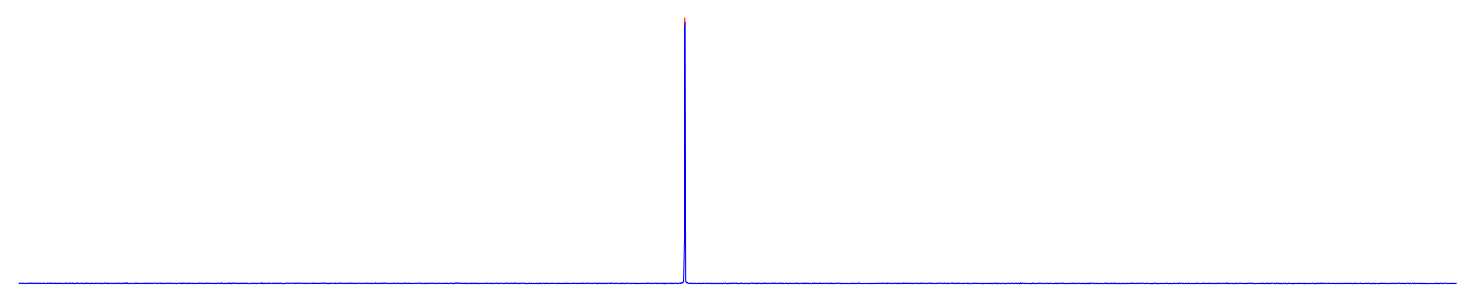

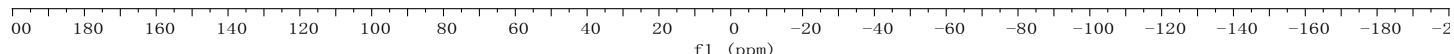

Solvent CD3OD

Nucleus 1H

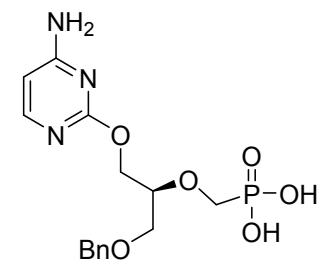

$18 \mathrm{~b}$

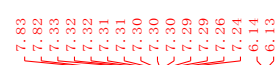

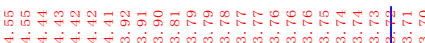

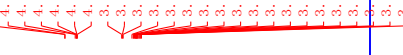

$\mathrm{Et}_{3} \mathrm{~N}$

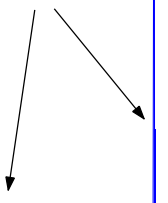



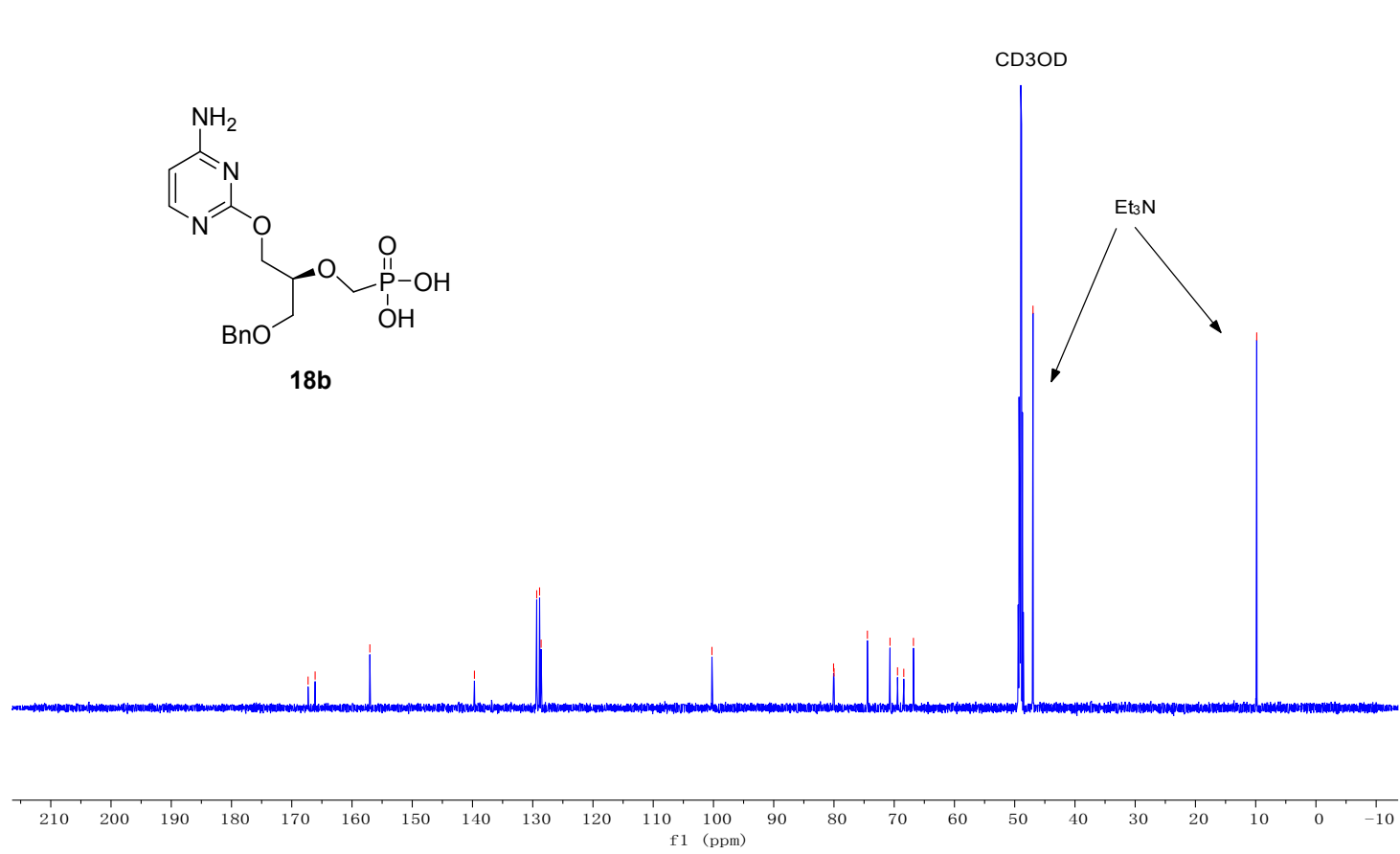

Solvent CD3OD

Nucleus 31P

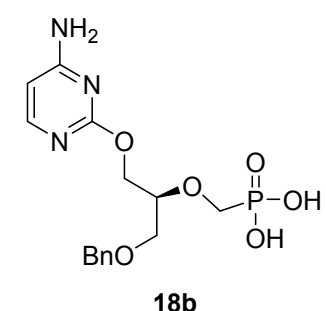

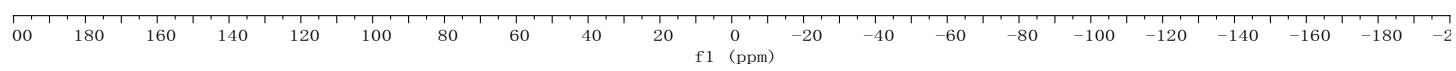


Solvent CD3OD

Nucleus 1H

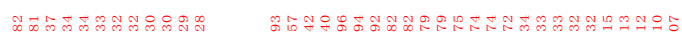
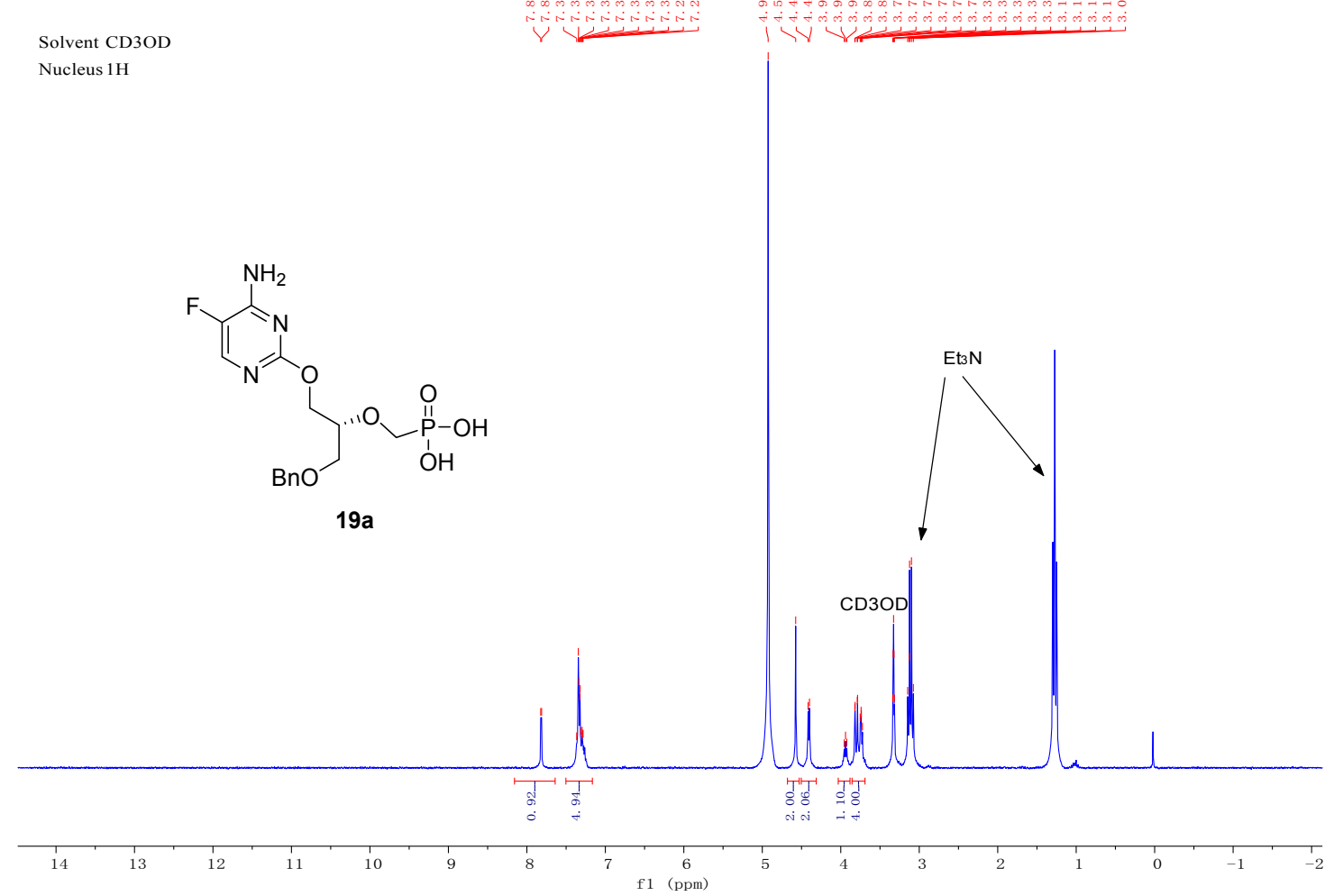

Solvent CD3OD

Nucleus 13C
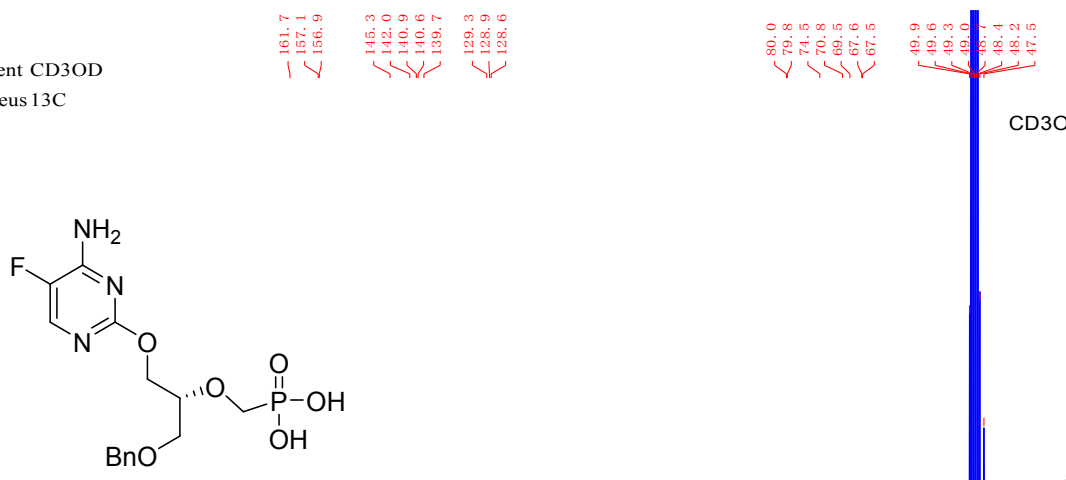

$19 \mathrm{a}$

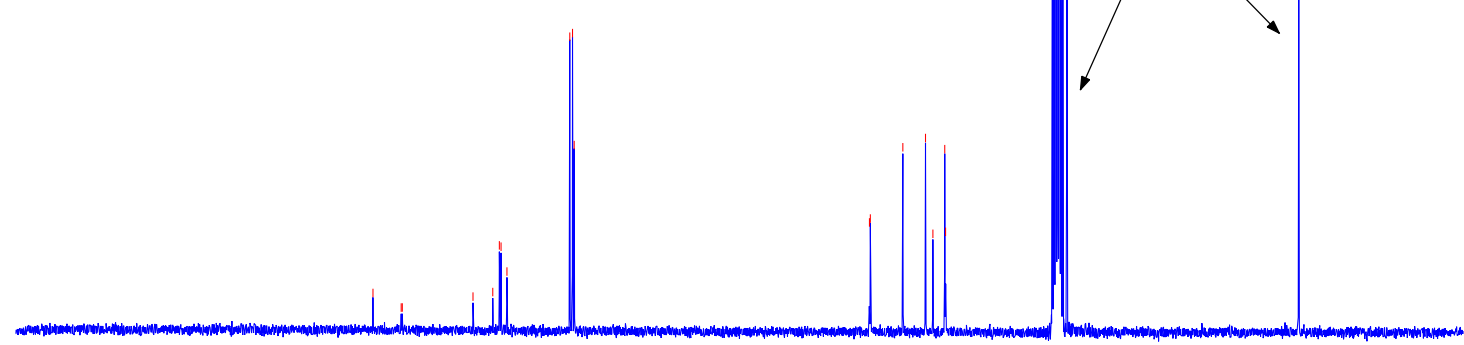

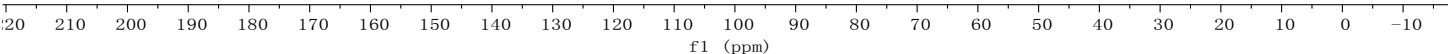




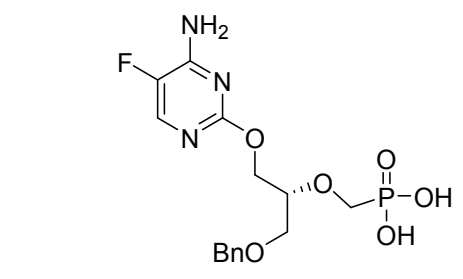

$19 a$

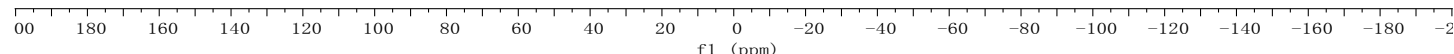

Solvent CD3OD

Nucleus $1 \mathrm{H}$

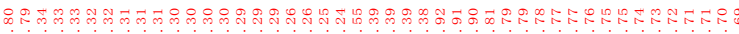

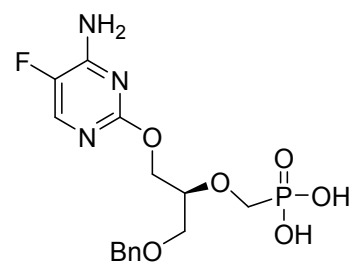

$19 b$

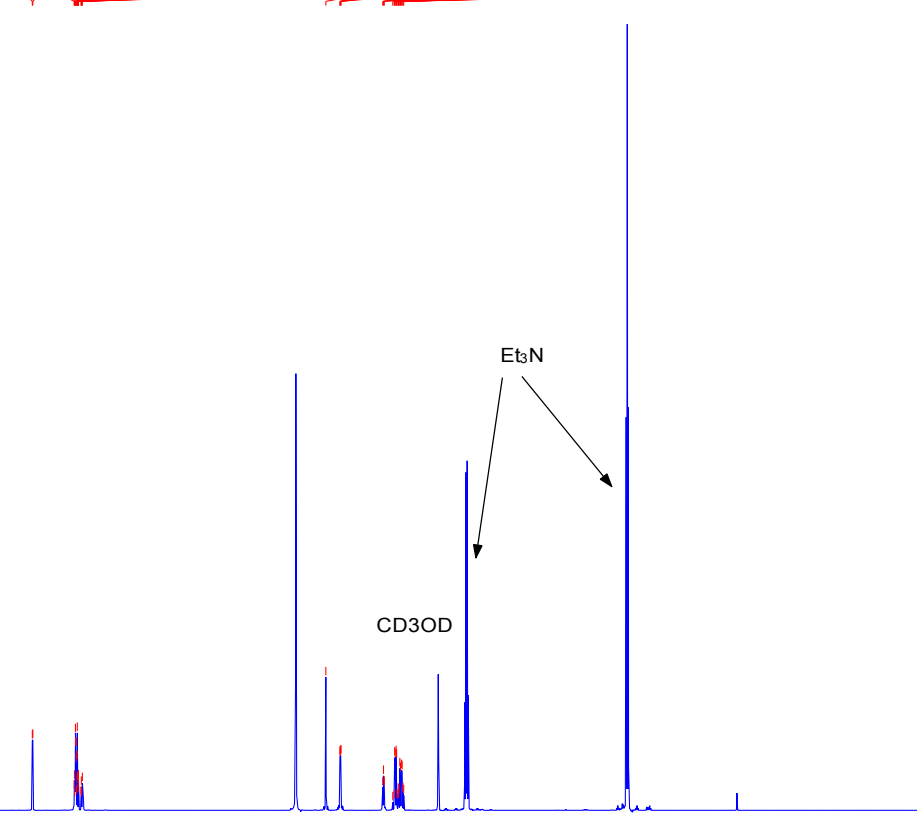

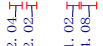

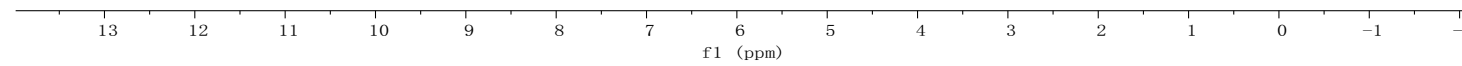




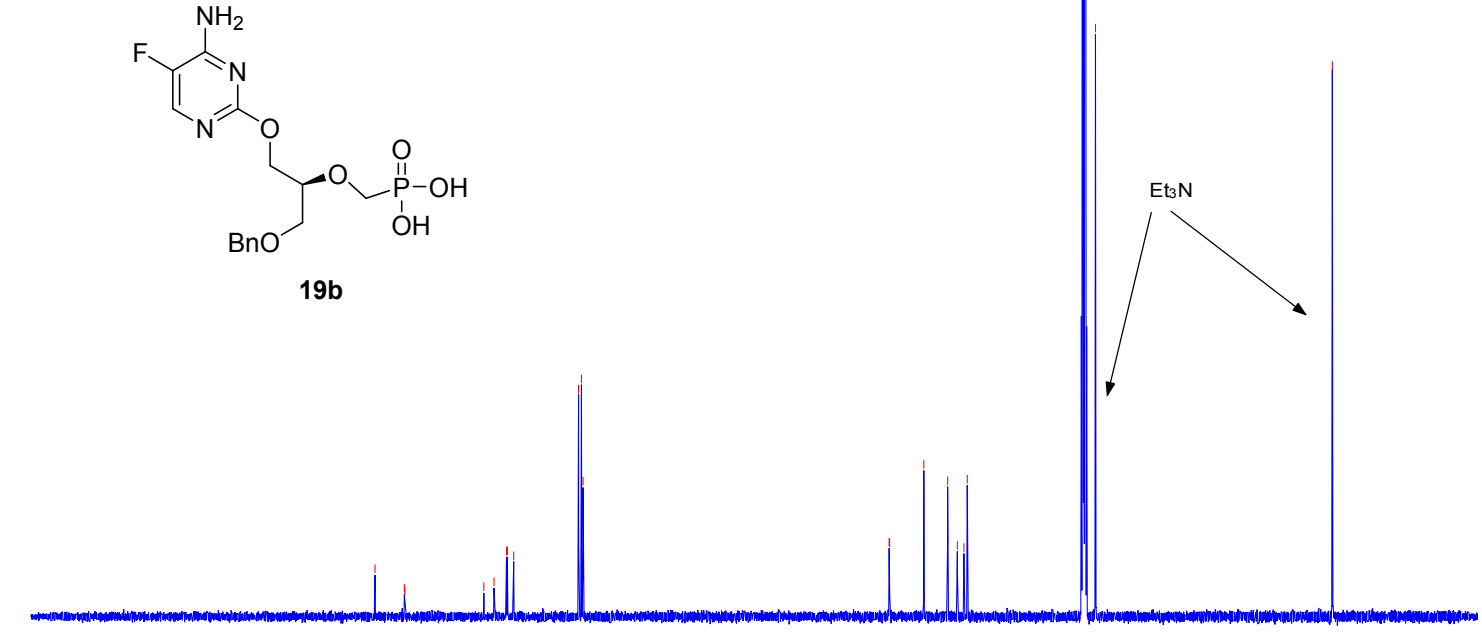

$19 b$

Solvent CD3OD

Nucleus 31P

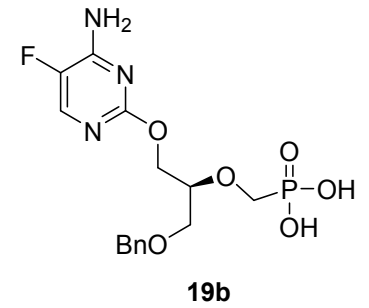

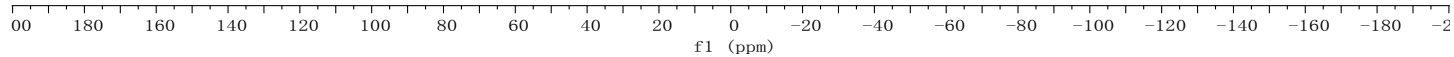




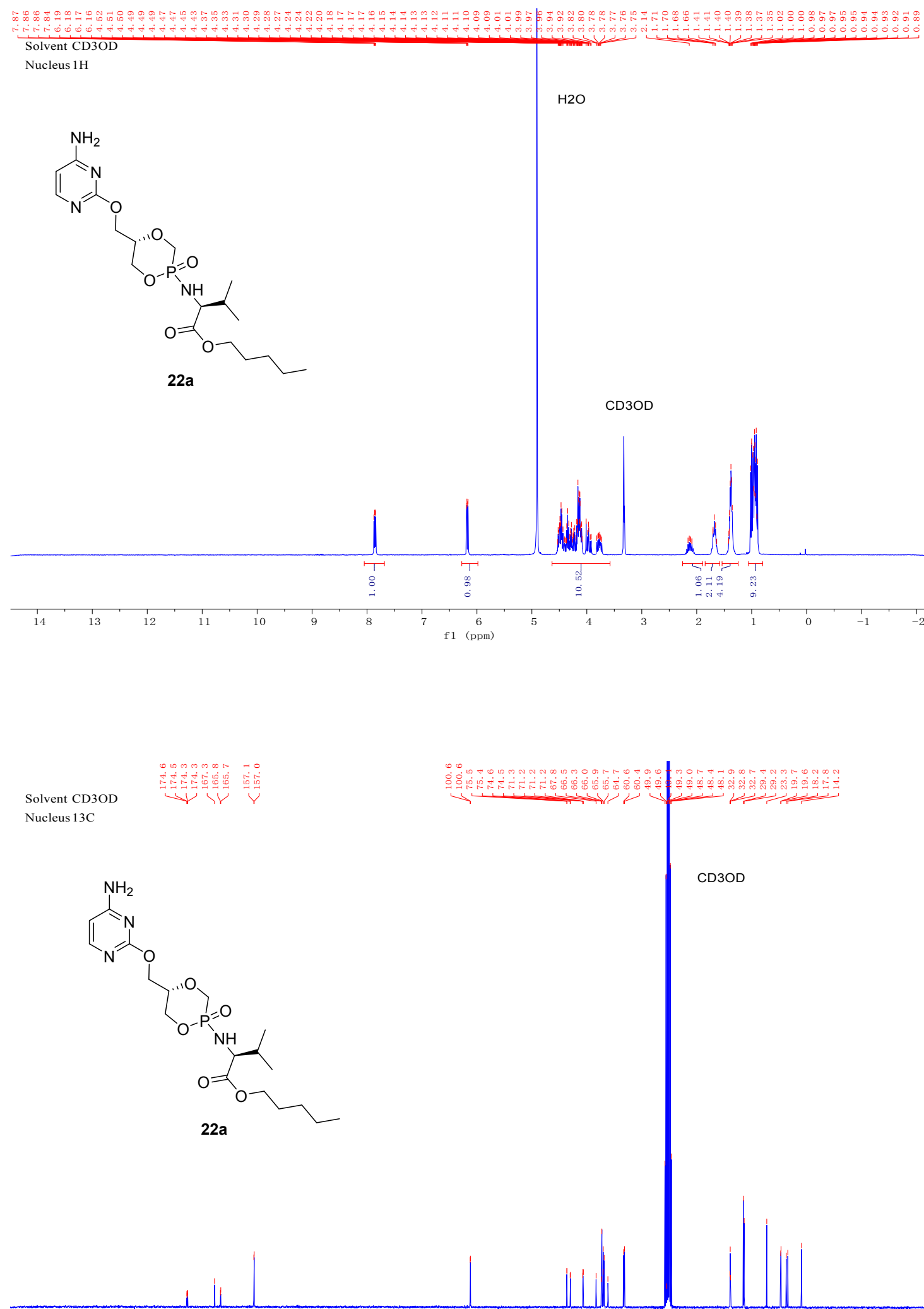

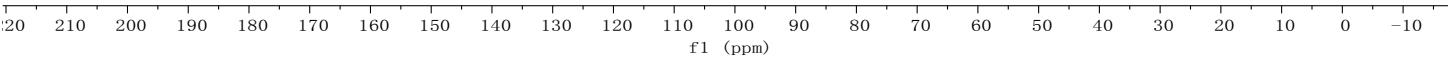




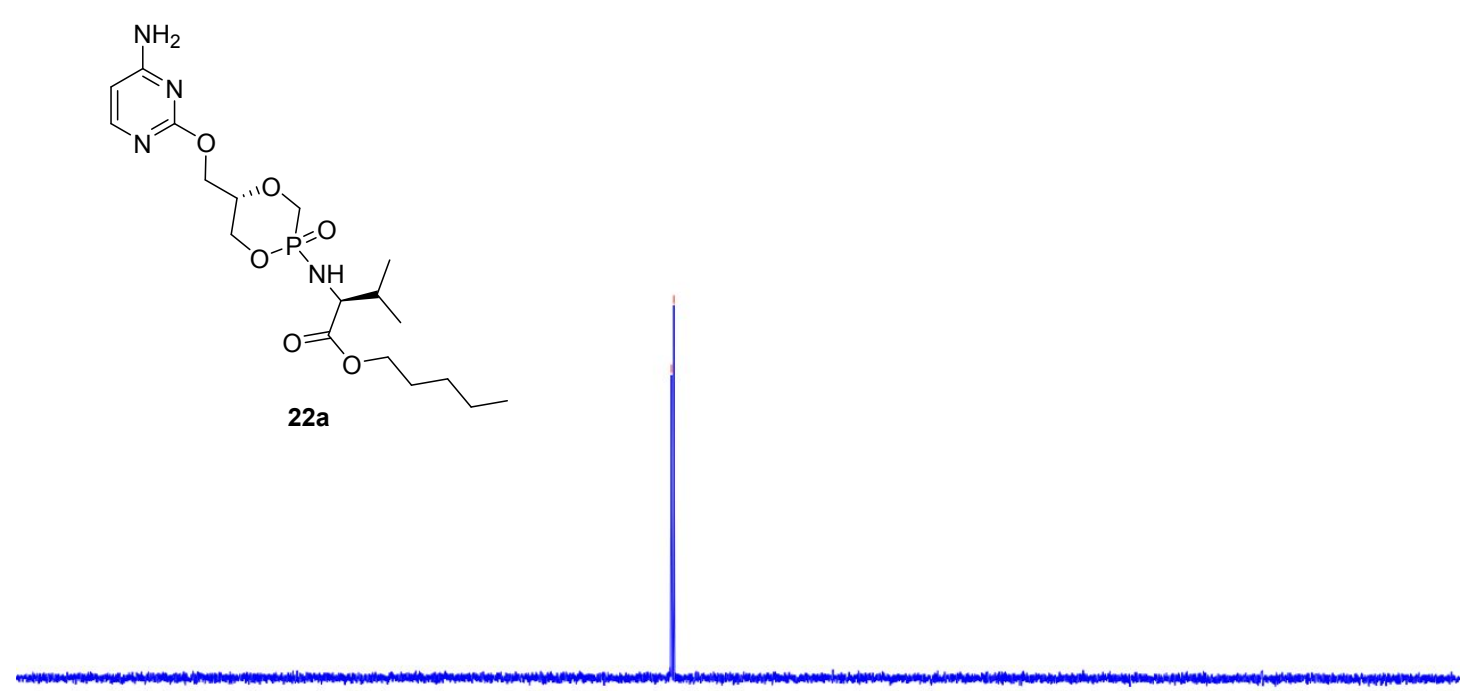

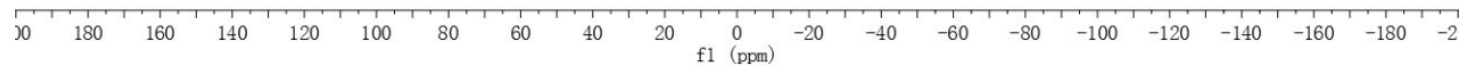

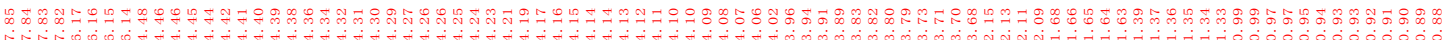
Solvent CD3OD Nucleus $1 \mathrm{H}$

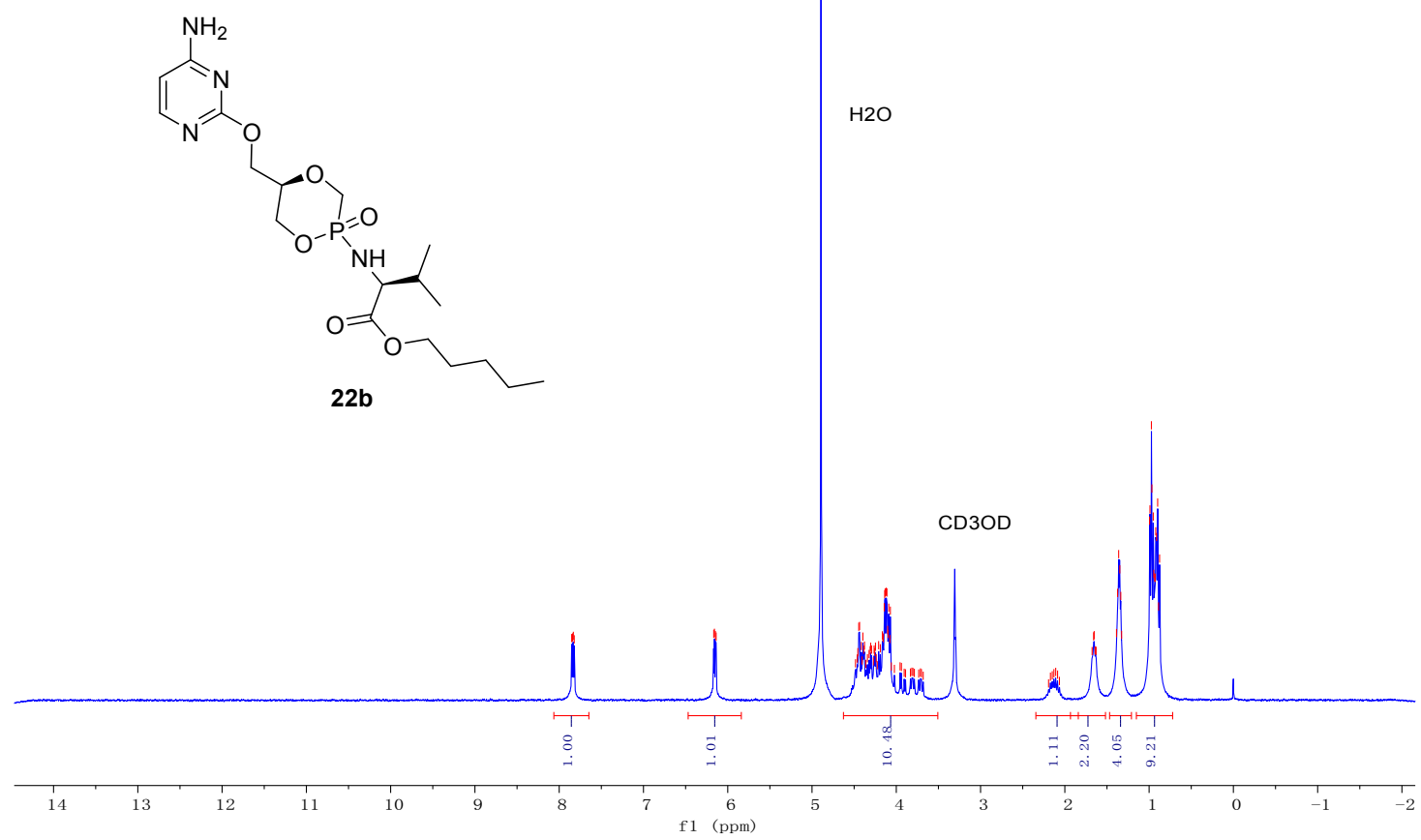




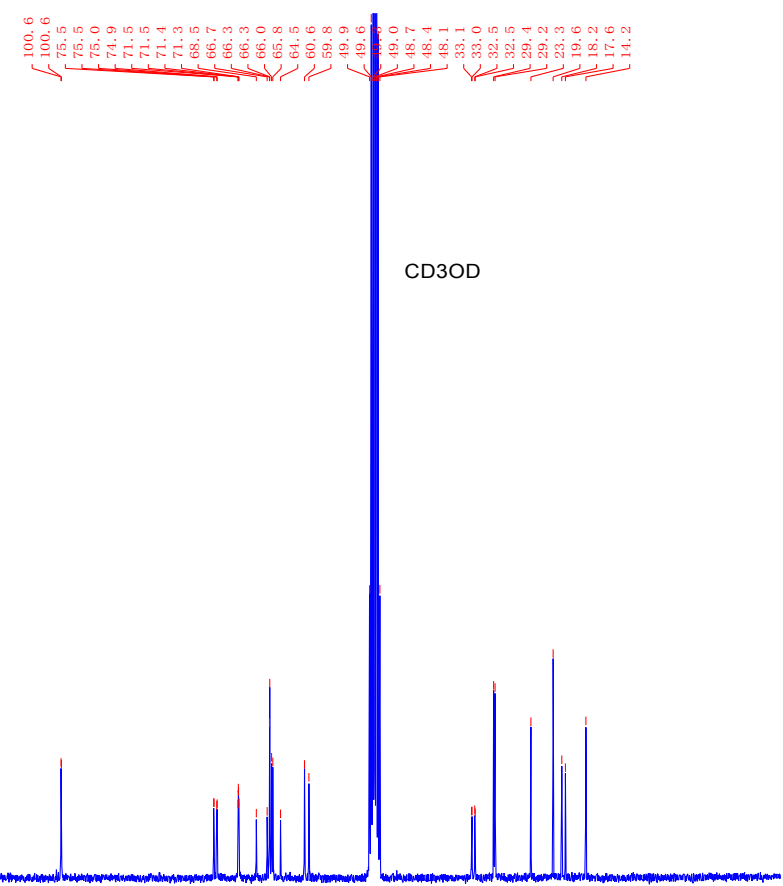

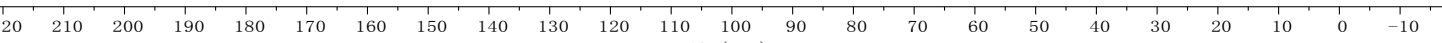

Solvent CD3OD

Nucleus 31P

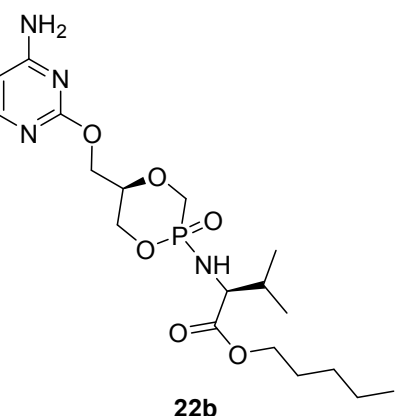

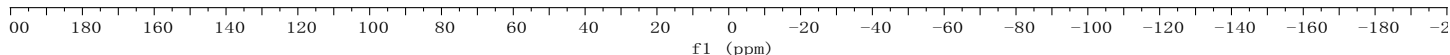




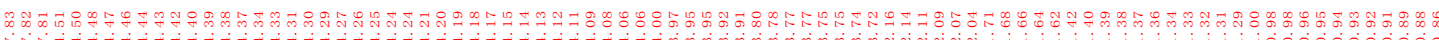
Solvent CD3OD Nucleus 1H

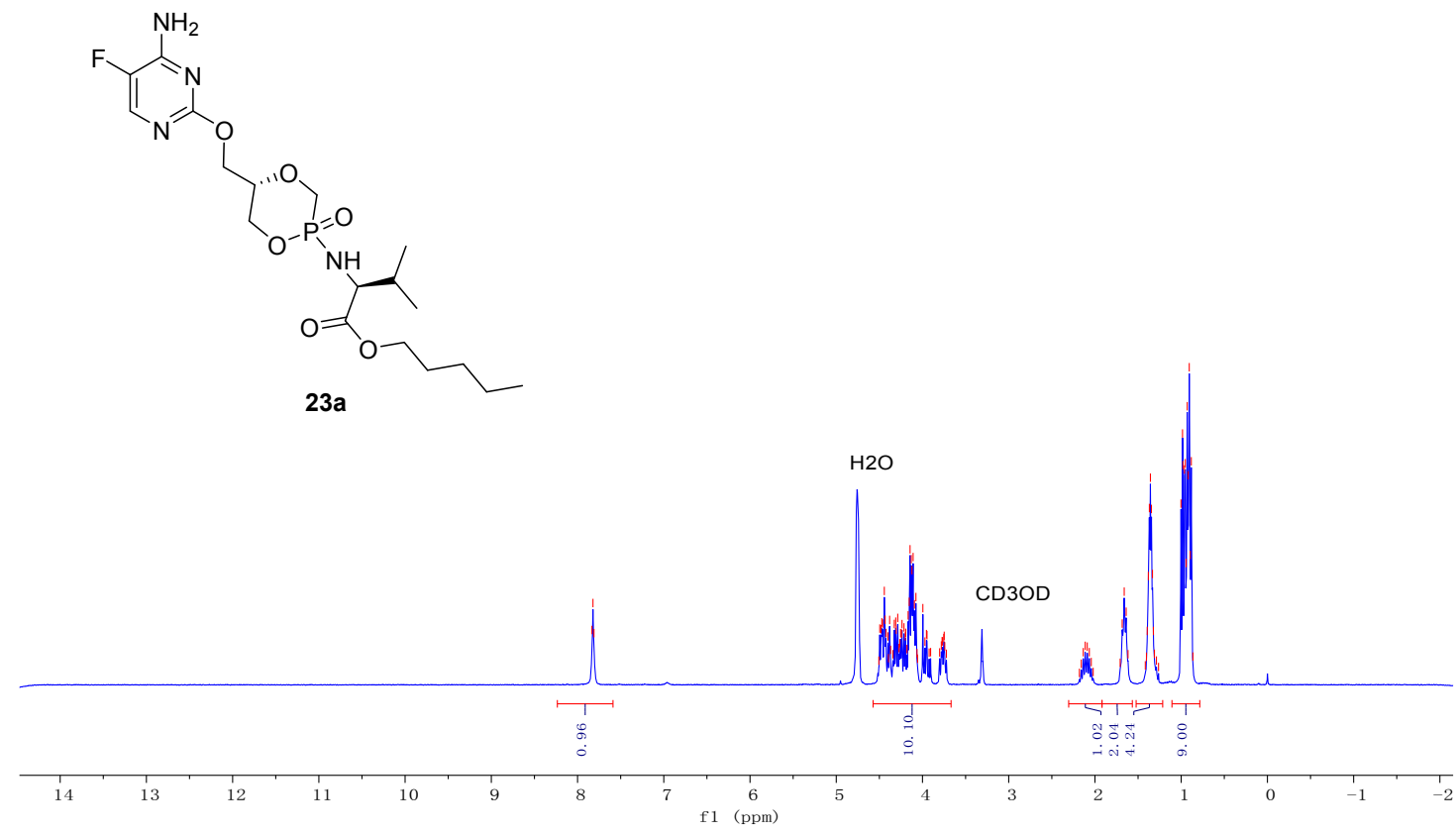

Solvent CD3OD Nucleus $13 \mathrm{C}$
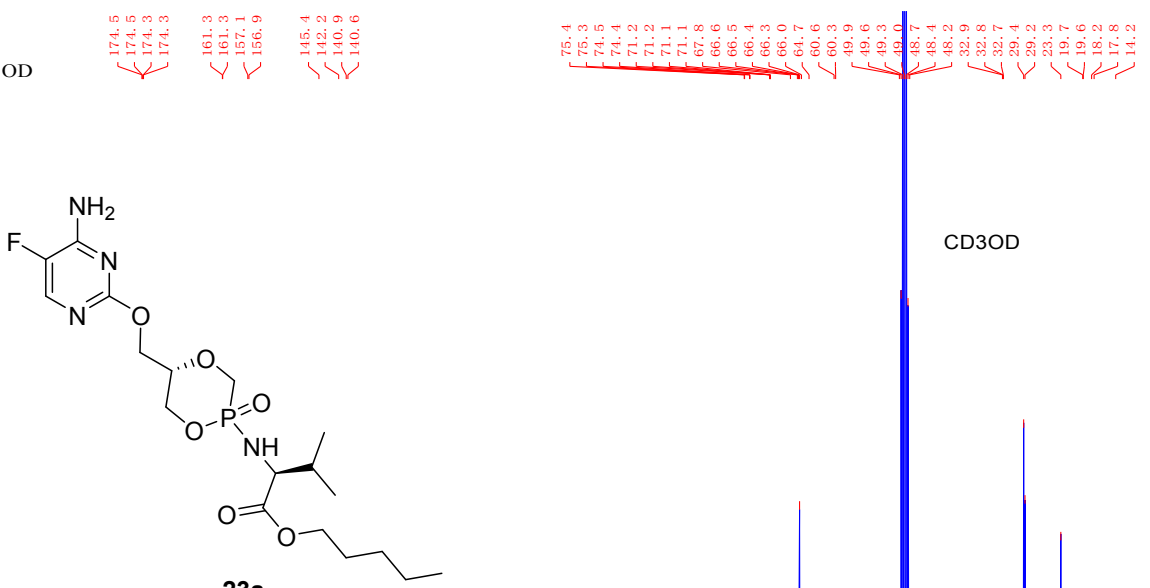

CD3OD

$23 a$

\begin{tabular}{l|llllllllllll}
\hline 20 & 210 & 200 & 190 & 180 & 170 & 160 & 150 & 140 & 130 & 120 & 110 & 100 \\
$\mathrm{f} 1$ & $(\mathrm{ppm})$
\end{tabular}

$\begin{array}{lllllllllll}1 & 1 & 1 & 1 & 1 & 1 & 1 & 1 & 1 & 1 & 1 \\ 0 & 80 & 70 & 60 & 50 & 40 & 30 & 20 & 10 & 0 & -10\end{array}$ 
Solvent CD3OD

Nucleus 31
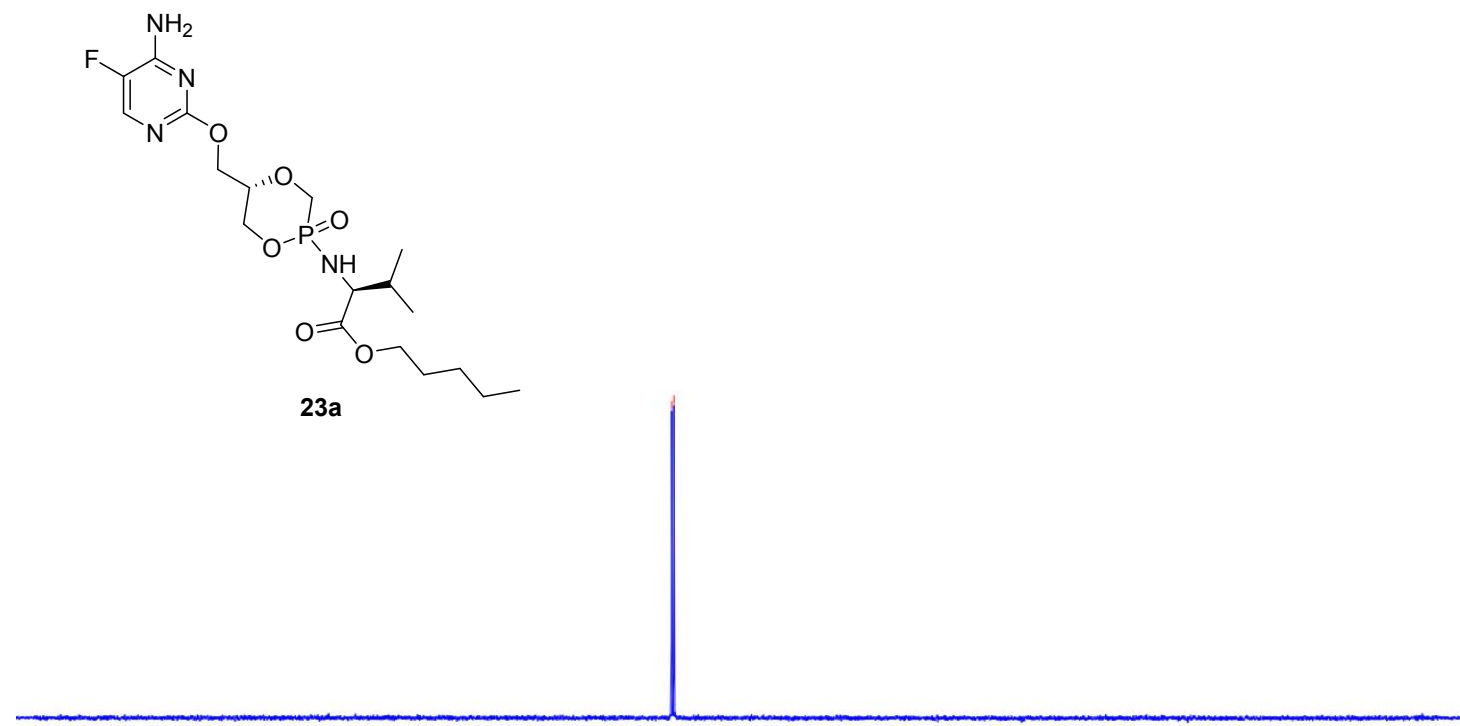

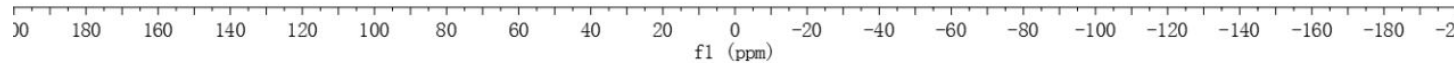

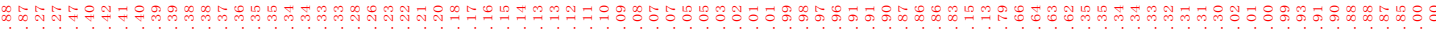
Solvent $\mathrm{CDCl} 3$

Nucleus $1 \mathrm{H}$

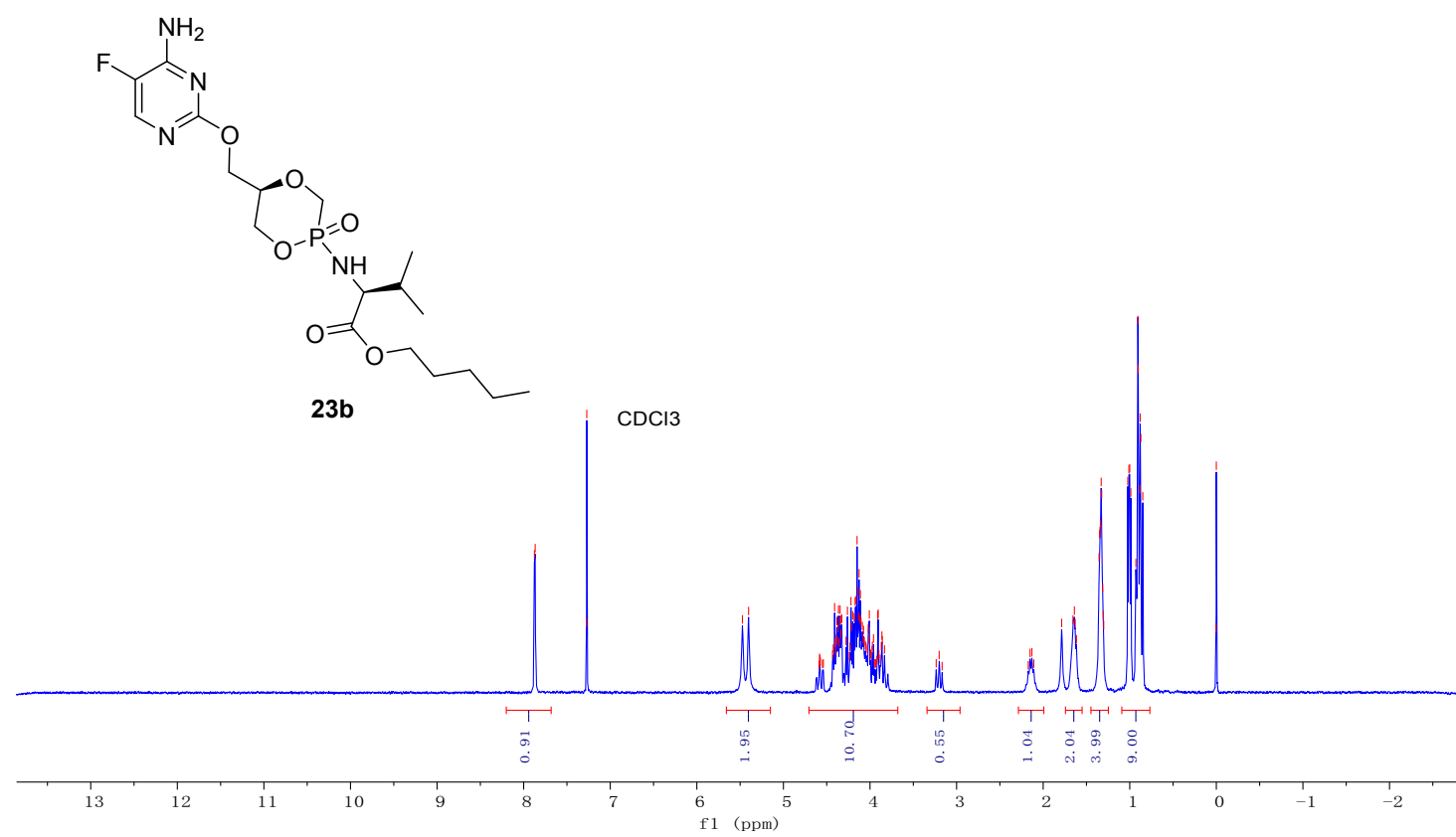




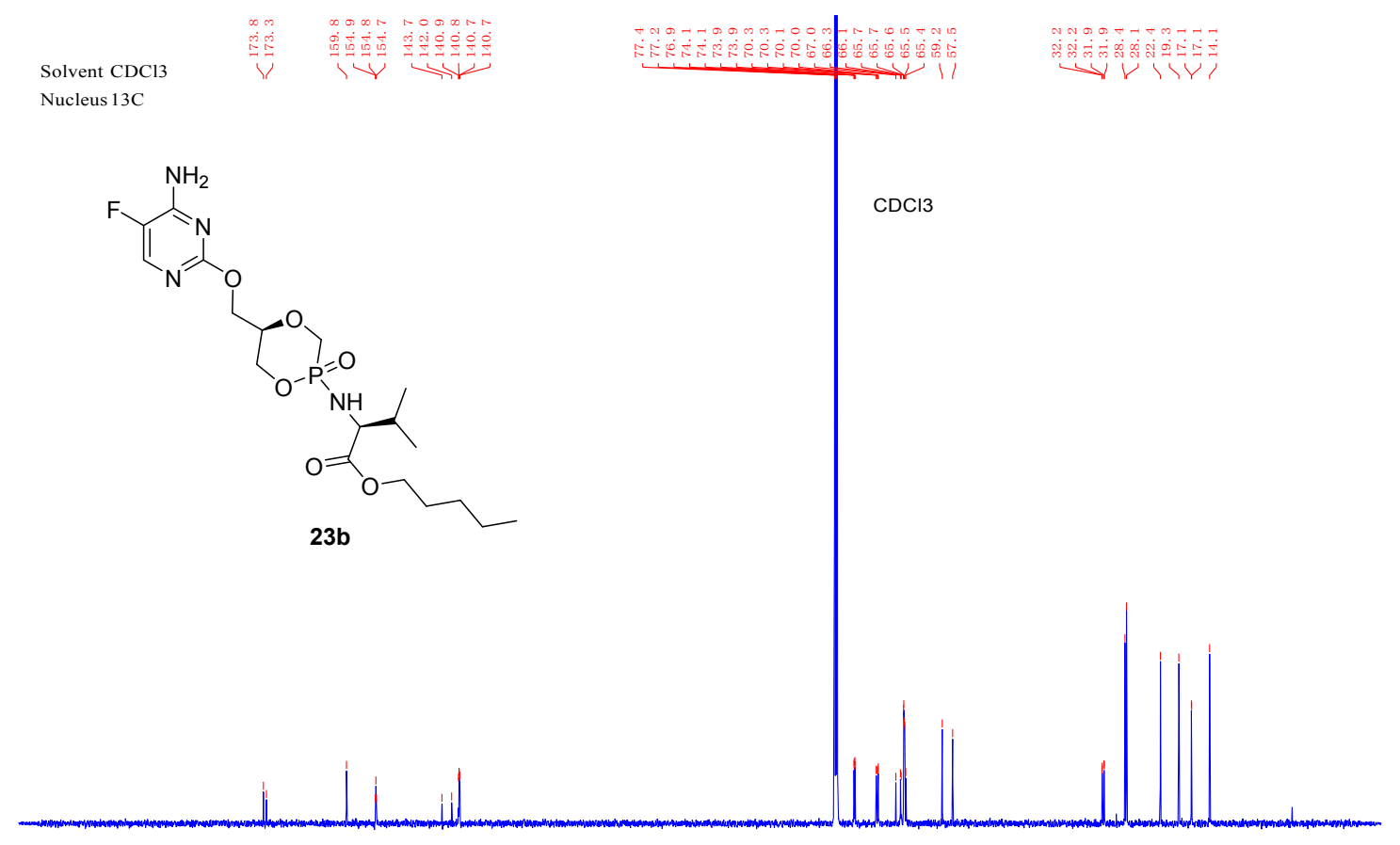

Solvent $\mathrm{CDC13}$

Nucleus 31P

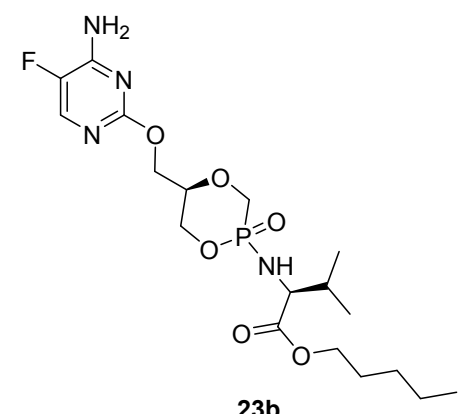

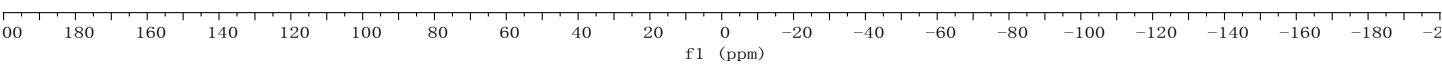




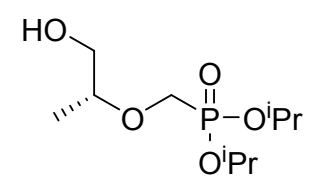

$24 b$

Solvent $\mathrm{CDCl} 3$

Nucleus 13C

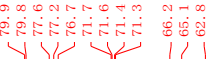

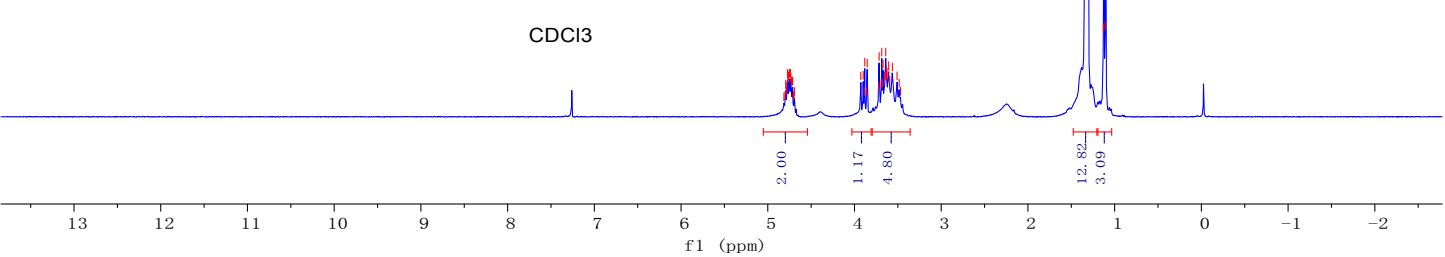<smiles>CCCOP(=O)(CO[C@@H](C)CO)OCC</smiles>

24b

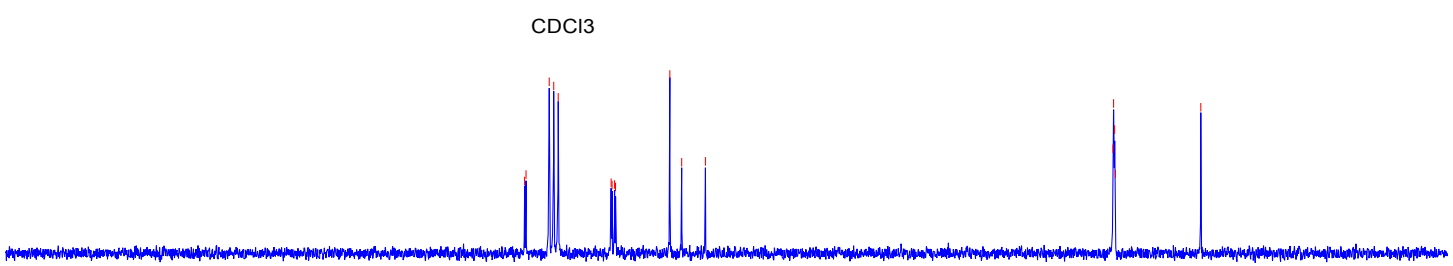

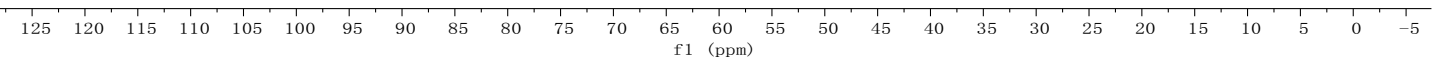




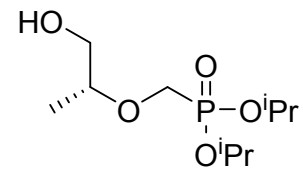

24b

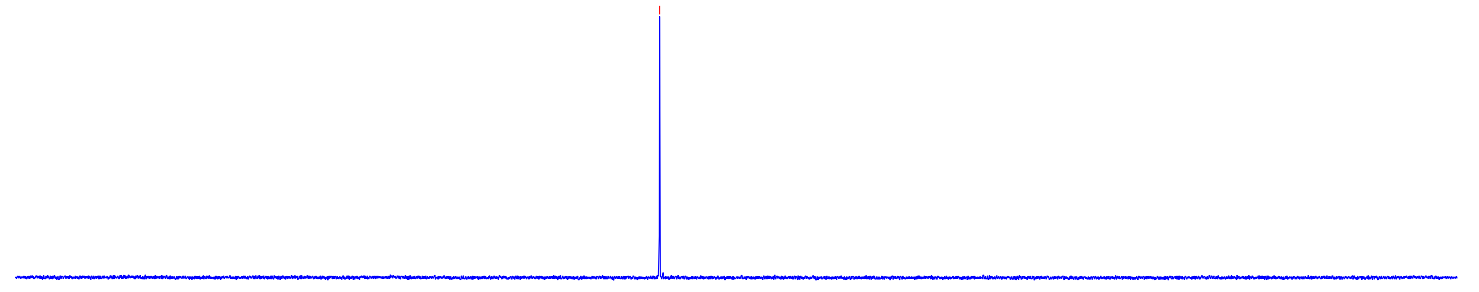

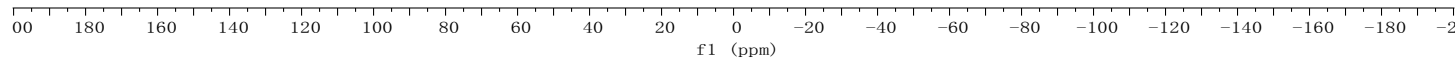

Solvent $\mathrm{CDCl} 3$

Nucleus $1 \mathrm{H}$

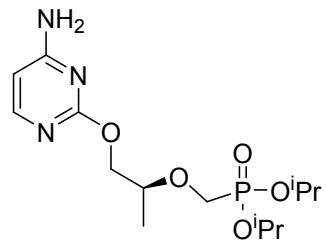

$27 a$

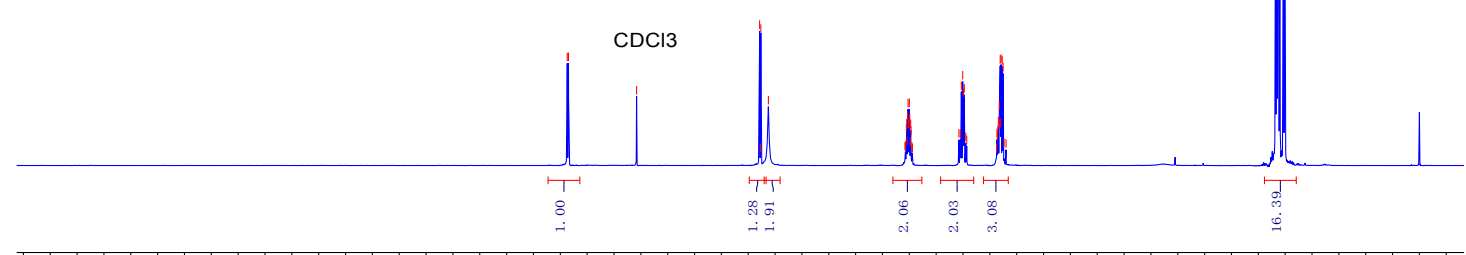

\begin{tabular}{llllllllllllllllllllllllllllllllll}
\hline 3.0 & 12.5 & 12.0 & 11.5 & 11.0 & 10.5 & 10.0 & 9.5 & 9.0 & 8.5 & 8.0 & 7.5 & 7.0 & 6.5 & 6.0 & 5.5 & 5.0 & 4.5 & 4.0 & 3.5 & 3.0 & 2.5 & 2.0 & 1.5 & 1.0 & 0.5 & 0.0
\end{tabular} (ppm) 


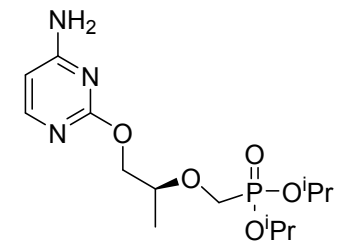

$27 a$

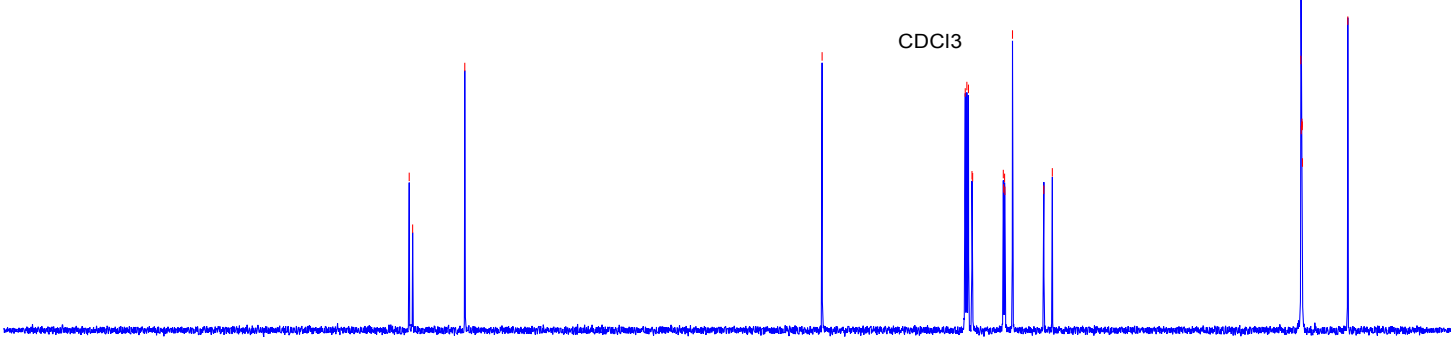

Solvent $\mathrm{CDCl} 3$

Nucleus 31P

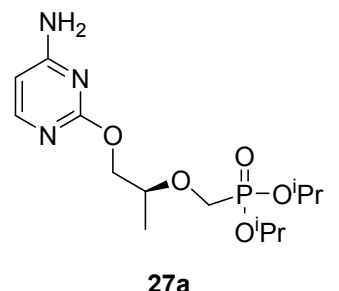

$27 a$

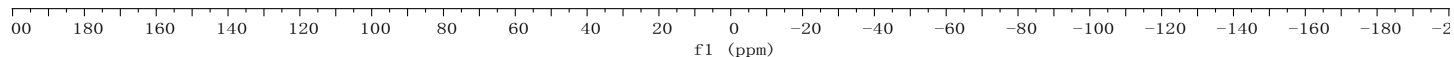


Solvent $\mathrm{CDCl} 3$

Nucleus 1H
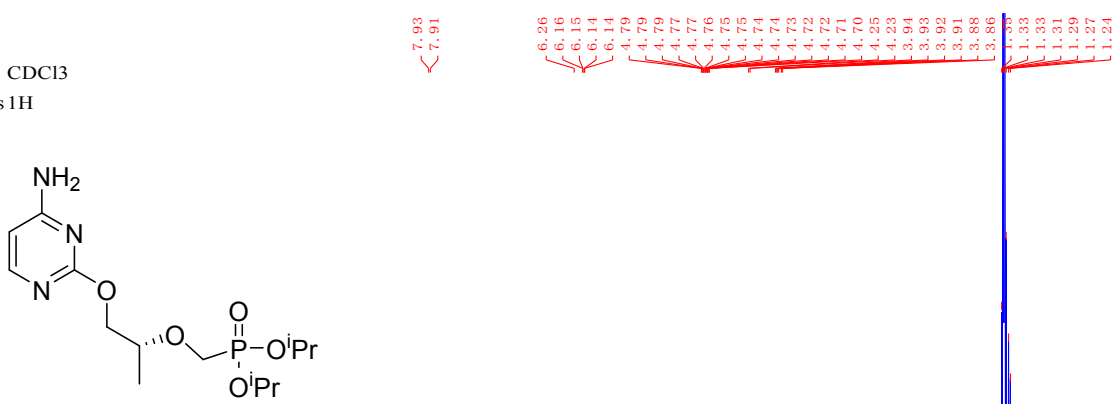

27b
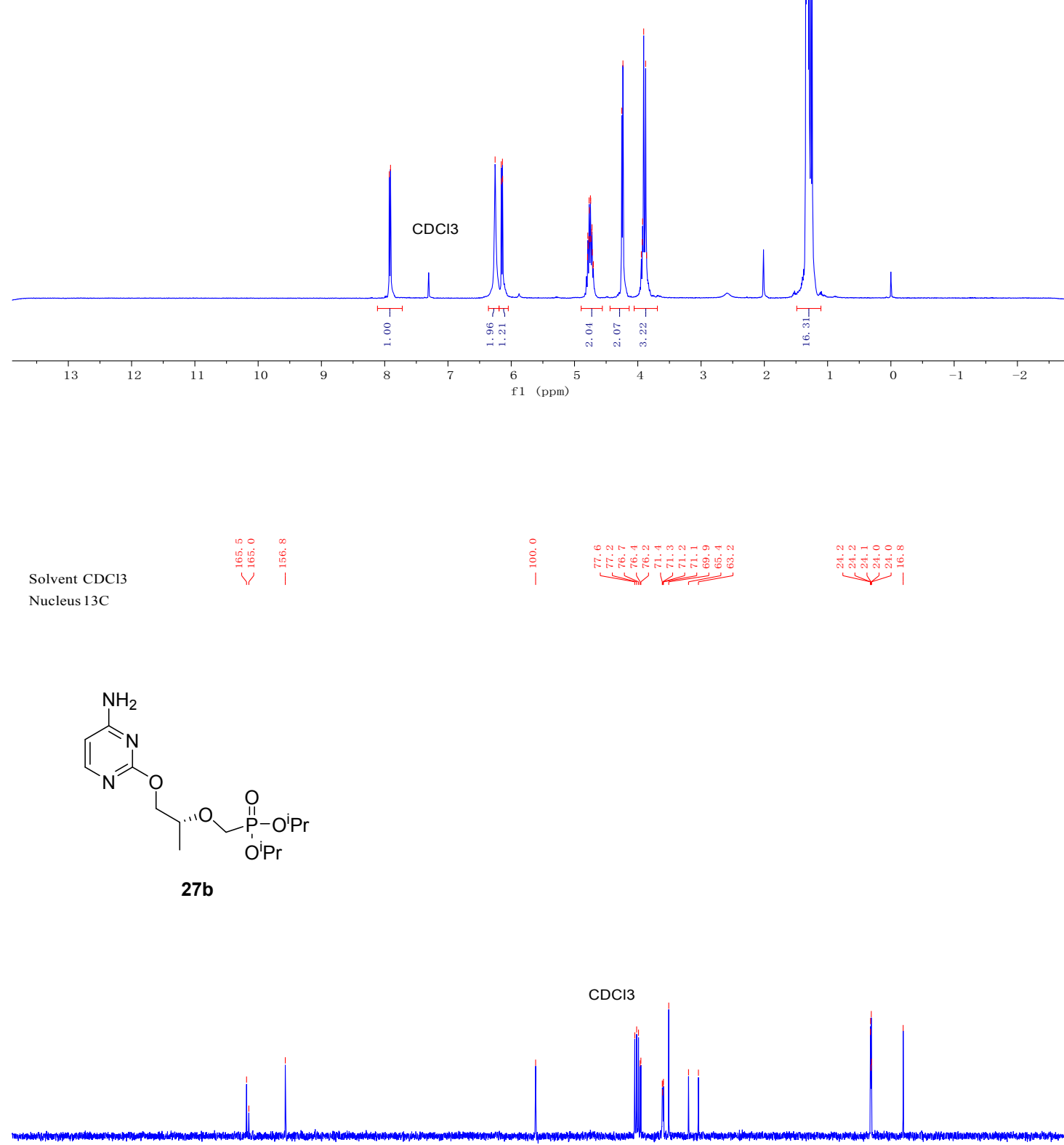

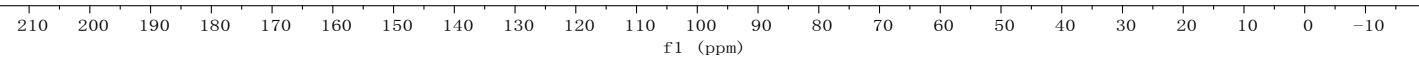




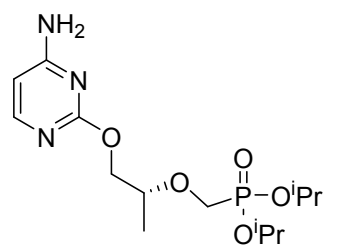

$27 b$

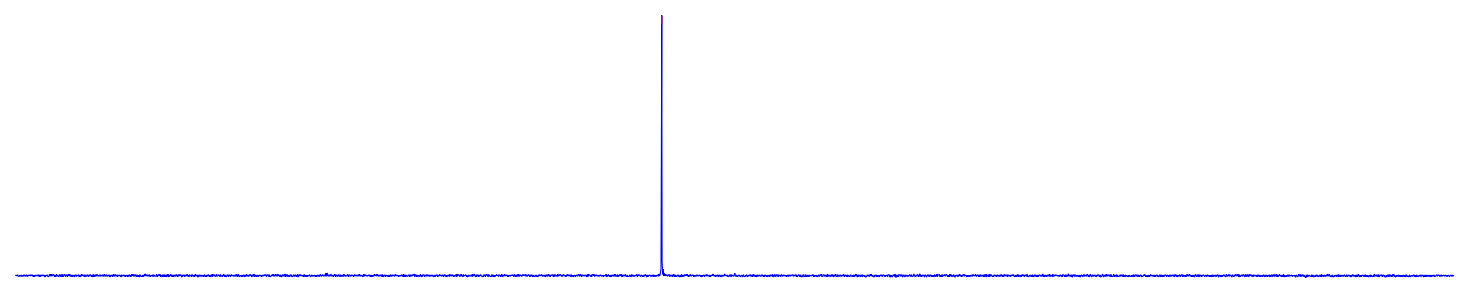

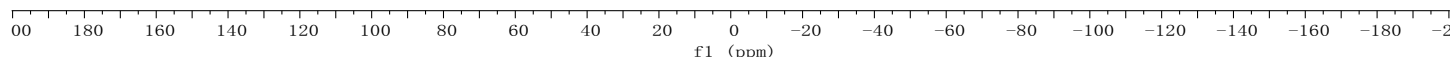

Solvent $\mathrm{CDCl} 3$

Nucleus 1H
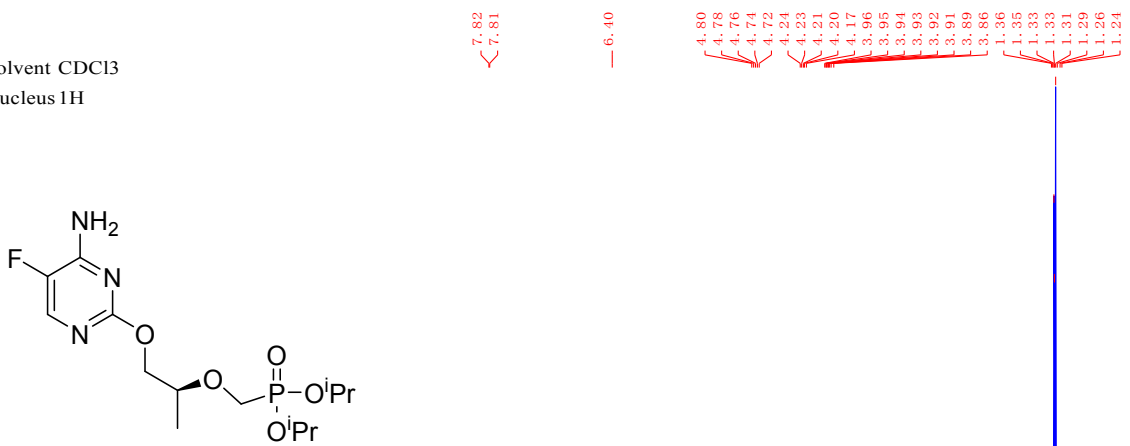

$28 \mathrm{a}$

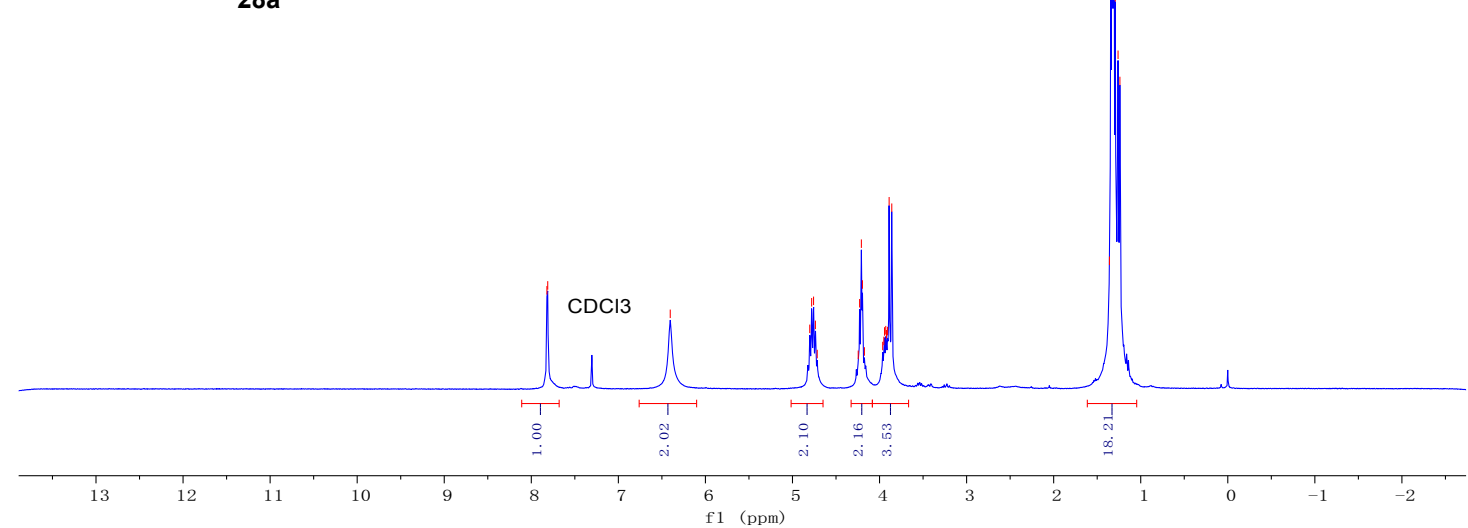




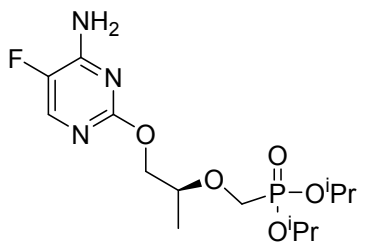

$28 a$

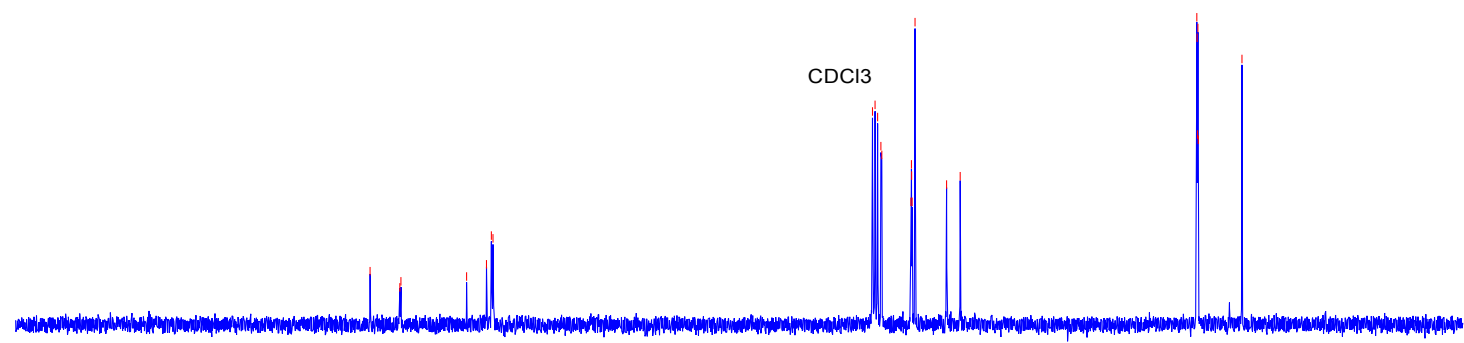

Solvent CDCl3

Nucleus 31P

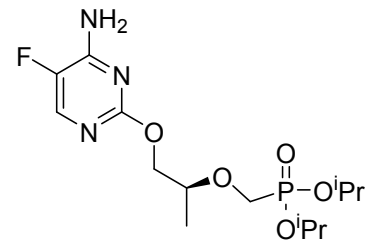

$28 a$

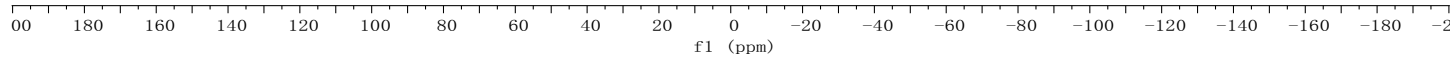




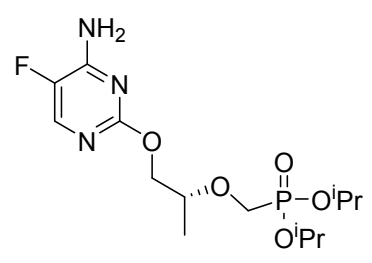

$28 b$

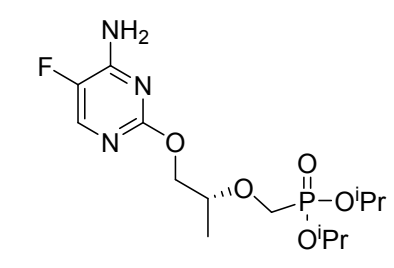

$28 b$
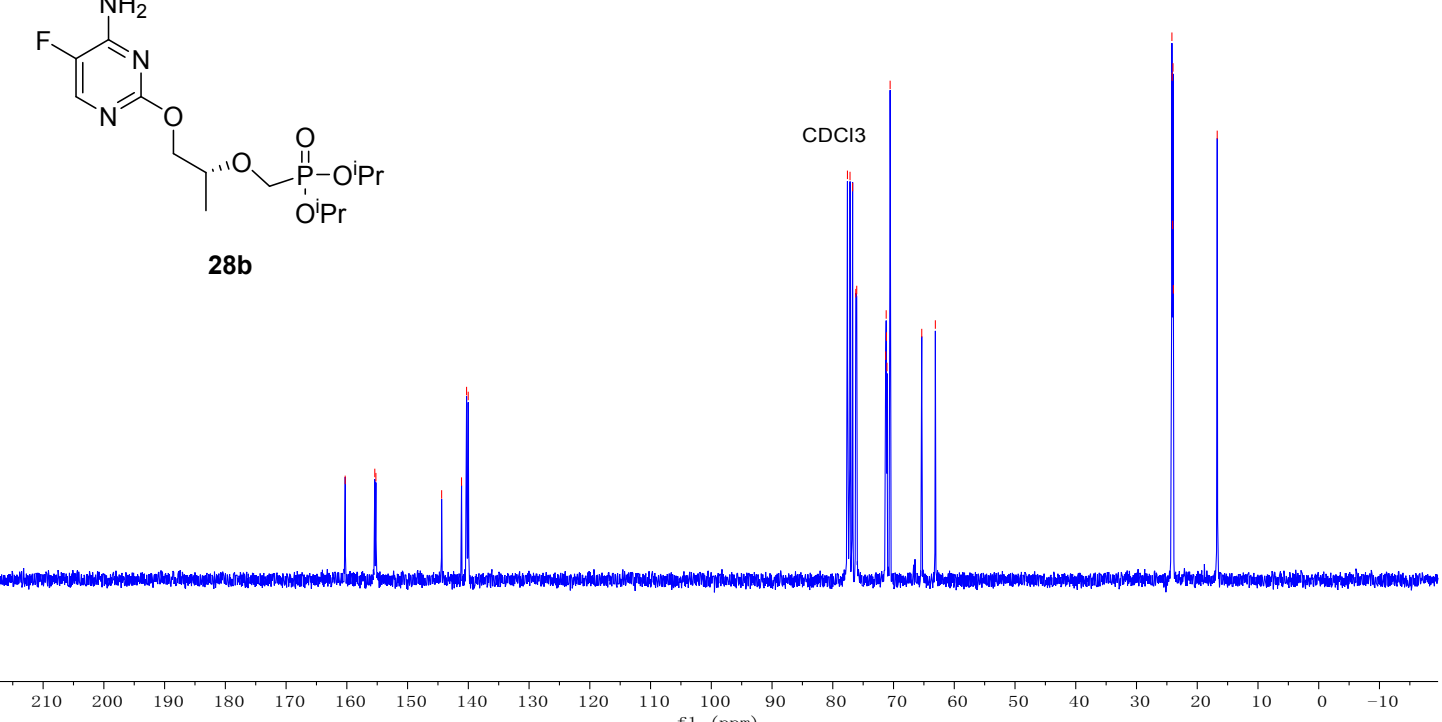


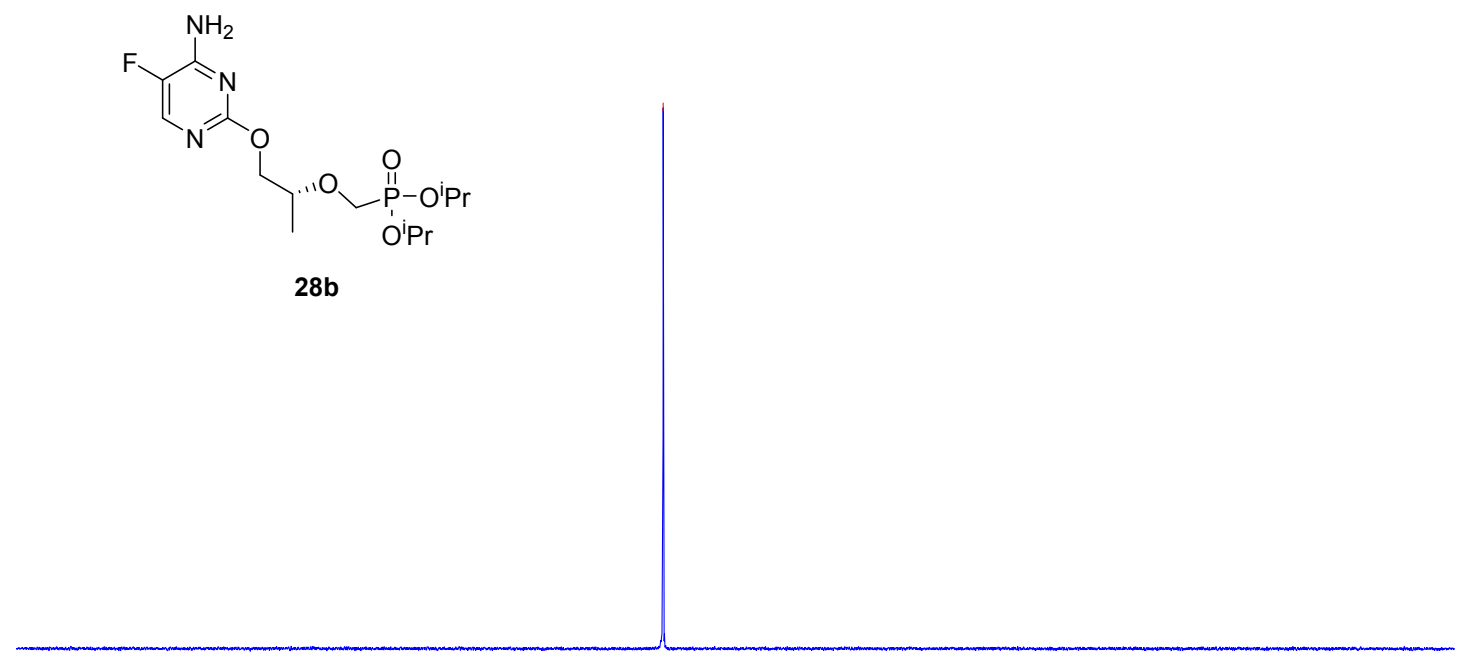

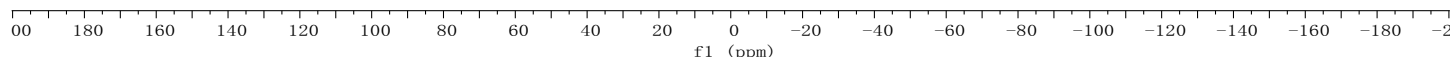

Solvent CD3OD

Nucleus 1H

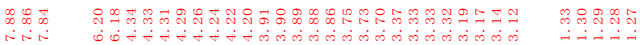

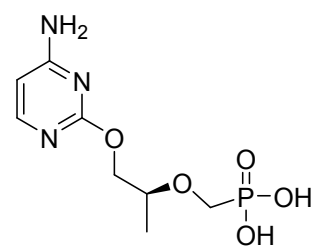

$29 a$
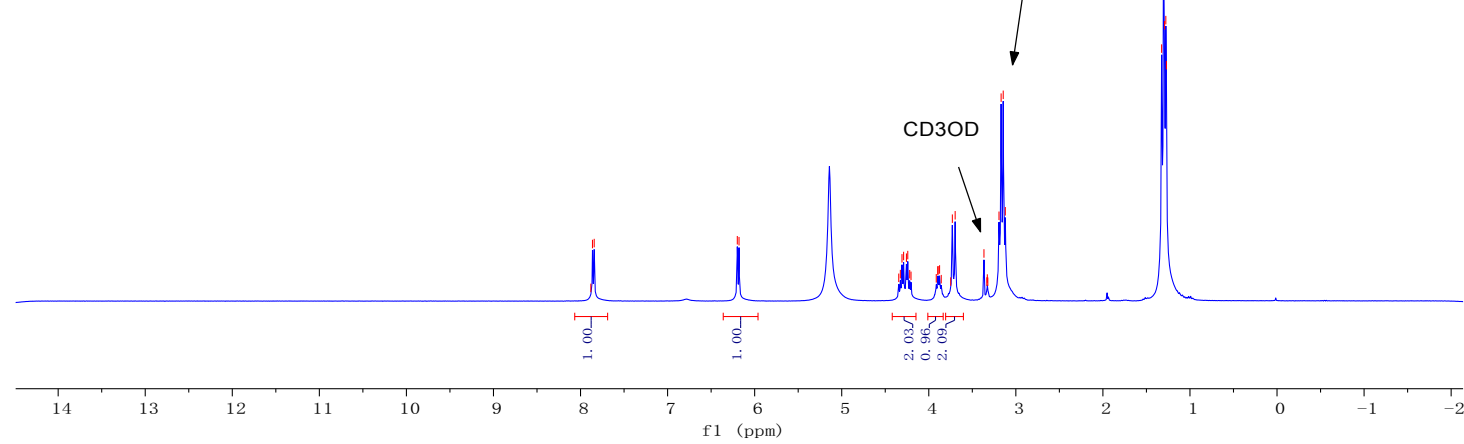


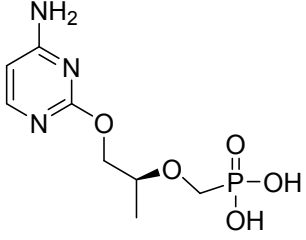

$29 a$

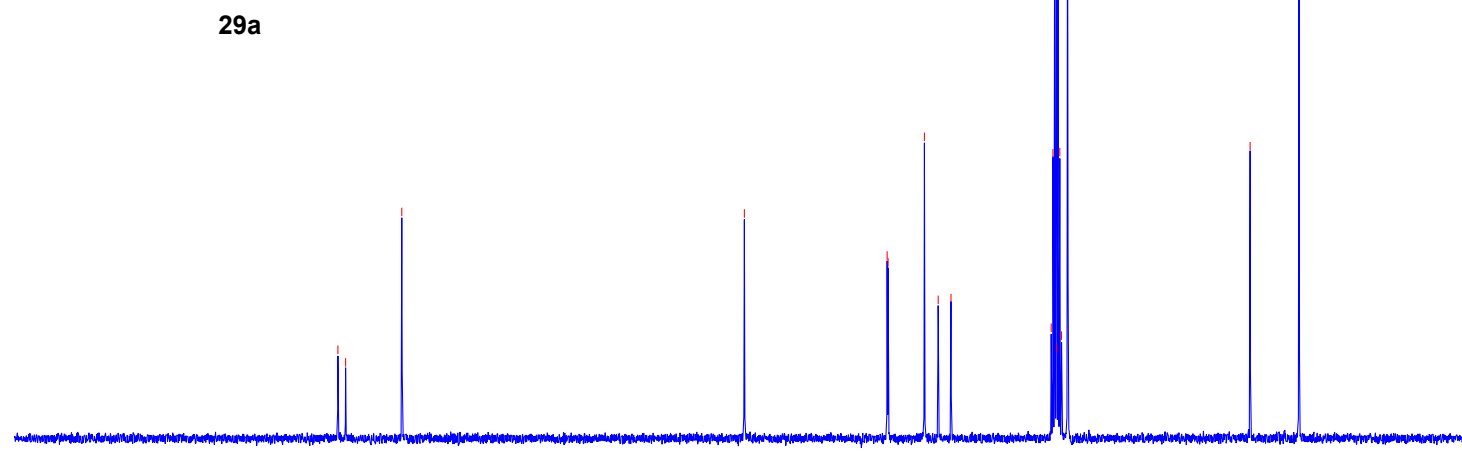

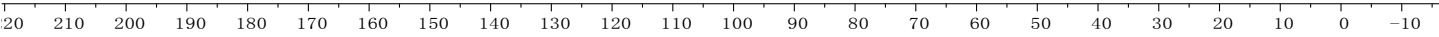

Solvent CD3OD

Nucleus 31P

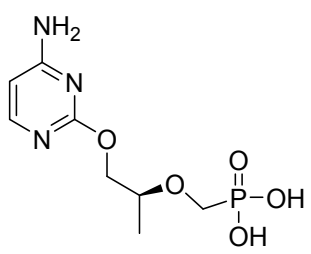

$29 a$

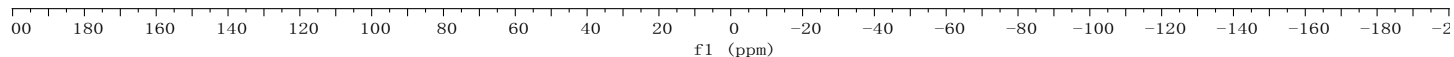




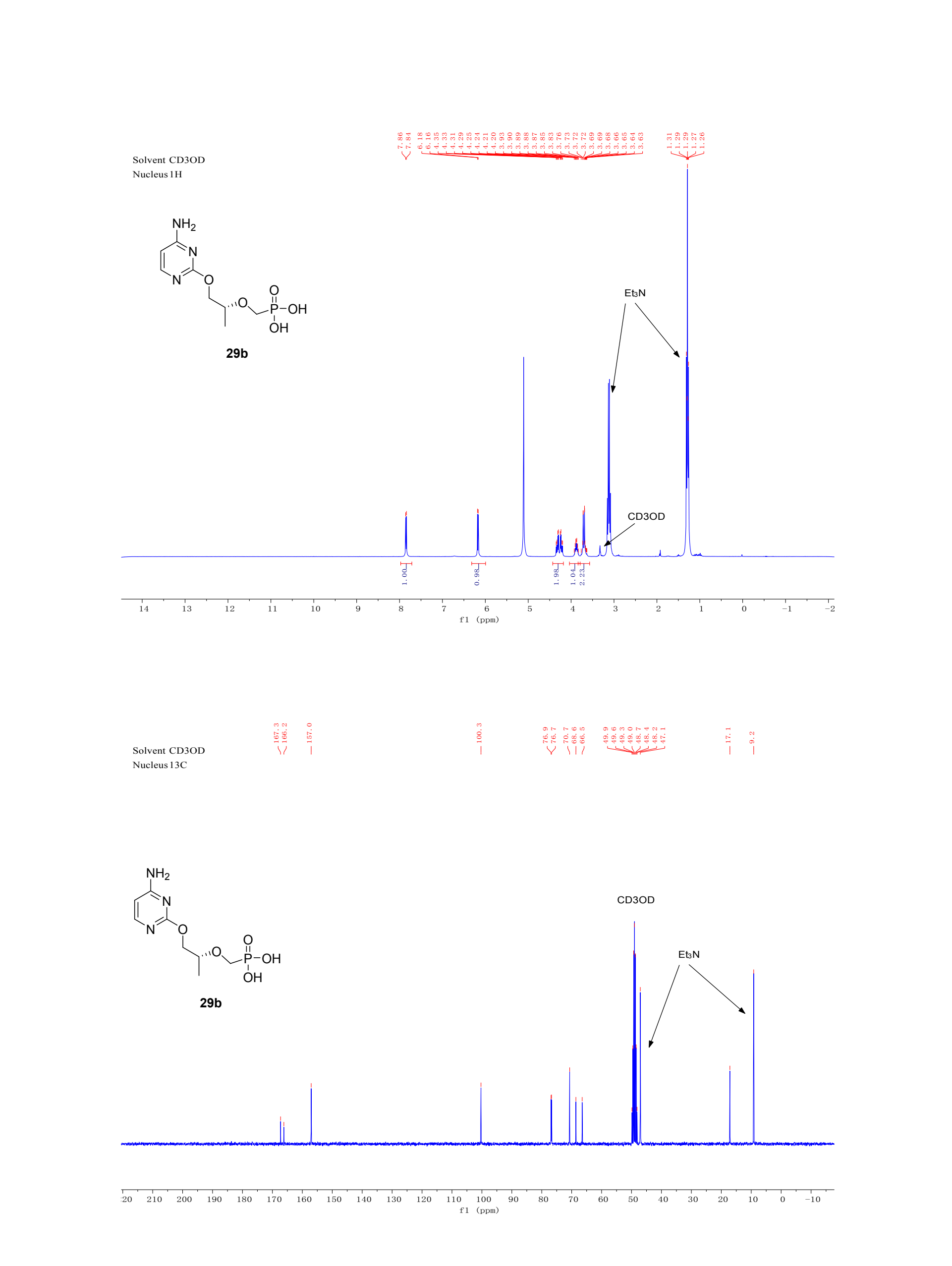


Solvent CD3OD

Nucleus 31P

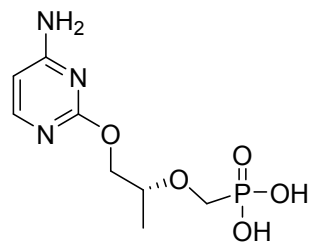

$29 b$

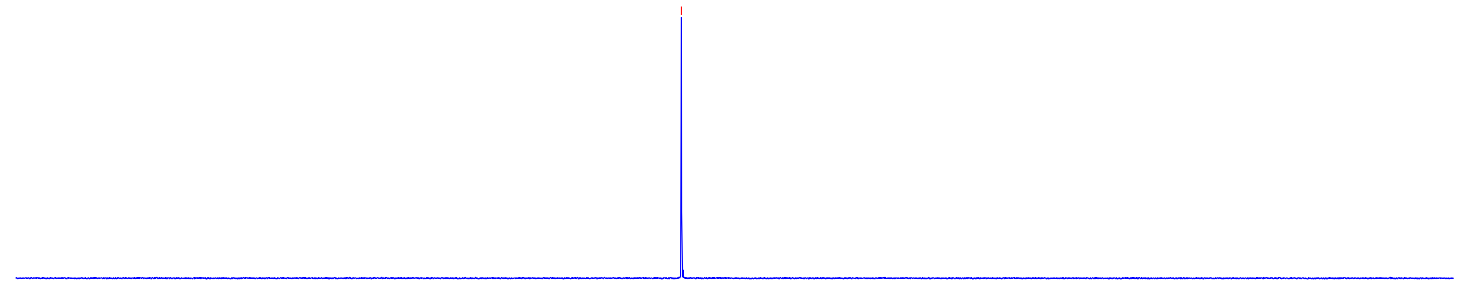

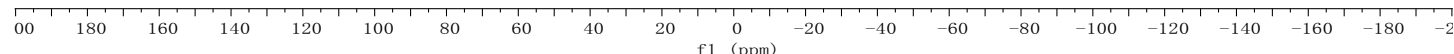

Solvent CD3OD

Nucleus 1H

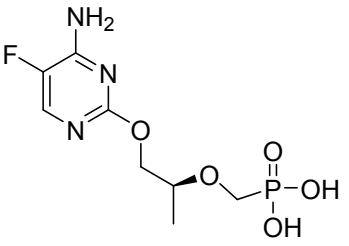

$30 \mathrm{a}$

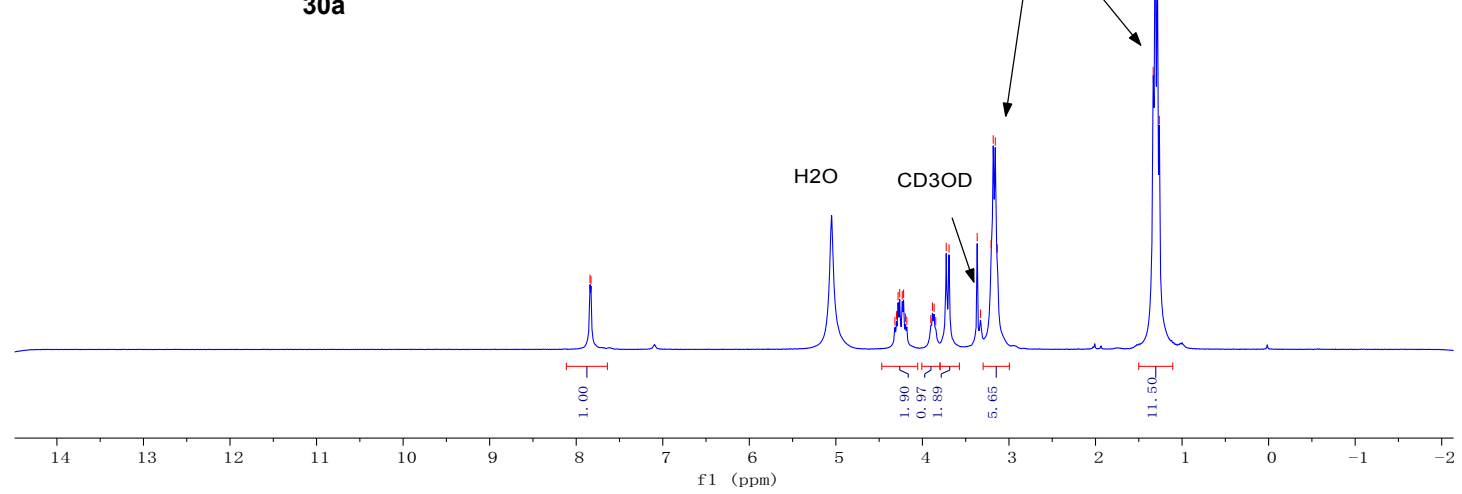


Solvent CD3OD

Nucleus 13C

$30 a$

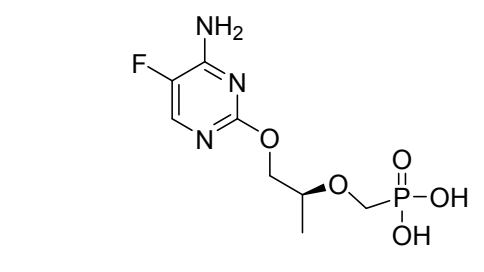

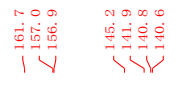

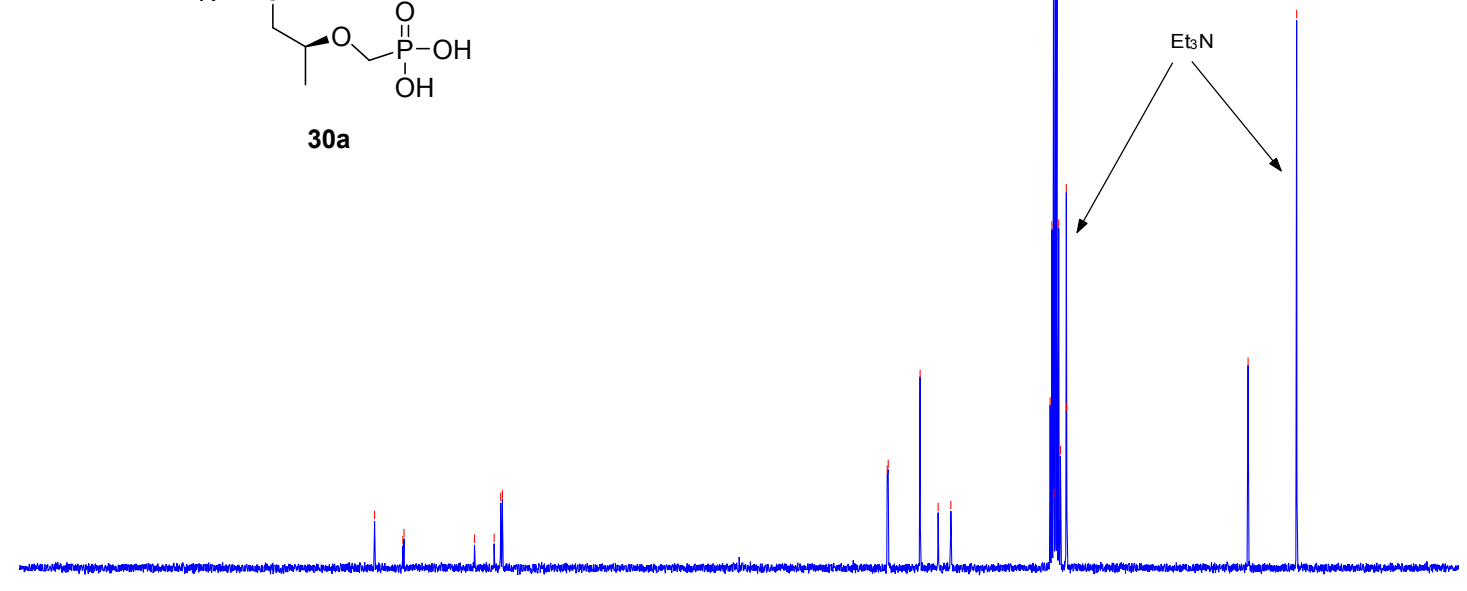

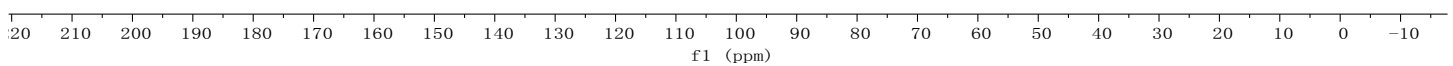

Solvent CD3OD

Nucleus 31P

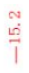

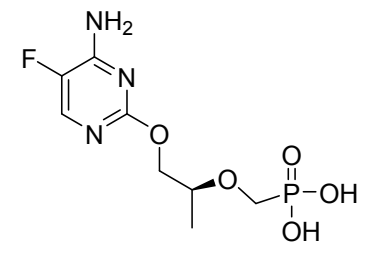

$30 a$

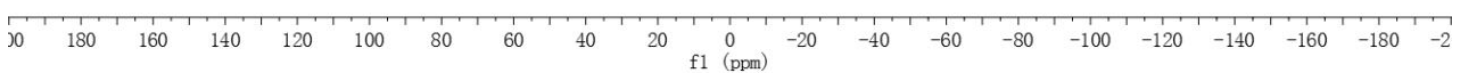


Solvent CD3OD

Nucleus $1 \mathrm{H}$

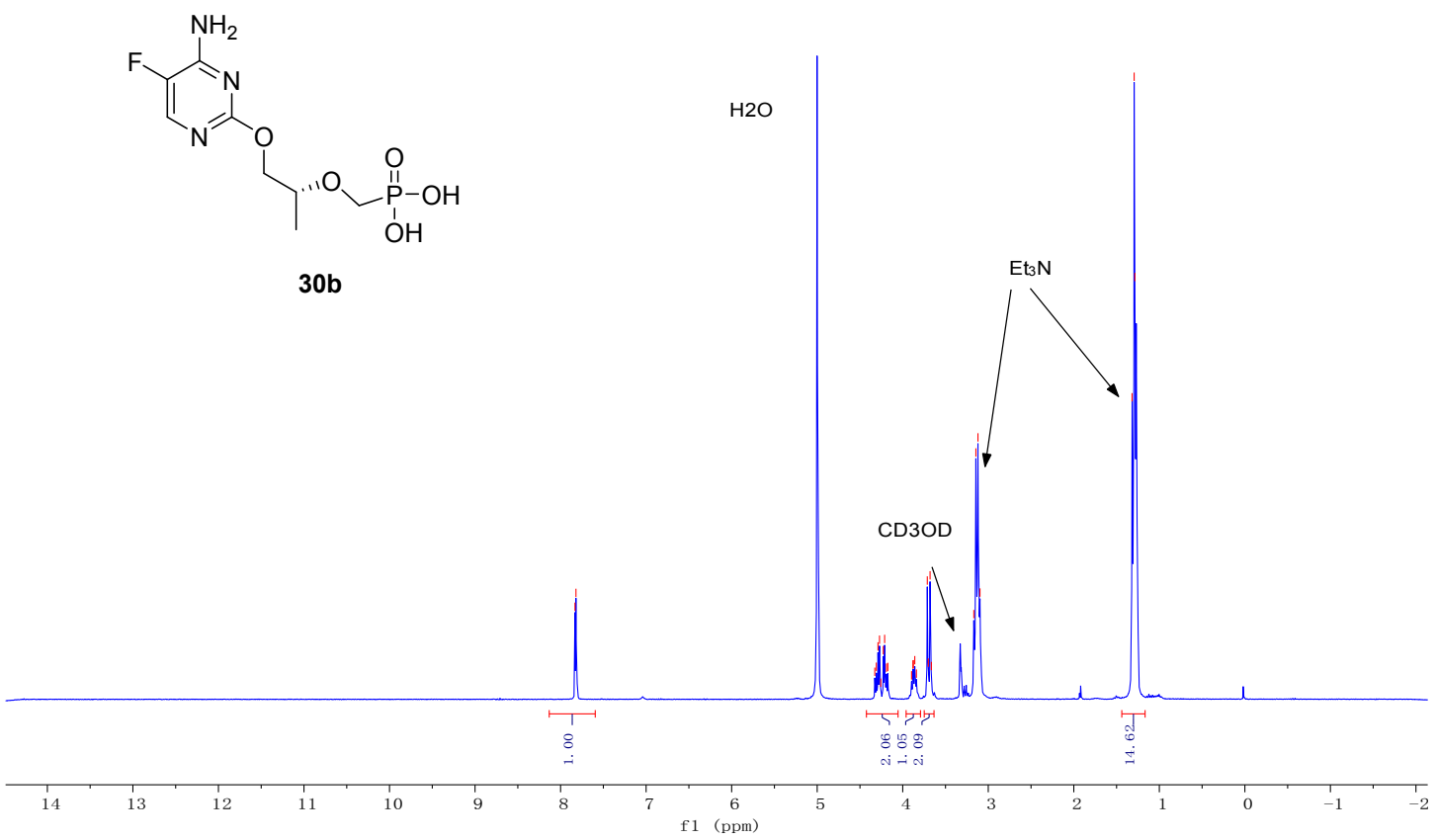

Solvent CD3OD

Nucleus 13C

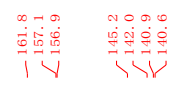

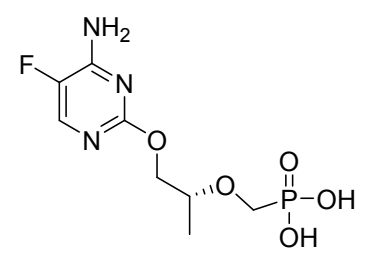

$30 \mathrm{~b}$

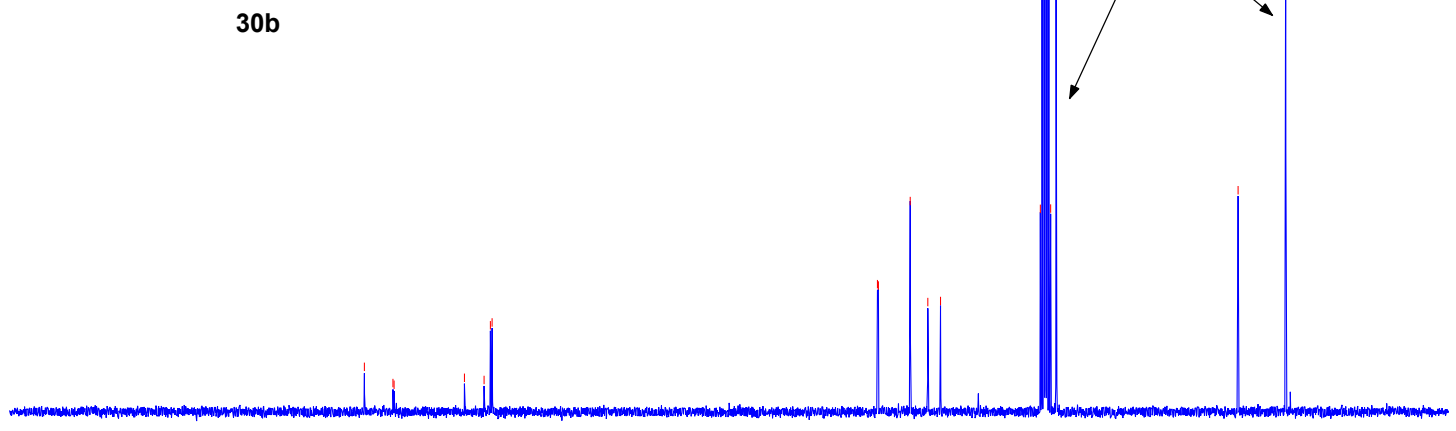

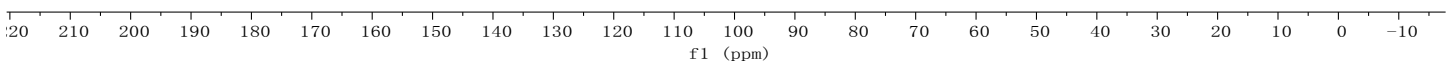


Solvent CD3OD

Nucleus $31 \mathrm{P}$

$\stackrel{0}{1}$

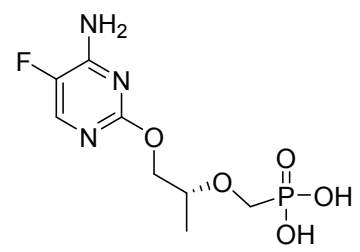

$30 \mathrm{~b}$

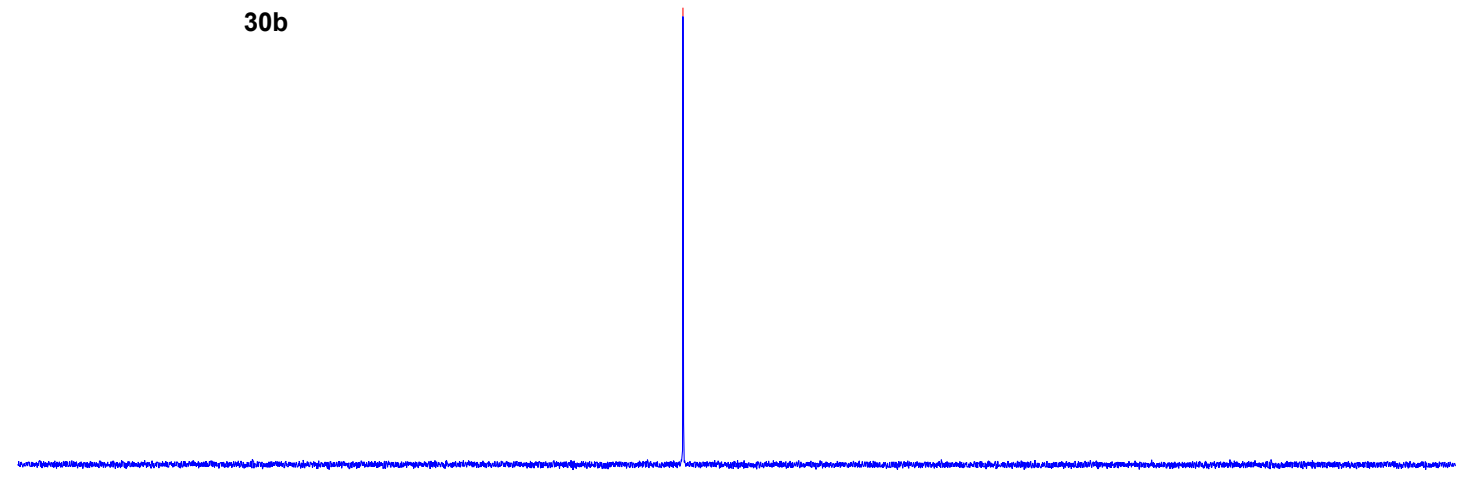

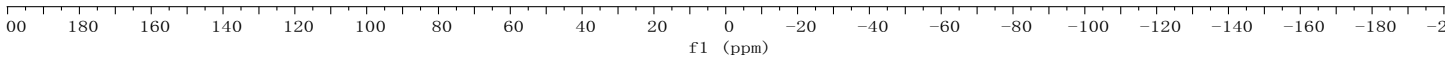

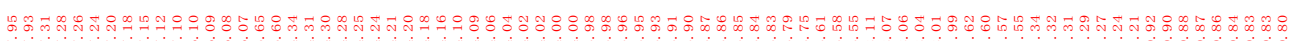

Solvent $\mathrm{CDCl} 3$ Nucleus $1 \mathrm{H}$

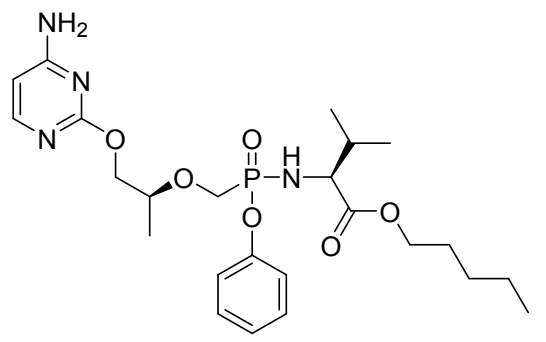

$31 \mathbf{a}$

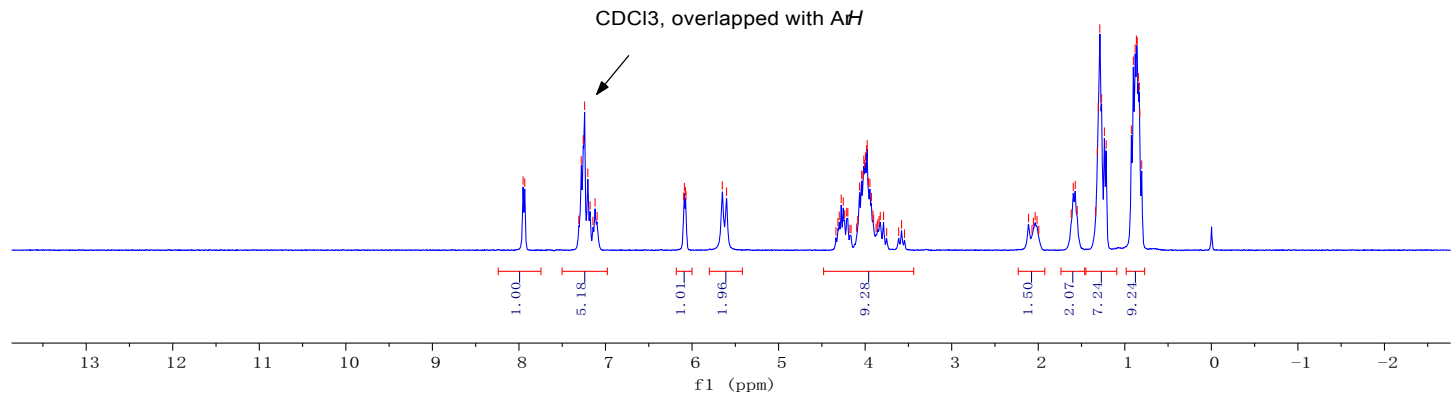



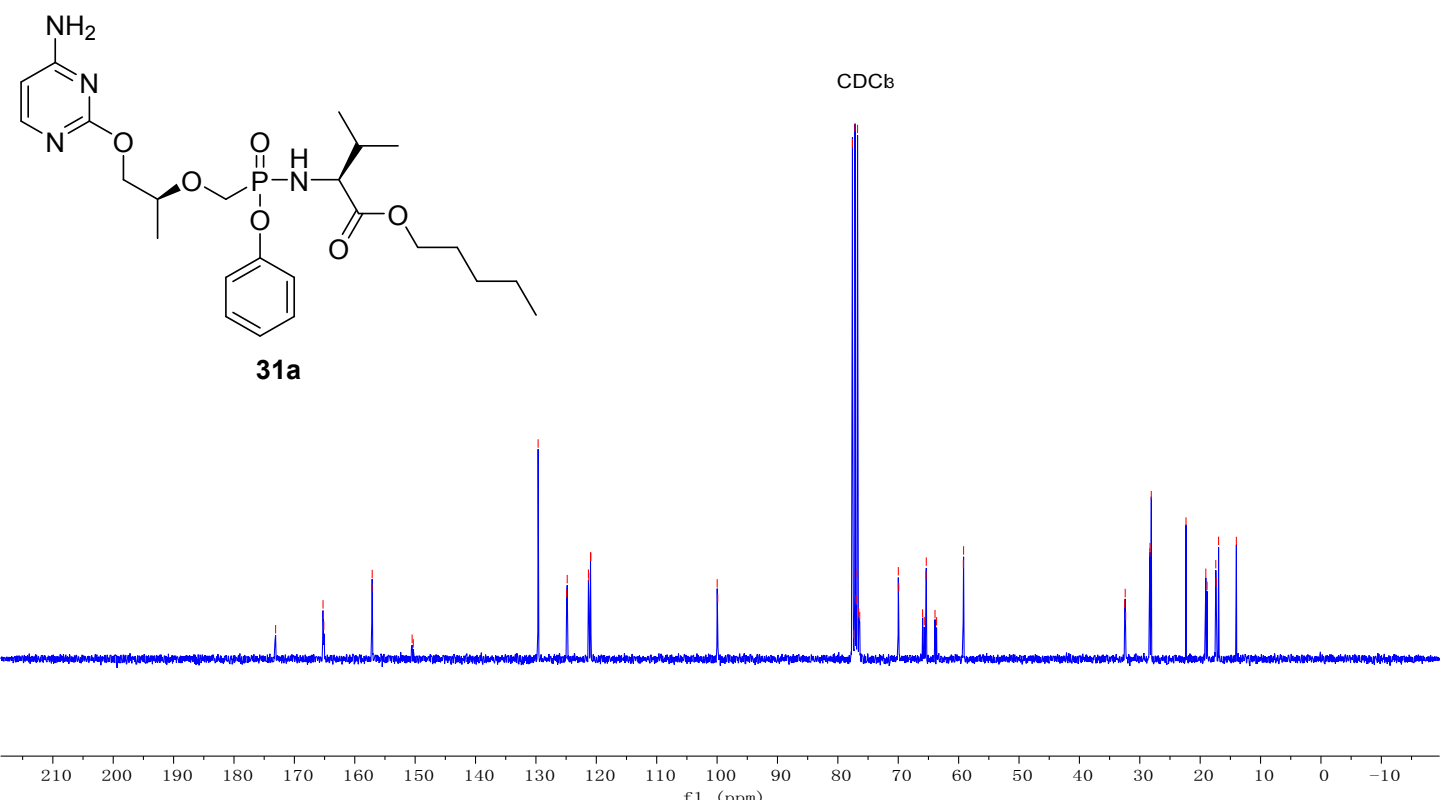

Solvent $\mathrm{CDCl} 3$

Nucleus 31P

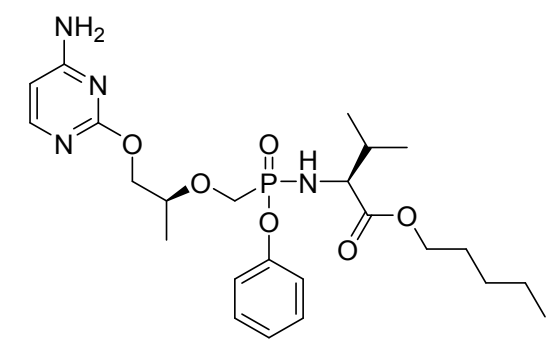

$31 a$

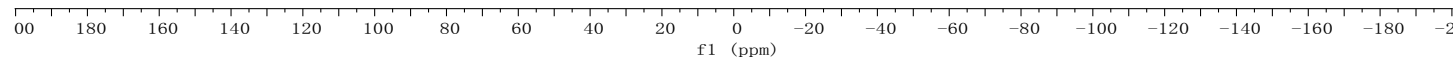




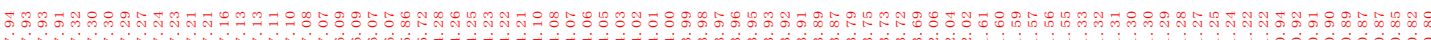
Solvent $\mathrm{CDCl} 3$

Nucleus $1 \mathrm{H}$

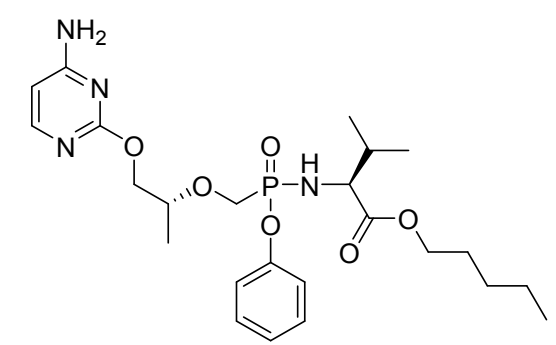

31b

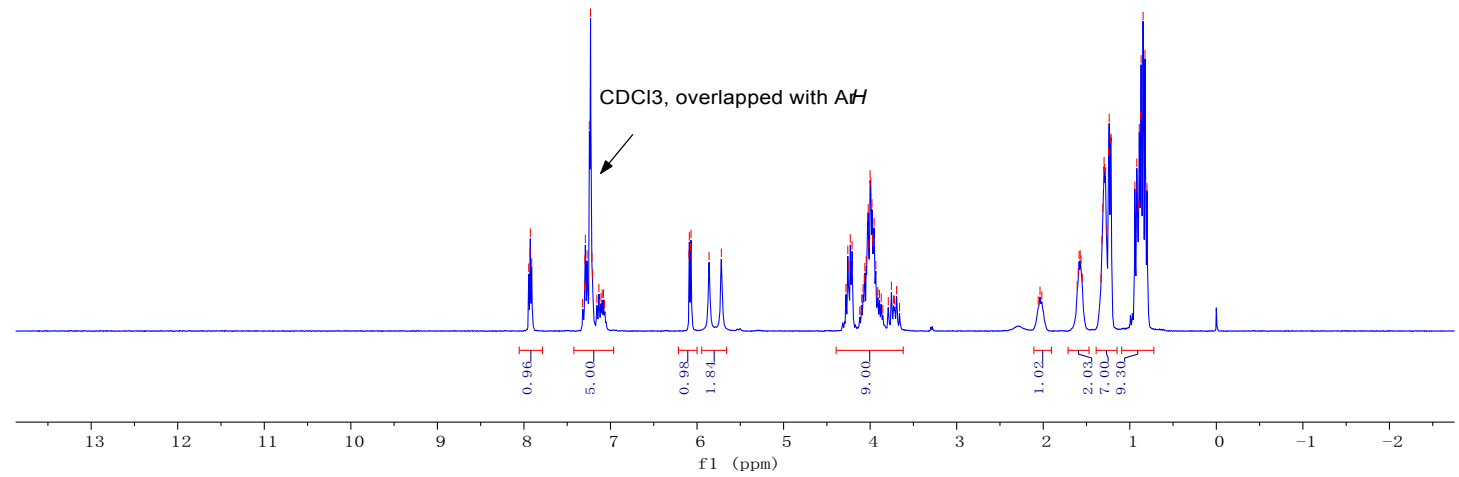

Solvent $\mathrm{CDCl} 3$

VU

$\checkmark V \quad$ F

Nucleus 13C

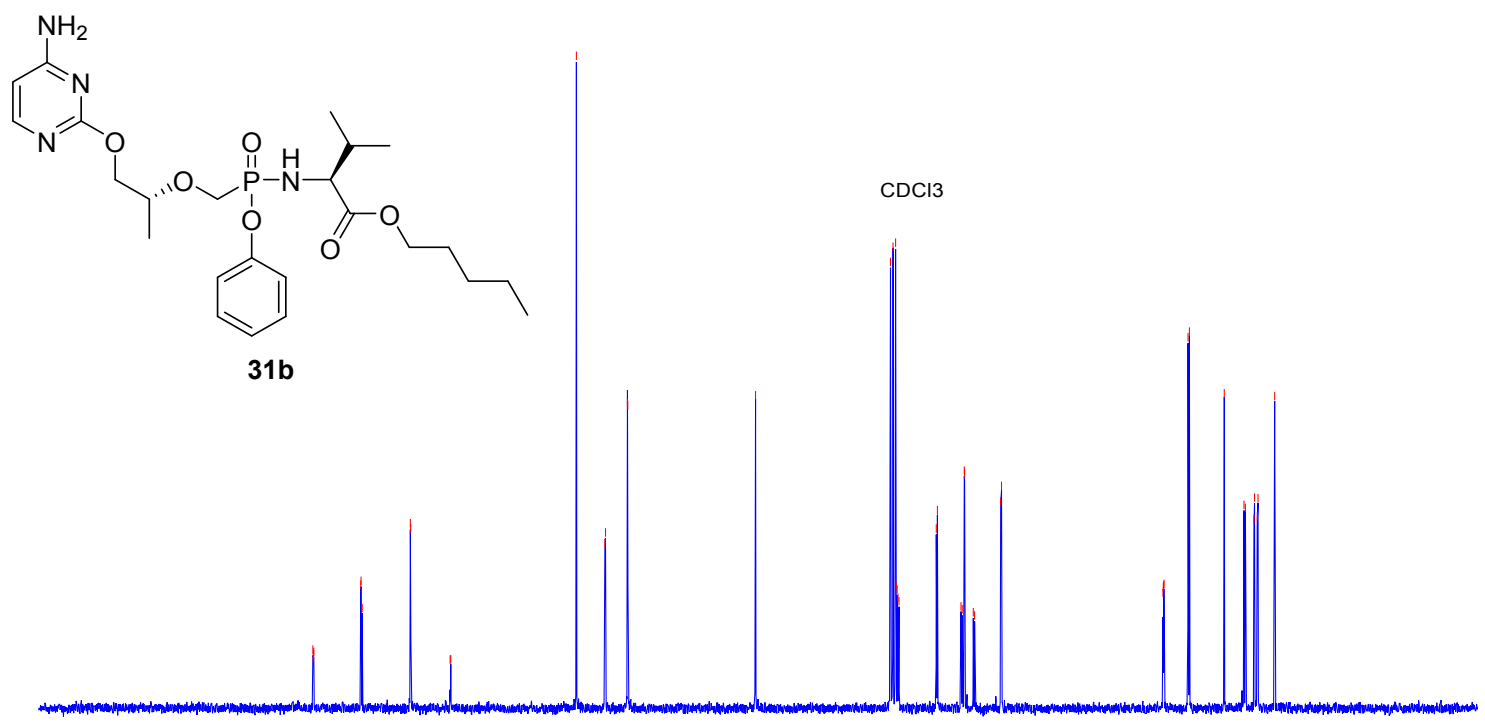

$\begin{array}{rlllllllllllllllllllllll}1 & 1 \\ 210 & 200 & 190 & 180 & 170 & 160 & 150 & 140 & 130 & 120 & 110 & 100 & 90 & 80 & 70 & 60 & 50 & 40 & 30 & 20 & 10 & 0 & -10\end{array}$ 

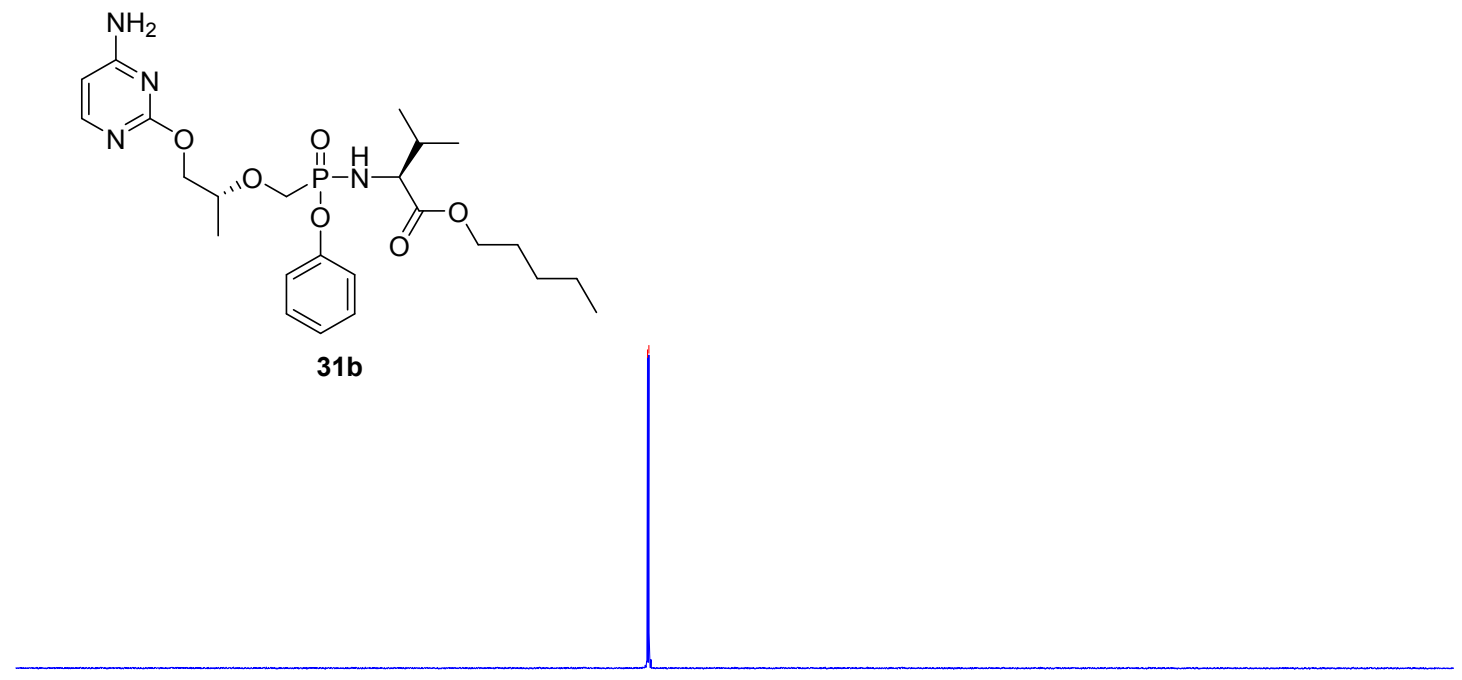

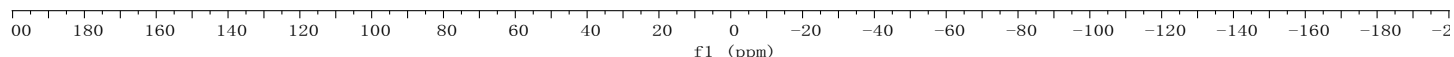

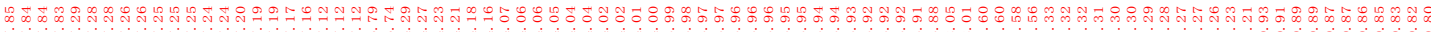
Solvent CDC13

Nucleus $1 \mathrm{H}$<smiles>CCCCCOC(=O)C(NP(=O)(COC(C)COc1ncc(F)c(N)n1)Oc1ccccc1)C(C)C</smiles>

$32 a$

$\mathrm{CDCl} 3$, overlapped with AH

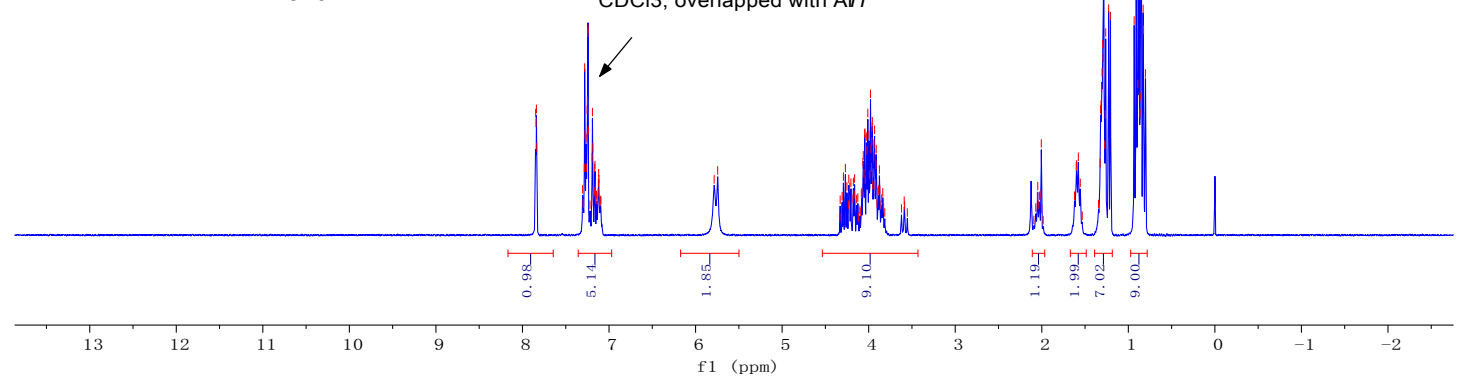




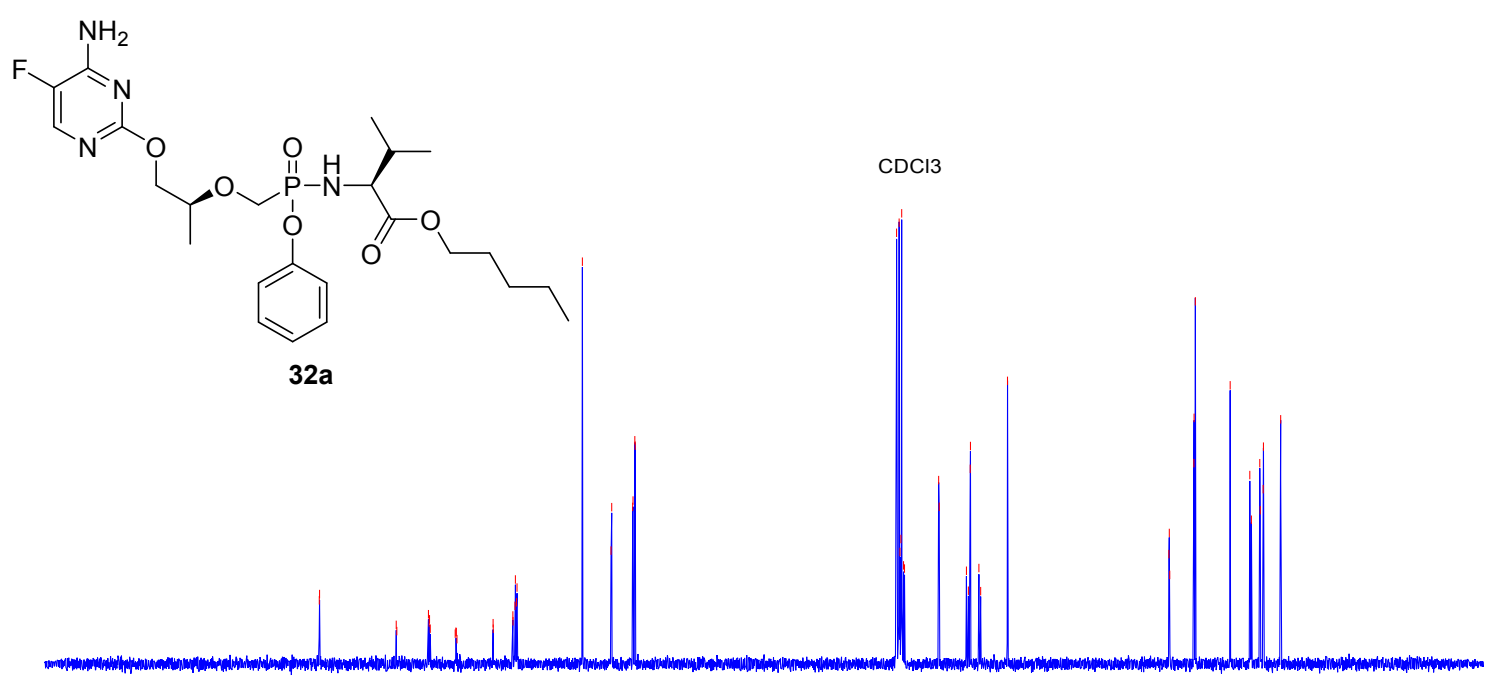

Solvent $\mathrm{CDCl} 3$

Nucleus 31P

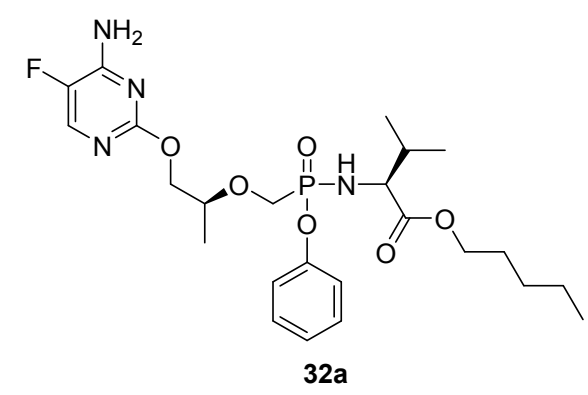

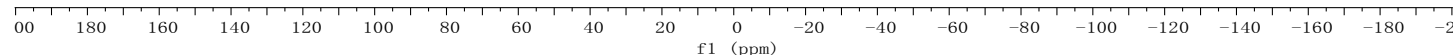




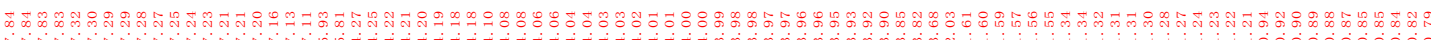
Solvent $\mathrm{CDCl} 3$

Nucleus $1 \mathrm{H}$

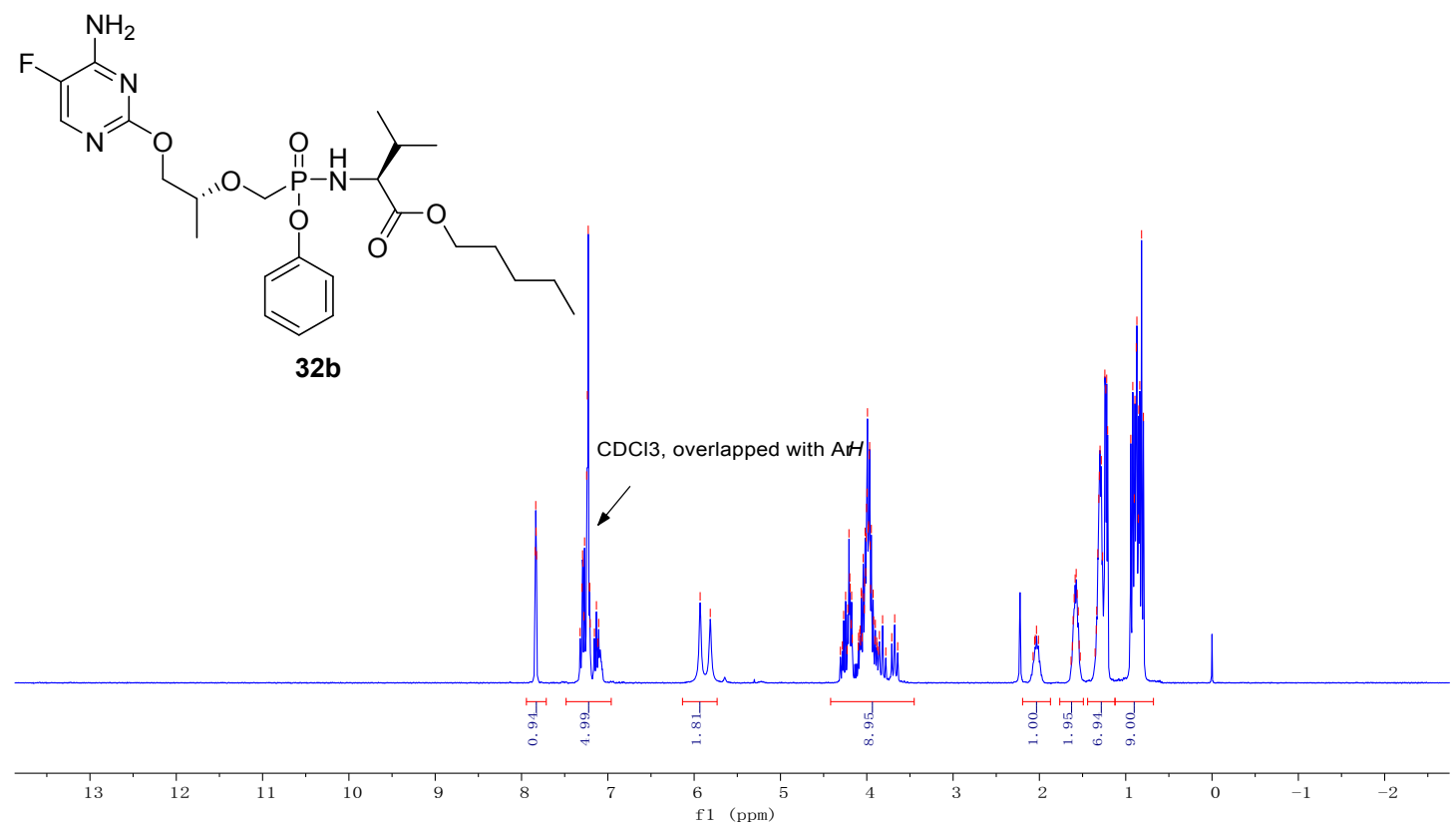

Solvent $\mathrm{CDCl} 3$

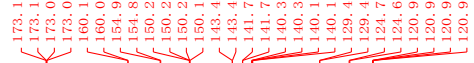

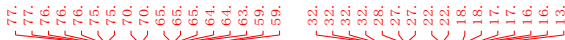

Nucleus 13C

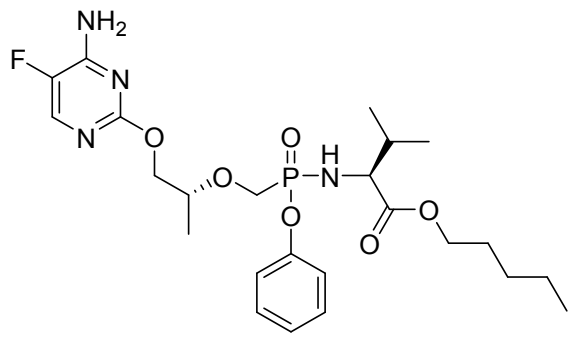

$32 b$

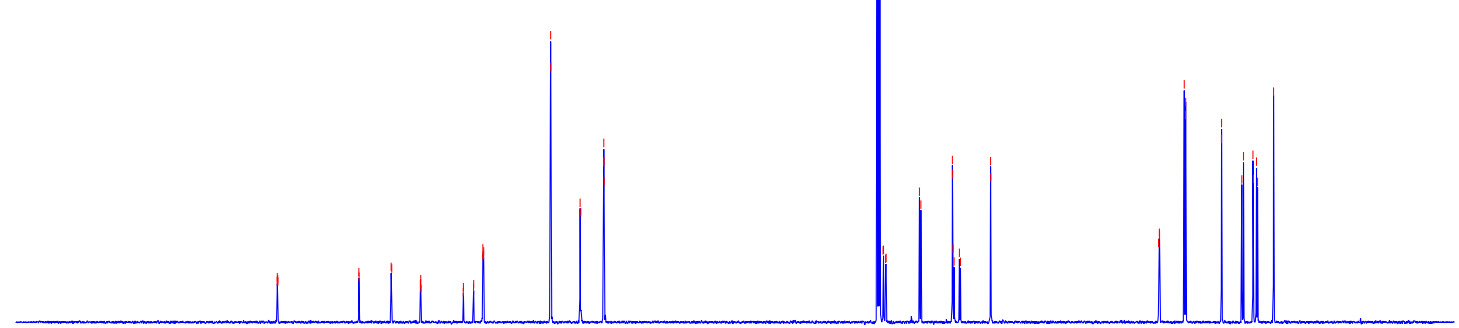

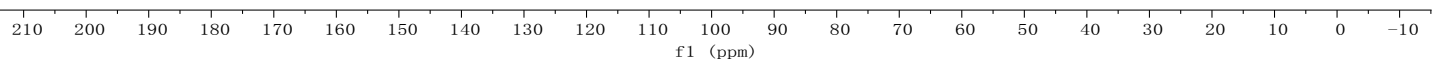


Solvent $\mathrm{CDCl} 3$

Nucleus 31P

$\underbrace{N}_{N}$

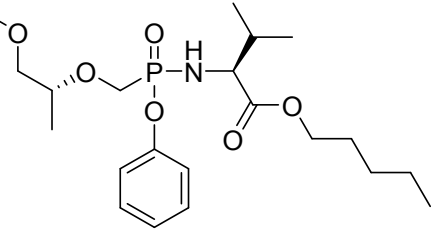

$32 b$

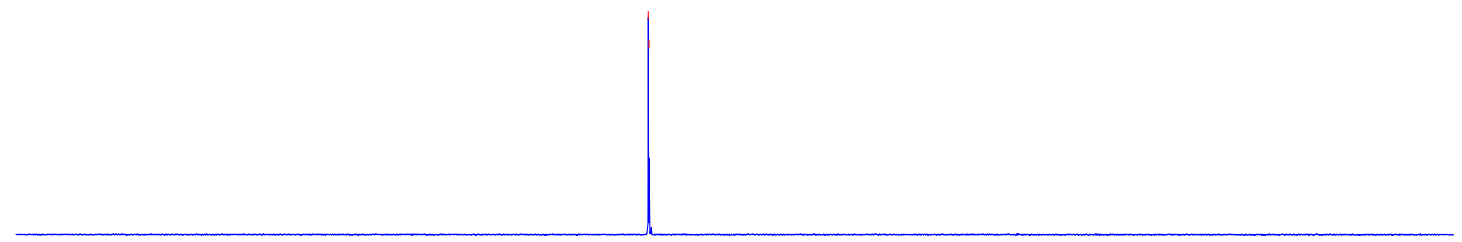

\begin{tabular}{llllllllllllllllllllll}
\hline 0 & 180 & 160 & 140 & 120 & 100 & 80 & 60 & 40 & 20 & 0 & -20 & -40 & -60 & -80 & -100 & -120 & -140 & -160 & -180 & -2
\end{tabular} 